GÖTTINGER STUDIEN ZUR ENTWICKLUNGSÖKONOMIK / GÖTTINGEN STUDIES IN DEVELOPMENT ECONOMICS

Philipp Albert Theodor Kircher

\title{
Poverty Reduction Strategies
}




\section{Philipp Albert Theodor Kircher}

\section{Poverty Reduction Strategies}

Poverty remains one of the greatest problems of our time, causing starvation and humiliation in poor countries and contributing to problems of conflict, migration and environmental degradation effecting also richer countries. This study provides a systematical analysis of today's donor strategies for development cooperation, which unite around the goal of poverty reduction. The most recent strategies of the World Bank and the German, British and Swedish official development agencies are compared and evaluated. Their broad consensus on goals and conceptual elements is comprehensively presented. Differences in accentuations regarding beneficiaries and implementation methods are highlighted. An empirical study of the poverty focus in project evaluations of the German Financial Cooperation rounds off the analysis by exemplarily pointing at the practical implications of the new strategies.

Philipp Kircher studied Economic Engineering in the diploma program of the University of Karlsruhe, Germany, and Business Administration in the masters program of the University of Wisconsin-Milwaukee, USA. During an internship at the Kreditanstalt für Wiederaufbau he developed the initial ideas for this study. The thesis was evolved in cooperation with the Ibero-America Institute on Economic Research at the University of Göttingen. The author currently conducts research at the University of Bonn. 


\section{Poverty Reduction Strategies}




\section{Göttinger Studien zur Entwicklungsökonomik Göttingen Studies in Development Economics}

Herausgegeben von/ Edited by Hermann Sautter

Band 10

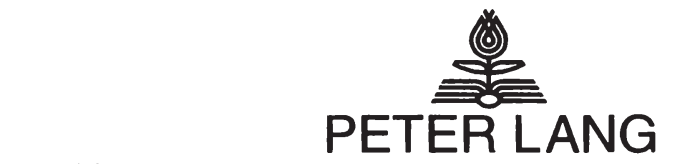

Frankfurt am Main - Berlin - Bern - Bruxelles - New York - Oxford · Wien

Philipp Kircher - 978-3-631-75366-8 
Philipp Albert Theodor Kircher

\section{Poverty Reduction Strategies}

A comparative study applied

to empirical research

\section{(i) \\ PETER LANG \\ Europäischer Verlag der Wissenschaften}


Die Deutsche Bibliothek - CIP-Einheitsaufnahme

Kircher, Philipp Albert Theodor:

Poverty reduction strategies : a comparative study applied to empirical research / Philipp Albert Theodor Kircher. - Frankfurt am Main ; Berlin ; Bern ; Bruxelles ; New York ; Oxford ; Wien :

Lang, 2002

(Göttingen studies in development economics ; Vol. 10)

ISBN 3-631-39384-9

Open Access: The online version of this publication is published on www.peterlang.com and www.econstor.eu under the international Creative Commons License CC-BY 4.0. Learn more on how you can use and share this work: http://creativecommons. org/licenses/by/4.0.

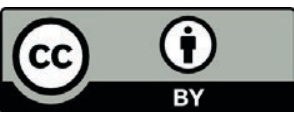

This book is available Open Access thanks to the kind support of ZBW - Leibniz-Informationszentrum Wirtschaft.

\author{
ISSN 1439-3395 \\ ISBN 3-631-39384-9 \\ US-ISBN 0-8204-5962-3 \\ ISBN 978-3-631-75366-8 (eBook) \\ (C) Peter Lang GmbH \\ Europäischer Verlag der Wissenschaften \\ Frankfurt am Main 2002 \\ All rights reserved.
}

All parts of this publication are protected by copyright. Any utilisation outside the strict limits of the copyright law, without the permission of the publisher, is forbidden and liable to prosecution. This applies in particular to reproductions, translations, microfilming, and storage and processing in electronic retrieval systems.

Printed in Germany 123467

www.peterlang.de 


\section{Foreword}

There is a growing consensus among development organisations that poverty alleviation should be a primary - or even the overriding - goal of cooperation between rich and poor countries. On the one side, this consensus may be seen as the consequence of many disappointing experiences. In spite of substantial efforts in development assistance and numerous undisputable success stories in this field, there are still 1.2 billion poor people living on less than one dollar a day in developing countries. On the other side, the consensus is due to the growing awareness that a widening international income gap threatens the wellbeing of people in rich countries. The benefit they draw from „global public goods" (security, peace, biodiversity etc.) is going to be diminished by actions of desperate people in the poverty regions of the world.

The author of this book gives an excellent overview on this emerging consensus. He shows how the understanding of poverty has been broadened - most clearly illustrated by the different approaches underlying the „World Development Reports" of 1990 and 2000. Philipp Kircher also clarifies the main elements of the commonly shared poverty-alleviation "strategy": good governance, an achievement-promoting incentive system, private as well as public safety nets in poor countries themselves, and an international framework which facilitates national self-help.

However, the consensus is limited. Individual donor organisations accentuate different elements. The author investigates the programmes of the World Bank as well as those of the United Kingdom, of Germany and Sweden. He reaches the following conclusions: the World Bank stresses macro-economic issues, it focuses on economic growth (without neglecting the problem of distributional inequality), but it places a relative small importance on human rights and democracy as components of a poverty reduction programme. These points, on the contrary, are stressed by the British „Department for International Development" (DfID). Moreover, the British concept gives a high importance to global political institutions, especially those of the UN system, multilateral development banks and the IMF. The UN system is considered by DfID as an institution which could - more as it presently does - promote an international „rule of law" including the protection of civil and social human rights. The German „Bundesministerium für wirtschaftliche Zusammenarbeit und Entwicklung" (BMZ) embarks strongly on international regulatory frameworks for conflict prevention, it accentuates rural development (in contrast to the DfID, which places special emphasis on urban development) and it shows a strong concern for the preservation of the environment and the resources it provides for poor people. The „Swedish International Development Organization“ (SIDA) 
focuses on „knowledge and education“ as key determinants of poverty reduction.

The author comes to the conclusion that these accentuations for the most part do not hinder the cooperation between agencies but represent opportunities for an efficiency-enhancing specialization. Obviously, each organisation has its own "comparative advantages" in following the commonly shared goal of poverty reduction.

How far does project evaluation reflect this focus on poverty reduction? In order to answer this question, Philipp Kircher investigates the evaluation practice of the German „Kreditanstalt für Wiederaufbau“ (KfW). His empirical study is based on 75 evaluation reports. It shows that an explicit focus on poverty was only found in the minority of final evaluations; mainly in projects with close proximity to the target group and associated with low financial involvement. Obviously, there is some scope for translating the general consensus on poverty alleviation to explicit (measurable) goals. This would give more substance to the consensus officially expressed by nearly all donor organisations.

Philipp Kircher offers a comprehensive study on the evolvement, the content, the different national accentuations and the problems of the international consensus on poverty alleviation. It is an interesting book for both scholars and practitioners of development cooperation.

Göttingen, October 2001

Hermann Sautter 


\section{Preface}

This study has been substantiated during a practical training period at the Kreditanstalt für Wiederaufbau (KfW) and it was devised in cooperation with the Ibero-America Institute on Economic Research at the University of Göttingen.

I would like to extend my sincere thankfulness to those people who have supported me in developing this treatise. Individually, I would like to thank:

- Prof. Dr. Hermann Sautter, head of the Ibero-America Institute for Economic Research at the University of Göttingen, for the insights which he has provided on this topic during long discussions and his dedication in giving advice on this thesis.

- Prof. Dr. Dres. h.c. Wolfgang Eichhorn, head of the Institute for Economic Theory and Operations Research at the University of Karlsruhe, for his support on this topic.

- Dr. Wolfgang Bichmann, Josef Gamperl, Sabine Kruse and Dr. Christoph Sigrist from the KfW for their helpful guidance in introducing me to the practical work of development cooperation, their insights on many topics currently under discussion and their support of my empirical ambitions.

- Stefan Trück for his constructive remarks on the empirical analysis.

- Benedikt Kircher and Liz Leathers for their dedication and their insightful remarks.

- Johanna and Helmut Kircher, Benedikt Kircher, Bernadette Kircher, Pia Kircher and Tanja Bofinger for their continuous encouragement.

My special gratitude is directed at the $\mathrm{KfW}$ for not only allowing but encouraging the kind of open minded, sometimes critical research as developed in the last part of this study.

It is the hope of the author that this book will provide systematical insights on and critical review of contemporary strategies for poverty reduction for the interested reader. If this book succeeds in spreading knowledge that helps to reduce poverty more rapidly, I believe it was worthwhile for all people involved.

Bonn, April 2002

Philipp Kircher 
Philipp Kircher - 978-3-631-75366-8 


\section{Table of Contents}

LIST OF ABBREVIATIONS …........................................................... XII

LIST OF FIGURES …….................................................................. XIII

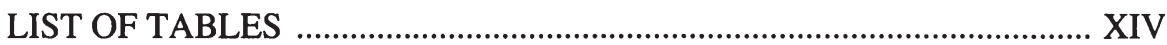

LIST OF ANNEXES …............................................................................... XIV

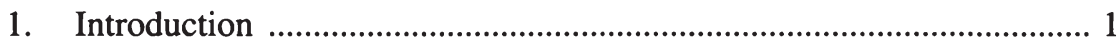

1.1. Aim of the Analysis ................................................................... 1

1.2. Examination Procedure ..................................................................... 3

1.3. Strategies Reviewed in the Analysis .............................................. 6

1.4. The Role of Poverty Reduction: Poverty Reduction vs. Other Developmental Goals ................................................................... 9

2. Poverty Reduction as Focal Point of Development Cooperation: The International Consensus ..................................................................... 19

2.1. The Evolution Towards the Current Consensus ............................. 19

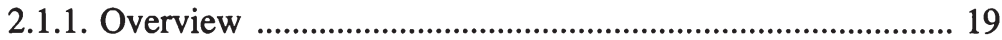

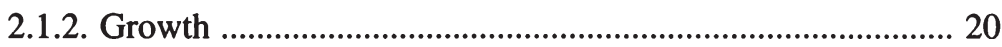

2.1.3. Redistribution with Growth ................................................. 21

2.1.4. Basic Needs Approach .................................................... 26

2.1.5. Free Market Forces ............................................................ 30

2.2. Today's Understanding of Poverty Reduction ................................ 34

2.3. Poverty Definitions beyond Monetary Income ............................... 37

2.3.1. Conceptual Dimensions of Poverty Definitions ................... 37

2.3.2. The Current Poverty Definition ............................................ 39

2.3.3. International Development Targets ..................................... 41

2.4. The Domestic Framework for Poverty Reduction .......................... 47

2.4.1. Economic Framework ......................................................... 47

2.4.1.1. Growth and Equality ............................................... 47

2.4.1.2. The Economic Incentive System ............................. 51

2.4.1.3. Creating Economic Opportunities ............................ 56

2.4.1.3.1. Poor People's Assets ............................... 56

2.4.1.3.2. Access to Markets .................................. 68

2.4.1.4. Excursion into Infrastructure Investment ................. 71

2.4.2. Necessary Political Condition ............................................ 77

2.4.2.1. Linkages Between Political Conditions and

Economic Issues ....................................................... 77

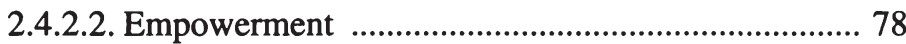

2.4.2.2.1. Human Rights and Equality .................. 78

2.4.2.2.2. Participation ............................................ 85

2.4.2.2.3. Democratization .................................... 91 
2.4.2.3. Good Governance ...................................................... 95

2.4.2.3.1. The Concept ........................................... 95

2.4.2.3.2. Accountability, Decentralization and Transparency ......................................... 97

2.4.2.3.3. Stemming Corruption .............................. 100

2.4.2.3.4. Rule of Law and Accessibility of the Law ........................................................ 102

2.4.3. Measures to Provide Security for Poor People ...................... 107

2.4.3.1. The Need for Security ............................................. 107

2.4.3.2. The Role of Private vs. State Security Provision .... 110

2.4.3.3. Measures of State Security Provision ..................... 112

2.4.4. Comprehensiveness or Excessiveness? ............................... 120

2.5. International Regimes ...................................................................... 121

2.5.1. International Institutional Framework ................................. 121

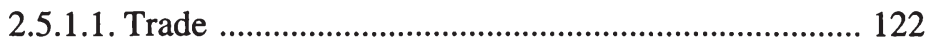

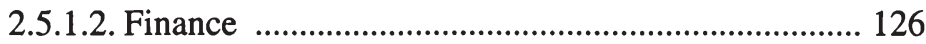

2.5.1.3. Environment ......................................................... 129

2.5.2. The Donor Community .......................................................... 135

2.5.2.1. The Meaning of Partnership: Ownership, Conditionality and Political Dialogue ..................... 135

2.5.2.2. Donor Responsibilities: Donor Coordination, Cooperation and Policy Coherence ......................... 139

2.5.2.3. Knowledge, Alliances and Awareness Raising ....... 141

2.6. Synopsis: Novelties and Challenges of the New Strategic

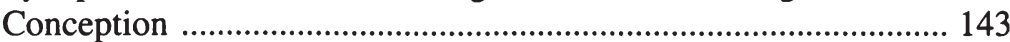

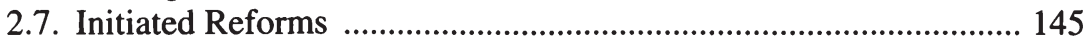

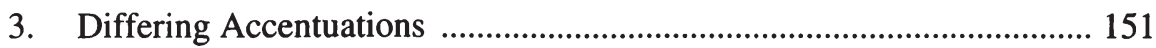

3.1. Merits and Difficulties of Differing Focal Points .......................... 151

3.2. The World Bank ......................................................................... 154

3.2.1. World Bank Background ..................................................... 154

3.2.2. Insights on Political Systems and Coalitions ....................... 155

3.2.3. National Security Schemes .................................................... 157

3.2.4. Concerns for Macroeconomic Policy and Inequality ............ 161

3.2.5. Reservation with Human Rights and Democracy ................. 161

3.3. United Kingdom ................................................................................ 163

3.3.1. UK's Background on Development Assistance .................... 163

3.3.2. Concentration ....................................................................... 164

3.3.3. International Development Targets and Impact

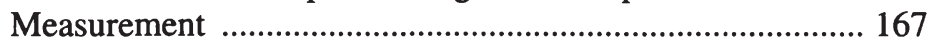

3.3.4. Knowledge ....................................................................... 169

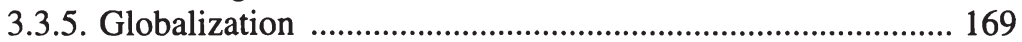

3.3.6. New Strategic Areas: Water Scarcity and the Urban Poor .. 172

3.3.7. Long-term vs. Short-term Benefits ........................................ 175 


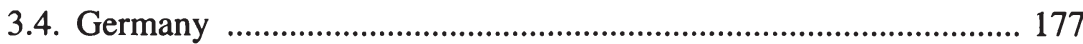

3.4.1. Germany's Background on Development Assistance ........... 177

3.4.2. Support for Middle-income Countries ................................. 181

3.4.3. Peace and Conflict Prevention ........................................... 182

3.4.4. Agrarian Development ...................................................... 184

3.4.5. Environmental Implications of Energy Supply .................... 185

3.4.6. Alliances within Industrialized Nations ............................... 186

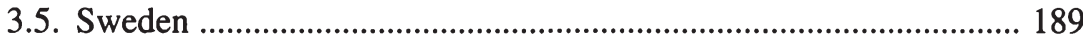

3.5.1. The Background of Sweden's Development Cooperation .. 189

3.5.2. Knowledge and Education ................................................... 191

3.5.3. Disabled People and Marginalized Groups .......................... 194

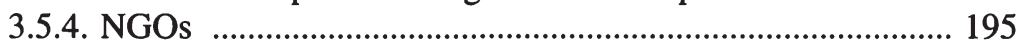

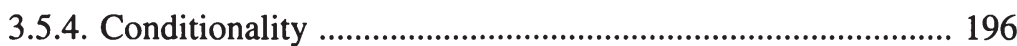

3.6. Accentuations: Benefits or Hindrance? .......................................... 197

3.7. Consolidation: Consensus and Accentuations ................................... 198

3.7.1. Consensus on Three Levels ................................................... 199

3.7.2. Stronger Accentuations with Decreasing Level of

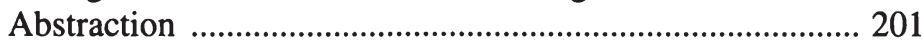

3.7.3. Synopsis of the New Consensus and its Accentuations........ 203

4. Implications for Project Evaluations ..................................................... 207

4.1. Increasing Importance of Impact Measurement ............................. 207

4.2. Background: The German Financial Cooperation and the KfW .... 208

4.3. Aim of the Empirical Study .......................................................... 214

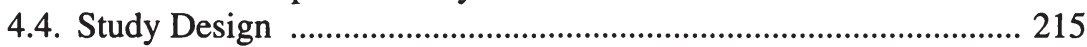

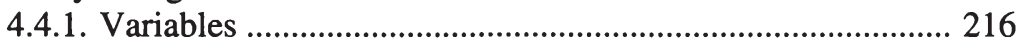

4.4.2. Sampling Procedure ………………………………......... 219

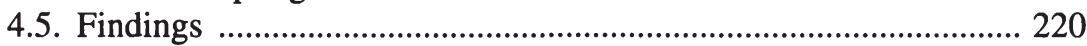

4.5.1. Procedure of Analysis ........................................................ 220

4.5.2. Quantitative Analysis ....................................................... 221

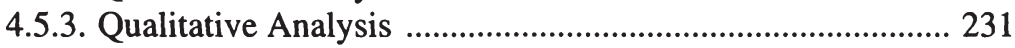

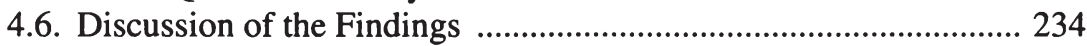

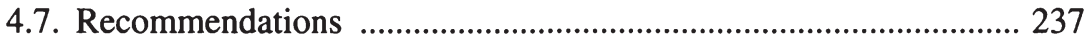

4.8. Synopsis of the Empirical Study .................................................. 238

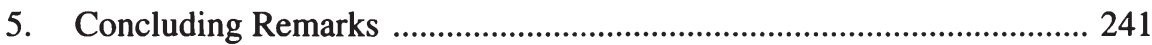

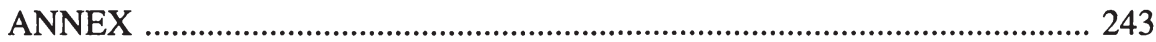

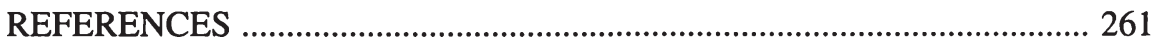




\section{List of Abbreviations}

AKA Arbeitskreis Armutsbekämpfung durch Hilfe zur Selbsthilfe

BMZ Bundesministerium für Wirtschaftliche Zusammenarbeit und Entwicklung

CBD Convention on Biodiversity

CCD Convention to Combat Desertification

CDF Comprehensive Development Framework

CDM Clear Development Mechanism

CER Certified Emissions Reduction

CLS Core Labour Standards

DAC Development Assistance Committee

DfID Department for International Development

EU European Union

FCCC Framework Convention on Climate Change

FDI Foreign Direct Investment

FSF Financial Stability Forum

GDP Gross Domestic Product

GEF Global Environment Facility

GNP Gross National Product

GTZ Gesellschaft für Technische Zusammenarbeit mbH

HIPC Heavily Indebted Poor Countries

IDA International Development Association

IDT International Development Target

ILO International Labor Organization

IMF International Monetary Fund

IT Information Technology

KfW Kreditanstalt für Wiederaufbau

MEA Multilateral Environmental Agreements

NGO Non-Government Organization

NSSD National Strategy for Sustainable Development

OECD Organization for Economic Cooperation and Development

ODA Official Development Assistance

OPA Output and Performance Analysis

PPP Purchasing Power Parity

PRGF Poverty Reduction and Growth Facility

PRS Poverty Reduction Strategy

PRSP Poverty Reduction Strategy Paper

Sida Swedish International Development Agency

TRIPS Trade-Related Aspects of Intellectual Property Rights Agreement

UK United Kingdom

UN United Nations

UNAIDS Joint United Nations Programme on HIV /AIDS

UNDP United Nations Development Organization 


\section{List of Abbreviations (continued)}

UNEP United Nations Environmental Programme

WDR World Development Report

WTO World Trade Organization

\section{List of Figures}

Figure 1: Poverty Reduction and its Interaction with Other Developmental Goals ................................................................ 13

Figure 2: World Population by Income Level .............................................. 43

Figure 3: Regional Distribution of People Living on Less than PPP1

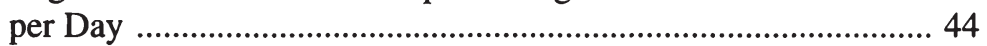

Figure 4: Changes in the Number of Poor People by Region ..................... 45

Figure 5: Poverty Reduction Strategy ....................................................... 147

Figure 6: Relative ODA Flows in 1998 as Percentage of GDP .................. 151

Figure 7: Absolute ODA Flows in 1998 ................................................. 152

Figure 8: Distribution of German Development Cooperation .................... 180

Figure 9: National Actors in the Fight against Poverty ............................... 197

Figure 10: Distribution of Sida's Development Contributions by Channel .. 190

Figure 11: Pyramid of Consensus ……………........................................ 200

Figure 12: KfW Regional Distribution in 2000 .......................................... 211

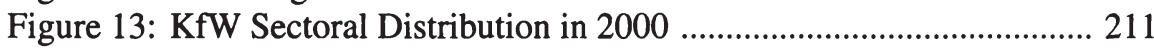

Figure 14: Success of Projects by Region (1996/97) ..................................... 213

Figure 15: Success of Projects by Sector (1996/97) .................................... 213

Figure 16: Projects by Poverty Category .................................................... 221

Figure 17: Histogram by CRS Code............................................................. 222

Figure 18: Histogram by Financial Costs ................................................... 222

Figure 19: Correspondence Analysis: poverty focus (pov), success (s),

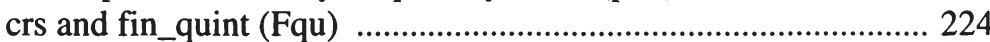

Figure 20: Correspondence Analysis: poverty focus (pov), impact level (IL), crs and fin_quint (Fqu) ............................................. 227

Figure 21: Correspondence Analysis: poverty focus (pov), crs and fin_quint (Fqu)

Figure 22: Correspondence Analysis: poverty focus (pov), impact level (IL), crs 


\section{List of Tables}

Table 1: Levels of Security Provision .......................................................... 111

Table 2: $\quad$ Sampling Distribution ................................................................ 220

Table 3: Poverty Focus .............................................................................. 221

Table 4: Results from Step-wise Regression ............................................. 229

\section{List of Annexes}

Annex 1: The Universal Declarations of Human Rights .............................. 243

Annex 2: Comprehensive Development Framework .................................... 244

Annex 3: Poor People's Priorities ..................................................................... 245

Annex 4: PRSP and HIPC Initiative ........................................................ 246

Annex 5: Proposed Urban Goals for Istanbul +5 (June 2001) ..................... 248

Annex 6: Scheme for Identification of the Poverty Impact Level ................ 249

Annex 7: Statistical Annotation Concerning Inverse Causality and Endogeneity .............................................................................. 250

Annex 8: Statistical Annotations to the Correspondence Analysis ............. 256

Annex 9: Results from Step-wise Regression (Extension of Table 4) ........ 258 


\section{Chapter 1}

\section{Introduction}

\subsection{Aim of the Analysis}

With 1.2 billion people - about a fifth of the world's population - living on less than a dollar a day in extreme poverty and nearly half the world's population earning less than two dollars a day ${ }^{1}$, lacking essentials like food, shelter, adequate health and education, poverty remains a great - possibly the greatest problem of our time. Some progress has been achieved over the last 40 years regarding life expectancy and health ${ }^{2}$, but the figures given above show that a lot more work needs to be done. How this should be achieved lies at the heart of development economics.

A series of new strategic proposals have been devised by development agencies during the last two years to tackle this question and to provide answers for the conditions and measures most conducive to reducing poverty. This treatise focuses on their content. These strategies aim at providing a framework that helps to reach the target of halving the proportion of people living in extreme poverty by $2015^{3}$; which requires progress at a much faster rate than has been achieved in the past ${ }^{4}$. The measures proposed on both national and international levels share a number of distinct elements common to all strategies, which indicate a consensus about how poverty could be reduced.

This consensus - its development, content, derivations and consequences for the development practice - shall be the concern of this thesis. It will help depict the main features that are common to a set of newly devised development strategies ${ }^{5}$ and help to expand the knowledge about these very recent strategies, some of which are still in the discussion phase even now. It is attempted to use the most broadly-based and perceptive analysis of each topic at hand in this synopsis and to present it as comprehensively as possible, while retaining a concern for all voices on the subject, so as to ensure overall agreement on the viewpoints presented. Those points that remain vague, unclear or inconsistent are scrutinized and alternatives and extensions are presented wherever possible. The analysis thus presents and questions the current consensus that can be inferred

\footnotetext{
${ }^{1}$ See World Bank (2000a), p. 3.

${ }^{2}$ See DfID (1997), p. 12.

${ }^{3}$ This goal is enshrined in the World Development Targets and is agreed upon by all OECD member countries.

${ }^{4}$ The progress in reducing poverty until the year 2000 is estimated at only one third of the required rate to reach the International Development Target for Poverty Reduction for 2015. See KfW (2001a), p. 18.

${ }^{5}$ The strategies include viewpoints of the World Bank and of the British, German and Swedish governments, plus their development organizations.
} 
from these common points in a set of development strategies. The evolution of this consensus from the 1950s to the present is presented to indicate the perspectives that led to its emergence, in order to make today's consensus more accessible.

Common points do not pervade the entire work in this area. A number of different accentuations remain within the consensus that are important to notice, since they shed light on those areas where full agreement has not yet been reached, or where new ideas have not spread into mainstream thought. Another concern of this analysis is to provide an overview of the distinctions between strategies. Differences between strategies can indicate the benefits of greater specialization, but they can also create obstacles towards the commitment to cooperation, which is one of the pillars of this new consensus and thus worthy of consideration. New ideas from individual agencies are discussed regarding their validity and effectiveness for reducing poverty.

Reducing poverty is more than just a theory. Its effects are very real and important for those who are affected by it. Even though a general consensus can be found on measures that are conducive to achieving these effects, procedures on how to operate and implement them remain ambiguous. One aspect of the actual work of development agencies, viz., the task of impact measurement, has been analyzed in order to gain some insights on these issues. How the practical concern of monitoring aid effectiveness is currently handled, how this corresponds to the demands of the new strategic direction and what could be changed to focus monitoring more on the dimension of reducing poverty, are the concerns of the empirical study on the German Financial Cooperation that complements this analysis. The answers that it provides can aid the process of translating new strategies into concrete action; with the aim of making development cooperation even more effective and responsive to poor people's needs.

It is the author's hope that this analysis will provide a useful review by portraying the extending and changing area of strategies for poverty reduction and by clarifying those parts that are reinforced by a series of strategies, as well as those that currently remain singular opinions. This analysis is coupled with the intention of indicating ways for practical implementation. Reflection and criticism of the presented strategic proposals and the exploration of areas for improvement round off this aspiration.

This study addresses an audience of politicians, administrators and scientists who deal with the evaluation and formulation of poverty reduction policies, of practitioners who apply these strategies in development cooperation agencies and of people generally interested in strategies for international development. 
This composition provides a review of the current developments regarding methods of reducing poverty, which might be beneficial to those readers who formulate policies or research this topic. It also indicates areas where further agreement needs to be reached, where incongruities in the argumentation need to be resolved and where there are shortcomings in current strategies that require further investigation.

Differences between the presented concepts are valuable for the practitioner to note, since the need for closer cooperation and coalitions ${ }^{1}$ in development assistance could be undermined if these differences are not openly discussed and resolved at a national, program or project level. This analysis also points out the practitioner's issues on which agreement has been reached internationally and the scope of such agreements. These factors permit an assessment of the way in which the methods and implementation mechanisms of development cooperation will most likely evolve over the coming decade. Knowledge of these trends might give guidance on the direction in which development agencies could intend to position themselves today.

For the general public the topic of international inequality and measures of development cooperation have reached high attention after the tragic terrorist attacks on New York in September 2001. It has been argued that discontent potentially driven by poverty might have provided the grounds for the recruitment of terrorist activists and for an environment that silently tolerates them ${ }^{2}$. If this holds true, it makes the reduction of poverty the more urgent. Still this book does not attempt to analyze the consequences of the attack for development cooperation as this is still too speculative, nor do the strategies presented reflect these events.

Nevertheless this book provides valuable insights for the reader who wants to judge future developments in this area on an informed basis. Chapter two includes a short overview over the recent history of development cooperation and presents in detail the current donor views in this area, providing the reader with a thorough picture of the current paradigm in international development that will serve as the baseline for any new developments.

\subsection{Examination Procedure}

This thesis focuses on official developments assistance (ODA) and the strategies pursued by bilateral and multilateral development organizations, especially those of the World Bank and the governments and development agencies of the United Kingdom (UK), Germany and Sweden. The charitable organizations of civilian society are only considered when they are integrated

\footnotetext{
${ }^{1}$ See Wieczorek-Zeul, H. (2000a)

${ }^{2}$ Regard for example the expression of Ingeborg Schäuble, head of the Welthungerhilfe: "Terrorism is not immediate consequence of hunger and poverty, but hunger and poverty provide fertile grounds for terrorism", as cited in FAZ (2001a). (Translation by the author).
} 
into the strategies of public development institutions, since their contributions important as they are - constitute only a small portion by comparison with ODA $^{1}$.

Conversely, foreign direct investment and private capital flows outweigh ODA by a ratio of nearly five to one ${ }^{2}$ and they significantly contribute to the growth and employment in some countries. Yet, to consider both private capital flows and ODA would go beyond the scope of this thesis. Private capital flows are presumably guided primarily by the search for the most profitable return on investment at a given level of risk $^{3}$. Increasing risks demand a premium on this return, under the usual assumption of investors who are averse to taking risks. The expectation of political, social, exchange rate, protectionist and other risks as well as expectations of the investment's income-earning potential - can be seen as being strongly dependent on the successes in social, economic and political terms that have already been achieved by a developing country. Private capital flows are currently available mainly to semi-industrialized countries ${ }^{4}$ and even then only to certain sectors, due to these reasons. The aim of most organizations providing ODA is to help nations by creating favorable conditions for national, private economic activity and foreign investment. This concern for the alteration of circumstances rather than responding to them is a far more proactive attempt and it shall be the concern of this study. Private capital flows are taken into account if the policies of the development agencies explicitly aim at stimulating them.

Having introduced the chapter topics, the strategies considered for investigation in this study are given in the remainder of this chapter, after a short explanation regarding the motivation for choosing them. Subsequently, an introduction into the subject of poverty reduction is provided in a discussion about the value of reducing poverty as the main goal of development assistance ${ }^{5}$. The role of poverty reduction is investigated in the light of other relevant and potentially conflicting developmental goals to the donor countries.

In the second chapter of this thesis, importance is placed on the evolution of today's overall consensus about the means to reduce poverty and on the general content of this agreement. The development of today's consensus is exemplified by an analysis of the ideas that most influenced the World Bank's strategy on poverty reduction, as one of the leading development organizations. The different emphasis on neoclassical or structuralistic elements which determined

\footnotetext{
${ }^{1}$ E.g. in Germany the private development contribution has been stable, at around one tenth of the public contribution. See Ashoff, G. (1996), p. 65.

${ }^{2}$ See Short, C. (2000), p. 48-49.

${ }^{3}$ For an expansion of this point in the context of investment in Africa see Hernádndez-Catá (2001), p 31.

${ }^{4}$ See BMZ (2001a), p. 20.

${ }^{5}$ The strategies reviewed for this analysis strongly favor this opinion.
} 
the agenda for reducing poverty over the last four centuries and the learning process that led to the accord we see today, are highlighted and placed in the context of their time.

The following discussion concerns the content of today's generally accepted view of effectively reducing poverty. A short analysis of the definition of poverty that has been broadened beyond the income aspect is presented. Then, an investigation of national policies and conditions conducive to reducing poverty is undertaken on the basis of shared views of the contemplated donor agencies. The proposals at national level are presented according to their relevance for the economical, political and protective environment in the developing country.

The analysis of necessities at the national level is followed by a discussion of proposals for an international framework that is favorable to the reduction of poverty. This international institutional framework shall as a first step be examined regarding trade, finance and the environment and their impact on poor countries. The views on interactions of donor countries with the developing countries and with each other shall be highlighted as a second step. The measures that the donor agencies themselves can pursue to decrease poverty's prevalence is discussed in this context. The chapter is concluded with an investigation of problems that are currently still unresolved and by an outline of reforms that are based on the new understanding of poverty already been brought about.

After dealing with the commonalities that dominate the current discussion on poverty reduction, the aim of chapter three is to highlight the accentuations that differentiate the positions of four donor strategies: those of the World Bank, the United Kingdom, Germany and Sweden. This shall serve to illustrate those aspects that have either not found overall agreement by these donor agencies, that have not found their way into the general consensus or that receive especially strong support in one strategy in comparison to the others. Thus, those points receive attention, which have not yet been embraced to the same degrees by the various strategies and are potential causes for conflict or for reevaluation. These 'specialties' are assessed in regard to their merit for poverty reduction and to the reasons why they have been included in a donor's strategy where inferable by the donor's history. Concluding, the implications of these differing accentuations for donor co-ordination and specialization are discussed. The motivation for the choice to regard the four above mentioned development organizations and their strategies is provided in the next sub-chapter.

Following the analysis of the differing emphasis and accentuations of these four strategies, in chapter four the focus is placed on the current praxis of impact evaluation as it relates to the new consensus. To illustrate the current situation, a selection of 75 completed projects of the German financial cooperation are analyzed in regard to the emphasis placed on poverty reduction in their final 
evaluation process. Descriptive methods as well as regressions and multivariate correspondence analysis were deployed for this purpose. Since improvements will be necessary to fully live up to the aspirations of the new strategies in the practical evaluation praxis, suggestions to reach a stronger poverty focus are presented.

Chapter five concludes the treatise with a short synopsis of the conclusions.

It should be pointed out that the newly formulated strategies investigated in this analysis have inherent potential to achieve real advances in poverty reduction in that they incorporate a broad view of poverty, integrate social, political and economical aspects, aim at refocussing the development efforts and foster international cooperation. Especially important is the potential for new institutional and individual commitment, bringing poverty reduction to the top of the political agenda and aiming at keeping it there. If the new strategic orientation leads to a measurable improvements in reducing poverty, the support for initiatives will increase and the efforts brought up currently might be sustainable for a lasting period of time. This would provide fertile ground for long-term, substantial progress for the situation of the many people still living in deep poverty. Since this potential of the new strategies is acknowledged by the author, the criticism presented in some parts of this thesis is aimed at reflecting and enhancing parts of the current strategic proposals, and is by no means directed to undermine the value of the new strategies as a whole.

\subsection{Strategies Reviewed in the Analysis}

This thesis focuses specifically on the strategic positions of the following organizations: the World Bank, the Department for International Development (DfID) of the United Kingdom (UK), the Ministry for Economic Cooperation and Development (Bundesministerium für Wirtschaftliche Zusammenarbeit und Entwicklung, BMZ) of Germany and the Swedish International Development Agency (Sida) as well as the positions presented by the governments of these countries in regard to development. All of these agencies have a strong focus on poverty reduction in their recent strategies. The bilateral agencies are chosen deliberately to be EU countries due to the high need for cooperation in this framework which makes agreements more noteworthy and differences more conflict-prone. The choice of these agencies shall be briefly motivated here:

The World Bank has taken a leading role in the fight against poverty for years and exerts large international influence due to the magnitude of its operations and the experience it has accumulated. Every decade the World Bank ${ }^{1}$ dedicates one World Development Report (WDR) to the topic of poverty reduction. The

\footnotetext{
${ }^{1}$ For a more in-depth discussion of the background of the World Bank see chapter 3.2.
} 
WDR 2000/2001 ${ }^{1}$ on this topic received worldwide attention ${ }^{2}$ because of the departure from the approach to poverty reduction pursued by the World Bank in the 1980s and early 1990s. The integration of social and economical policy into a single strategy, ${ }^{3}$ and also the broadening of the definition of poverty and the incorporation of political and legal considerations mark the main new themes. Its assertion that a sound structure to reduce poverty rests on the three pillars of opportunities, empowerment and security for the poor has influentially shaped the way poverty reduction is currently seen. It has even found its way into the strategies of $\mathrm{DfID}^{4}$, into the German action program for poverty reduction ${ }^{5}$ and into the guidelines of the Development Assistance Committee (DAC) ${ }^{6}$ of the Organization for Economic Cooperation and Development (OECD). Due to this influence the position of the World Bank as presented in the WDR 2000/2001 has been included in this analysis.

The Department for International Development has published an extensive amount of material on poverty within the last four years, starting with the first White Paper on International Development in $1997^{7}$. In this paper the newly elected Labor Party confirmed its commitment to poverty reduction. The determination of the government was underlined by DfID's new strategy for poverty reduction laid down in great detail in nine consultation documents for public debate in $1999 / 2000^{8}$. The detail of the analysis, the concern for measurability of results and the focus on concrete steps for action provide a broad basis for analysis and its implemented actions have already served as an example for other agencies ${ }^{9}$. The recently published Second White Paper on International Development with a focus on globalization ${ }^{10}$ is covering a field not yet deeply analyzed in most donor strategies and provides additional insights. The richness of the material presented serves as a reason to include these positions of DfID and the UK government into this analysis.

The position of the German government and with this the position of the BMZ presents possibly the most current view of poverty reduction. The action

\footnotetext{
${ }^{1}$ World Bank (2000a).

${ }^{2}$ See e.g. Arbeitskreis Armutsbekämpfung durch Hilfe zur Selbsthilfe (2000a), p. 1.

${ }^{3}$ See Goldberg, J. (2000).

${ }^{4}$ See DfID (1999b), p. 2.

${ }^{5}$ See BMZ (2001a), p. 6.

${ }^{6}$ See DAC (2001), p. 11.

${ }^{7}$ UK government (1997).

${ }^{8}$ DfID (1999 a,b) and DfID (2000 a-g). The documents regarded are in the discussion phase. Some have been finally released, yet too late to be incorporated into the analysis. Since the differences between the discussion version and the final version are small, this analysis claims to correctly portray the views currently held by DfID.

${ }^{9}$ E.g. the exemplary character of the new orientation of the British export credit security scheme ECGD was noted in the draft for the German action program, BMZ (2000). (The final version, BMZ (2001a), does not contain this element any more).

${ }^{10}$ UK government (2000).
} 
program on poverty reduction ${ }^{1}$ of the German government, which portrays its most recent strategic view on poverty reduction and has been used in this analysis, has just passed the consultation stage and was released in May 2001. This comparably late formulation of a strategy has the advantage that the positions of other agencies are already known and it is already perceivable that this strategy will deliberately depart from some generally agreed principles such as the reduced funding for threshold countries. Thus, additional insights can be expected from its analysis. The inclusion of the German position is also of interest because of Germany's changed political situation and its increased awareness of its influence after the reunification and its potential impact on development-strategy formulation. This position also takes into account the view of one of the world's largest donors.

This is contrasted by the Swedish position, which reflects the considerations of one of the smaller donor nations. As a group, they make up a broad share of the European development assistance. Sweden's tradition of reaching and superceding the limit of $0.7 \%$ ratio of official development assistance to $\mathrm{BSP}^{2}$ laid out by the UN General Assembly and confirmed at the Rio conference shows its strong commitment to development assistance. Its emphasis on poverty reduction was reinforced already in 1996 by a poverty reduction action program $^{3}$ that serves as the main document for this analysis alongside its more recent Programme for Global Development ${ }^{4}$. Both programs do not share the unorthodox views Sweden held in the past ${ }^{5}$, yet points out some original thought regarding research and higher education, which provide interesting contra points to the other strategies.

The material recently published by the World Bank and the UK that has been analyzed for this thesis is far more extensive than the programs recently published by Swedish and German agencies. Therefore the former have naturally presented some themes in more detail. Since the analysis of the overall consensus takes the most in-depth and most appropriate statement as reference, the World Bank and UK strategies are stronger represented in chapter two in terms of references.

\footnotetext{
${ }^{1} \mathrm{BMZ}$ (2001a).

${ }^{2}$ See Lembke, H. (1996), p. 192.

3 Formal title: Sida's Poverty Programme. Action Program to Promote Sustainable Livelihoods for the Poor and to Combat Poverty. SIDA (1996).

${ }^{4}$ Sida (2000 a-k).

${ }^{5}$ Sweden has had a history of strong opposition to generally accepted methods of poverty reduction, which peaked in the 1970 s with a proposal of a third way between capitalism and communism and has turned in a more conformational direction with the breakdown of communism. See Lembke, H. (1996), p. 191-194.
} 


\subsection{Poverty Reduction vs. Other Development Goals}

To provide a start into the topic at hand this analysis will begin by critically assessing the role of poverty reduction in the new strategic proposals. The aim to reduce poverty lies at the heart of many organizations in the field of development cooperation. The World Bank's "mission to fight poverty with passion and professionalism, putting it at the center of all (... its) work"1 , states this point as clear as in the UK position 'to focus all our development effort on the reduction of poverty' ${ }^{2}$. Similar statements build the basis for the Swedish ${ }^{3}$ position, and are spread even further for example in the programs of the $\mathrm{EU}^{4}$ and the DAC ${ }^{5}$. Even though this position is less pronounced compared to the other strategies ${ }^{6}$, the German action program also acknowledges poverty reduction as an important part of the overall German political agenda and as an overarching goal for development assistance ${ }^{7}$. These pronouncements necessitate a reflection on the justification of placing poverty reduction at the center of development cooperation and the implications of this approach.

First it has to be established that poverty reduction is a goal worth pursuing in development cooperation. Therefore it has to be acknowledged that moral responsibilities arise for individuals, while the government's responsible for development cooperations can be viewed as that of an agent who is supposed to act in the interest of its population as its constituent. For the individual, the point for a moral obligation for helping the poor can be drawn out of religious as well as ethical considerations, even though the emphasis shall be placed mainly on an ethical viewpoint here.

The contrast of 1.2 billion people living on less than one dollar a day ${ }^{8}$ and almost half the world's population on less than two dollars a day ${ }^{1}$ to the average

${ }^{1}$ Wolfensohn, J. (2000), p. V.

${ }^{2}$ Short, C. (2000), p. 7.

3 "Reducing poverty is the overriding goal of all Sida's operations". Sida (2000a).

It should be noted that despite this declaration poverty reduction is not one of the six developmental goals laid down by the Swedish parliament. See Sida (2000b).

${ }^{4}$ See EU (2001).

${ }^{5}$ See DAC (2001), p. 8.

${ }^{6}$ While in other strategies, e.g. DfID's, this point is drawn continuously and presented as the center of all its work, the German action program mentions the overarching position of poverty reduction only in one occurrence. See BMZ (20001a), p. 6 . Nevertheless the establishment of an action program for poverty reduction on the governmental level rather than on the level of the ministry points at the fact that poverty reduction receives some attention in the overall debate in the Germany. Also the German Minister for Economic Development and Co-operation points at the foremost priority of poverty reduction in the German Development cooperation. See Wieckzoreck-Zeul (2000b).

${ }^{7}$ See BMZ (2001a), p. 6.

${ }^{8}$ Dollar terms as part of poverty definitions refer throughout the text to Purchasing Power Parity conversions with the base year 1993 and might be slightly rounded. See exact definition on p. 42. 
income of $\$ 69$ e.g. in Germany ${ }^{2}$ shows a disparity which cannot be reconciled with a religious philosophy of sharing ${ }^{3}$. Nor can it be reconciled with ethical considerations such as those developed by Rawls, who utilized the concept of the veil of ignorance in explicating his ideas. ${ }^{4}$ In short: From under a veil of ignorance, with no idea about which life will be one's own destination, one presumably would choose an income distribution where no one lives in extreme poverty to avoid the chance of having to live this life. Rawls goes even further in his difference principle to conclude that social and economic inequalities are to be arranged so that they are to the greatest benefit of the least advantaged. Following Rawl's theory, there is a moral obligation for poverty reduction. ${ }^{5}$

Aside from purely moral-oriented demands, poverty reduction can also be pursued because of mutual benefits for developing countries as well as industrialized countries, enabling a situation of cooperation in which the interests of both industrialized and developing nations can be better realized jointly ${ }^{6}$. While the benefits of development and poverty reduction are evident for developing countries ${ }^{7}$, benefits also result for developed nations when conflicts are reduced and social tension released through improvements of the situation of the poor population.

The prosperity of the industrialized nations can be broadly defined as the availability of private and public material goods and intangible goods. Cooperation with developing countries can lead to greater productivity through specialization, thus increasing prosperity in terms of private goods. Economic development provides the developing nations with the skills, infrastructure and capital to use its productive forces efficiently. This enables them to participate meaningful in the international division of labor.

In the case of global public goods such as the availability of tropical rainforests necessary to stabilize the global climate, development cooperation can lessen the tension on these resources by compensating the developing

\footnotetext{
${ }^{1}$ See World Bank (2000a), p. 3.

${ }^{2}$ See World Bank (2000a), p. 274. (Value of 1999, which does not incorporate Purchasing Power Parity and has been converted from years to days by division of 365 .)

${ }^{3}$ For the Christian viewpoint see e.g.: 'Give to him that asketh of thee and from him that would borrow of thee turn not away.' The Bible, Matthew 5,42; 'And do not forget to do good, and to impart; for by such sacrifices God's favour is obtained.' The Bible, Epistles to the Hebrew 13,16 or the simile of the 'Good Samaritarian'.

${ }^{4}$ Rawls, J. (1971).

${ }^{5}$ For a discussion on the applicability of Rawl's theory to the ethical considerations in international contexts, see Beitz, C. (1979). He justifies the interdependencies of actions in the international context, which build the basis for the application of Rawl's theory. Based on this he uses the concept of the veil of ignorance to conclude that the income differential for individuals in rich countries is only justified as long as it is used for the improvements of the situation of poor individuals in poor countries.

${ }^{6}$ For the following discussion see Sautter, H. (1999), p. $13-28$.

7 Even though the benefits to the ruling social elite are debatable and require further conditions. See Sautter, H. (1999), p. $23-25$.
} 
nation. As for intangible goods such as external peace, security from terrorism and protection of human health, developing countries play a major part in providing these goods and can be encouraged to this end by development assistance.

Poverty reduction plays a key role in the provision of benefits for developed countries ${ }^{1}$, since it enables the poor people to participate in global specialization, and in the provision of global public goods. The reduction of poverty lessens the need of poor people to exploit scarce natural resources for pure survival, and contributes to intangible goods by lessening social tension. Thus the point can be made that poverty reduction is valuable also under the considerations of mutual benefit ${ }^{2}$.

The same considerations that point at poverty reduction as a goal for the mutual benefit of industrialized as well as developing nations already hint at the fact that poverty reduction might not be the only goal worth pursuing in development cooperation. For example, environmental concerns might warrant the compensation of medium-income inhabitants in the rain forest areas. Viable aims other than poverty reduction are for example the six goals laid down by the Swedish parliament for development cooperation: economic growth, economic and social equality, economic and political independence, democratic development, environmental quality and equality ${ }^{3}$. The German action program for poverty reduction refers to four dimensions of sustainable development: social justice, economic efficiency, political stability and ecological equilibrium ${ }^{4}$.

Goals that might contribute but are not limited to poverty reduction appear throughout the observed donor strategies. They include democratic development; human rights, equality and social justice; peace and international stability; prevention of migration; environmental concerns; and growth. Additionally, national political considerations such as extending trading opportunities $^{5}$ or the political sphere of influence have historically played a role

\footnotetext{
${ }^{1}$ The benefits for developing countries are obvious in terms of better life for its citizens.

${ }^{2}$ It has to be mentioned here that the mutual benefits are seen to arise only by committing to self-imposed obligations by the industrialized as well as the developing nations to make cooperation worthy in the eyes of both parts. For developing countries these include e.g. the rule of law, monetary and fiscal stability, reduction of protectionism, sustainable resource management and provision of health and education to the poor. For industrialized nations these include open foreign trade policies, promotion of financial stability and non-distorting agricultural policies. (For a deeper discussion on this see Sautter (1999), p. 25 - 27.) As will be seen in chapter two, these are among the demands included in the strategic proposal

${ }^{3}$ See Sida (1996), p. 1 and Sida (2000b).

${ }^{4}$ See e.g. BMZ (1997), p. 5.

${ }^{5}$ Notably this is still a strong reason justifying the Swedish development assistance. See Sida (2000c).
} 
in development assistance and are likely to continue to be influential. ${ }^{1}$ In most recent strategy papers these goals are refuted, as they are seen as counterproductive to development efforts.

These goals might also be interrelated to one another and to the aim of poverty reduction in mutual conducive or disadvantageous ways. The value of many of these concepts cannot be denied, as for example environmental concerns aim at securing our future survival and human rights build the foundation of our understanding of a fair society. These are by themselves valuable goals independent of the existence or absence of poverty.

Modern poverty reduction strategies which place poverty reduction as the main objective of development cooperation reconcile this single objective with the pursuit of the above mentioned other considerations (which will be referred to a secondary or auxiliary goals in the further text $\mathrm{t}^{2}$ ) by subsuming these as integral parts of poverty reduction ${ }^{3}$. In the cases of human rights and social justice this is achieved by broadening the definition of poverty to integrate the lack of political participation and exclusion from social life. For the other concerns, it can be shown that their pursuit - except for national political considerations contributes to a degree also to the reduction of poverty ${ }^{4}$. Thus, the aim to focus all activities on poverty reduction is assumed to be reconciled with the pursuit of other objectives.

The current approach to reconcile various goals of development assistance has two disadvantages that have to be taken seriously: The inhibition of change and the delusion of accountability. The assumption behind this criticism is that the pursuit of other goals besides poverty reduction leads only in part to a reduction in poverty while other parts (or projects) do not contribute to this but serve a cause on their own behalf. Figure 1 illustrates this point simplistically ${ }^{5}$. The dark shaded area marks those projects that serve poverty reduction as well as environmental or peace concerns. The entire shaded area shows those projects that do not have to cope with conflicting goals, while all projects or parts of projects that belong to the uncolored areas are conflicting in the way that they

\footnotetext{
${ }^{1}$ See e.g. Ashoff, G. (1996), p. 67 and 75 for remarks on German national political goals of development co-operation in regard to political ambitions against the accreditation of the DDR and regarding economic opportunities prior to the reunification.

2 'Secondary' and 'auxiliary' are used here to describe the view expressed in most strategic papers and is not intended to reflect the opinion of the author on the value of these goals in their own right.

${ }^{3}$ In figure 1 this would mean to extend the circle for poverty reduction to encompass the circles for the other goals, in this case environmental goals and concerns for peace and democracy.

${ }^{4}$ E.g. aims to protect the environment can also improve the living conditions of the poor. This argument will be taken up later in this chapter.

${ }^{5}$ The scale of the circles, their proportion to one another and the proportion of the overlapping zones to the non-overlapping zones are stylized and will vary by country or by region.
} 
contribute to a worthy goal but do not yield maximum benefits to the poor population. To make the interpretation of the figure more realistic, the white areas can be interpreted as those projects where the impact on poverty reduction is lower than for projects in the colored areas. Therefore they should not be conducted, even though their impact on one of the non-poverty dimensions might be large.

Figure 1: Poverty Reduction and its Interaction with Other Developmental Goals

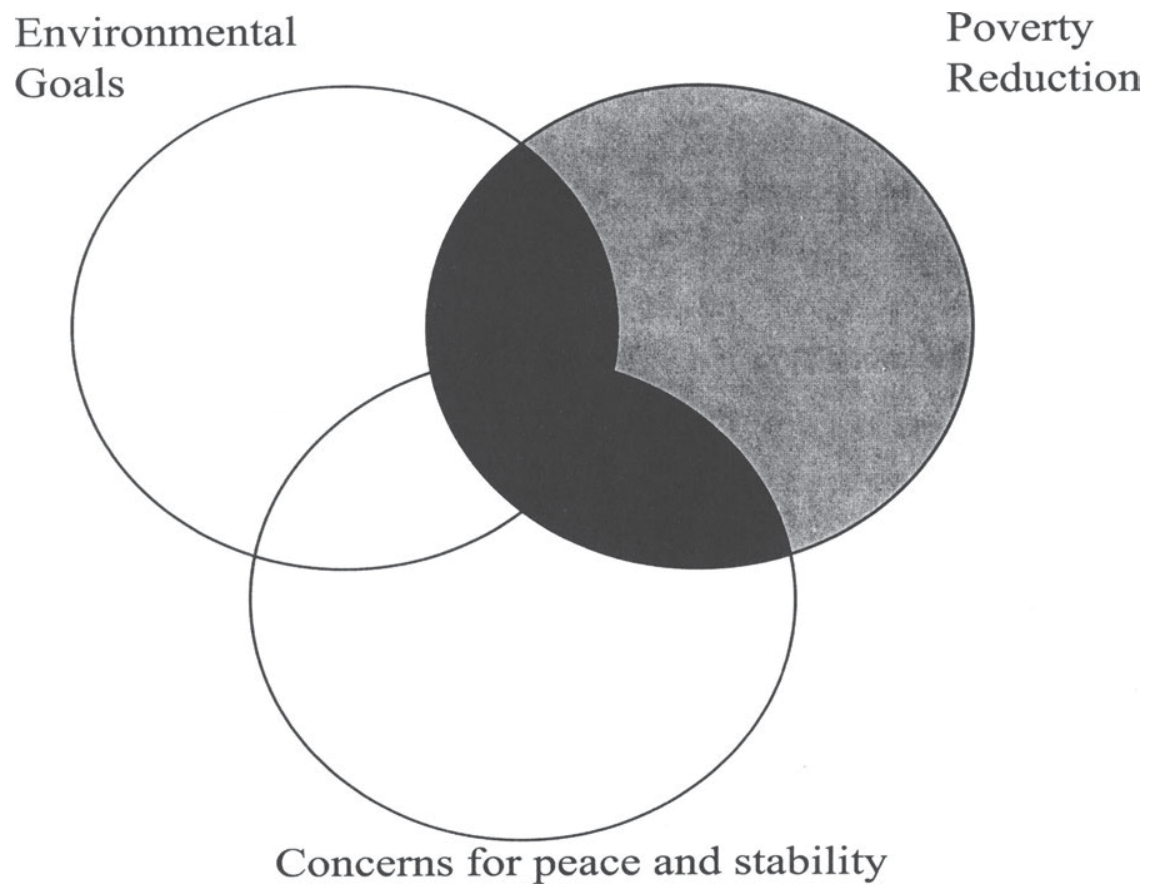

While the new strategies try to subsume all goals under the heading poverty reduction (in the figure also the non-colored areas) a strict limitation of poverty reduction as the goal of development assistance necessary limits the range of projects pursued to those with the highest impact on the reduction of poverty alone (only the shaded areas in the figure). This inherent conflict in using poverty reduction as the main goal while retaining all other goals has not been adequately addressed in the new strategies.

Environmental considerations make a strong case in this point. While it is undeniable that projects related to combat desertification have a strong impact 
on the poor inhabitants of marginal land and inner-city smog reduction measures will reach the urban poor (as well as the non-poor), this connection becomes far less stringent when looking e.g. at biodiversity ${ }^{1}$, as shall be shown with a short example:

In a dam project in Africa the preservation of a frog species living alongside the river has associated costs ranging at six million dollars. Due to the convention on biodiversity, the donor community is willing to preserve this species at a cost of six million dollars. In this fictitious example based on a real case it is hard to believe that the six million dollars spent on the preservation of this frog species have an impact on poverty reduction. Neither the option of potential use of the frog's genes, cited regularly as a reason to preserve biodiversity, nor the preferences of the local population, least the preferences of the poor, will justify the costs. The costs incurred ${ }^{2}$ are due to the legitimate will and preference of the western civilizations to protect the global environment, which the western world can pursue due to their relative prosperity ${ }^{3}$. Since these six million dollars will have hardly any effect on the poverty situation in the recipient country even in the long run, these costs should not be attributed to poverty reduction.

This example portrays an extreme view. Most real cases in development cooperation are less obvious in regard to their direct and indirect, short and longterm benefits for the poor people. Still, the general point of the example remains relevant for these projects as well. Not all projects conducive to the pursuit of secondary goals necessarily help in reducing poverty. Therefore, the assumption that poverty reduction, promoted as the overarching goal of development cooperation, can be pursued by aiming also at auxiliary goals only holds true for a certain portion of projects aimed at secondary goals, while for other projects the impact of poverty reduction remains low despite their value for secondary aims. To be able to make any meaningful distinction at all on the impact of projects on the poverty dimension, the current discussion claiming the value of many auxiliary goals on the poverty dimension has to be extended to a discussion about the criteria that describe a projects impact on poverty. This will help in judging the relevance of projects and in preventing the mislabeling of projects as reducing poverty when they in fact serve mainly other purposes.

\footnotetext{
${ }^{1}$ The CDB convention on the biological diversity has been accepted in its own right by most donor countries.

${ }^{2}$ The costs of preserving the frog species, not of building the damn that might bring the desired effect in poverty reduction.

${ }^{3}$ The benefit of the existence of the frog species to the western world will be less than the benefit for the local community due to the remoteness of the western population to it, but the utility of the money forgone by the western society is considerably less due to saturation effects of the benefit of money. Therefore the cost-benefit calculation for the western society might prove positive while the cost-benefit calculation of the extremely poor local population will be negative. The poor will likely use the money towards some more immediate aid.
} 
If it can be accepted that the pursuit of secondary goals does not necessarily contribute to poverty reduction, and if we accept that poverty reduction should serve as the central goal of development cooperations, projects that do not contribute considerably to current or future poverty reduction cannot be pursued given the premises. If all projects currently pursued under any of the secondary goals can be continued or extended on the basis that the secondary goals necessarily contribute to poverty reduction, the reform-oriented potential of the new initiatives is severely limited. If poverty reduction is sincerely believed to be the challenge to be tackled in the next decade, each development project has to be assessed in regard to its impact on poverty reduction. Due to limited resources those projects with the highest contribution to poverty reduction have to be pursued, while taking into account the long-term effects, indirect effects and the synergies of projects.

Next to inhibiting reforms the realization of non-poverty focused projects also reduces the accountability of the development organizations to its constituents. Concerns about the effectiveness of developmental assistance have led to public reluctance to provide the necessary funds. Projects not aimed at poverty reduction constitute costs without measurable benefits in this respect and therefore dilute the picture.

This assessment allows two possible ways to cope with the situation. First, poverty reduction could be placed as the overarching goal with the consequence of eliminating all projects that do not contribute to this single goal. Such a strategy has the advantage of a strong focus, simplifies the cooperation between donors and uncompromisingly tackles one of the greatest sources of injustice of our time. Out of moral considerations this might be the appropriate solution for some people, maybe a majority of them, which would in turn justify this approach for an industrialized country's government. If such a strategy is pursued, it should be done deliberately and with knowledge of the consequences, free from all forms of delusion of this goal and knowing that other goals will not be attainable if they are not contributing to poverty reduction, yet also knowing that this will be the only way to minimize poverty. This approach has the disadvantage of tackling mainly one problem - poverty reduction - while considering the others only as long as they contribute to the primary goal.

\footnotetext{
${ }^{1}$ This holds true by definition, since projects under this strategy are assessed only in regard to their impact on poverty. This impact needs to be broadly viewed to include projects directing money to other sources, maybe even to the middle or upper income groups, if that is seen to indirectly be of most benefit to the poor people. Thus, the choice of the aim does not easily hint at the strategy to be pursued. Nor does it provide any guidance on the time frame to be used in maximizing the impact, so that trade-offs between projects resulting in immediate but vanishing impact on poverty and projects contributing to the reduction of poverty in the long term is not resolved. The discount factor placed on a delay of betterment of their situation by the poor themselves might be of guidance here.
} 
A second way that allows for a minor integration of other development goals while retaining a high degree of focus could be described as minimumacceptable poverty focus. A strategy with this orientation would establish poverty reduction as a main goal with a certain minimum degree of contributions going to this goal ${ }^{1}$. Additional secondary goals that are considered as especially important can then be stated and pursued even if the associated projects do not contribute primarily to poverty reduction. They are financed from the remaining funds not designated exclusively to poverty reduction. These funds should be accounted for separately to enable a better transparency of inputs and outputs of development assistance. Since other issues than poverty reduction especially concerning the environment are also pressing, this second approach seems to be the more practical solution.

This allowance for other goals besides poverty reduction will also help to avoid a credibility trap, in which the development agencies promise poverty reduction to its citizens while they themselves cannot (or can only marginally) influence the success factors of the promised outcomes, since these are mainly determined by the policies of the autonomous governments of developing countries $^{2}$. If poverty reduction fails to manifest as promised due to uncontrollable decisions of third parties - despite high efforts of the development agencies - the credibility of the agencies is strongly reduced and the willingness of their constituents to commit resources to the purpose of poverty reduction will likely tend to decline ${ }^{3}$.

Except for a stated minimum contribution to poverty reduction the Swedish International Development Agency (Sida) has embraced the second way ${ }^{4}$. In the selection of its projects their impact on poverty is the main criterion', while 'in exceptional cases projects (...) which do not have any demonstrable connection with poverty reduction' ${ }^{\prime}$ can also be supported if they are otherwise strongly motivated. These will be accounted for in a separate category.

This approach is no panacea to all problems, as it might be difficult to quantify exactly the effect of projects on poverty reduction and on other matters in advance, especially for long term, structural oriented projects. A move away from structurally oriented projects towards short-term self-help oriented approaches only because of measurability problems would be counterproductive. On the other hand, given the premise that poverty reduction has already been agreed upon as the primary goal, this framework takes the consequences that follow from this premise seriously. The limited amount of resources available for development cooperation will in all cases demand a

\footnotetext{
${ }^{1}$ E.g. $90 \%$ of all ODA funds has to go into poverty reduction.

${ }^{2}$ See Sautter (1995), p. 135.

${ }^{3}$ This idea will be expanded in the later discussion of the international development targets.

${ }^{4}$ Despite declaring poverty reduction as its overarching goal.

${ }^{5}$ SIDA (1996), p. 7.

${ }^{6}$ SIDA (1996), p. 8.
} 
judgment about the extend to which one project will reduce poverty compared to another to determine which will receive funding. To link these considerations to a framework where poverty reduction has to be served at least to a predetermined extent has the advantage to institutionally prevent other goals to gain the upper hand and to provide the development cooperation with a clear focus, while being honest about the level at which other goals are pursued.

Still, the concentrated organizational focus that can be reached through aiming exclusively at the single 'overarching' goal of poverty reduction will be harder to achieve in a 'minimum-acceptable poverty focus' setting allowing for several goals. No matter which solution will prove superior, the current assertion of many development organizations to be able to concentrate fully on poverty reduction while fulfilling all other relevant obligations as well will be hard to defend in the long run. This is due to the inherent conflicts of goals that cannot be fully reconciled. The limited amount of resources available for development cooperation will make choices between goals necessary, and the current notion that everything from education over health care to environmental protection is poverty reduction does not provide the decision criterion needed to make these choices.

Summarizing, poverty reduction can been established as a worthy goal based on considerations of the moral obligation of the affluent individual. A series of other goals exist, with potentially equally valid justifications, which cannot in all cases be pursued simultaneously with the goal of poverty reduction. Therefore, the want to fight poverty while fully accommodating all other goals is not feasible. Two ways to cope with this are presented: First, Poverty reduction is established as overarching goal, with the consequence that some other relevant goals might not be attainable. Second, a minimum-acceptable poverty focus, i.e. a minimum financial involvement dedicated to this purpose, is prescribed. The fraction of remaining funds could be used for other purposes in cases of high importance. Both ways are feasible, yet the second seems to be better suited to the real conditions and goals in development cooperation.

The development of the consensus that led to the current focus on poverty reduction within the development community and to the commonly proposed measures within the newly published strategies on how to translate this focus into actual benefits for the poor is at the core of the following chapter. 
Philipp Kircher - 978-3-631-75366-8 


\section{Chapter 2 \\ Poverty Reduction as Focal Point of Development Cooperation: The International Consensus}

\subsection{The Evolution Towards the Current Consensus}

\subsubsection{Overview}

The current consensus on the measures most conducive to poverty reduction, which will be the concern of the majority of this chapter, is in large part influenced by the experiences gained in the development process over the last 50 years. The problems that arose from any conception for development that had been adopted since the 1950s led to subsequent reformulation of the conception to address these. This 'trial and error' approach has also preceded the current proposals on poverty reduction, as is most pronouncedly voiced by the UK government:

"There have been two flaws in models of development over the past halfcentury. The first was characterized by a belief that the State (sic!) should extend its control over production and trading activities, and over the allocation of resources and prices, in a way which created distortions and led to inefficiencies and corruption. The second was a belief in a minimalist State (sic!) and unregulated market forces, which failed to secure economic growth, and led to increases in inequality across the world. There is now an opportunity to create a new synthesis".'

This quotation shall serve to motivate the following discussion of the evolution of development strategies. The discussion provides the basis for understanding the current strategic conceptions and the problems they want to address. It will be seen that much of the current consensus has been retained from previous approaches, yet with a strong concern for avoidance of the shortcomings of these. The quote of the UK government also hints at a strong dispute over the last five decades between a more structuralist view of development in which the states takes an active role of intervening in the markets and a neo-classical view in which the play of the free market forces is the paradigm. A short explanation of both will be integrated into the discussion of the past strategies.

This discussion will reflect the main trains of thought that have influenced the policies of the World Bank. This approach has its limitation: It focuses only on one agency and neglects other viewpoints. In order to provide a comprehensive view of the past strategies but also to stay comprehensive in the analysis the

${ }^{1}$ See UK government (1997), p. 12. 
constraint to one viewpoint was necessary. The choice for the World Bank has its advantages as it represents 182 member countries ${ }^{1}$ and can thus be seen to provide broad-based picture. ${ }^{2}$ The World Bank has also been extremely influential on the direction in which development strategies have turned, which is due to the high volume of its transactions and the high level or research conducted by its staff. Therefore, an understanding of the evolution of the viewpoint of the World Bank on development can provide valuable insights on the overall viewpoints on this topic.

The mainstream ideas that have dominated the discussion on development within the World Bank and many other development agencies in the past can be described in four eras where the different goals of development were seen as

1. Growth in the 1950 s

2. Redistribution with Growth in the 1960s

3. Fulfillment of Basic Needs in the 1970s and

4. Free market forces and a solid economic framework in the 1980s and the beginning of the 1990s.

5. Poverty reduction through increasing the self-help potential of the poor in a conducive national framework in the late 1990 s and today ${ }^{3}$.

These shall be discussed in turn.

\subsubsection{Growth}

After the Second World War, the way to help the people living in poverty was seen in a path of steep growth in terms of real income per head ${ }^{4}$. Poverty was seen as a purely economic matter of lack of income. Growth was promoted as the dominant goal in development on the basis that, independent of the method used in its advancement, growth leads automatically to a higher degree of employment and to a higher standard of living ${ }^{5}$. It was assumed that the benefits of increased wealth through the growth process would spread to the entire society even if the initial benefits accrue to the non-poor or even only to the rich, as their spending, consumption and investment in turn leads to employment and

\footnotetext{
${ }^{1}$ This number is for 2001. For a more detailed discussion of the background of the World Bank see the chapter on 'World Bank Background'.

2 The 182 member nations 'own' the World Bank according to their contributions to the worlds economic activity, which implies that rather than a majority opinion the World Bank presents a weighted majority view with a bias towards the industrialized countries. Yet since the strategies analyzed in the remainder of this thesis refer also to industrialized countries and the World Bank itself, this should not harm the value of this viewpoint in understanding the new donor strategies presented later.

${ }^{3}$ This goal is expended upon in later chapters.

${ }_{5}^{4}$ See Meier, G. (1989), p. 82.

${ }^{5}$ See the discussion on the historical views of the International Labor Organization (ILO) in ILO (1996), p. 2.
} 
wage opportunities for those people in social and economical positions below them. The spreading of wealth to those on the immediately lower level would spur the income of those people in a social and economical position on an even lower level by increasing the demand for their services and products and offering new employment opportunities, with this spiral continuing until the proceeds of growth have "trickled-down" to all levels of the society. Distributional effects were already discussed at that time ${ }^{1}$, but did not gain prominence in policy formulation due to the prevalence of the above-mentioned assumption of a trickle-down effect. The strategies for development focused "mainly on large investments in physical capital and infrastructure as the primary means of development"2.

\subsubsection{Redistribution with Growth}

This growth-based strategy builds the mainstream focus for about a decade before the dissatisfaction with the low impact of the strategy on the situation of the poor led to a shift in the approach to development. It was realized that growth alone does not suffice to reduce poverty and that growth accruing to the poor does not necessarily trickle down to them. Growth accruing more directly to the poor, fostered by a stronger role of the state in the economic sphere, was placed in the center of the discussion that was at the heart of Chenery's, Ahluwalia's and others work on 'Redistribution with Growth'.

Their argumentation rests on the observation "that more than a decade of rapid growth in underdeveloped countries has been of little or no benefit to perhaps a third of their population." ${ }^{3}$ In pursuit of an explanation to this evidence, they came to reject the assumption of a trickle-down effect as well as the traditional assumption of welfare economics. Welfare economics assumes that optimal growth should be achieved by any measure and that - after this optimal economic performance is achieved - the optimal distribution can be undertaken by fiscal measures. This traditional view thus regards growth and distribution as phenomena that can be tackled independent of one another. Chenery on the contrary emphasizes that at least for poorer countries a development strategy will have "growth implications for different groups in society that can be modified by fiscal measures only within fairly narrow limits." ${ }^{4}$ This implies that growth, investment and distribution cannot be separated, but have to be integrated into one single strategy.

\footnotetext{
${ }^{1}$ See e.g. Lewis' extensive work on surplus labor in which he considers lack of growth in the subsistence sector as a cause for worsening income distribution. See Lewis (1954).

${ }^{2}$ See the outline provided by the World Bank on the history of poverty reduction strategies in World Bank (2000a), p. 6 f.

${ }^{3}$ See Chenery, H. et al (1974), p. xiii.

${ }^{4}$ See Chenery, H. et al (1974), p. xiii.
} 
The mechanisms that promote economic growth as their main concern are rejected because they are assumed to promote greater income concentration at the beginning of the growth process. This hypothesis, emphasized most strongly by Kuznets ${ }^{1}$, leads if accurate to the worsening of the relative and possibly absolute position of the poverty groups in the society ${ }^{2}$. To counter this, a development goal is postulated that focuses more on the growth of the poorer population. Instead of the GNP as a measure of the welfare advancement to society Chenery et al. propose a weighted measure giving higher importance to increases in growth in poorer socio-economic groups ${ }^{3}$. This measure of welfare shows that poverty in this concept is still based solely on monetary income $^{4}$, while the novelty consists in the reflection that the marginal contribution to welfare accruing from an income increase is greater at lower income levels, as reflected crudely by assigning the attached weights according to welfare considerations. ${ }^{5}$

In his theory to maximize this welfare function, Chenery does not want to rely on either neoclassical or Marxist wage theories ${ }^{6}$, since both regard income distribution as determined by the level of employment and the remuneration of the factors of production, capital and labor, with differences resulting from assumptions on market behavior. Chenery refutes already the basic idea of employment and the interaction of capital and labor, on the basis that in underdeveloped countries many poor people can neither be classified as employed or unemployed, but "half of the poor are self-employed and do not

\footnotetext{
${ }^{1}$ For an expansion on the Kuznets curve and its underlying hypothesis see Kuznets, S. (1955). The validity of this hypothesis is empirically controversial and current poverty reduction strategies rather consider the impact of growth on equality as a determined by forces like distribution of education, changes in the returns to education, labor market choices as well as initial inequalities prior to the growth process without a concern of the time frame of the growth process. For an expansion of this see World Bank (2000a), p. $52-57$.

${ }^{2}$ See Chenery, H. et al (1974), p. 1 and 11 to 19.

${ }^{3}$ See Chenery, H. et al (1974), p. $38-42$. Here the welfare function is exemplified as $\mathrm{G}=$ $\mathrm{w} 1 * \mathrm{~g} 1+\mathrm{w} 2 * \mathrm{~g} 2+\mathrm{w} 3 * \mathrm{~g} 3+\mathrm{w} 4 * \mathrm{~g} 4+\mathrm{w} 5 * \mathrm{~g} 5$, where $\mathrm{w}$ indicates the weight given to the growth of the income of the population in a certain quintile of the income distribution and $g$ is the corresponding growth rate of the income in this quintile. If welfare concern were placed only on the poorest quintile, all weights wi would be zero except w1, which would equal one (with 1 being the poorest and 5 the richest quintile).

${ }^{4}$ The income concept is discussed in detail regarding absolute and relative income and the pros and cons of income vs. consumption as a measure (See Chenery, H. et al (1974), p. 4 11). Measures of poverty beyond a monetary focus are of no importance in this discussion.

${ }^{5}$ This will generally look like $w 1 \leq w 2 \leq w 3 \leq w 4 \leq w 5$ and at least one wi $<$ wj with $i, j \in$ $\{1,2,3,4,5\}$. This will generally give a higher priority to the welfare of low-income quintiles and also satisfies the concern for only the poor where $w 1=1$ and wi $=0$ for all $i \in\{2,3,4,5\}$ (see footnote above).

${ }^{6}$ See Chenery, H. et al (1974), p. 43.
} 
enter the wage-economy"" In this condition, rather than relying mainly on employment creation, higher concern is placed on the distribution of various forms of assets among the different groups of society. This is the concern of the integrated theory of "growth-cum-distribution". Thus, the traditional objective of promoting employment in order to increase the total wage bill, leading to partial benefits to the poor, is only a part of the objective of this strategy. The alteration of the pattern of concentration of productive assets in favor of the poorer groups of society over time and the reduction of barriers to entry into more profitable types of production and employment is regarded as equally important ${ }^{3}$.

Out of the four perceived generic strategies of (i) maximizing GNP growth with benefits for all; (ii) redirecting investment to poverty groups; (iii) redistributing income to increase the consumption of the poor; and, (iv) transfer of existing assets, Chenery and others regard the second strategy as most promising. They posit that the first lacks focus, the third cannot be sustained for an extended period and the fourth is politically unlikely to be successful. The redistribution of investments in favor of the poor in forms of e.g. human capital in form of education, provision of public services and access to credit is projected to result in higher productivity and wages in the organized sectors as well as greater output and income in the self-employed sector ${ }^{4}$.

To achieve this, Chenery and his colleagues rely on elements of private as well as public ownership and democratic as well as authoritarian features, based on a diagnosis of the available administrative and political options available. ${ }^{5}$ Yet a tendency in favor of a structuralist viewpoint over a neoclassical, freemarket oriented approach can be made out. The general paradigms of the structuralist viewpoints shall therefore be discussed here in short.

At the core the structuralist viewpoint rejects the assumption of mainstream neoclassical economic thought that free markets are the most efficient way of economic interaction. They should be free of state intervention. The structuralist approach is based on the perception that the fundamental concepts of the neoclassical theory cannot readily be transferred to the situation in developing countries due to technical and behavioral rigidities in these countries ${ }^{6}$ and due to

\footnotetext{
${ }^{1}$ For a greater analysis of the rejection of neoclassical and Marxist employment concepts see Chenery, H. et al (1974), p. 43, 44.

${ }^{2}$ See Chenery, H. et al (1974), p. 38. (Highlighted by the original author).

${ }^{3}$ See Chenery, H. et al (1974), p. 44.

${ }^{4}$ For a discussion of the benefits of the redistribution of investment and the general build-up of assets by the poor see Chenery, H. et al (1974), p. 46-49.

${ }^{5}$ See Chenery, H. at al (1974), p. xvii. This in turn is the major source for the criticism that Jungfer expresses about this strategy roughly two decades later. See Jungfer, J. (1991).

${ }^{6}$ Even the basic assumption that increased prices lead to higher supply while lower prices lead to lower supply due to the potential to make a greater profit when prices are high is rejected in some extreme views on economic interaction in developing countries. It is claimed that a mentality focused on the fulfillment of a given level of needs would lead to an increase
} 
market imperfections ${ }^{1}$. These imperfections are attributed to lags in the adjustment process to demand or trade changes, shortages and surpluses, low elasticities of supply and demand, and other characteristics attributed to developing countries. For example, population growth too high to be absorbed into the high-productivity sector of the economy is seen as the cause for elastic ${ }^{2}$ supply of unskilled labor concentrated in the agricultural and service sectors ${ }^{3}$, refuting the classical assumption of more inelastic ${ }^{4}$ demand for the labor market and the associated policy implications. Further, transformations in the productive structure are regarded as the cause for disequilibria in the factor markets because the adjustment takes an extended amount of time and might be inhibited by low factor mobility or lack of incentives for producers to enter new markets. This inhibits the fast, in the neoclassical analysis immediate, return to economic equilibrium conditions.

These disequilibria that are assumed to result due to failures to reallocate resources efficiently build the basis for the policy advice of the structuralist approach. Disequilibria leading to differences in returns to labor and capital in different uses ${ }^{5}$ open the chance for economically preferable state interventions. Growth is supposed to be spurred by transferring factors that are, due to market imperfections, occupied in less productive uses to occupations with higher productivity - creating an obligation for the state to foster this transfer. The state is called for to take an active role by detecting and reducing bottlenecks, reallocating resources in disequilibrium situations and enabling the adoption of productive technology from higher developed countries. Since disequilibria are considered to be larger in developing countries than in developed countries due to more frequent and higher-impact shocks, the interventionist role of the state is supposed to be correspondingly larger. In some cases these thoughts were coupled with dependency theoretical views strongly refuting international trade. ${ }^{6}$

in production when the prices rise, because more has to be sold to achieve the same level of satisfaction, while with rising prices the output can be reduced. For a discussion of these views see Dürr, E. (1981), p. 580.

${ }^{1}$ See Jungfer (1991), p. 13.

${ }^{2}$ While generally the structuralist argument points out the prevalence of inelastic demand and supply, referring to an unresponsiveness of citizens to the price mechanism, this argument is different for the labor sector. Here the argument relies of full elasticity, as abundant labor supply from the informal sector is willing to enter any open positions in the formal sector.

${ }^{3}$ See Chenery, H. (1986), p. 98, 99. This inability to absorb labor in the high productivity sectors is partly explained by the low substitution ability between labor and capital.

${ }^{4}$ In the structuralist viewpoint the labor supply is nearly fully elastic, portrayed by extremely high wage elasticity. The neoclassical viewpoint on the contrary relies on a more, though not fully, inelastic supply portrayed by moderate wage elasticity.

${ }^{5}$ Chenery, H. (1986), p. 99 views this as the more likely result of market imperfections, rather than the total failure of markets to clear.

${ }^{6}$ The dependency theory assumes an exploitative nature of the relationship between the advanced industrialized nation and the dependent developing nation. It is seen contrary to the industrialized nations interest to compete with another industrialized nation. Therefore they co-operate with traditional national elites and use their influence to access domestic resources 
Overall, the strong role of the state in planning and management of the economy for its greatest contribution to the national development is demanded in the structuralistic viewpoint.

Chenery et al. considered as areas suitable for intervention the factor markets, ownership and control of assets, commodity markets and the state of the technology ${ }^{1}$. Notable emphasis in this context is placed on the intervention in capital markets, the redirection of investment, taxation of wealth, restrictions of domestic production, restrictions of foreign trade and the adaptation of technology, which rest on a strong believe in the state's ability for efficient planning and control.

Chenery et al. did not unambiguously support the structuralist viewpoint. In some cases they also opted for a greater play of free market forces and in other they proposed both structuralist and neoclassical options dependant on the specific situation. Especially in capital markets institutional barriers were perceived as leading to under pricing of capital in the modern sector while leading to marked overpricing of capital in the traditional and unorganized sectors. Policy action is required to reduce this discrimination of the laborintensive sectors by reducing state intervention and distortions ${ }^{2}$, which presents an element of the neoclassical school of thought. Concerning the build-up of assets, two strategies are seen as viable, with more or less structuralist tendencies. One proclaimed strategy would yield an increasing socialization through restriction of private sector expansion combined with growing public investment rate and thus a transfer of assets to society and, in turn, to the poor. The other viable strategy is seen in providing direct investment in favor of private assets by increasing income through infrastructure investments and other inputs such as irrigation and land improvement.

Special emphasis is placed on human development due to its impact on productivity of the poor. While investment in the modern sector might provide faster growth, this is not seen as aiding the poor because trickle-down effects are seen unlikely to occur in the medium-term ${ }^{3}$. The two strategies mentioned above show the ambiguity of the authors in regard to their policy proposals, leaving them open to structuralist as well as neoclassical alternatives. This can also be seen in the strategic recommendation for commodity goods. On the one hand quantitative restrictions on both domestic production and foreign trade, indirect taxation and production controls are proposed to shift demand from capitalintensive modern goods towards more labor-intensive goods. On the other hand

for surplus extraction to prevent economic development. This leads to domestic surplus being in large part expropriated by foreign capital. The policy recommendation is the withdrawal from trade with industrialized nations. For a deeper analysis see Palma, G. (1978), p. 105, 106.

${ }^{1}$ See Chenery, H. et al (1974), p. 73.

${ }^{2}$ See Chenery, H. et al (1974), p. $79,80$.

${ }^{3}$ See Chenery, H. et al (1974), p. $78-83$. 
foreign trade possibilities should be seized for labor-intensive products if the first approach is difficult to implement ${ }^{1}$. The demand for adaptation of technology for the local conditions by research rounds up this strategy ${ }^{2}$.

\subsubsection{Basic Needs Approach}

In the 1970s this view was challenged because the experience with this strategy did not have the desired impact on the reduction of poverty. It became visible that a pure concentration on monetary growth even if accruing to the poorest quintile $^{3}$ of the population was not sufficient to improve the living conditions of the poor people. A new focus on the individual and his personal well-being also in non-economic terms, aided by a stronger role of the state towards this end, becomes the dominant strategy.

While the strategy of redistribution with growth proposed a focus on the poor and promoted investment in poor people's assets, its main focus remained on the growth of monetary income. Investment in poor people's assets was seen as one of the means to achieve this. This perception was reversed with the introduction of the Basic Needs Approach, which postulated the fulfillment of the basic needs of each individual as the goal of development, while growth of income was regarded as only one of the means to achieve this. This shift in perception was evident in the influential speech of the president of the World Bank Robert McNamara at the board of governors meeting of the World Bank in 1973 in Nairobi, in which he depicted the devastating situation of the developing countries and called for a new strategy ${ }^{4}$. He supported the work of Paul Streeten et $\mathrm{al}^{5}$ who substantiated the Basic Needs approach towards a comprehensive supplement to existing strategies ${ }^{6}$. The following discussion is based on the view of Streeten, which is a limitation the comprehensive literature on this topic, yet legitimated by the fact that he was on of the leading voices of this development.

It will be seen at the end of this discussion that Streeten et al., while retaining the conception of the market for general allocation, favor a strong state. This is true not only in regard to public service provision, but also to drastic limitations of the market mechanism if it is conducive to the fulfillment

\footnotetext{
${ }^{1}$ See Chenery, H. et al (1974), p. $86-88$.

${ }^{2}$ See Chenery, H. et al (1974), p. 88f.

${ }^{3}$ The percentile was not predetermined in Chenery's argumentation and could be set at any other value.

${ }^{4}$ See McNamara, R. (1973).

${ }^{5}$ Streeten, P. et al (1981).

${ }^{6}$ It could be seen as a full flagged strategy in its own right, but the authors point out that in a full strategy goals other than basic needs will have to be accommodated as well. To bring out sharply the distinctive features of this approach, they see it as "supplementing or complementing existing strategies." Streeten, P. et al (1981), p. 33.
} 
of basic needs. Thus, they subscribe to a strongly structuralistic viewpoint ${ }^{1}$. Even though the views of Chenery et al. have influenced the thinking of the World Bank in terms of focussing stronger on the basic needs of the individual, their structuralistic viewpoint was not adopted to this extend by the World Bank or most other donor nations. A notable exception to this is the Swedish position. Influenced among others by Gunnar Myrdal who refuted the applicability of high elasticities of supply and perfect markets ${ }^{2}$, Sweden's government proposed of a Third Way between capitalistic free markets and socialist regulation in development based on markets with a high degree of state intervention ${ }^{3}$ in the 1970s. The Swedish position in regard to development strategies changed in the 1980s to embrace again a more market oriented mainstream orientation. The structuralist view also received strong support among many developing nations. ${ }^{4}$

A strong contrast of the Basic Needs strategy to those prior is the broadening of the definition of poverty beyond the lack of monetary income. "Poverty is characterized by hunger and malnutrition, by ill health, and by the lack of education, safe water, sanitation, or decent shelter" of the basic needs as perceived by Streeten et al ${ }^{6}$. This concern with nonmaterial needs in their own right ${ }^{7}$ does not include a disregard for growth or productivity. It is claimed by Streeten et al that the Basic Needs approach indeed fosters productivity by increasing the demand for more basic goods that are more labor intensive and by increasing the quality of the labor force through better health

\footnotetext{
${ }^{1}$ Even though the view of Chenery et al. have influenced the thinking of the World Bank in terms of focussing stronger on the basic needs of the individual, their structuralistic viewpoint was not adopted to this extend by the World Bank or most other donor nations. A notable exception to this is Swedish position.

${ }^{2}$ See Myrdal, G. (1968).

${ }^{3}$ Which is basically the same as structuralism. For an expansion on the Swedish tradition of development see e.g. Lembke, H. (1996).

${ }^{4}$ See e.g. Reynolds, L. (1983), p. 92, 93. This change of orientation towards greater structuralism in developing countries is also reflected in Sen (1983), p. 747. The reasons why different policies have been adopted might not necessarily have been economically induced, but might as well be a political concern, yet the economic theories have provided the ground for justification.

${ }^{5}$ See Streeten, P. et al (1981), p. 159.

${ }^{6}$ An exact definition of basic needs is not provided. Rather, a discussion of various forms to determine basic needs is undertaken. According to this discussion, basic needs can be determined either by minimum specified quantities, consumers themselves could determine what basic needs are and chose only constraint by a the necessary income (which is a difficult construct, since the income constraint itself depends on the wishes of the individual, the author), the state should determine the needs, and last basic needs could not be stated but fulfilled implicitly by the participation of the poor in the decisions and implementation of projects, e.g. political mobilization. For a lengthier discussion of this see Streeten, P. et al (1981), p. $25 \mathrm{f}$.

${ }^{7}$ See Streeten, P. et al (1981), p. 33.
} 
and education ${ }^{1}$. Thus quantity and quality of labor increases lead to growth at least to the people living in poverty.

This is seen as one contributor to the goal behind this strategy: To meet basic needs in a short period of time, possibly in one generation. ${ }^{2}$ With the growth strategies pursued prior to the Basic Needs strategy this would not be possible, according to Streeten et al, even when redistribution is taken into account. ${ }^{3}$ The Basic Needs strategy purportedly enables the fulfillment of basic needs at a substantially lower GNP per head by affording fewer resources to reach the same impact due to a more focused approach. And it attracts a larger amount of resources, as more people are willing to commit resources to concrete human goals rather than to abstract concepts such as egalitarianism as proposed by redistributive arguments (which lack intrinsic value for most people ${ }^{4}$ ). Streeten summarized his perception of the advantages of the Basic Needs approach over prior concepts in the following points ${ }^{5}$ : The approach provides "all human beings with the opportunity for a full life" 6 because a full live presupposes meeting basic needs no matter how 'full' is defined. The concept also is less abstract and more specific and disaggregated because it looks at individuals and their immediate problems. This takes up the concept of individual poverty, in contrast to a concern about poor nations. This in turn provides organizing and integrating power for intellectual as well as political considerations, since focus on concrete problems is provided. Specific humanitarian problems of individuals also appeal stronger to members of the national and international community and therefore can help attracting resources.

Regarding the implementation of the approach, the Basic Needs concept does not prescribe a fixed set of measures in an integrated framework. Still some themes reoccur and provide insights into measures that are seen important in achieving the fulfillment of basic needs. Regarding the provision of services, the state is seen as the most efficient provider for services in the areas of education, health, water and sanitation. Since these aspects are linked in their effects, they should be pursued together. For example female education is seen as beneficial to nutrition and health practices, reduced fertility and improved education.? Subsidization or transfer payments should ensure affordability, with finance

\footnotetext{
${ }^{1}$ See Streeten, P. et al (1981), p. 40.

${ }^{2}$ See Streeten, P. et al (1981), p. 3.

${ }^{3}$ Even with transfers of $2 \%$ of the GNP per year, the consumption of the poorest $40 \%$ can only be raised $23 \%$ over a 25 -year period according to the computations in Streeten, P. et al (1981), p. 16. But this computation leaves out human development aspects that were already incorporated in Chenery's view on Redistribution with Growth.

${ }^{4}$ For a detailed discussion on the advantage of the humanitarian view over the egalitarian concept see Streeten, P. et al (1981), p. $17 \mathrm{f}$.

${ }^{5}$ See Streeten, P. et al (1981), p. $21-23$.

${ }^{6}$ See Streeten, P. et al (1981), p. 21 . (Highlighted by the original author).

${ }^{7}$ For a deeper discussion on the linkage effects see Streeten, P. et al (1981), p. $153-155$ and $48 \mathrm{f}$.
} 
provided through progressive taxation and indirect taxation of luxury goods. ${ }^{1}$ Transfer payments are also considered as a means to reach the substantial proportion of people who cannot contribute productively due to sickness or old age and are therefore neglected in a growth-oriented approach. ${ }^{2}$ Still emphasis is placed also on the productivity of the poor, especially in the sector of smallscale farming and the production of food for domestic consumption where small-scale farmers have at least the same saving quota and produce more labor intensive and efficient as large-scale producers ${ }^{3}$; a point among many that has been taken over into today's strategies. This applies also to the ideas on the political situation.

In the political sphere Streeten et al see the problem that a basic needs approach is inevitably connected to a shift in the power distribution in a country, which needs to be achieved by mobilizing the poor themselves. ${ }^{4}$ The participation of the poor in the organization, implementation and delivery of services is essential for this ${ }^{5}$ and needs to be accompanied by a reorganization of the administration through decentralization and simplification of procedures. ${ }^{6}$ Streeten et al demand the focus of the work of the administration on the fulfillment of the basic needs of the people. They assume a time of transition from the former growth oriented strategies to the new strategies in which the increased demand for goods fulfilling basic needs, e.g. basic food items, will drive up their prices in a count-productive way that places especial burdens on poor consumer. ${ }^{7}$ National measures and the support of the international community should counter this effect.

This rather weak conception calls to attention one of the deficits of this approach, which is the supply side. An increase of demand for basic needs items is fostered, while impacts of shortages in the supply of low cost basic needs items are not further investigated but are to be bridged by national or international aid efforts. In concern of the international community, further demands regard a need to qualify their people employed in labor-intensive industries for better, more remunerative positions to enable the developing countries to expand in labor-intensive low skill industries. The developed countries are furthermore encouraged to provide development assistance only to poor countries that implement basic needs oriented strategies. ${ }^{8}$

As will be seen in the later sections of this chapter, many of the points emphasized by the Basic Needs strategy were adopted by the modern

\footnotetext{
${ }^{1}$ See Streeten, P. et al (1981), p. 35.

${ }^{2}$ See Streeten, P. et al (1981), p. 37.

${ }^{3}$ See Streeten, P. et al (1981), p 11 and 151.

${ }^{4}$ See Streeten, P. et al (1981), p. 26.

${ }^{5}$ See Streeten, P. et al (1981), p, 148.

${ }^{6}$ See Streeten, P. et al (1981), p. 51, 58 and $152 \mathrm{f}$.

${ }^{7}$ See Streeten, P. et al (1981), p. 59.

${ }^{8}$ For a deeper discussion on the role of the international community see Streeten, P. et al (1981), p. $166-168$.
} 
strategies proposed today. These include the broad definition of poverty, the creation of opportunities for the poor, investments in their human capital and conditionality on the donor side. One major demand that was not taken over was the call for strong state intervention. Some "forms of direct management of supply so that the intention of the policy are not frustrated"1 was justified by Streeten at al. on the grounds of externalities and market imperfections. ${ }^{2}$ The demands of a Basic Needs- oriented approach require in their opinion such large and sudden changes that total prohibition for imports and domestic production of non-basic needs items were deemed the most appropriate solution to control consumption and, indirectly, technology and income distribution. ${ }^{3}$ These rather drastic state interventions into the market mechanism mark the strong structuralistic tendencies, which underlie Streeten's strategic conception.

\subsubsection{Free Market Forces}

The experience with the structuralist conception of the basic needs approach led to another shift in the approach to development in the 1980s. Most states who had adopted a strongly structuralist viewpoint proved to be over-burdened by the responsibilities of intervening in the market place or by fully regulating the economic activities. This became obvious in the stagnation of their economies relative to the growth rates and associated prosperity achieved in some nations, mainly in South-east Asia. The debt crisis and the global recession of the 1980s exacerbated the problems of many countries. To counter the negative effects, a stronger value was placed on improving economic efficiency and allowing greater play for market forces. ${ }^{4}$ This resurgence of neoclassical economics ${ }^{5}$ refused structuralistic intervention in the market mechanism. It was based on strong criticism of policy-induced distortions and the non-market failures associated with public interventions, which led to the critique of comprehensive and detailed administrative controls and called for a removal of all kinds of price distortions. Since the neoclassical viewpoint is at the heart of the strategies of the 1980s, the main paradigms of the neoclassical school of thought are presented here briefly.

Neoclassical economics have been traditionally occupied with the allocation function of the market mechanism, which is regarded as the most efficient form of resource allocation and economic interaction. The neoclassical view draws on the concept of Adam Smith's invisible hand. The self-interest of all participants in the market yields the highest return for everybody and brings about optimal

\footnotetext{
${ }^{1}$ Streeten, P. et al (1981), p. 43.

${ }^{2}$ See Streeten, P. et al (1981), p. 26.

${ }^{3}$ See Streeten, P. et al (1981), p. 44.

${ }^{4}$ See World Bank (2000a), p. 6.

${ }^{5}$ See Meier, G. (1989), p. 84 .
} 
social welfare. This results from the equalizing pressures of demand and supply on the market price. No state intervention is required or desired, the price mechanism leads to optimal results in competitive markets. These markets are assumed to develop without the need for intervention if the incentive system is right. The institutions in the form of regulations and enforceable standards are considered to evolve on their own and are not assumed to need governmental interference.

This school of thought assumes high flexibility within the system characterized by high elasticity of substitution among commodities and factors in response to market signals. This allows the retention of equilibrium prices even in the face of shifts in internal demand or external trade. The paretooptimal results that are achieved under these conditions, with each factor receiving returns equal to its marginal productivity no matter to what use it is deployed, rejects the notion that state intervention could possibly do any good in terms of spurring growth by shifting resources to other uses.

Linked to the concept of neoclassical theory is the modernization theory. It postulates that promotion of open trade and a gradual advance towards the world market forces an economy to modernize to keep up with international competition, which yields benefits of increased productivity and fosters a catchup process with more advanced economies. Both theories rely on the forces of the markets to bring about positive results in terms of efficiency. The intervention of the state is seen as a limitation to the economic gains possible in a 'free' market environment.

In his presentation of the neoclassical conception prevalent in the $1980 \mathrm{~s}$, Jungfer ${ }^{1}$ presents the criticism of the structuralistic viewpoint by outlining the negative effects of price distortions. Price distortions in his analysis are seen as detrimental to social welfare due to negative side effects. Price stops and price limits have the effect that the market cannot fulfill its allocation mechanism since according to the behavioral assumption of the neoclassical model producers reduce their output with decreasing price while the demand increases, which leaves a discrepancy. The allocation has to be arbitrary or administered by the state. Since the reduction in output is unintended, the government is compelled to regulate the output of the industry or has to increase the price to producers through subsidies to encourage higher production. A spiral of increasing state intervention is necessary to prevent the unintended side effects in the case of regulation. Due to the spread between demand and supply, consumers are willing to pay a higher price than the regulated one, opening up opportunities for corruption and black market activities ${ }^{2}$. These cannot be hidden for long, which bear potential for social unrest and upheaval.

\footnotetext{
${ }^{1}$ The following discussion on the detrimental effects of price distortions and the national framework conducive to the mechanisms of the free market economy is strongly based on the analysis undertaken by Jungfer, J. (1991), p. 179 - 210.

${ }^{2}$ Which is according to Jungfer the only way in which such price regulation can be sustained.
} 
Especially serious effects are expected in capital markets. Interest ceilings with sometime negative real interest rates are assessed to deprive owners of monetary capital of their property, while in turn enabling arbitrary projects or projects with corrupt links to authorities instead of investment in the most profitable alternative. Under these conditions entrepreneurial spirits are excluded from the market for capital. These developments lead to a reduction of overall productivity in the state. This is propelled as the willingness to save decreases at lower-than-market, sometimes even negative, interest rates; at least in terms of savings in local currency. ${ }^{1}$ To counter this, states introduced forced saving practices, leading to impoverishment of their society and capital flight to foreign countries. Furthermore, artificial under-pricing of capital leads to increased investments in capital-intensive production techniques at the reduction of labor input, with negative effects on the income position in the society. Similar negative effects are noted in cases of price distortions in the foreign exchange market and the labor market. Effects of these price distortions include criminalization of those members of society who try to avoid the regulations, the unavailability of goods, the proliferation of corruption and black market activity and the diversion of resources for unproductive uses.

When interventionist practices are stopped due potentially to the inability of the state to keep up the subsidies used to intermediate demand and supply, those groups in society that are negatively affected are likely to protest against this development. This can lead to social unrest and attempts of usurpation. The more the subsidies are financed by foreign borrowing, the harder the adaptation process will be for the country, because it has to cope with the consequences of the internal shock of a sudden price increase as well as with the repayments of foreign debt and interest limiting the room for maneuver ever more. Thus, the shocks that result from a return to neoclassical policies are seen as inherent in prior price distorting policies and not as attributable to the neoclassical model.

A remedy to prevent these negative developments of price distortions is in the neoclassical conception a regulatory framework conducive to free market interactions. Jungfer points out that developing countries need entrepreneurs as much as developed nations because the diffusion of existing technology and its adaptation to local conditions require the ability to take risks and to be innovative. In order to evolve their economic potential, entrepreneurs need a minimum degree of individual liberty rights, which excludes totalitarian regimes as viable to foster economic activity ${ }^{2}$. Individual liberty rights also comprise free market access. This argument is placed in favor of dismantling monopoly

\footnotetext{
${ }^{1}$ Some studies have shown the real interest rate as little or no influence of the savings ratio. (For reference on this see Jungfer, J. (1991), p. 195 - 198 or Frey, M. (1980), p. 317 - 319.) Yet it can be assumed that despite an approximately equal savings ratio the from of savings changes with decreasing real interest rates below the inflation rate - from monetary savings in local currency to savings in real equity or foreign currency to prevent the reduction in value.

${ }^{2}$ See Sautter (1985).
} 
situations and price distortions such as price ceilings and credit and foreign exchange restrictions.

Free international trade is, according to the neoclassical view, a promising way to ensure competition in national markets and thus an environment conducive to entrepreneurial behavior. To reap the benefits of international trade and to be able to detect at all those areas where a nation has comparative advantages, liberal foreign trade policies and a market-based price mechanism for exchange rates and production factors are seen as preconditions. Additionally, a stability-oriented price and foreign exchange policy is recommended because inflationary tendencies and currency devaluation are seen as root causes for enacting price distortions with all the negative effects in regard to investment efficiency, saving quotas and corruption mentioned above. Budgetary discipline is a precondition for this and is regarded as best protected by an independent federal bank.

This neoliberal approach in the 1980s and early 1990s guided the structural adjustment programs of the International Monetary Fund. The effects of these programs are generally viewed as beneficial ${ }^{1}$, yet the immediate effects sometimes resulted in severe declines in GDP per capita and overall welfare ${ }^{2}$. These negative effects are seen as inherent in the prior misleading policies of market intervention ${ }^{3}$ as discussed above.

Adjustment programs of the early 1980s focused mainly on the demand side by lowering the exchange rate and imposing import restriction, while progress on internal problems such as budgetary deficits and inflation was slow. The resource outflow associated with the improved trade balance through exchange rate depreciation led to reductions in investments in the private and economic area including the area of human capital. Despite the efforts of the majority of developing countries to cut social expenditures less than average expenditures", a "sharp reversal in the trend toward the improvement in standards of child health, nutrition, and education" of investments and the pertaining internal problems did not only impose high social costs but also reduced the long-term prospects for growth. ${ }^{6}$

To improve the growth prospects second-phase reforms concentrated on three issues established in the so-called Washington Consensus: expenditure reduction through governmental expenditure cuts, increased tax revenues and limitation on credits; expenditure switching through exchange rate devaluation that increases the relative prices of tradable goods; and reform measures in a

\footnotetext{
${ }^{1}$ See World Bank (2000a), p. 62.

${ }^{2}$ For the Latin American experience see Meier, G. / Rauch, G. (2000), or for a broader overview Inter-American Development Bank (1995).

${ }^{3}$ See Sautter, H. / Schinke, R. (1994), p. 1.

${ }^{4}$ See Pinstrup-Andersen / Jaramillo, M. / Stewart, F. (1988), p. 77.

${ }^{5}$ See Cornia, G. (1988), p. 34.

${ }^{6}$ See Sautter, H. / Schinke, R. (1994), p. 2,3.
} 
narrower sense such as deregulation of capital and labor markets, enforcement of ownership rights and trade and capital account liberalization. ${ }^{1}$ The negative effects on the poor resulting from the elimination of subsidies and loss of jobs due to intensified international competition coupled with a deregulation of capital markets were taken into account in the Washington consensus. Measures like social funds and protection of social spending were implemented to mitigate this effect. These measures have in some cases led to efficiency improvements due to stronger focus of the expenditures on the poor population that have outweight the negative implications of the expenditure cuts ${ }^{2}$. Yet the aim of these measures to secure acceptance of the reform program rather than to eliminate poverty led impact mainly to the prevention of new poverty rather than the fight of existing poverty. ${ }^{3}$

The results of these adjustment programs have been mixed. In many cases they have delivered growth ${ }^{4}$ and led to mainly small reductions in poverty ${ }^{5}$. Yet some reforms have failed to deliver benefits to the poor because of slow or unassertive reforms, capture by the special interests of elites or because of the failure to build supporting institutions. ${ }^{6}$ This last point shows that a neglect of the role of the state in building up adequate institutions to support the market oriented reforms can lead to strongly negative impact on reform process.

\subsection{Today's understanding of poverty reduction}

The high social costs of necessary but dragging and inadequately sequenced reforms experienced in the 1980s have led to a rethinking of the development strategy. To avoid some of the negative impacts on the poor, a concern for propoor spending and for securing this spending even in times of fiscal austerity emerged in the new strategic conception. The negative impacts on the poor are also considered to result from a neglect to focus on the following criteria: On the empowerment of the poor to ensure that their concerns are taken into account, on expanding their endowments to increase their opportunity for economic progress and on their security to reduce the effects of sudden changes in their income situation. These themes have been taken up with vigor in the new strategies.

The lessons learned from the trials and errors of past experiences ${ }^{7}$ have also led to the agreement that markets as well as sufficient regulatory

\footnotetext{
${ }^{1}$ See Sautter, H. / Schinke, R. (1994), p. 4, 5.

${ }^{2}$ An often-cited example for such a development is Chile. See e.g. Sautter, H. / Schinke, R. (1994), p. 15.

${ }^{3}$ See Sautter, H. / Schinke, R. (1994), p. 13.

${ }^{4}$ See World Bank (2000a), p. 62-64.

${ }^{5}$ See Thiele, R. / Wiebelt, M. (1999), p. 29.

${ }^{6}$ See Tommasi, M. / Velasco, A. (1996).

${ }^{7}$ The faults of the past are summarized in the first British White Paper: "The first (flaw) was characterized by a belief that the State should extend its control over production and trading
} 
frameworks are needed for development, expressed in a call for a strong but limited state. Coupled with a focus on improving the situation of poor individuals this has shaped today's understanding of measures of development. The historical conversion of the concepts of mainstream economics and structuralism towards a common understanding, focussing on the benefits of a combination of both while avoiding the pitfalls of a pure strategy, contributes importantly to the evolution the consensus we see today. It is commonly understood today that the state cannot fulfill the allocation mechanism and planning for the economic activities within a nation, but needs to establish accepted frameworks and institutions that enable the market mechanisms to function correctly and provide for social balance.

The core of this consensus is portrayed in the remainder of the chapter by the assessment of the strategies of the World Bank and the British, German and Swedish conception for poverty reduction ${ }^{1}$. In all cases the most recent documents have been taken to assess the current viewpoint. Even though the selection of only four strategies might seem a rather small sample, their general views are also accepted in other contemporary strategies such as the Norwegian strategy ${ }^{2}$ or the strategy guidelines of the $\mathrm{OECD}^{3}$. For the presentation of the general consensus in the remainder of this chapter, the most stringent representation will be sought and divergent views from any one strategy will only be hinted at. The discussion of the peculiarities of individual strategies will form the core of the following chapter.

The key point of today's orientation is the focus on the abilities of the poor themselves. According to this poor people shall be enabled to use their own potential to manage to earn a sustainable living and an achievement of progress on non-income poverty. ${ }^{4}$ Thus, the new concepts place a high emphasis on the role of the poor individual. His abilities and his will to achieve a better

activities, and over the allocation of resources and prices, in a way which created distortions and led to inefficiencies and corruption. The second was a belief in minimalist State and unregulated market forces which failed to secure economic growth and led to increases in inequality across the world." UK government (1997), p. 12.

${ }^{1}$ For the view of the World Bank, the World Development Report 2000/2001 is the main source. See World Bank (2000a). For the British position, both White Papers on International Development as well as the eight DfID Consultation Documents on Strategies for achieving the International Development Targets are regarded. See UK government (1997 and 2000), DfID (1999 a and b) and DfID (2000 a to e). For the German viewpoint the government's Plan for Action 2015 serves as the main source. See BMZ (2000a). Viewing the Sida's Poverty Programme and Sida's Programme for Global Development assesses the Swedish position. See Sida (1996) and Sida (2000a to 2000m).

${ }^{2}$ See Norwegian Ministry of Foreign Affairs (2000).

${ }^{3}$ The draft guidelines on poverty of the Development Assistance Committee of the OECD assure "full compatibility of the Guidelines (sic!) with similar international frameworks." DAC (2000), p. 6. This gives support to the view that a general consensus in poverty issues has occurred and that the guidelines are in line with this consensus.

${ }^{4}$ See Sida (1996), p. 3. 
living are seen as the driving force that has to be at core of the attempts to reduce poverty. Appropriate allocations or resources and changes to the political system have to be made to enable the poor to take over this proactive role that is assumed for them in the new strategies. It is realized that currently the power to help themselves and the will of many poor individuals are suppressed by conditions that prevents them from using their assets and will power most effectively. Many forces affecting poor peoples' lives are seen to be beyond their control. This necessitates a view on poverty reduction that changes these conditions towards greater responsiveness to the needs of the poor ${ }^{1}$. Special emphasis is placed on providing poor people with economic opportunities, empowerment in terms of participation on decisions regarding his life and security, which are deemed as essential for the full utilization of his resources ${ }^{2}$.

Measures proposed in this regard comprise a regulatory framework conducive to the expansion of activities by the poor; public service provision aiming at increasing the human capacity and the access to basic services; provision of market access for the poor; political reorganizations to increase the political participation of and accountability to the poor; and private and public insurance schemes extending security against adverse changes in living conditions to poor people. The strategies thus integrate ideas of the basic needs approach $^{3}$, demands for free play of market forces embedded in a conducive institutional framework and considerations on favorable governance issues. The focus on governance and institutions, including investigations on the negative effects of corruption, in-efficiency und unresponsiveness to the poor population, as well as a concern about the vulnerability of the poor are the main new concerns of the strategies developed at the end of the $1990 \mathrm{~s}^{4}$.

The main approaches to achieve progress on poverty reduction that are similar in most modern strategies are at the heart of the remainder of this chapter. But before they can be tackled the question of who is considered poor under the new strategies and how poverty is defined must be explored, as this provides the base line against which the effectiveness of the approaches needs to be assessed ${ }^{5}$.

\footnotetext{
${ }^{1}$ For an expansion on this point and on measures for action see World Bank (2000a), p. 7 12.

${ }^{2}$ This three-dimensional approach has been introduced by the World Bank as the structure by which the measures for development are assessed in the WDR 2000/20001, but can be found in equal or similar terminology in other recent strategies.

${ }^{3}$ See e.g. World Bank (2000a), p. 32: "And expanding the human capabilities of poor people remains central in any poverty reduction strategy, both for the intrinsic value of such capabilities as health and education as for their instrumental contribution to other dimensions of well-being, including income.

${ }^{4}$ Similarly see World Bank (2000a), p. 6.

${ }^{5}$ The definition of poverty is not a task of mere academic value; it crucially influences the measures pursued in its reduction since the definitions determine which problems are focused on and which are peripheral or neglected.
} 


\subsection{Poverty Definitions beyond Monetary Income}

\subsubsection{Conceptual Dimensions of Poverty Definitions}

Parallel to the trial and error approach that led to current consensus on poverty reduction there has also been a development concerning the development of the definition of poverty. Before this is discussed the conceptual dimensions by which poverty definitions can be classified shall be shortly introduced.

Poverty definitions can differ along three dimensions ${ }^{1}$. First, poverty can be measured against a minimum standard necessary for a life in dignity or against the general living standard in a society: The dimensions of absolute vs. relative poverty.

Absolute poverty in a narrow sense is the state in which a person cannot secure his physical survival in the long run ${ }^{2}$. This measure is applicable for all countries and time periods and has the advantage of international comparability. An example of this would be a minimum amount of calorie intake.

Absolute poverty in a broader sense can be defined as a state in which a person cannot achieve a socio-cultural minimum necessary for a life in dignity in a given society. Here the various needs besides pure physical survival and their different characteristics in different cultures are taken into account at the expense of intercultural comparability. Thus the broader definition already includes a certain amount of relativity. An example for this has already been provided by Adam Smith, who assesses that the ownership of certain things such as leather shoes might be necessary in one society to achieve social acceptance, while in another their possession is not relevant. Social circumstances and customs determine to a high degree the goods seen as necessities for a life in dignity $^{3}$. The concept is considered 'absolute' in that it is derived from unfulfilled minimum needs, which are relatively stable in a given society.

The term relative poverty refers to the divergence of the prosperity of an individual from the mean prosperity of the society. Relative poverty thus is prone to change if the average societal prosperity changes. Examples for poverty definitions in this category include people in the lowest $20 \%$ of the income distribution or people earning less than $50 \%$ of the mean income.

The applicability of a relative vs. an absolute poverty definition depends on the need for comparability between countries and the overall wealth of a country ${ }^{4}$. In attempts to illustrate the global progress in poverty reduction,

\footnotetext{
${ }^{1}$ For reference of the following discussion of the three dimensions and further details, see Sautter, H. / Serries, C. (1993), p. 12 - 15.

${ }^{2}$ See Hauser R. / Neumann U. (1992), p. 245.

${ }^{3}$ Smith, A. (1976), p. 870.

${ }^{4}$ If the average person cannot even sustain physical survival, the relative poverty definition becomes meaningless.
} 
preference is usually given to absolute poverty criteria in a narrow sense ${ }^{1}$, while in the assessment of national or regional poverty absolute poverty in a broader sense or relative poverty concepts are preferred ${ }^{2}$.

A second dimension portraying differences in poverty definitions consider primary vs. secondary poverty. Primary poverty is concerned with the resources available to a household. These are related to the satisfaction of needs by the assumption of perfect utilization of these resources. That means that the usage of resources by the household is not considered since inefficiencies in the spending of the resources are not anticipated. Secondary poverty, on the contrary, is concerned directly with the utilization of resources. Inefficiencies in utilization are seen to lead to a lower ability to satisfy one's needs than under a primary poverty definition assumed. Reasons for this are assumed to be information and transaction costs, societal customs such as burial rites, or simply squandering assets, such as with drug or alcohol abuse ${ }^{3}$. Thus, the outcomes of the activities of the poor are of concern for the secondary poverty definition, while the inputs serve as the base line for the primary definition.

A third way to distinguish poverty definitions rests on the considerations of resource vs. non-monetary poverty conception. In a resource-based definition, all forms of monetary and non-monetary income such as work and property income or reception of public services are taken into account. It is implicitly assumed that the goods necessary to satisfy the basic needs can be obtained with these resources. This approach is easy to operationalize and measure, but neglects the fact that discrimination or corruption might impede the obtainment of services and goods, especially intangible goods such as participation in political and social life. Also the obtainment of public goods such as education, health care and sanitation might be impeded due to remoteness form public service facilities.

The non-monetary poverty conception looks at the overall situation of the individual in regard to all poverty relevant areas and conditions such as aspects of work, education, habitation, health, and participation in the political, social and cultural life. It incorporates the entire surrounding in which the individual can act to achieve his or her fortune. This allows an assessment of a person's life beyond his monetary income and consumption, but complicates the measurement of poverty and aggravates the comparability of the situation

\footnotetext{
${ }^{1}$ See the IDT criteria of income below US $\$ 1$ per day in purchasing power parity in the next paragraph.

${ }^{2}$ See World Bank (2000a), p. 18.

${ }^{3}$ Squander can be regarded as an effect of the apathy that the poor might develop because of their experiences that changes tend to even worsen their situation. This apathy can extend to economic considerations. On this topic see Rein (1970), p. 60 as portrayed in Sautter, H.; Serries, C. (1993), p. 13.
} 
between two individuals. It can be said that most modern strategies borrow from the resource as well as the non-monetary poverty conception.

\subsubsection{The Current Poverty Definition}

The definition of poverty has developed over time alongside the overall evolution of development cooperation. During the 1950s and 1960s it was characterized by a concern for mainly economic matters of income and physical assets of the poor, relying exclusively on a resource based, primary definition of poverty. This poverty definition has been extended beyond measuring the lack of monetary income to incorporation of the non-resource based, secondary measures of basic needs in health and education already by the Basic Needs conception $^{1}$ of the $70 \mathrm{~s}$ and even prior to that ${ }^{2}$. It was retained throughout the $80 \mathrm{~s}$ and builds the basis even for today's strategic conceptions.

The new aspect regarding the definition of poverty in the contemporary strategies is the inclusion of the additional, non-resource based, secondary measures of vulnerability and deprivation of participation in economic, social and political life. The focus on vulnerability is based on the consideration that gross insecurity about the future and uncertainty about being able to cope with it can be a psychological strain, especially since people with little income or assets have to fear for their very survival. Further, it overly limits the current choices about ones life since proactive, higher-risk-higher-return decisions could ruin one's future existence ${ }^{3}$. The inclusion of deprivation of participation in economic, social and political life as a form of poverty takes into account the negative impact of discrimination, powerlessness and deprivation of a person's dignity, which can take from of humiliation, exploitation and inhuman treatment ${ }^{4}$.

By taking this social and political dimension into account the current definition also affirms the Universal Declaration of Human Rights (UDHR) which asserts the right to participate in political process and to participate in cultural life $\mathrm{f}^{5}$. The inclusion of "voicelessness and powerlessness" is especially noteworthy because it provides the focus on aspects of good governance and participation ${ }^{7}$ within the new strategies with a legitimization of being worth on

\footnotetext{
${ }^{1}$ See the discussion in Chapter 2.1.

${ }^{2}$ Already in the 1950 s voices within the United Nation pointed at a stronger focus on the basic needs of the poor population.

${ }^{3}$ For a more detailed discussion about the effects of insecurity on the poor see World Bank (2000a), p. 135, 138 and 161.

${ }^{4}$ See e.g. World Bank (2000a), p. 35, 36 for a discussion on this.

${ }^{5}$ See DfID (2000d), p. 2.

${ }^{6}$ World Bank definition of poverty, World Bank (2000a), p. 15.

${ }^{7}$ The explanation of these words is provided later. In short, good governance is concerned with favorable political conditions attributable to poverty reduction and includes responsiveness to the needs of the population, especially the poor, lack of corruption, rule of
} 
their own behalf, and not only because they contribute to the reduction of some other measure of poverty. That means that exclusion from social life or political decisions cannot be justified by progress on economic terms ${ }^{1}$ since the lack of inclusion is a form of poverty itself.

This view of poverty has been made explicit by the World Bank, which is the only one of the four organization to take up the challenge to define poverty explicitly. As it is similar to the views presented in the other strategies, it shall serve as the definition for poverty within the further argumentation of this thesis. The expression given in the WDR states:

Poverty is "encompassing not only material deprivation (...) but also low achievements in education and health. Low levels of education and health are of concern in their own right, but they merit special attention when they accompany material deprivation. This report broadens the notion of poverty to include vulnerability and exposure to risk - and voicelessness and powerlessness."2

The German action program, even though not explicitly providing a poverty definition, relies on the poor person's perception of poverty ${ }^{3}$ to come up with the following criteria: lack of material well-being; social deprecation, voice- and powerlessness, lack of self-confidence, lack of dignity; lack of basic infrastructure; illness; lack of education; and lack of resources. ${ }^{4}$ This aims in the same direction as the poverty definition of the World Bank ${ }^{5}$. Instead of a definition on poverty, Sida relies on a statement of "quality of life," which reflects the absence of poverty as "peoples' opportunities for making a secure living in a manner that is foreseeable and safe, to be in good health and to have access to education and other social services." It specifies later that this means "guaranteeing the poor, particularly women and children, their human rights and freedoms, opening up their range of choice, improving their environment and security and enabling poor women and men to participate in development

\footnotetext{
law, decentralization, accountability and transparency of political and administrative decisions. Participation is used to describe the inclusion of the poor or of civil society in the political decision making process.

${ }^{1}$ Which some supporters of the focus on the political dimension would deny in the first place since they see the inclusion of the poor in the political system affecting them as a precondition for reaching substantial economic progress for them.

${ }^{2}$ World Bank (2000a), p. 15.

${ }^{3}$ Borrowed from the World Bank survey Voices of the Poor.

${ }^{4}$ See BMZ (2001a), p. 2. (Translated by the author.) This selection has been extracted from the original work of World Bank (2000b).

${ }^{5}$ Which is not surprising since the report Voices of the Poor influenced the viewpoint of the World Bank on poverty as well. The issue of security is not included in these indicators, but is a central theme in the later discussion on the measures of poverty reduction.

${ }^{6}$ See Sida (1996), p. 2.
} 
processes"1. This provides similar criteria for reducing poverty as established in the prior two statements.

It can be argued that the British position regards similar criteria on the basis of their strong concerns about the achievement of human rights in accordance to the UDHR, which comprises the views presented already for the other three definitions. Yet it is astounding that the extensive work comprising two White Papers and eight strategic documents does not contain a clear definition of poverty from the British point of view. Rather, the "UK's policy on international development is based on a commitment to an internationally agreed set of development goals and time-bound targets." ${ }^{2}$ These targets known as International Development Targets (IDTs) are referred to throughout the British strategic proposal, and are accepted also by the other OECD member states as well as the World Bank, the International Monetary Fund (IMF), the United Nations Development Program (UNDP) and other development organizations. They are targets rather than a definition, but their content also specifies certain dimensions of poverty. Due to the widespread acceptance of these targets and the focus they can provide for work of the development community, they shall be presented and analyzed in the following paragraph.

\subsubsection{International Development Targets}

The international development targets (IDTs) represent the current state of international consensus about the measurable goals that are to be pursued in development cooperation. The overall consensus extends beyond these goals and also encompasses the means by which they are to be pursued as well as agreements on issues such as cooperation or trade where measurable goals are difficult to operationalize.

The measurability of the IDTs is their great strength in order to track the effectiveness of the new strategies. Their second major contribution is their international acceptance. While the consensus that is examined in the rest of the chapter is only inferred from the strategies of the agencies without being formally agreed to, the IDTs are officially accepted by the UN, the World Bank and the $\mathrm{OECD}^{4}$ and its member countries. This broad based international acceptance of a fixed set of measurable goals is one reason for the enthusiasm about the ability to cooperate more efficiently in the future due to shared aims and about improvements in aid effectiveness because of improved accountability 5 .

\footnotetext{
${ }^{1}$ See Sida (1996), p. 2,3.

${ }^{2}$ See DfID (2000d), p. 1.

${ }^{3}$ See World Bank (2000a), p. 5, 6.

${ }_{5}^{4}$ See OECD (2000).

${ }^{5}$ This enthusiasm is visible throughout the International Development Target Strategy Papers of DfID, which aim directly at meeting these targets. See e.g. DfID (1999a), p. ii. The
} 
The IDTs comprise:

Well being in that they demand

1. a reduction by one-half in the proportion of people living in extreme poverty by 2015 ,

human development in their request for

2. universal primary education in all countries by 2015 ,

3. demonstrated progress toward gender equality and the empowerment of women by eliminating gender disparity in primary and secondary education by 2005 ,

4. a reduction by two-third in the mortality rates for infants and children under age five and a reduction by three-quarters in maternal mortality, all by 2015 ,

5. access through the primary health-care system to reproductive health services for all individuals of appropriate ages as soon as possible and no later than the year 2015

and environmental sustainability and regeneration through

6. the implementation of national strategies for sustainable development in all countries by 2005 so as to ensure that current trends in the loss of environmental resources are effectively reversed at both global and national levels by $2015 .{ }^{1}$

These goals by themselves do not contain a clear poverty definition but rather present measures, which implicitly rely on a certain understanding of poverty. Therefore these goals do not waive the need to define poverty properly in order to give guidance in individual decisions. The first goal in this set is concerned with income poverty because the poor in this definition are defined as people with less income than US $\$ 1,08$ per day in Purchasing Power Parity ${ }^{2}$ at prices of $1993^{3}$. This describes people who can obtain less goods and services with their daily income as could have been obtained with one ${ }^{4}$ US dollar in the United

importance placed on these goals is also visible in the speeches of the German Minister for Economic Development and Cooperation, Wieckzoreck-Zeul (2000b): These goals will only be achievable by the international community if everyone aims at reaching them with all their power. (Translated by the author.)

See DfID (2000e), p. 1, OECD (1999) or World Bank (2000a) p. 5.

${ }^{2}$ Purchasing Power Poverty (PPP) refers to the ability to obtain the same amounts of goods and services in the developing country as could be obtained from the dollar amount in the USA. PPP conversions should is not be confused with conversions by the official exchange rate. One dollar converted at the official exchange rate can result in significantly higher value in local currency then when converted at PPP, since especially services and labor-intensive goods can be obtained cheaper in the developing country dew to the low labor costs.

${ }^{3}$ See World Bank (2000a), p. 17.

${ }^{4}$ Slightly rounded for easiness of reading. This will be kept in poverty definitions throughout the text. The correct value is 1.08 . 
States in 1993, which is deemed insufficient to provide nutritional intake, not to mention essential services such as education and medical care ${ }^{1}$.

This measure is, thus, based on an absolute poverty and relies heavily on resource considerations, since it infers from daily income on daily goods that can be obtained. It is also based on a primary poverty definition because no considerations are given to inefficient use of resources. Thus, this is a rather crude measure of progress on poverty reduction. The limit of around one dollar is set rather arbitrarily ${ }^{2}$ and due to the absolute and resource based definition the applicability to the situation of a poor individual in a specific country context is quite low. Still, this criteria provides an overall, easy to understand and easy to measure base line for the progress on the international scope of poverty reduction.

The current international, aggregated situation on poverty in economic terms is depicted in figure 2 and 3.

\section{Figure 2: World Population by Income Level (in billion people)*}

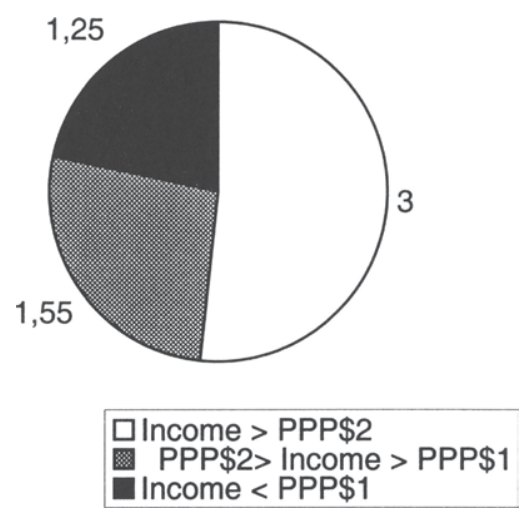

* Source: WDR 2000/2001

\footnotetext{
${ }^{1}$ See DfID (1999b), p. 1.

${ }^{2}$ It does have some descriptive meaning, though, since it is constructed as the most typical poverty line in terms of purchasing power parity out of 33 national poverty lines and thus can claim to have legitimacy based on the national view of poverty in the poorest countries. Still a certain amount of arbitrariness cannot be dismantled for this method of construction, because the choice of countries and the definition of "most typical" leave ample room for variations. For a construction of the one dollar criteria see World Bank (2000a), p. 17.
} 


\section{Figure 3: Regional Distribution of People Living on Less than PPP\$1 per Day**}

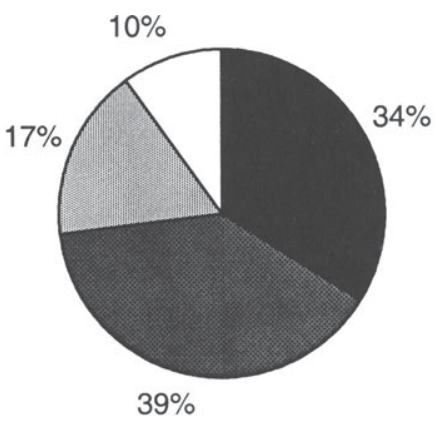

Asia \& the Pacific $\mathbf{E}$ South Asia $\square$ Sub-Sahara Africa $\square$ Other

** Source: UK government (1997), p. 10.

The figures show the ambition of the first and most pronounced of the international development targets: Four people that are non-poor are to lift one poor person out of poverty ${ }^{1}$. If the people that live below PPP $\$ 2$ per day are not accounted for because they are living in poverty themselves and need support rather than provide it, the ratio is down to 2.5 to 1 . The large number of poor people is one reason why the new strategies rely heavily on enabling the poor to contribute themselves to a betterment of their situation as will be pointed out in more detail in the discussion of the general consensus.

The regional distribution of poor people (figure 3) shows that their majority lives in South Asia and Asia and the Pacific. While in the latter large progress has been achieved in terms of poverty reduction in the 1990s, poverty actually increased in all other regions of the world, as shown in figure 4. To reach the target of halving the world's poverty, these trends need to be reversed in the near future.

\footnotetext{
${ }^{1}$ Actually the modern view of poverty reduction places the greatest burden of changing the economic situation on the poor people themselves. The international community's main input is to provide the right international framework and some support. Therefore, the comparison of numbers of people presented here is mainly for illustration purposes.
} 


\section{Figure 4: Changes in the Number of Poor People by Region*}

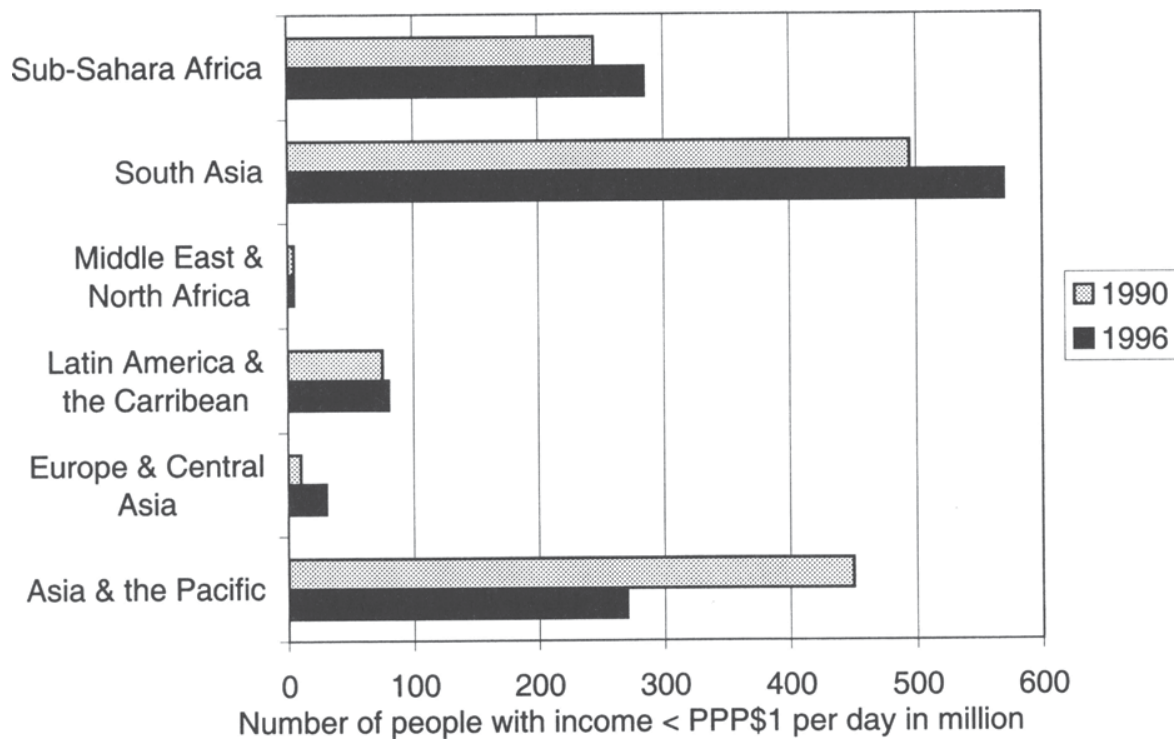

* Source: DfID (1999b), p. 2.

To supplement this economic viewpoint by considerations of non-monetary oriented nature, the goals were extended towards measuring progress in terms of health, education and environmental concerns. The assessment of the circumstances in which a person lives cannot be achieved by the income approach alone, and thus measures such as the availability of health and educational services, the freedom from gender discrimination and the prospect of hazardless environmental conditions receive their justification. The nonmonetary approach underlying goals two to six are also based on absolute considerations in that the average population is of no concern. It is related to a secondary poverty definition in that outputs are considered rather than inputs ${ }^{1}$ and, thus, widens the perspective to look at inefficiencies that are incurred by

\footnotetext{
${ }^{1}$ This is definitely the case for the health sector, but remains to be seen for the environmental and educational sector, where measures such as achieved environmental preservation and achieved literacy and mathematical proficiency should prevail over easier to determine but less meaningful input measures such as money spent on environmental projects or years of mandatory schooling.
} 
the poor. Thus, the IDTs together try to incorporate a broader perspective than a consideration for income alone ${ }^{1}$.

This corresponds to the broad-based definition of poverty presented in the preceding sub-chapter. In its underlying definitions, the first IDT is concerned with "material deprivation", while goals two, four and five aim at "achievements in education and health". Goal three can be argued to encompass a focus countering "voicelessness and powerlessness", at least concerning the situation of gender inequalities. Still this is a very limited measure of the success on the political and social dimension. Insecurity as a part of poverty is fully omitted from these goals. This might be partly so because political and social freedom and security from adverse shocks are hard to measure. The last IDT on environmental progress extends beyond the consideration of the poverty definition to encompass the broader concern about environmental degradation ${ }^{2}$. Therefore it can be concluded that the IDTs do not reflect all dimensions of the currently discussed poverty definitions, but shed a light on many of the relevant considerations in this regard.

The acceptance of the IDTs has its virtues and drawbacks. As a promise and a proclaimed aim of the development agencies, they contain the threat of leading into a credibility trap for the official development assistance. As has been argued prior $^{3}$, the development agencies proclaim goals that the donor governments and the development agencies cannot fully influence since the most important decisions for the reduction of poverty are taken autonomously in the developing countries themselves ${ }^{4}$. And within the development community the contribution of each agency towards these goals is difficult to assess due to the global scope of the goals and due to measurement problems, leading to ambiguity about the individual agency's performance and to possibilities of freeriding. Yet even if this interagency problem could be solved, the first problem remains: The major success factors for poverty reduction are not set by the development agencies. Thus, the IDTs proclaim a development that is to a high degree determined by factors beyond the control of the development agencies, which bears the threat that a potential failure to achieve them is attributed by the national constituents to their development agencies despite high efforts on their part. This might lead to reduced confidence in their work and potentially reduced financial resources.

Another drawback is that the IDTs measure only a very small part of the incidences that mark poverty. For example the measures on health omit many

\footnotetext{
${ }^{1}$ Still, the one-dollar a day criterion remains the most popular in the current discussion and dominates the perception about the progress reached so far.

2 The concern for the environment can be seen as contributing to some degree to the reduction of poverty, while to some degree this is not the case. See the discussion in the chapter on 'poverty reduction vs. other development goals'.

${ }^{3}$ See the chapter on poverty reduction vs. other development goals.

${ }^{4}$ For an extension of this idea see Sautter (1995), p. 135.
} 
factors contributing to longer life expectancy and focus mainly on birth and young age. This bears the threat that other important issues, e.g. support for the elderly, are disregarded to reach the highest impact towards the achievement of the development targets.

These potential drawbacks have to be evaluated against the virtues of this approach. A strong mutual understanding between the donor nations about the direction of development efforts can be achieved. Projects and sector policies are evaluated against quantitative measures that account - at least partially - for their performance, focussing mainly on the delivery in terms of output measures rather than on inputs. Cooperation becomes easier because the general aims are clear to all participants, and thus the chance for greater impact due to concerted actions increases. These are strong benefits, which have led to the general adoption of the IDTs. In the current situation, where the decision in favor of the IDTs has already been taken, the development agencies should aim at making the greatest use of the advantages, while trying to reduce the negative aspects where possible ${ }^{1}$.

\subsection{The Domestic Framework for Poverty Reduction}

The broad agreement on the international development targets is one aspect of the grown international consensus on poverty reduction. However, the IDTs only aim at the direction of what shall be achieved, but do not provide insights on how this shall be attained. On their own they provide a weak case for proclaiming an international consensus. Yet the consensus extends beyond an agreement on goals towards acceptance of a number of broadly defined measures for domestic as well as international action for poverty reduction. The proposed domestic conditions favorable for poverty reduction can be shown along the three dimensions of economic framework, political conditions and security concerns. These shall be outlined in this chapter, while the international conditions are presented thereafter.

\subsubsection{Economic Framework}

\subsubsection{Growth and Equality}

The new consensus on poverty reduction, in line with the strategies of the past, gives close attention to the economic aspects of development. This follows from the perspective that, despite the broadening of the poverty definition to non-monetary measures, low economic achievements of the individual

\footnotetext{
${ }^{1}$ As one measure to this extend DfID proposes the extension of the IDTs by additional measures on a country and sector basis to avoid the threat of a too narrow focus on the pure achievement of the IDTs while disregarding other problems. See e.g. DfID (1999a), p. 35, 36.
} 
contributes greatly to his own feeling of poverty ${ }^{1}$. On a broader perspective economic performance is also seen as a factor aiding the advancements on nonmonetary factors such as health and education, which tend to increase on average as GNP grows ${ }^{2}$.

The foremost point of all strategies regarding economic performance is the requirement for growth as a necessary condition to reduce poverty ${ }^{3}$. The rate of growth needs to be substantially larger than the population growth to have an impact on the individual, meaning that per capita growth is the main determinant. It needs to be achieved over an extended period of time ${ }^{4}$.

The value of growth is assessed in terms of its impact on the poor. A 'trickle-down' effect promoted in early strategies of development is not a consideration in any of the strategies reviewed here. Rather, empirical evidence is consulted to conclude that growth on average accrues to the poor to the same extend as to the rich. E.g. growth in the consumption of the poorest fifth of the population tracked economic growth in their countries on average one-for-one in the $80 \mathrm{~s}$ and $90 \mathrm{~s}^{5}$. Additionally, the fact that no country has managed to reduce poverty without economic growth provides justification for its promotion within the strategies ${ }^{6}$. The case for economic growth as a precondition for poverty reduction is further supported by the assessment that economic growth also aids growth on non-monetary factors such as education and health, which become more affordable as national income rises?

Growth in itself is not seen as a panacea to reduce poverty and is considered only as a necessary, but not a sufficient condition for the reduction of poverty $^{8}$. The fact that the "trickle-down" effect is not regarded to bring the desired changes for the incomes of the poor and the realization that growth, even rapid growth, can occur without a reduction in poverty, led to the discussion of inequality as a determinate of poverty reduction.

\footnotetext{
${ }^{1}$ See citations of the World Bank report Voices of the Poor - World Bank (2000b) - cited in World Bank (2000a), p. 34 and in BMZ (2001a), p. 2, where missing material well-being in terms of nutrition, housing and land is assessed as the first of the main problems of the poor.

${ }^{2}$ See World Bank (2000a), p. 46.

${ }^{3}$ See e.g. "Economic growth is essential for sustainable poverty reduction." Sida (1996), p. 3. For similar views see BMZ (2001a), p. 10, 11; UK government (1997), p. 15 and World Bank (2000a), p. 46, 47.

${ }^{4}$ See. DfID (1999b), p. 2.

${ }^{5}$ Study covering 65 countries. See World Bank (2000a), p. 47.

${ }^{6}$ See e.g. Sida (1996), p. 3.

${ }^{7}$ See World Bank (2000a), p. 57. There are deviations from this average, though, which point at the possibility to increase non-income factors such as health and education without increases in GNP. This will in fact be argued later as a measure to boost the national growth, which can be seen as a reversal of the thought presented here. Still, this does not refute the fact that stronger economic performance makes achievements on non-income measures easier affordable and on average more likely. Thus, the case of a "vicious" or "virtuous" circle of non-income progress and economic performance seems possible.

${ }^{8}$ See Sida (1996), p. 3.
} 
The impact of growth depends on the change in inequality in a nation. GNP growth accompanied by a reduction in inequality leads to over-proportional growth for the poor, since the proceeds from growth are in this situation more equally spread than the initial distribution within the society. On the contrary GNP growth coupled with rising inequality leads to under proportional growth for the poor ${ }^{1}$, which could even lead to a situation where poverty increases despite growth because the inequality of income distribution rises even faster.

On average there does not seem to be a clear connection in the direction from growth to a change in inequality, neither increasing nor decreasing it on average. This provides the basis for the reasoning that growth is on average helpful to the poor. Even growth with rising inequality is not necessarily a negative phenomenon if the increase in inequality still leads to improvements in the situation of the poor, to an increase in their economic opportunities and is not accompanied by dysfunctional forces such as discrimination ${ }^{2}$.

While the link from growth to changes in inequality does not show a clear tendency, there seems to be a case for initial levels of inequality in monetary and non-monetary assets and incomes ${ }^{3}$ having strong impact on growth for the poor. This is based on two considerations. First, inequality can lead to lower overall growth rates, since "unequal societies are more prone to differences in collective action, possible reflected in dysfunctional institutions, political instability, a propensity for populist redistributive policies, or greater volatility in policies - all of which can lower growth"4. For some cases this can even be argued out of considerations on the productivity per asset, which can e.g. in agriculture be greater for small farms owned by many than by large farms owned by few ${ }^{5}$.

Second, high initial inequality will also lead to most of the overall GNP growth accruing to the non-poor under the assumption of relatively stable levels of inequality, implying that growth is distributed according to the initial levels of assets or incomes ${ }^{6}$. The same level of growth will thus yield higher impact on reducing poverty in countries with low inequality. The poor will receive a greater share of the growth according to their greater share in initial assets or incomes in these countries compared to poor people living in countries with high inequality - under the assumption that the proceeds of growth will occur

\footnotetext{
${ }^{1}$ For a deeper insight on the following discussion see World Bank (2000a) p. $52-59$ and DfID 10 - 14.

${ }^{2}$ See World Bank, p. 54 and 55.

${ }^{3}$ See DfID (1999b) p. 11 . On p. 14 the inequality in assets is seen as even more relevant than the initial distribution of incomes.

${ }_{5}^{4}$ See World Bank (2000a), p. 56.

${ }^{5}$ This is exemplified in World Bank (2000a), p. 57 by citing the land reforms in the Indian state of West Bengal that led to output improvements of $18 \%$.

${ }^{6}$ See World Bank (2000a), p. 55.
} 
according to the initial distribution. Since inequalities are hard to change ${ }^{1}$, this assumption seems reasonable ${ }^{2}$.

The conclusions drawn from this discussion of the necessity of growth on the one hand and the need for more equality on the other hand are twofold: On the one hand the overall economic incentive system has to be adjusted to support growth on all levels. Therefore the institutions have to be conducive to growth and private initiate - which is seen as the driver of growth - and obstacles inhibiting economic activity leading to growth need to be removed. On the other hand special attention has to be given to ensuring that growth occurs to the poor and that opportunities open up for all, in particular through the "advancement of the disadvantaged"3. This is termed pro-poor growth and is to be achieved through measures spurring the growth for the poor and, thus, overall GNP growth according to the new strategies. These two concerns - the economic incentive system and the creation of economic opportunities, especially those for the poor - shall be analyzed in more depth in the remainder of the chapter after a brief discussion of the significance of growth for development.

The assumption that growth is a necessary condition for poverty reduction is, despite its general acceptance, not unchallenged in the contemporary debate between practitioners in economic development ${ }^{4}$. Therefore the claim to be able to reduce poverty without growth is discussed here briefly.

In this context it is argued that poverty is reduced by conducive policies. These also tend to favor economic growth, so that growth rather moves together with poverty reduction and does not necessarily influence it. Also, it is claimed that progress on poverty reduction can be achieved by more efficient use of existing governmental resources, increase of government resources for redistribution by more efficient taxation and shift in government allocation. Additionally, non-income poverty in regard to social and political rights is considered to be reducible without growth.

There is some virtue to these considerations in that they point at the need to strive for poverty reduction and human resource development through better use of governmental resources and better institutions even in countries lacking growth - and thus lacking the claimed precondition for poverty reduction. The possibility to improve non-income measures such as health, education and human rights and even to increase the income of the poor - by reducing wastage in the government system and possibly by transfers from the non-poor - does

\footnotetext{
${ }^{1}$ See e.g. DfID (1999b), p. 12.

${ }^{2}$ It seems reasonable given many countries that face difficulties to change the distribution of income. Yet there are noteworthy examples in which inequalities have worsened in relatively short periods of time, such as in Mexico, or have been reduced as in Brazil, implying that in these cases growth must have occurred in strongly different patterns than the initial distribution.

${ }^{3}$ See DfID (1999b), p. 8.

${ }^{4}$ The mainstream thought on growth as a necessary condition is e.g. challenged in Jentsch, G. (2000), which shall serve as a base line for the brief discussion presented here.
} 
not seem unreasonable. In fact, the strategies that confirm the role of growth for poverty reduction partially recommend these steps, such as land reform and expenditures in education and health as will be discussed later.

The difference in the views lies in the scope of poverty reduction. Sustainable reductions in poverty ${ }^{1}$ in the meaning of enduring reductions in poverty ${ }^{2}$ require growth for two basic reasons. First, a minimum amount of growth is necessary to offset the tendencies of population growth, which will at constant GNP reduce the living conditions of each individual, reducing directly the living conditions of the poor as well as the scope for redistribution. Second, even when growth is considered per capita, the current average GNP per capita limits the scope for redistribution. In some poor countries this value is currently so low that even perfect equality would only lead to a level where everyone would live in poverty ${ }^{3}$. Since the maximum scope for redistribution can be considered as limited - by political considerations and powers of elites - to a level far above a point of perfect equality, in most developing countries the poor will earn a living substantially below the average GNP and below a material income allowing for a live in dignity. Without growth, there is no chance for a change of their destitute beyond the low level determined by per capita GNP and the maximum possible redistribution.

Therefore, the conclusion can be drawn that despite certain achievements in poverty reduction that can occur without economic growth and which should be pursued where possible, for many poor countries a sustainable reduction in poverty for the masses will only be achieved if growth increases average incomes. This is not to say that growth alone is the important determinant. As is pointed out in the strategies that quality of growth is more important than the quantity, pointing at the need to extend growth to the poor and to expand their economic opportunities. How this shall be achieved and how economic benefits for the poor can be reached is the concern of the following paragraphs.

\subsubsection{The Economic Incentive System}

The success of an economy is strongly related to the incentive system influencing each economic actor in his decisions. Since the interactions of the decisions and their resulting actions between the individuals amount to the overall economic performance within a nation - and in an open economy further than that - any concept aiming at increased economic performance has to pay special attention to its economic incentive system. It should be designed to

\footnotetext{
${ }^{1}$ See e.g. BMZ (2001a), p. 9.

${ }^{2}$ Not limited to the preservation the environment, as is sometimes implied by the term sustainable development.

${ }^{3}$ E.G. Mali, Yemen and Zaire have a per capita GNP below US\$360 a year and even in purchasing power parity the GNP per capita is below PPP\$700 a year, which allows the minimum of PPP\$1 a day, but not even the value of PPP\$2 per day considered as the minimum for ensuring housing, clothing and other essentials next to bare survival. This PPP\$2 line is used e.g. by the World Bank as a secondary line to assess poverty next to the PPP\$1 line.
} 
encourage individual efforts and to allow for the most efficient and effective way of interactions between the efforts of individuals.

The recent consensus on poverty reduction views the market economy combined with a proper regulation as the most effective system to encourage economic growth and with it poverty reduction ${ }^{1}$. The World Bank even goes to the point to consider reforms in this direction inevitable for many developing countries that have pursued a more interventionist path including public ownership and heavy protectionism in the preceding decades, since "the absence of reforms to develop vibrant, competitive markets and create strong institutions condemns countries to continued stagnation and decline." ${ }^{2}$ The governments are advised to "liberalize markets, to move out of activities best undertaken in the private sector and (to) institute effective regulation"3,

This calls for an establishment of predictable rules encouraging investment and private economic activity. This includes freedom of and incomeearning-opportunities for entrepreneurial engagement in innovation and business expansion $^{4}$. It requires regulations preventing inefficient or sub-optimal outcomes for the entire economy despite (or because of) individually optimal decision-making; such as in monopoly situations or overly risky banking activities. On the other hand, over-regulation has to be capped to reduce administrative obstacles to business activity. The practice of corruption impeding effective competition and equal chances has to be curbed. Overall, the role of private business activities needs to be strengthened while a "sound government policy (needs to be) in place, exemplified by a sound macro and micro policy and an aspiration to establish viable institutions and rules and regulations which promote legality, openness and efficiency."5

In more specific terms, the demands placed on the governments include low inflation, moderate budget deficits in line with sound monetary and fiscal policy, open international trade without extensive trade barriers and reductions of overregulations. The World Bank refers to these as "first-generation"" reforms due to their straightforward implementation possibility. The benefits from low and stable inflation arise from increased incentives for domestic savings leading to more funds available for investment. It is also conductive to reducing market inefficiencies, since the currency keeps its wealth-storing function and transactions with a longer time frame can be undertaken more easily. The wealth-storing function is seen as especially valuable for the poor who are lacking other forms of wealth conducive to saving ${ }^{7}$. Furthermore, the increased

\footnotetext{
${ }^{1}$ See DfID (1999b), p. 7, BMZ (2001a), p. 11, Sida (2000b).

${ }^{2}$ See World Bank (2000a), p. 62.

${ }^{3}$ See DfID (1999b), p. 7

${ }^{4}$ See DfID (1999b), p. 7.

${ }^{5}$ See DfID (1996), p.19.

${ }^{6}$ See World Bank (2000a), p. 64.

${ }^{7}$ See DfID (1999b), p. 7 and World Bank (2000a), p. 143.
} 
predictability enabled by low and stable inflation reduces the uncertainty of business decisions, thereby leading to superior investment decisions. This is especially valuable to attract mobile capital and foreign investments.

Low inflation as a measure of sound monetary policy depends in part on low budget deficits, since the financing of a budgetary deficit in the absence of an independent central bank tempts governments to expand the monetary base, which usually leads to high inflation. The fiscal policy as a determinate of the budgetary deficit should aim at efficient taxation avoiding distortions in the market mechanism and, on the expenditure side, at constraining spending. Stable macroeconomic policies as described above, together with efficient and business friendly administration and competitive and regulated markets contribute to an investment-friendly environment ${ }^{1}$ favorable for the extension of business activity and economic growth. Also necessary for this is a well-regulated and healthy financial sector channeling savings to the most productive use.

Productive investment and business initiatives are strengthened by open international trade that expands business opportunities. Through foreign investment additional capital, new technologies, additional markets and modern ways of working become accessible to the domestic industry; thus spurring its economic potential ${ }^{2}$. The competition on an international level also provides the incentives for domestic firms to become competitive, which - if achieved sharpens the possibilities to expand into export markets and at the same time makes products less costly on local markets. This obviously also bears the risk that certain companies or even whole industries do not succeed in becoming internationally competitive and will vanish, including the job opportunities for those prior employed in these companies. The reasoning in support of international trade is that all change brings about benefits and costs, with the costs being concentrated heavily on particular groups, yet being smaller in magnitude than the benefits accruing to the entire society. Therefore, the costs are seen as justified but need to be lessened for marginalized groups by social policies. These social policies are an important element, since poor people affected adversely by reforms can suffer irreversible harm, especially when children are taken out of school in economic downturn or are permanently negatively affected by nutritional deprivation, which might propel poverty for a further generation ${ }^{3}$. Therefore, the impact of reforms on the poor has to be carefully evaluated and measures to limit the adverse effects have to be implemented. Even those companies that are capable of meeting global competition might need time to adjust to the new environment. Special attention has to be given to the timing of reforms to open protected markets for worldwide competition.

\footnotetext{
${ }^{1}$ See BMZ (2001a), p. 11.

${ }^{2}$ See DfID (1999b), p. 7.

${ }^{3}$ See World Bank (2000a), p. 66. Social policies and mechanisms for the poor to cope with adverse changes in their economic position are discussed in the chapter on 'Measures to provide security'.
} 
The opening of the domestic economy towards international markets places special importance on the exchange rate regime. For this it is argued that real exchange rate devaluations of artificially overvalued currencies are especially successful ${ }^{1}$. Such a policy reduces the pressure on the nations foreign currency reserves and favors conditions for export. Yet, in turn this increases prices for imports, thus putting pressure in the inflation rate and increasing the burdens of loans taken in foreign currency. The benefits of increasing the competitiveness of domestic products are seen as outweighing the negative implications.

The chances of globalization that are attainable through open policies include increased access to ideas, information, technologies, products, services and financial resources. ${ }^{2}$ These foster economic growth and provide incentives for individuals in developing countries by opening up new opportunities for businesses ideas and private initiative. Open markets in general - domestic as well as for export - are regarded as conductive to the provision of the necessary incentives for economic performance via the price mechanism and competition. They also open up necessary opportunities for production ${ }^{3}$.

The liberalization of state monopolies in favor of competitive markets is demanded in the new strategies in those situations where the private sector can undertake the activities at least as efficiently ${ }^{4}$. Government-owned companies are seen as inefficient, because they "are given precedence by the government and drain the state of capital and expertise, use existing expertise inefficiently and push aside the needs of the poor" ${ }^{5}$, as is confirmed strongly in the Sida's poverty program. ${ }^{6}$ Centralization tendencies are also seen as encouraging political cronyism and grand corruption ${ }^{7}$, and therefore their dissolution has favorable side effects.

These "first-generation" reforms, which can be summed up as fiscal and monetary prudence, deregulation, privatization and internal and external openness of markets, by themselves are not seen as sufficient today. They need to be accompanied by "second-generation" reforms that have been hinted at

\footnotetext{
${ }^{1}$ See DfID (1999b), p. 18.

${ }^{2}$ See BMZ (2001a), p. 10.

${ }^{3}$ See DfID (1999b), p. 7 and 8 for a comprehensive view on the requirements for market economies and their regulation.

${ }^{4}$ This does not seem possible in some sectors like national defense and is complicated in other such as education and health care, as can be seen by the experiences of the developed nations. Nevertheless, there is much room for liberalization and privatization in the manufacturing sector in many developed countries, where the public sector share has increased from nearly zero in the 1940 s to about $25 \%$ percent (and in some countries even up to $80 \%$ ) in the middle of the 1980s (see Reynolds, G. (1983), p. 93). This trend has been reversed since the $1980 \mathrm{~s}$, but scope for further progress remains.

${ }^{5}$ Sida (1996), p. 19.

${ }^{6}$ This underlines the fact that also the Swedish position favors the market based approach presented here as the consensus, in contrast to their more strongly state oriented views of the 70 s.

${ }^{7}$ See DfID (2000e), p. 7.
} 
already: The buildup of institutions in difficult areas including the advancement of an independent judiciary system and independent and effective regulatory agencies, which require as pre-requisites a high amount of professionalism within the public sector ${ }^{1}$. This is seen as a time-consuming and difficult activity, potentially facing strong opposition from influential groups whose interests are negatively affected. Yet the insight prevails in the new strategies that "when reforms leave an institutional vacuum, performance suffers"2. This point of view marks a departure from the call for free markets forces as the sufficient mechanism for efficient operations that prevailed in the 80 s. Today, institutions in the form of enforceable rights and applicable rules supported by sensible legislation, able administrations and accessible judiciary systems are emphasized in order for market economies to function efficiently ${ }^{3}$. The entire legal system has to be shaped in such a way that contracts become binding, enforceable and their interpretation predictable in order to provide fertile grounds for private economic interaction.

In regard to reforms - e.g. the sudden opening of prior monopolized markets, the privatization of state enterprises or the change from centralized allocation mechanisms to price determined markets - problems of underregulation have to be tackled. Inefficiencies are likely to arise if the appropriate institutions for regulation cannot be established prior or simultaneous to the market oriented reforms or if their enforcement and oversight is weak due to lack in administrative ability ${ }^{4}$. Therefore, the appropriate legislative frameworks for privatization including the establishment of sound regulatory bodies have to be pursued to enable efficient functioning of the newly created markets and to limit market-dominating power. The ability to regulate newly privatized industries, and market-dominating industries in general, depends also on the specification of the information demands necessary to enable the legislators to deter the inherent incentives for monopoly business practices. The autonomy of regulators and their accountability is seen as important to prevent arbitrary intervention of politics in the regulatory process as well as arbitrary judgments on the part of the regulators. The high demands on regulatory ability during the privatization of state-owned enterprises are also visible in industrialized countries. The ongoing disputes e.g. in the German telecommunications sector since the deregulation in the early 1990s despite well-developed and able administrations ${ }^{5}$ shed light on the scope of regulatory demands that is placed on the far more restricted administrative capacity in developing countries.

\footnotetext{
${ }^{1}$ See World Bank (2000a), p. 64 and for a similar view DfID (2000e), p. 9.

${ }^{2}$ See World Bank (2000a), p. 69.

${ }^{3}$ See DfID (2000e), p. 7. These measures are also important for the achievements of political and social rights for the poor and shall be portrayed later in this regard.

${ }^{4}$ For the general idea of the following discussion see the remarks in DfID (1999b), p. 9.

${ }^{5}$ See for example the difficulties in the regulation of the resulting telecommunications market in Germany after the privatization of the Deutsche Telekom AG because of its still dominating position. The frequent decisions of the regulating body, the Regulierungsbehörde für Telekommunikation und Post, and the challenges of its decision in the court system, which
} 
A resort given special attention in the current concepts is the banking sector and the appropriate regulation of it. In the light of the Asian financial crisis and in consideration of the role of the banking sector for the economy as a whole, regulations for financial transaction are seen as a priority. Stability and transparency in this sector are sought through reporting requirements for commercial banks, encouragement of competition and deepening of the financial sector $^{1}$. Regulations on the maximum exposures in short-term foreign currency obligations and on other risky investments are possible further measures. Improvements of banking supervision, of insolvency laws and the surrounding legal system shall reinforce these measures ${ }^{2}$.

Overall, the economic incentives system within the new strategies is based on a view that the incentives of the market mechanism are most effective in exerting private economic activity. State intervention in economic activities aside from basic state obligations in the realms of security and social services is rejected. The role of the state is seen in the efficient regulation of the markets. It has to set the legal foundations and the regulatory framework for the efficient interplay of market participants. This does not mean that governments have to give up all their responsibility for ensuring public interests. Rather, as is pointed out in the strategies of DfID, "Governments are having to learn how to represent the public interest through regulation rather than ownership and control, and through the creation of an enabling environment rather than direct participation in economic activity.",

\subsubsection{Creating Economic Opportunities}

An economic incentive system based on well-regulated competitive markets is a starting point for the achievement of growth. But growth by itself does not guarantee improvements of the situation of the poor if inequalities rise. Therefore, special attention is recommended to measures that enable the poor to share in this growth. These recommendations can be summed up under two main headings: the augmentation of poor people's assets and the provision of access to markets, which shall be discussed in turn.

\subsection{Poor People's Assets}

The fact that governments refrain from direct state control of many industries in favor of private initiative coupled with a well-regulated, competitive market mechanism, as recommended in the new strategies, does not mean that the market has taken over and will solve the social problems of a society. Under a

nearly weekly makes the top stories in German business news (see e.g. FAZ (2001c)), show the frequent and ambiguous problems that arise from privatizing a state-owned industry.

${ }^{1}$ See DfID $(2000 \mathrm{e})$, p. 9. This point will also be taken up in the discussion of international institutional frameworks in the chapter on 'Finance'.

${ }^{2}$ See BMZ (2001a), p. 21, 22.

${ }^{3}$ See DfID (2000e), p. 9. 
market environment possibilities for the government to pursue social objectives persist, and with them the obligation to tackle these issues, the most important of which being poverty reduction in most developing countries.

The adoption of a market mechanism does not allow for direct measures such as state owned enterprises were employment policies and incomes can be set by government command limited only by the government budget ${ }^{1}$. Measures in a market environment have to be more subtle and long-term. These measures include mainly the fiscal policy of the state $^{2}$, on the revenue as well as the expenditure side, and regulatory and legal policies ${ }^{3}$. These have to be shaped in a way that is conducive to pro-poor growth. Pro-poor growth is based on the extension of opportunities for all, and in particular for those that are lacking these opportunities currently, as is the case for most of the poor people ${ }^{4}$. This decision to concentrate on growth patterns that are most conducive to the participation of the poor in this growth is obviously based on the social objective to increase the incomes of the poor.

It also reflects the assumption currently held that the poor themselves can be the main drivers of growth, without whose contribution of assets and skills substantial growth rates in many developing countries are not deemed possible ${ }^{5}$. A central problem in this regard results from the fact that the necessary skills and assets are not yet attainable for the poor because of absence of public services, constraints on the affordability of these service provision or because of lacking poverty rights and other legal measures, demanding reforms in fiscal policies, government spending priorities and legal frameworks.

In terms of fiscal policy, the considerations regarding the revenue side are rather limited in the current strategic positions. For once, the reduction of agricultural taxes is proposed in order to yield higher farm prices benefiting the poor on the countryside, where still the majority of the poor live $e^{6}$. This would directly increase the income-earning opportunities of the poor on the countryside and would enable them to accumulate assets for further growth. Yet, a general decrease of revenues is not desirable because this would restrain state spending

\footnotetext{
${ }^{1}$ Forms of commanded employment and wage policies are one reason for some of the inefficiencies of state-owned systems. Also it should be noted that the government can use state owned systems only to a certain degree for employment generation and other measures, limited by the government funds available to finance the incurred inefficiencies.

2 The change from a centralized system to a market based system is likely to free up funds that were prior tied in inefficient state-owned enterprises, leading to more funds going to productive investments and possible expanding the fiscal position of the government in turn.

${ }^{3}$ These will be discussed here in terms of their contribution to economic assets of the poor, such as the provision of land rights, and not to the political environment limiting the participation of the poor in political decision-making, as this will be the topic of the chapter on 'National Political Condition'.

${ }^{4}$ See DfID (1999b), p. 8.

${ }^{5}$ See e.g. DfID (1999b), p. 14.

${ }^{6}$ See DfID (1999b), p. 18.
} 
on measures extending the economic opportunities of the poor if the budget deficit is to be kept constant.

In this regard it is assessed that revenue raising measures, as part of the attempts to reduce the budgetary deficit or at least to prevent its rise, should not be regressive in impact. Therefore, value added taxes should be viewed carefully in their impact on poor people if they are to replace more progressive taxes, e.g. on income, that have not effected the poor people since the poor either did not qualify for them or avoided them ${ }^{1}$. On the other side low rates of taxation on profits and incomes are deemed necessary to foster enterprise development and investment ${ }^{2}$, which limits the ability to raise progressive taxes.

This short discussion on taxation shows that their impact is not disregarded in the current strategies, but no generally applicable framework for just taxation and fiscal revenue raising seems yet to have been found. The dilemma of a need for low progressive taxes on the one hand and the reluctance towards regressive taxes on the other hand can be overcome, since even slightly regressive tax reforms can have progressive results if the additional revenue is devoted to expenditures targeted towards poor people. This underlines the current presumption that the redistributive power of public finance lies on the expenditure side rather than the revenue side ${ }^{3}$.

On the expenditure side of fiscal policy the by far most important point in the current discussion is the demand to invest in people's human capital, especially in the spheres of education and health and other social services ${ }^{4}$. This point is forcefully drawn in the Second White paper of the British government: The "unique and indispensable role of government remains that of setting policies and priorities, ensuring that basic services are provided to all, and regulating to ensure quality and standards." 5 This investment in basic needs is seen as a concern in its own right, since poor health, education, nutrition and lack of other basic needs is by itself a form of poverty that needs to be reduced. Also, they are seen as key assets to foster economic activity of the poor ${ }^{6}$, to increase their opportunities to benefit from overall growth and to strengthen their ability to provide the main source for economic growth. Since many poor people own only marginal material assets, the expansion of their human capital is seen as one of the most influential ways of increasing their asset base.

\footnotetext{
${ }^{1}$ See World Bank (2000a), p. 70.

${ }^{2}$ See DfID, p. 8.

${ }^{3}$ See World Bank (2000a), p. 70.

${ }^{4}$ This is strongly reflected in all strategies. E.g. Sida sees its first two priorities for the creation of the right conditions for development in "Basic education of acceptable quality" and "Human resource development" (Sida (2000)), while the German action program promotes the "securing of social services (basic education, basic health, alimentation and safe water)", BMZ (2001a), p. 24 (translation by the author).

${ }^{5}$ UK government (2000), p. 25.

${ }^{6}$ See DfID (2000b), p. $\mathrm{i}$ and ii for a general view on the value of education. For an introduction into the benefits of health see DfID (1999a), p. 1-3.
} 
Especially investments in education allow the poor to become more productive in their current occupations as well as to increase their potential to move into different, higher return occupations ${ }^{1}$. This development is in turn viewed as conductive to overall growth. High returns on education are for example expected due to agricultural innovations that require a comprehension of new farming methods. Their application requires a willingness and ability to learn. The opportunities for the poor to share in the growth provided by international openness are also increased, due to higher flexibility and a higher level of skills.

This increase in education is attempted primarily by an increase in the scope of primary education, which is to be extended to all children. The reasoning behind the focus on primary education is based for once on a general concern for human rights. Yet more often the believe is expressed that primary education yields the highest returns. The reasons for the latter assertion are assumed to lie in productivity improvements and expansions of economic opportunities on a broad scale. Literacy, numeracy and the capabilities for lifelong learning, which are conveyed through primary education, help the individual to acquire new skills and production methods. Indirect returns accrue from the strong influence of the provision of primary education on health and nutrition intake, which augment the value of this basic education strategy. Especially the education of girls is seen as strongly beneficial, since empirical research points at the fact that educated women have smaller and healthier families and are more likely to send their children to school, propelling the impact on education and leading to increased growth ${ }^{2}$. The overall value of primary education, especially for girls, is a central part of the new strategies as a way to increase poor peoples' assets and, thus, their income-earning potential.

The believe within the strategies that investments in primary education yield the highest returns in terms of poverty reduction and economic growth is firmly established within the strategies. The World Bank even promotes a reduction of higher education in favor of basic education. ${ }^{3}$ This strong bias towards primary education is questioned in some of the newer research findings, at least as far as its impact on national growth is concerned. Since primary education receives especially strong attention in the new strategies, some of the research findings contrary to this opinion shall be presented in a short excursion into the economic benefits of primary education.

In his empirical study on 114 countries Barro $(1997)^{4}$ does not detect any statistically significant effect of male primary education on growth when male higher education is included in the regression. He does acknowledge though the indirect effect of male primary education as a prerequisite to higher education.

\footnotetext{
${ }^{1}$ For the following discussion is influenced by the ideas in DfID (2000b), p. 1-15.

${ }^{2}$ See DfID (2000f), p.1.

${ }^{3}$ See World Bank (2000a), p. 82. A more explicit view of this issue is presented in Thiele, $R$. / Wiebelt, M. (1999). This discussion is taken up in more detail in chapter 3.5.2.

${ }^{4}$ Barro, R. (1999), p. 19, 20.
} 
As for the discussion of the value of female education, which is even to the World Bank's acknowledgment still ongoing ${ }^{1}$, Barro finds no significant relationship to growth. This is the case for all levels of education. Even by allowing for the indirect effects through reduced fertility rates female education did not appear as a significant factor. Thus, neither the special value of primary education nor the value of female education for economic growth receive support in this study. Human rights and social aspects have not been integrated in this analysis.

Similar findings on the level of education and its impact on growth are presented in Graff (1995). In his approach based on assumptions taken from production theory Graff presents support for the hypothesis that individual education below four to six school years is nearly ineffective on growth ${ }^{2}$. Individual primary education as well as individual attainments in terms of literacy have insignificant effects on growth. Yet his support for the 'AndersonBowman-Hypothesis' of a minimum threshold of literacy in the economy as a precondition for growth ${ }^{3}$ points at the potential for countries with a minimum educational level below $20 \%$ to $40 \%$ literacy rate or average schooling time of less than three years to gain substantial momentum for economic development from efforts to extend primary education. ${ }^{4}$ While individual primary education is overall found as insignificant ${ }^{5}$, secondary and tertiary education are estimated as significant contributors to growth in developing countries. Thus, Graff's findings do not support the view that higher levels of growth are attainable through primary at the expense of higher education. The analysis is not disaggregated by gender.

These strong findings of Graff and Barro concerning the ineffectiveness of primary education are not upheld in Timmermann $(1999)^{6}$. His empirical analysis of 37 developing countries establishes a positive connection between

\footnotetext{
${ }^{1}$ See annotations to World Bank (2000a), p. 49 on p. 209.

${ }^{2}$ See Graff, M. (1995), p. 174 - 182, which serves as reference also for the rest of this paragraph. Graff's analysis covers data from 75 developing and developed countries. A difference of the ineffectiveness of education based on the wealth of a country is not detected in his findings. The analysis does not investigate different effects of education by gender.

${ }^{3}$ The 'Anderson-Bowman-Hypothesis' proposes a minimum level of around $40 \%$ literacy as the precondition for sustainable growth. This threshold is seen as the basis to achieve the structural changes within society that are necessary for continuous growth. See Bowman, M. I Anderson, A. (1963) and for a more recent affirmation Morris, C. / Adelman, I. (1989), p. 1426. Graff's findings generally support this minimum threshold view, yet the level he proposes is somewhere between $20 \%$ and $40 \%$, thus potentially below the 'AndersonBowman-Hypothesis'. Also he does not recognize an 'impediment to growth', but a 'more difficult' task to attain growth for countries below this level. Above this level, the benefits from increased primary education are insignificant, as pointed out prior.

${ }^{4}$ See Graff, M. (1995), p. 192.

${ }^{5}$ This is due to the fact that a majority of countries already have extended literacy beyond the threshold level, where further increases in literacy are hypothesized (and here empirically supported) to have only marginal effects on growth.

${ }^{6}$ Timmermann, V. (1999).
} 
primary education and growth. He also establishes a nearly equally high connection of higher education on growth. Thus, he lends support to the view that all levels of education should be taken into account to spur growth, not only the primary level. His analysis is not disaggregated by gender and does not take other non-knowledge based investments into account. Therefore, neither the special value of female education nor the assertion that primary education yields higher returns than other investments can be analyzed.

These findings point in the direction that, on economic grounds, the entire educational sector - if at all - needs to be given priority in the strategic conceptions, not just the sector of primary education. On theoretical grounds Birdsall (1996) explains the potential underestimation of the benefits from higher education in contrast to primary education by unmeasured social benefits from higher education in form of "non-training public goods", e.g. basic and applied research, adaptation of research and technology to domestic demands and the training of administrators and managers, among others. She also points at the fact that the benefits from primary education could be declining with increasing levels, while the benefits of higher education might be increasing due to the demands on high-qualified staff arising from globalization and increased competition. $^{2}$

The research findings referenced here question strongly the emphasis on primary education brought forth in the new strategies. Especially they question the assumption that returns to primary education are higher than for other investments; here mainly investments in higher levels of education. While the support for primary education is emphasized in all strategies, its relationship to higher education is still under discussion among donors. This is taken up in the discussion of the accentuations of the strategies in the section on the Swedish program.

As a last point in this excursion it should be annotated that all studies presented have the limitation taking gross domestic product (GDP) or the gross national product (GNP) as the only measure of economic return of the investment in education. These measures reflect the growth of the entire economy and do not account for the economic growth the poor individual can achieve through investment in education vs. investments in other alternatives. Thus, while the impact of primary education on growth on the national level might truly be insignificant, it might still have the highest overall benefit for the poor people to whom the education is extended. ${ }^{3}$ The analyses also have the shortcoming that they only regard economic matters and leave out other

\footnotetext{
${ }^{1}$ See Birdsall (1996), p. 411.

${ }^{2}$ See Birdsall (1996), p. 416.

${ }^{3}$ This can be theoretically motivated by the fact that the economic activity of the poor is of limited scale in comparison to the overall economic activity. Therefore, the GNP is probably dominated by the activities of the non-poor in most countries. Thus, while basic education might provide higher growth of income for the poor population than any other investment, this growth might not show up equally strong in the entire economy, as the large proportion of GNP of the non-poor remains largely unchanged.
} 
dimensions of poverty. Human rights related views and concerns for participation place a high value on education for all, thus shifting the balance towards general provision of basic education.

Back to portraying the international consensus, it has to be assessed that quality of education receives high importance next to its quantity. This is fostered by a concern within the new strategies for the output that the educational system provides in terms of skills development ${ }^{1}$. Able teachers, conducive teaching environments, availability of learning materials and adaptation of the curriculum are regarded as key factors towards high quality eduction ${ }^{2}$. Local monitoring and community participation enhances the quality of education by providing strong incentives for teacher performance, good maintenance of school infrastructure and provision of supplies ${ }^{3}$.

While the factors that contribute to good performance are stated, the ends to which the educational system should contribute remain unclear. The broad content of a valuable curriculum remains ambiguous. There seems to be a preference for basic skills in literacy and numeracy over the provision of specific skills for employment opportunities, yet this point remains implicit ${ }^{4}$. The World Bank acknowledges that the pure provision of services does not necessarily increase demand if the service is too poor or unresponsive to the poor peoples needs 5 . Whether the poor people deem special skills e.g. in agriculture or craftsmanship as important parts of the curriculum, potentially to an equal degree as literacy and numeracy, and whether that could be beneficial or should be rejected is not part of the discussion. While the need and value of primary education seems to have acquired general acceptance, the necessary content of the curriculum did not received much attention in the new strategies.

Next to education the health sector plays a major role building up of assets of poor people ${ }^{6}$. Good health is a precondition for the use of the poor people's main asset, their labor. While good health increases this asset - and also contributes to non-economic benefits of happiness and joy of life, the lack of which is obvious to anyone being sick - illness diminishes this asset, resulting in serious economic consequences for the poor individual who might not be able to support his livelihood anymore. Poor health is seen to extend beyond the individual to

\footnotetext{
${ }^{1}$ See DfID (2000e), p. 11.

${ }^{2}$ See DfID (2000e), p. 11.

${ }^{3}$ See World Bank (2000a), p. 88 and 89.

${ }^{4}$ Literacy is used by DfID next to enrollment to measure progress towards the IDTs regarding development (see DfID (2000e), p. 32), literacy and numeracy are claimed as essential skills (DfID (2000e), p. 2) and female literacy is claimed as important by the World Bank (World Bank (2000a), p. 49).

${ }^{5}$ See World Bank (2000a), p. 81.

${ }^{6}$ This is also a strong emphasis in all strategies. See e.g. DfID (1999a) p. i, ii and 1 - 15, is used for most of the following argumentation as a guide for deeper analysis because of its comprehensiveness.
} 
the entire family, which has to take time from other activities for support and care and might struggle with their very survival if the ill person is the family's breadwinner. This points not only at the impact of poor health for the individual and its family, but also its influence on overall growth. A pandemic such as HIV not only poses serious human problems, it also reduces the national growth rate by more than a percentage point for a heavily struck country such as Zimbabwe $^{1}$, where in some regions $40 \%$ to $50 \%$ of all pregnant women are infected $^{2}$.

The problems of poor health in developing countries thus place a strong burden on development in non-economic and economic terms. Poverty and illness can be interpreted as a vicious circle, in which poverty leads to exposure to higher personal and environmental risks, increases in malnutrition, less access to knowledge and information and diminished ability to access care, which contribute to ill health. Ill health in turn leads to diminished household savings and debt, lowered learning ability, reduced productivity and diminished quality of life leading to increased poverty ${ }^{3}$.

This vicious circle is supposed to be broken by a combined strategy of improved education, improved access to health care, provision of sanitary systems, access to clean water and concerns for the social and physical environment. These measures are seen as highly conducive to improvements in health. For example education of women influences better health outcomes for their children, as does nutrition provided to women. Education generally is seen to lead to a more sensible use of clean water and sanitation systems ${ }^{4}$.

Of special attention is also the accessibility of health centers. Rather than on highly specialized medical care, the emphasis is placed on the provision of basic services in acceptable reach. Problems of petty corruption, which obstructs access to medical care and medicine, have to be tackled, as well as problems of remote areas that are not able to attract skilled staff.

Further problems to be tackled to improve the assets of the poor in terms of health are, first, incentives for researchers to develop medicines for the poor and, second, the low-cost provision of necessary medicines to developing countries. For the first, fond structures are considered that guarantee to pay a predetermined prices for medicine of the first company that can develop the desired cure, thus hoping to provide the lacking economic incentives. The

\footnotetext{
${ }^{1}$ Zimbabwe's growth rate for 1998 was reduced from estimated $2.5 \%$ to only $1.1 \%$. Most other African countries fare better, even though for many of them the epidemic already reduced GNP by between 0.2 and $0.5 \%$. Source: US Bureau of Census Population Profile as cited in DfID (1999a), p. 13.

${ }^{2}$ This number taken from Vogel, U. (1999) is cited to provide an insight on the magnitude of the problem. Exact numbers for the entire working population were not obtainable.

${ }^{3}$ See DfID (1999a), p. 2.

${ }^{4}$ Many 'faults' in the use of clean water can prevent the benefits from it to manifest. For example the storage of water for a several hours in warm climates in ordinary reservoirs already leads to the spread of bacteria. The correct usage of these systems is seen to increase with extended education.
} 
second point will be discussed later under international intellectual property rights.

Rather than paying greatest attention to the cure of already incurred diseases, focus in the new strategies is placed on the prevention of illnesses. Since communicable diseases contribute most to the health problems of poor people $^{1}$, social services such as the provision of clean water and sanitary systems are important to reduce the outbreak of these. Further measures include educational advertising and contraceptive prevalence, which is seen as especially conducive in the case of HIV. Reproductive health in general becomes an important issue, since population growth places a high burden on the spread of development. Especially when the aims regarding health care become reality, such as higher life expectancy and lower levels of illness ${ }^{2}$, the spread of reproductive health services will be necessary to keep the number of birth in line with progressions in life extension ${ }^{3}$. Otherwise the problem of too rapid population growth will be exacerbated. ${ }^{4}$

An additional point that is emphasized regarding the build-up of assets of the poor in terms of education as well as health is a concern with demand side constraints. Demand side constraints, which can apply basically to all government services, can result from unwillingness of the poor to use the services because it does not meet their needs or is of too low quality, or because the costs are too high ${ }^{5}$. This leads to conclude that the government has to find ways to adapt the service to the needs of the poor. This will be facilitated by efforts for decentralization of state power and participation of the poor, as will be examined closer in the chapter on necessary political conditions. It also points at the fact that subsidies might have to be provided to the poor in order to enable them to afford the services. Costs might be accrued because of user charges, which are seen as effective financing measures at least in the health sector but might have to be reduced to enable the poor to access the service. Further impediments can occur if the opportunity costs of the poor are too high in terms of distance, forgone help of the children when they are in school or

${ }^{1}$ See DfID (1999a), p. 10, 11.

${ }^{2}$ See DfID (1999a), p. 2.

${ }^{3}$ This problem has been reflected in Reynolds, G. (1983), p. $82-91$. He assesses that in the last centuries famine, war and plague were prevalent to a degree where families were not sure weather the desired number of children would survive and where due to this uncertainty the number of desired children was greater than the natural fertility rate, rendering birth control meaningless. Yet, the progress in medical care in this decade has reduced death and illness even in poor countries while birth rates are only beginning to adjust, leading to a doubling of the population growth between the 1920s and 1970s.

${ }^{4}$ Other factors that might impede lower fertility rates despite the availability of reproductive health services, such as the security that high number of children provide for their parents, are not explicitly taken into account in the new strategies.

${ }^{5}$ Note that this is an artificial distinction, since the quality of the service and the price together determine the willingness to demand the service. For reference see World Bank (2000a), p. 81. 
costs of school books, which can impede the inclusion of the poor even at free charge and might have to be additionally compensated.

Generally, public investments - in education, health care, water supply, electrification, and other services - are supposed to be targeted in their benefits to the poor ${ }^{1}$ and non-poverty oriented investment should be checked for the necessary level and for possibilities of reallocation, as is pointed out especially for military expenditures.

Aside from fiscal policies legal and regulatory frameworks can also expand the asset base of poor people ${ }^{2}$. Of especial concern in this regard are the agricultural sector and property rights for women. The agricultural sector, which has been neglected by many developing countries especially in SubSahara Africa for an extended period of time, is seen as especially important for economic development that favors the poor, who are in the majority living in rural areas, and for spurring overall growth ${ }^{3}$.

The absence of land and tenure rights in many poor regions is regarded as problematic because it increases the insecurity of the poor regarding the sustainability of their livelihoods. It also limits the expansion of their economic activity due to insufficient access to capital, which could be raised if land titles could be used as collateral. Research establishing the view that small farms are more productive and have a higher savings rate than large farms has given rise to the promotion of land reforms, which is deemed important to increase productivity and to spread the benefits of this increase to the poor ${ }^{4}$. Next to land titles legal reforms opening the market for long-term rental agreements between proprietor and tenant are also seen as beneficial for poverty reduction; directly for the farmers and indirectly for the entire rural population that experiences positive spillover effects. ${ }^{5}$ Further improvements aside from legal reforms are attributed to research on seeds ${ }^{6}$, education on farming methods and reduction of price distortions. Nevertheless, the legal system is seen as largely responsible for the low agricultural productivity and the low opportunities for the rural poor in some developing countries and, thus, deserves special attention.

\footnotetext{
${ }^{1}$ In some developing countries the expenditures on education (and health care) benefit the highest quintile compared to the lowest quintile of the population up to a ratio of 4 to 1 ( 3 to 1 in health care). Gross differences also occur in subsidies of water, electricity and infrastructure. See World Bank (2000a), p. $80-83$.

${ }^{2}$ The general incentive system, which also benefits the poor by encouraging private effort and extending opportunities for business activity and therefore can be argued to contribute to the increase of assets by the poor, has been discussed above and shall not be the concern of this paragraph.

${ }^{3}$ See BMZ, p. 11 and 12.

${ }^{4}$ See DfID (1999b), p. 13 and 14.

${ }^{5}$ See World Bank (2000a), p. 67. Through better enforceable and more reliable agreements the position of the tenant is improved. If the farm population prospers, so the reasoning, the demand for goods from non-farm employment increases as well.

${ }^{6}$ See Sida (1996), p. 17.
} 
A second area where legal reforms are seen as beneficial to asset formation is the extension of rights towards women. This demand can also be strongly placed out of human rights concerns and shows the interaction of social dimensions with the economic dimension. Apart from the benefits accruing to women from a social perspective, there are potentially strong economic benefits in extending rights to women. Women are discriminated in inheritance, property and land concerns as well as in regard to employment opportunities and access to resources ${ }^{1}$. Deprivation from property rights extend in some countries so far that in the case of death of the husband the wife loses the rights to his property and land, endangering the livelihood of the entire remaining family ${ }^{2}$. Even in less dramatic cases the economic potential of women including their innovativeness and their opportunities for returns on labor is reduced by regulations limiting their economic rights ${ }^{3}$.

A third aspect of concern in the strategies in regard to the assets of the poor, somewhat standing aside from the investment and legal considerations, relates to the environment and its influences on poor people. The reasoning for the inclusion of environmental aspects as parts of the factors that influence the asset base of the poor results from the negative effects of environmental deterioration on the poor people's assets and livelihoods ${ }^{4}$.

Poor people are more prone to inhibit marginal land and to suffer form extending desertification and erosion of the soil, which reduce the incomeearning and subsistence performance of their land. Poverty in return is also thought to contribute to this situation in some cases by increasing environmental degradation, e.g. through uncontrolled deforestation of arable land leading to reduced wood resources in the future ${ }^{5}$ and to lower ground water. ${ }^{6}$ This in turn reduces agrarian yield, worsening the situation of the poor even further. In urban sectors, the economic situation of the poor forces them into housing and working under more hazardous environmental conditions caused by pollution affecting their health and, thus, their labor ${ }^{7}$. While in some cases - such as the concern for the preservation of biodiversity as part of the efforts to fight

\footnotetext{
${ }^{1}$ See BMZ (2001a), p. 31.

${ }^{2}$ See DfID (2000c), p. 4.

${ }^{3}$ Where again the roots of the problem lies in social perceptions and attitudes.

${ }^{4}$ See BMZ (2001a), p. 27.

${ }^{5}$ See BMZ (2001a), p. 27.

6 The strategies emphasize that poverty leads to environmental degradation and vice versa. Yet they aim at avoiding the notion that it is the poor who are responsible for environmental degradation. Rather the notion that "All people affect the environment, and vice versa, but the rich have a disproportionately higher impact and the poor tend to be the most vulnerable to the effects of environmental degradation" prevails. Statement of UNEP, US NASA and World Bank cited in DfID (2000c), p. 1. This view is even more reversed at other placed such as DfID (2000c), p. 4: "Globally, most environmental degradation is caused by the non-poor as the poor's consumption levels are still low relative to the rich", pointing at the need for action beyond looking at the poor.

${ }^{7}$ See DfID (2000c), p. 3.
} 
poverty $^{1}$ - the impact of environmental preservation on the poor is arguable, for many other areas this relationship holds true and is therefore integrated into the strategies.

The extent of the impact of environmental degradation on the entire economy can be startlingly high, reaching more than $3 \%$ of GDP in some countries $^{2}$. Also the effects on other determinates of poverty are substantial; for example on health where environmental factors are estimated to be responsible for almost a quarter of all diseases in developing countries ${ }^{3}$.

Causes for environmental degradation include income inequalities and unsustainable consumption, both in developed and developing countries. It is also associated with market failures, which cause goods and services related to the environment to be systematically undervalued, and poor and ineffective governance, which leads to the environment being relatively neglected and not integrated into the development of national policies and programs ${ }^{4}$.

On the national level this calls for measures restoring the correct price of environmental goods by internalizing the effects of pollution and environmental degradation that do not figure into the individual actors calculations. Also, measures to fight desertification ${ }^{5}$ and local management of forests should be attempted on a national or sub-national level. To give the local population, especially the poor, economic incentives to secure the sustainable management of the ecological environment at the local level is seen as the key to integrate pro-poor growth strategies with sustainable development, while at the same time evading free-rider problems associated with public management ${ }^{6}$. This is seen as essential in preserving the natural assets on which the poor people today, but also people in the next generations will rely for their living.

Yet, some problems such as over-fishing in international waters, which affect the nutritional support for the poor in coastal regions, and climate change, which is seen as particularly harmful to poor countries and the poor people within them because they can least protect themselves against the resulting

${ }^{1}$ Expressed as part of poverty reduction programs e.g. in BMZ (2001a), p. 17 and DfID (2000c), p. 27. That the proceeds of the commercial use of biodiversity shall be shared with the developing countries can be seen as partly contributing to poverty reduction. Yet the overall interests in the preservation can be argued to lie in the interests of the developed countries. The promotion of efforts to secure biodiversity as part of poverty reduction can only be justified if the benefits of this are greater than those of other, more direct efforts or if the resources for such action are supplementary. For a more detailed discussion see the introductory chapter on the role of poverty reduction: 'Poverty Reduction vs. Other Developmental Goals'.

${ }^{2}$ E.g. in Pakistan the cost is estimated at $3.3 \%$ in the 1990 s and for China at $4-7 \%$ of GDP in 1990 by the Asian Development Bank (1997): Emerging Asia: - changes and challenges, as cited in DfID (2000c), p. 21.

${ }^{3}$ See DfID (2000c), p. 7.

${ }^{4}$ See DfID (2000c), p. i.

${ }^{5}$ See BMZ (2001a), p. 28.

${ }^{6}$ See World Bank (2000a), p. 91 and 92 for the application of this concept to forestation, and DfID (2000c), p. 2 for a generalization of this view. 
adverse effects, are beyond the scope of intervention by the individual governments and are subject to international efforts. These are discussed in more detail in the later chapter on international institutional framework on environment.

\subsection{Access to Markets}

The need to increase the assets of the poor through various measures relating to human asset, natural assets and material assets is based on considerations on the inner value of these assets for poverty reduction, as in the case of health and education, and their influence on the economic situation of the poor. Aside from subsistence considerations these assets only receive their economic value if they are connected to markets. There the assets themselves, as in the case for labor or cattle, or their proceeds, as for agricultural or small business output, can be offered and the inputs for the most profitable use of these assets such as credits or fertilizers can be demanded.

Physical, social or regulatory barriers to markets severely limit economic opportunities. Since barriers to markets are seen as especially high for poor people because they tend to live to a greater proportion in remote areas, lack connections and face higher barriers of social discrimination, there is a need to focus on their needs. General measures towards the extension of markets such as privatization and dissolution of state monopolies, removal of price distortions and a framework conducive to a well-regulated market mechanism, have already been discussed in regard to the economic incentive system. Extended efforts in regard to the value that markets provide to the poor are important in regard to agriculture, financial markets and infrastructure.

As argued prior, agricultural growth is regarded as an important source for propoor growth justifying land and tenure reforms, yet other reforms are needed as well to make this market beneficial to the poor ${ }^{1}$. These include the dismantling of state interventions that limit the full functioning of this market and its growth. Reducing regulation and liberalizing trade possibilities and prices have generally led to increases in producer prices ${ }^{2}$. Gross distortions such as marketing boards as the only allowed intermediary for the farmers should be changed into a competitive system, not only to increase the price to market value, but also because it has been observed that competitive, market-based structures offer better service for the smallholder farmers. Next to higher efficiencies these services include the provision of extension and input services including fertilizers. These raise agricultural productivity to the benefit of the small farmers. The competitive intermediary environment brings new ideas and knowledge to the small farmers and allows for an increasing variety in their production.

\footnotetext{
${ }^{1}$ For the following discussion see World Bank(2000a), p. 67 - 69.

${ }^{2}$ Yet the negative side of these reforms on the urban poor, who face higher prices, has to be anticipated and appropriate measures have to be taken if the increase is too detrimental.
} 
Of strong importance for the successful and fruitful functioning of the agricultural sector is also the availability of credit to be able to invest in fertilizers and other necessary inputs that increase the yield and the productivity of the soil. This also helps to smooth the consumption over the agrarian seasons. Similarly, financial services in form of credit, savings instruments and insurance are also needed by poor people outside the agrarian sector in order to manage risks, smooth consumption but especially to take advantage of opportunities and increase their earnings potential ${ }^{1}$. Many poor lack access to financial services, though, because they do not have any securities for loans and without effective supervision the risk of lending to them is too high for commercial banks. Moreover, the transactions of poor people tend to be small, up to a degree where financial transactions of regular banks become unprofitable.

A solution to this problem is seen in micro-finance schemes, which provide financial services for poor people ${ }^{2}$. Pioneered by private initiatives like the Grameen Bank in Bangladesh, these schemes use group lending to supply credits. The local management keeps costs low, while the collective monitoring of the correct, productive use of the loan and of the financial situation resulting from it increases repayment rates by overcoming the problems of asymmetric information such as adverse selection and moral hazard ${ }^{3}$. This expansion of credit to the informal sector ${ }^{4}$ allows the great number of poor working in this sector to achieve access to the financial markets which can substantially increase their ability to expand or newly build their business and thus their incomeearning potential; and for those who are saving it enables the provision for and coping capabilities with adverse influences.

To return to the agrarian sector, neither assets nor credits suffice for the establishment of a market if the physical connection between supply from the remote farms and demand is not available, thus leading to the question of necessary infrastructural investments. Infrastructure is one of the basic preconditions for a framework conducive to poverty reduction ${ }^{5}$.

The provision of rural roads provides the necessary physical conditions that connect rural areas to broader markets, which is a precondition if these areas are to benefit from growth accruing from increased national and international trade. This is the case not only for agriculture, but also for other products crafted in rural areas. International connections might also increase the need for national roads and railways.

\footnotetext{
${ }^{1}$ See World Bank (2000a), p. 74.

${ }^{2}$ Yet not necessarily for the poorest, as a review of 13 microfinance institutions indicates. See Hulme, D. / Mosley, P. (1996).

${ }^{3}$ See World Bank (2000a), p. $74-76$.

${ }^{4}$ See Sida (1996), p. 32.

${ }^{5}$ See BMZ (2001a), p. 11.
} 
Next to transport, essential infrastructure regarding water supply and energy are to be addressed to assure access of the poor to these markets ${ }^{1}$. Water and electricity augment the living conditions of people and also increase their economic base through access to these markets for inputs required by many production processes. This might benefit the poor directly, but also contributes to indirect benefits of increased employment e.g. in the manufacturing sector. The expansion of modern technology, enabled by electrification and extending towards telecommunication ${ }^{2}$, is also conducive to connecting the poor to remote markets.

Telecommunication infrastructure is seen as important to bring new information and influences to rural areas and, thus, to provide links to larger, more remote markets. Possible further areas for the use of modern technology are in secondary and tertiary education, teacher continuing education and administration $^{3}$. Strategies for this are still very basic, as will be discussed in the subsequent chapter. These strategies relying on cellular phones accessible through local entrepreneurs as pioneered by Grameen Telecom of Bangladesh ${ }^{4}$, and on reductions in user fees and extension of coverage in a well-regulated and competitive telecommunications market, that is yet missing in many developing countries ${ }^{5}$.

Further infrastructure requirements include social infrastructure for a connection to health care and education as discussed prior, and certain aspects of economic infrastructure including for example irrigation as inputs for the agrarian industry.

In infrastructure investments involving government financing special concern is placed on the fitness of projects to needs and on recurrent costs ${ }^{6}$. To tackle these problems local ownership is the seen as a key ${ }^{7}$. The participation of the local community in the decision making and their acceptance of ownership for the infrastructure, e.g. rural roads or water supply, helps in choosing priorities, especially in difficult choices such as on social vs. productive investment. This demand-based approach has in many cases to be supplemented by supply-side inputs such as local capacity building and information provision. In some situation where the overall sectoral strategy does not figure into the individual calculation at community level or where projects of a broader scope than the community level are pursued, a bottom-up approach will not be feasible. Yet

\footnotetext{
${ }^{1}$ See DfID (1999a), p. 26.

${ }^{2}$ See Sida (1996), p. 33.

${ }^{3}$ See UK government (2000), p. 41 and 42.

${ }^{4}$ See World Bank (2000a), p. 87.

${ }^{5}$ See UK government (2000), p. 40.

6 These problems arise more in governmental projects than in private projects, which determine their initiative on market needs and on possible returns. Projects that are foreseeable to not cover their recurrent costs or not to meet the needs of the population will likely not be undertaken in a market environment.

${ }^{7}$ For this discussion see World Bank (2000a), p. 90 and 91.
} 
wherever feasible ownership of the project by the community should be sought since it also ensures good operation and maintenance of the infrastructure investment. It also might enable community-based cost sharing of the investment or the operation. Tackling the problem of recurrent costs and maintenance needs is essential to insure that the investments undertaken to provide long-term access to markets for the poor (and the non-poor in most cases) can actually provide the benefits and increased economic opportunities and do not falter early because the necessary upkeep was not undertaken.

In conclusion, the new strategies' focus on the advancement of the poor is based in part on an approach to expand their assets and the return to those assets. This is pursued mainly through investments in human capital and legislation granting property rights to the poor. To enable the poor to use their assets effectively, the need for integration into the market economy is stressed. The access for the poor to markets is attempted through promoting agricultural markets, micro-finance schemes and infrastructure investments. The strategies thus rely strongly on the market mechanism while stressing the role of the state to set the regulatory framework and to enable the poor to participate successfully in these markets.

\subsubsection{Excursion into Infrastructure Investment}

As has been pointed out before, infrastructure is important for the provision of social services, market access and the sprout and development of business activities. Irrigation is needed for improved agricultural yields; water supply is essential to fight diseases and to reduce the work load for women who fetch water traditionally; sanitation is necessary to fight communicable diseases; rural roads are needed to connect the poor to the markets; basic service infrastructure is needed to provide schooling and health care for human capital accumulation and in their own rights; electrification is essential for a region to be attractive for business activity, to preserve more inefficient natural forms of energy and raise the quality of life; national roads and railways are a precondition to link people to export markets; and communication and new media access is important for the availability of information, the broadening of the views and to reap some of the benefits of globalization. This shows the vast difference of infrastructural projects, ranging from small cost, small reach projects for local dwells with immediate impact on the poor to projects of high costs, extended reach such as energy projects, where the benefits to the poor are indirect and hard to assess. The limited resources in developing countries do not permit all projects to be pursued at once in all areas. Facing this constraint, it is astounding that the new strategic proposals shed little or no light on three important questions: The priorities of projects, their sequencing and the inclusion of new technologies. 
Do projects on economic infrastructure and services justify their more than fourfold costs over projects for social infrastructure and services ${ }^{1}$ due to their greater outreach and potentially broad, but difficult to measure indirect effects? And if economic infrastructure is desirable, are then road networks more desirable for poverty reduction, or rather electrification? The strategies give some hints. Social services in regard for schooling and health care receive high emphasis, thus implying the need for social infrastructure in their support. Also, the bottom-up approach of the World Bank that points to participation in order to determine the priorities on a local level seems sensible, as it links the priorities to the needs of the local population. The local perspective does not help though in decisions where at least one of the alternatives has overcommunal reach such as for electricity, where the benefits are difficult to determine or where large external benefits might exist due to interrelations with other projects or cross-communal linkages. Here the local benefits do not coincide with overall benefits.

The vacuum concerning answers to the question of priorities stems from the focus of the new strategies. The need for infrastructure, also economic infrastructure, is confirmed, yet only certain aspects of infrastructure have been reflected, such as rural road networks and sanitation, while others like national transportation and electricity have been neglected. And even those aspects taken into account stand side by side rather than in ordered priority. Priorities are difficult to generalize; yet even the discussion of ways and criteria to determine them are missing, with the bottom-up approach of the World Bank being the notable exception ${ }^{2}$.

The discussion of priorities is strongly connected to the reflection on sequencing issues. Whether a vast road network is preferable to electrification should rather be turned into the question whether a vast network of roads should be implemented at the expense of late electrification or rather a few roads but therefore early electrification? A further question concerns investments in more than one geographic area: for two distinct areas, should one receive both infrastructure services, i.e. electricity and broad road access (or any other two infrastructure investments) due to synergies either in the provision or their impact? Or should both first receive one service, and later both receive the other? There seems to be an understanding that broad provision of basic social infrastructure for health and education is essential, implying a view of broad

\footnotetext{
${ }^{1}$ The survey presented later on projects in the German financial cooperation found this ratio of average investments in both sectors to be above four. See the chapter on implications for project evaluations.

2 The potential annotation that the developing countries themselves should determine the priorities since they are the owners of their national strategy does not relieve the strategists from this concern, since the strategies are aimed at guiding national choice in a whole range of national priorities reaching from the role of the state to social perceptions of the role of the women, and the reflection on this very cost-intensive matter in regard to infrastructure investment should as well be taken up.
} 
based but basic rather than punctual but profound social infrastructure ${ }^{1}$. On the other hand DfID acknowledges the possibility that migration from rural areas to centers might be sensible since the spread of business infrastructure to thinly populated rural areas might be too costly in terms of their economic returns ${ }^{2}$, pointing at a more concentrated approach.

Since a framework for setting priorities is missing, a very simple one is outlined here. The following discussion is included to illustrate the point made above: In a financially constraint setting not only the different possibilities have to be listed, but there have to be some ideas on which of these possibilities are most important in a given situation as the scarce resources prohibit the pursuit of all of them. It does not claim to cover all relevant issues here - this cannot even be attempted in this short exposition - but rather tries to point out the direction a sensible discussion on financially constraint recommendations could follow to give guidance for the national discussion in the developing country:

Theoretically, under abstraction from the concrete problems of a specific country and starting from scratch, a simple framework could work as follows: As a first priority and first step in a sequence the construction or rehabilitation of a road connecting a rural community is proposed. This has the potential of fostering private initiative, since the physical connection is important for merchants and industries to reach the community as well as for the rural community to seek the interaction with external markets. Private initiative might then already be able to increase the provision of other infrastructure services because the physical inaccessibility is removed.

This also eases the provision of social services, which in this train of thought would be the second priority swiftly following road construction. Physical access facilitates the delivery of medicine and the attraction of qualified personnel in health care and education necessary for the delivery of the service. While health care is important for the people for their well-being and their returns from labor, education is the main concern here because it can serve as a means to foster an attitude of learning and entrepreneurial spirit, prepare the children for the changes of a more open world and expands their skill level, if the curriculum is set right. This process will take some time.

A third step in the sequence will then be the extension of business infrastructure such as water supply and electricity to the region after a time sufficient for educational efforts to show effect, but fast enough so that increased physical access and education does not result only in migration of those seeking business opportunities. This business infrastructure will, in an optimal case, provide a fertile ground for the entrepreneurial spirit induced by education to extend into business activity. For outside entrepreneurs it increases

\footnotetext{
${ }^{1}$ Both will not be feasible at once due to budgetary constraints without which this discussion and the discussion on priorities for development as a whole would be superfluous.

${ }^{2}$ See DfID (1999b), p. 19.
} 
the incentives to bring their know-how to an already sufficiently skilled and open-minded labor force. The benefits from education and later business infrastructure could accrue from adaptation of more profitable methods in agriculture or from the start of small businesses which use the newly provided inputs for their advantage; both leading to better economic performance and result in higher living standards for the local population.

Summarizing, the sequence: physical infrastructure followed by social infrastructure followed by economic infrastructure is tentatively proposed. Yet it is not the results of this analysis that is of importance, but the way to look at the problem. The framework is included to portray the need to focus on priorities in implementing the new strategies: i.e. to give guidance on the way to reap the highest benefits given the constraints that not all projects will be able to be financed due to the limited resource availability. This is mostly omitted in the new strategies.

The very simple framework presented here obviously abstracts form the individual problems within each country and region, from the priorities of the urban population and from rural-urban interactions. It also assumes a development from scratch and does not tackle the question of additional infrastructure investments when basic infrastructure exists but is not sufficient or improperly maintained. Furthermore, it does not look at potential synergies in service provision. If the costs of laying electricity and telecommunication lines or water pipes is substantially reduces if this is conducted jointly with efforts of road construction, since manpower and possibly earth moving equipment is already at the sight, a case for a more concentrated approach providing several services at one time might receive stronger support over the presented sequential approach.

This opens up the question to how such a framework looks like under more realistic conditions. Despite all these obvious drawbacks, the approach presented above steps in a direction where not all infrastructure investments are favored, but where priorities and sequencing play a role. A broader framework in this respect could give guidance in those cases where the most helpful solution cannot be determined by assessing the local demand because of conflicts of interests in the community, projects with over-communal character and highly interrelated projects. Such a broader framework will have to draw on empirical analysis on the interrelation of projects as well as on country or regional specific knowledge, but would positively extend the current strategic proposals. Its benefits would include the integration of different sector policies into one framework and a contribution to development effectiveness. These prospects make a pursuit of such a framework for setting priorities worthwhile.

One further point to be made regards the emphasis for new technologies within the new strategies. The "stronger application of modern technology" is demanded, yet the areas in which this should be applied and the ends to which

${ }^{1}$ See BMZ (2001a), p. 12. 
they shall serve remain unclear in most strategies. One interpretation for the increased demand for information technology is the concern with international inequality, implied by the phrase "Digital Divide", which describes the divergence in the use of advanced information technologies (IT), mainly of computers and the internet, in industrialized countries in contrast to developing countries.

This divergence by itself does not justify the inclusion of information technology in strategies for poverty reduction, since a further departure of the developed world has no influence on the poor, whose misery is mainly reflected by their distance from the absolute minimum necessary for survival and their relative position in their society than their distance to living conditions in industrialized countries. Yet if increases in the use of information technology are seen as conducive to poverty reduction because they increase overall economic growth and growth that occurs to the poor, and not just as a global objective of international equality, they receive distinctive value for poverty reduction strategies.

This second interpretation seems to be reasonable, since the economies of the developed world that provide most of the export opportunities for developing countries rely increasingly on the use of the Internet in business-tobusiness transactions. That implies that the availability of new technologies increases the opportunities for exports and growth, while the unavailability decreases these possibilities. Since in contrast to manufacturing facilities the costs of Internet access are rather small, there seems to be a case in promoting these in bigger manufacturing environments.

For smaller, informal manufacturing, the costs of Internet access including the hardware are much less favorable, and even though there are still benefits by circumventing the middleman, broadening the market and increasing administrative productivity, the cost/benefits ratio will tend to be smaller than for larger companies. For the rural sector, especially for the agricultural sector, the value of the internet in economic terms is especially questionable in the short to medium time frame, since individual exports to industrialized countries are unlikely and a broadening of the domestic markets is unrealistic, since on the domestic front business to business solutions to agriculture are unlikely to exist.

These differences remain unreflected in the new strategies. Considerations beyond the economic sphere that give rise to the promotion of information technology are hardly presented at all. On the countryside new technologies can have positive impacts by broadening the horizon of the young generation ${ }^{2}$ and expanding their comprehension of the possibilities in this world. News can be accessed and learning opportunities can be opened. For this to happen, there has

\footnotetext{
${ }^{1}$ See UK government (2000), p. 39.

${ }^{2}$ For the aged generations as well, yet the young generations seems to be more responsive to the advance of new media, as the experience of the industrialized countries shows.
} 
to be a strategy ${ }^{1}$ for the provision of the services and also about the provision of content especially when learning is an aim. International content does not make superfluous local or national content due to language barriers and different content needs, as for example in rural areas simple farming techniques might be of interest. Adaptation of content to the national or local language might also need to be undertaken.

Most of the current strategies either provide no further reference than stating the need for new technology ${ }^{2}$, or stay with currently tried and realistic, yet not very visionary implementation proposals such as pre-paid phone cards ${ }^{3}$ and local entrepreneurs offering cell-phone access ${ }^{4}$. Real concern about the preconditions for the effective use of new technologies and communication systems and their integration into a strategy that links these new technologies to the development process are for the most part missing.

The Second British White Paper on International Development ${ }^{5}$ is a notable exception to this, since it defines areas where new technologies could successfully be deployed, i.e. secondary and tertiary education, teacher training, common virtual marketplaces and public sector efficiency. It extends its investigation beyond considerations of modern IT. Concerns about limited access to information from new technology stimulated ideas to couple new and old technology. For example the connection of radio stations to the internet is proposed, so that the information gained through internet access can be broadly communicated. To increase access and reduce costs the deregulation of the telecommunications market, limitation of monopoly power and increased competition are promoted. Also concerns regarding content, language and marginalization of rural areas that are less likely to be connected are raised.

Such a discussion, extending beyond solely stating the need for new technology into a direction of a meaningful analysis of the impact that new technologies can actually have and about ways to bring these to full potential, will have to be undertaken in greater detail to lead to a sensible strategy for the application of new technologies in developing countries.

\footnotetext{
${ }^{1}$ It could be argued that a strategy is not always necessary and that the market does not need a strategy, but in many developing countries there is not yet a framework for a functioning market, thus the changes in regulations have to be part of the strategy. Furthermore, areas where the return from market investment is too low might have to be a concern for strategic intervention, as has to be the case in regard to the provision of content that might in many developing countries not serve the needs of the users and which could be enhanced by initiatives spurring private, and if necessary public content for the new media.

${ }^{2}$ As in BMZ (2001a), p 12, 13. As areas of implementation improved health services, improved education especially for women and the extension of economic commerce are mentioned. The vague implementation reference summarized in a single sentence only hints at a possible direction of implementation of these ideas, yet is far from illuminating concrete steps. Even new academic advice to the $\mathrm{BMZ}$ on the topic of globalization neglects this point nearly entirely. See BMZ (1999b), p. 13.

${ }^{3}$ See Sida (2000), p. 33.

${ }^{4}$ See World Bank (2000a), p. 87.

${ }^{5}$ See UK government (2000), p. $39-42$.
} 


\subsubsection{Necessary Political Conditions}

\subsubsection{Linkages Between Political Conditions and Economic Issues}

Economic issues play an important part in the reduction of poverty, as has been shown in the preceding section. Yet the economic sphere in a society cannot be separated from the political framework prevailing in a country. The importance of political and social considerations for the lives of poor people and on the outcomes of their economic activities is acknowledged and deeply rooted in all analyzed strategies. This is most evident in the inclusion of the political and social dimensions in the definition of the poverty ${ }^{1}$, and receives strong attention in the discussion on strategic actions.

The concern for political considerations is strongly based on their inherent value for the attainment of human rights regarding the life and personal freedom of each individual. These rights are seen as " means of empowering all people to make decisions about their own lives rather than being the passive objects of choices made on their behalf ${ }^{\prime 2}$. Additionally, political considerations are also regarded as important in the pursuit of economic development. The impact on the economic activity is supposed to be achieved by empowering the people to claim their rights. This shall enable them to access the opportunities and services made available through pro-poor development ${ }^{3}$. Empowerment is pursued by demanding a political concern for human rights and equality, participation of the poor or their representatives in the decision-making process and democratization. ${ }^{4}$ These measures are regarded as conducive to improve the availability and quality of public service inputs for poor people due to increased influence on and accountability by the administration and to create a nonrestrictive political and social environment conducive to economic activity. ${ }^{5}$ This is claimed to better the overall economic situation of the poor.

In contrast, if good governance cannot be achieved, economic opportunities are stifled; for example by corruption and absent rule of law ${ }^{6}$. Thus, increased attention is being given within the new strategies to governance matters on the part of the government, the legal system and the administration. Corruption and lacking rule of law do not only hamper the initiative of poor people, they diminish also overall economic incentives, reduce domestic investments and deter foreign capital inflow, leading to reduced overall economic performance. Another major concern is paced on gender equality, since discrimination on the base of gender is still widely spread and massively impacts the situation of women, as the fact that about $70 \%$ of the poor are

\footnotetext{
${ }^{1}$ See the chapter on 'Poverty Definitions beyond Monetary Income.

${ }^{2}$ See DfID (2000d), p. 1.

${ }^{3}$ See DfID (2000d), p. 4.

${ }^{4}$ See e.g. BMZ, p. 6 and 30.

${ }^{5}$ See World Bank (2000a), 99 - 101.

${ }^{6}$ See World Bank (2000a), p. 102, 103.
} 
women ${ }^{1}$ points out sharply. This also has economic implications, since women have great potential for increasing their economic activity ${ }^{2}$ and, thus, their equal treatment is seen as a prerequisite for sustainable development ${ }^{3}$.

Yet while political and social aspects influence economic outcomes, this relationship holds true in the other direction as well, where measures fostering economic activity also influence the political sphere. For example, education not only expands peoples economic possibilities, but also their will and potential to engage in politics and diminish social inequalities. Especially education of girls, which is seen as strongly conducive to economic growth, changes the balance in society towards greater acceptance of women ${ }^{4}$.

Due to these interactions between economic and political issues, the strategies extend their focus beyond economic considerations and strongly regard the political dimension, which has its virtues in its own right as well as in their contribution to economic advancements and also to the provision of security ${ }^{5}$. This political dimension is the concern of this chapter. The empowerment of the poor in terms of human rights and equality, participation in decision-making and democratic reforms is investigated first, while in the second part the measures of good governance relating to legislative, legal and administrative issues necessary for empowering the poor are discussed.

\subsubsection{Empowerment}

\subsection{Human Rights and Equality}

In the pursuit of the reduction of poverty in developing countries, the compliance with human rights standards such as the Universal Declaration of Human Rights (UDHR) is claimed as a guideline for goals and actions that the government should adopt to progress in the right direction. ${ }^{6}$ The new strategies emphasize the strong linkage between the attainment of human rights and increasing empowerment of the poor. Thus, need to focus on the empowerment of the poor is stressed. Empowerment means in these strategies the ability of people to take decisions on their own lives instead of being passive objects of

\footnotetext{
${ }^{1}$ See UNDP (1995).

${ }^{2}$ See DfID (2000f), p.4.

${ }^{3}$ See Sida (2000b).

${ }^{4}$ See DfID (2000f), p. 1, 3.

${ }^{5}$ Which will be the concern of the chapter on 'Measures to Increase Security'.

${ }^{6}$ Human rights are mainly a concern of the three bilateral strategies, while except for few mentionings (like "culture of human rights" World Bank (2000a), p. 122) they do not play an explicit role in the World Development Report 2000/2001. This is due to the interpretation of the mandate of the World Bank, which focuses on economic matters, which is strongly criticized by DfID (DfID (2000f), p. 15 and 16). Since human rights play implicitly a strong role in the WDR, they can still be considered overall consensus. For more detail on this see the chapter on 'Different Accentuations: the World Bank'.
} 
the decisions other people make on their behalf ${ }^{1}$. For an abstract of important human rights see annex 1 . These comprise a wide array of goals from mere physical survival and integrity - the right to live and the right to the highest attainable standard of physical and mental health - over personal liberty, freedom from discrimination and cultural inclusion to economic goals of just and favorable conditions of work and political aims of freedom of religion, opinion, speech and expression and the right of political participation ${ }^{2}$.

The breadth of these goals is broad. The governments who signed one of altogether six human right treaties commit themselves to doing everything within its capacities ${ }^{3}$ to meet the human rights standards enshrined in that treaty. This points at a problem if this capacity is limited, as can be assumed for some poor countries. This is the especially so for the rights on economic conditions. Yet other conditions concerning individual, social and political aspects are not very costly in other terms than in the reduction of the power of the administration and the government, and are also seen as conducive to the achievement of better economic conditions. The most important aspects in regard to human rights are related to: The strengthening of social priorities of government spending, the importance of core labor standards and the curbing of discriminatory practices, most importantly in regard to the situation of women.

In the first chapter on the domestic framework for poverty reduction, the need for spending in favor of the poor was justified mainly from an economic perspective, which might or might not be accepted by the government in their design of national policies, since a government could retain a standpoint claiming non-poor oriented projects as most conducive to the poor due to indirect effects. The human rights based view provides a different approach to the justification for pro-poor spending ${ }^{4}$. The poor are in a human rights

\footnotetext{
${ }^{1}$ This definition is taken in very close relation to the statement: "They (the human rights, the author) provide a means of empowering all people to make decisions about their own lives rather than being the passive objects of choices made on their behalf." DfID (2000d), p. 1 . Despite a great concern for empowerment, the other strategies neglect the definition and rather jump right into the solution. For example the World Bank (2000a), p. 33 states: "Facilitating empowerment: making state institutions more accountable and responsive to poor people, strengthening the participation of poor people in political processes and local decision making, and removing the social barriers that result from distinctions of gender, ethnicity, race and social status." Yet from the concern for the ends we see that the definition given for empowerment by DfID well could be the goal behind these ends, thus accepting its overall value.

${ }^{2}$ See DfID (2000d), p. 2.

${ }^{3}$ See DfID (2000d), p. 4.

4 A consideration of social perspectives is also implicitly included in the economic perspective (otherwise a concern could be fully concentrated on overall economic growth). The given social objective of improving the situation of the poor is the base line for the economic policies on poverty reduction to be judged against. Yet the difference between the economic perspective and the human rights perspective, despite nearly equal demands, is the
} 
approach not seen as appellative, but rather as demanding a right that has been granted to them. ${ }^{1}$ The value of investments in health and education is not measured in terms of progress on another dimension such as economic growth. The need to undertake such investments is linked to the inherent right of every person of attainments in education and health. This opens broad potential for the poor or their representatives to claim these rights ${ }^{2}$.

The concern that public actions might be more prone to rent-seeking behavior of elites than to socially justified actions and the inferred need for strong priorities for public actions in favor of the poor ${ }^{3}$ can be tackled by a human rights based framework, because it increases the obligation of the state to focus on those deprived of their human rights, provides support for people who strive to claim or provide these rights and gives guidance on the ends to which public actions should be taken. The focus of the new strategies to encourage the inclusion of the human rights into national $\mathrm{law}^{4}$ and to make them accessible should aid this development ${ }^{5}$. Increasing the obligations of the state and its government to improve the living conditions of its poorest citizens is a way of turning the share of government funds and the directions of policies, laws and regulations in favor of the poor, with potentially great effects on their lives and on poverty reduction as the abstract objective.

One important issue in the context of human rights in the new strategies is the adoption of core labor standards, which are politically binding for the members of the International Labor Organization (ILO) since their acceptance in $1998^{6}$. They include the freedom of association and the right to collective bargaining, elimination of forced labor, effective abolition of child labor, and the elimination of discrimination in employment and occupation, which are seen as a basis for the socially responsible economic process. ${ }^{7}$ The value of these norms is strongly acknowledged and it has been widely agreed that the standards themselves represent worthy targets for economic development. ${ }^{8}$ That the poor and powerless are most prone to exploitative working conditions which are not reconcilable with human rights standards can be explained by their minor position in bargaining about these conditions and the according payments in cases where the demand for labor is relatively low and supply is high, as is the condition in many poor developing countries.

perception of social indicators such as health and education as a means in the former and as a goal in the latter.

${ }^{1}$ This right can constitute a direct claim on state action or an indirect claim to preconditions that allows the individual to attain the entitlements of the right by his own efforts.

${ }^{2}$ For this argument see e.g. DfID (2000d), p. 19.

${ }^{3}$ See World Bank (2000a), p. 100.

${ }^{4}$ See DfID (2000), p. 13.

${ }^{5}$ See BMZ (2001a), p. 31.

${ }^{6}$ See BMZ (2001a), p. 31.

${ }^{7}$ See BMZ (2001a), p. 31, 32.

${ }^{8}$ See World Bank (2000a), p. 73. 
While abusive and hazardous working conditions are univocally regarded as contributing to poverty at least on the non-economic dimensions, the ways in which rights to better working condition and core labor standards should be enforced remain ambiguous. Most strategies favor the promotion of these rights as part of a broad-based development strategy through information, technical assistance, capacity building and complementary initiatives. ${ }^{1}$ A concern for labor standards in public contracts on development assistance and educational work on human rights as a whole are further proposals to foster these standards. ${ }^{2}$ International sanctions in terms of trade barriers imposed through the WTO system are disputed in their effectiveness. WTO trade sanctions are discussed in more detail in a later chapter on international regimes on trade.

Discrimination in employment and occupation, one of the concerns of the ILO that supervises the adherence to the agreed upon standards, is only one form of discrimination, which reflects underlying discriminatory tendencies in the society. Discrimination on the basis of gender, ethnicity, race, religion, or social status can effectively exclude people from social life and lock them in long-term poverty traps, ${ }^{3}$ which points at the fact that discrimination causes deprivation in economic and non-economic terms. These poverty traps do not only result from discrimination at work, but also from exclusion from social services, legal representation, property rights and political representation. This limits economic opportunities in terms of dependent employment through direct discrimination and of self-employment because of lack of inputs in from of health, education and administrative services. It also reduces the ability to change this situation because of low political and social influence. Discrimination is a phenomenon deeply rooted in a society, resulting in exclusion in social, economic and political terms.

Therefore, a comprehensive response to the interdependent social, economic, cultural, civil and political relationships of power that lead to discrimination and inequality has to be found. ${ }^{4}$ Currently proposed measures comprise support for minority languages and cultures ${ }^{5}$, educational material breaking with traditional stereotypes, provision of disaggregated information by ethnicity, gender or religion ${ }^{6}$ and the emphasis of role models out of the discriminated group ${ }^{7}$. Affirmative action on part of the government is proposed for deeply stratified countries where the disabilities from long-standing discrimination are so entrenched that in order to compete in economic and political terrain the people discriminated against need special assistance in

\footnotetext{
${ }^{1}$ See e.g. World Bank, p. 73, 74.

${ }^{2}$ See BMZ (2001a), p. 33.

${ }^{3}$ See World Bank (2000a), p. 117.

${ }^{4}$ See DfID (2000d), p. 19.

${ }^{5}$ See Sida (1996), p. 22.

${ }^{6}$ See DfID (2000d), p. 21.

${ }^{7}$ For this and the following argument see World Bank (2000a), p. 125, 126.
} 
acquiring education, information and self-respect. This assistance can be provided by developmental policies aiming at improving the skill level of the target group through financial, educational and managerial allowances. ${ }^{1}$ For long-term solution, special emphasis is placed on the inclusion and advancement of children and adolescents since they can carry future developments that will enable a society to overcome social disintegration and lack of perspective ${ }^{2}$.

The concerns about discrimination span every form of discrimination, which could be based on ethnicity, race, gender, religion, social status or other criteria. Gender inequalities receive special attention in the new strategies. One reason for this is the fact that about twice as many women are estimated to live in absolute poverty compared to $\mathrm{men}^{3}$. Concerns are also raised about high levels of violence and abuse of women, which is partly caused by the inability of women to pursue their rights as many countries still continue to discriminate against women in the law. ${ }^{4}$ Gender inequalities and gender discrimination is seen as a gross violation of human rights. ${ }^{5}$ Also on economic terms the gender bias raises worries since the predominant part of the women work in the informal sector in underpaid conditions and constitute a only a very small part of the formal sector employment, despite a proportion of $40 \%$ in the worldwide paid-labor force. ${ }^{6}$ The sheer number of women that are deprived of their economic opportunities and the economic potential lost thereby places equality of women as one of the prerequisite for poverty reduction ${ }^{7}$.

The exclusion of women from political decision-making processes ${ }^{8}$ also places gender equality as a major concern for the achievement of democratic systems. These concerns highlight the important role that the development organizations ascribe to gender equality. Since there is a perception that gender

\footnotetext{
${ }^{1}$ The World Bank also debates the use preferential policies looking to decrease inequality by giving opportunities to members of the disadvantaged groups even when they are less qualified. It cautions this approach because of the associated risk of increasing the negative stereotypes against the target group. See World Bank (2000a), p. 126.

${ }^{2}$ See BMZ (2001a), p. 35, 36.

${ }^{3}$ See DfID (2000f), p. i, which cites the UNDP (1995) figure that $70 \%$ of the poor are female.

${ }^{4}$ See DfID (2000d), p. 3.

${ }^{5}$ The support for gender equality is sometimes countered by the right of respect for a people's culture, which would prohibit the intervention of donor nations on this matter. This argument has been clearly rebutted by DfID (2000d), p. 8: "Donor countries which support women's equality have sometimes been accused of seeking to impose their own values on others. While respect for people's culture is a right, so too is respect for the human rights of women. Both are recognized in the Universal Declaration of Human Rights. Women have been oppressed and treated unequally in all cultures, and in all cultures this is an abuse of human rights."

${ }^{6}$ See BMZ (2001a), p. 34. Since it remains unclear to what extend the $40 \%$ are due to the paid labor women undertook in industrialized countries, the ratio on paid labor might well be lower in developing countries. Yet the problem of circumstances preventing women from accessing work either totally or to adequate conditions remains.

${ }^{7}$ See Sida (2000b).

${ }^{8}$ See BMZ (2001a), p. 34.
} 
equality does not necessarily depend on the economic development of a country ${ }^{1}$, there has been extensive thought about the measures needed to increase gender equality. To achieve progress on the demands for greater gender equity requires participation of women in political and economic decisionmaking ${ }^{2}$, as well as legal rights reforms, access to public and private services and educational work ${ }^{3}$.

Women are poorly represented in the political life in many countries, which explains the widespread neglect of women's priorities in laws and regulation. ${ }^{4}$ This is attributed to the fact that "(norms) for gender roles and rights form part of the moral order of a community and permeate other institutions, including those of the state" and training for underprivileged women for leadership roles on the communal level and the advancements of women's organizations and their linkage are proposed. ${ }^{6}$ This is also conducive to pressure for necessary changes in laws and regulations, especially in terms of marriage rights and inheritance laws, the bias of which strongly effects the role of women within the society ${ }^{7}$. The inheritance laws form a special case of overall economic laws, that in some countries do not grant any economic rights to women who are under the guardianship of their husbands, while in others land rights, property rights or the right to freely choose employment are severely limited. This propels dependency situations and inhibits change of the situation of the women. Therefore, the legal system should incorporate gender equality and gender related rights as part of human rights. ${ }^{8}$ While the equality in front of the law is a necessary condition for equal opportunities, impediments in the access to these rights or to the services granted by them can limit the positive impact of legal reforms.

Poor women are highly dependent on basic services in terms of transport, energy, water, secure shelter and sanitation, which heavily impact their ability to fulfill their social tasks and their economic aspirations, yet are difficult to obtain because the combination of low availability to the poor and discrimination against women. Therefore, reform of public services and administrations towards a focus on the needs of poor women is demanded in the new strategies?

Beyond the provision of material services the need to provide education to women is stressed because the returns to female education are assessed to be

\footnotetext{
${ }^{1}$ In DfID (2000), p. 3. it is pointed out that those occurrences where the Gender-related Development Index is higher than the Human Development Index, depicting gender equality (or even inverse gender inequality, which shall not be of concern here) occurs in developing as well as developed countries.

${ }^{2}$ See Sida (2000b).

${ }^{3}$ See World Bank, p. 121.

${ }^{4}$ See DfID (2000d), p. 8.

${ }^{5}$ See World Bank (2000a), p. 118.

${ }^{6}$ See BMZ (2001a), p. 35.

${ }^{7}$ See World Bank (2000a), p. 118.

${ }^{8}$ This area for political dialogue is emphasized in BMZ (2001a), p. 34.

${ }^{9}$ See DfID (2000d), p. 8 and 13.
} 
especially high for the women, their children and the society. ${ }^{1}$ This is claimed on the basis that farm outputs and overall economic performance tend to increase, the nutritional and educational attainments for their children tend to rise and the number of children and thus the population growth tends to fall with improved female education ${ }^{2}$. Girls' education is assessed to lead to higher productivity. It is also a means of strengthening their ability for later participation in decisionmaking by increasing the women's self-confidence and their ability to communicate and analyze material, not least due to fostering the ability to comprehend and compose written and numeric material. To give the pupils a positive role model and to provide education in a way that is inclusive of girls, women teachers have an important role and domestic employment and training policies should reflect this.

A special concern permeating the needs on legal, administrative and educational reforms is the concern about all forms of violence against women. The measures to prevent violence against women are not explicitly stated because of the variety of influences on these crimes, yet the need to progress in terms of increased security for women is clearly pronounced in the new strategies ${ }^{3}$.

This discussion of potential areas where reforms towards gender equity could be undertaken focusses strongly on areas of public policy, such as women's political representation, issues concerning the legal and administrative environment and public service provision, because these can be influenced comparatively easily by governmental policy. Yet gender inequalities, similar to other forms of discrimination, reach beyond the public sector and are deeply rooted in the attitudes and perceptions of people, which are hard to change and beyond the direct control of the government. These have to be tackled because inequalities will not be removed solely by changing the framework of public action, not the least because the views held in society also influence the administration. Therefore, educational campaigns and the activities of women's associations for changing broad based social opinions need to be strengthened in order to achieve lasting changes towards greater gender equality ${ }^{4}$.

Developmental strategies try to achieve a lasting impact by integrating a focus on the impact on gender equity in every project (gender mainstreaming). This is accompanied by special projects focussing directly on gender questions.

\footnotetext{
${ }^{1}$ See World Bank (2000a), p. $118-120$.

${ }^{2}$ See World Bank (2000a), p. $118-120$.

${ }^{3}$ See e.g. BMZ (2001a), p. 35 on "efforts (...) to fight trade of women, forced and child prostitution" (translation by the author) and DfID (2000d), p. 7 "The most shocking manifestation of women's inequality is violence."

${ }^{4}$ The difficulties and the long time frame that will be required to achieve full gender equality becomes evident when looking at the performance in many developing countries, where gender equality has only been reached by very few nations - mainly the Scandinavian despite a comparatively long history of the women's rights movement.
} 
These efforts are supposed to be supplemented by increasing genderdifferentiated data collection and dissemination ${ }^{1}$.

To end this overview on approaches aiming at greater gender equality, a point only mentioned in the British strategy concerning the influence of the women themselves is worth to be mentioned: "An underlying guiding principle in addressing attitudes and social values is the importance of moving forward at a pace, and in a direction, which women themselves support."2

\subsection{Participation}

The discussion on human rights already pointed at the fact that influence of the people on the decisions that effect their lives is of great importance in achieving progress on the full adoption of these rights. The new strategies rely heavily on the concept of participation ${ }^{3}$, which broadly represents the ability of people - in this case, especially the poor people - to influence the political and administrative decisions affecting their life. Participation is proposed not only to achieve progress on human rights, but also on a variety of other goals such as efficient public service delivery, effective public investment corresponding to the needs of the poor and a greater focus of national policy on the interests and concerns of that part of the population living in destitute. The reasoning relies on the implicit assumption that the poor people know what services they want and need and what framework best contributes to their needs. ${ }^{4}$ By enabling them to express and enforce their interests, the circumstances, in which they live and

\footnotetext{
${ }^{1}$ For gender mainstreaming, see BMZ (2001a), p. 35 and for gender mainstreaming and data issues DfID (2000d), p. 17 and $24-27$.

${ }^{2}$ See DfID (2000d), p. 8.

${ }^{3}$ Participation is a pillar for developmental progress in all strategies; see e.g. BMZ (2001a), p. 35, 36, DfID (2000f), p. ii, Sida (1996), p. 33, 34 and World Bank (2000a), p. 88 - 90 and 99. The BMZ has made this issue to its priority in its participatory concept BMZ (1999).

${ }^{4}$ This is a necessary assumption for participation to be a viable means for the efficient reduction of poverty. That the poor possess this knowledge about the means most effective for their advance is not explicitly stated in most strategies. Phrases like "Also poor women and men are actors (in the development process). They are not the problem, but part of the solution." (BMZ (2001a), p. 5 - translated by the author) hint in this direction, yet do not clearly attribute the formulation of the solution to the abilities of the poor. Yet without this notion, the concept of participation becomes useless. If the poor people would not know what contributes to the fulfillment of their needs, their input in the decision-making process would not yield important improvements over the status quo where other people take the decisions. The mere statement of their problems - which they are attributed to know - does not reward the title 'participation'. On what level the poor can formulate the solutions self-responsible without government help is under debate. The World Bank expresses the concern that for over-communal projects the local government needs to integrate the opinions of various communities, which might have too narrow a view to determine the overall value of the project. This does not challenge the general validity of the assumption that the poor know what is good for them, but searches for means to aggregate their perceptions. Still it is surprising - and undermining the value of participation - that the World Bank regards economic analysis as more valuable in setting priorities, and where this becomes difficult participation is regarded as particularly helpful. See World Bank, p. 90, 91.
} 
pursue their livelihoods, will change in their favor. To give the poor people a voice and to make public official's policies dependent on that voice - by measures that increase the downward accountability to the poor through decision-making processes that are closer to those affected and that guarantee their involvement - will guide public officials to take better, more pro-poor decisions. ${ }^{1}$

A concrete definition of participation is hard to find throughout the analyzed texts, since most strategies rely on a vague terminology such as "engaging poor communities and poor people" , which is then used to present broad virtuous of this concept in various fields. One definition can be found in the strategy papers of DfID in the context of human rights:

"Participation: enabling people to claim their human rights through the promotion of the rights of all citizens to participation in, and access to information relating to, the decision-making processes which affect their lives."

This definition hints at the important point that participation is a right for everybody, needs to be accompanied by the provision of appropriate information and provides a way of demanding ("claiming"). Yet the definition has the disadvantage to define the phrase participation by using this phrase in the definition. A proposal for a broad definition of participation incorporating the benefits of the prior shall be attempted here:

Participation is a personal right to exercise knowledgeable influence on all decisions taken by third parties according to the impact of this decision on the person's life relative to the life of others.

Under this definition participation can be claimed as a right, yet that the amount of influence of each person decreases as the impact of a decision on this person's life decreases relative to the impact on the lives of others. This includes the notion that decisions that can be taken at the local level should be guided by the local people's preferences, decisions taken in regard to a certain group such as the poor people should be guided by their preference (and if the decisions can be taken on an individual level, should be guided by the preferences by the individual poor person), but even decisions of national scope require the consideration of the individual interests according to the effect imposed on them. The term 'knowledgeable' refers to the fact that to make participation feasible, information has to be provided to those that have a right to participate in order to make them aware about their possibility of taking influence and to

\footnotetext{
${ }^{1}$ See DfID (2000e), p. 15 for an expansion of this thought towards public service delivery.

${ }^{2}$ See World Bank (2000a), p. 88. The question that remains in this notion is to what extend and in what ways the communities and the people should be engaged.

${ }^{3}$ See DfID (2000f), p. ii. (Accentuations as in the original text.)
} 
provide the background to exert one's influence on a competent and informed basis ${ }^{1}$.

This definition, based on the understanding on the way participation is used in the strategic documents, is still broad based and leaves open many questions about how to make participation operational on various levels. This is for due to the scope in which participation is perceived as useful. Participatory concepts influencing central government and local authorities are desired ${ }^{2}$; yet require quite different methods on the two levels ${ }^{3}$. It can already be noted here that methods for increasing participation on local decisions rather than on national strategies have received the foremost attention within the strategies.

Despite these operational uncertainties, the concept of greater participation is regarded to strongly benefit the pursuit of poverty reduction and human rights realization. The World Bank attributes three objectives to be achieved via participation ${ }^{4}$ : The reflection of preferences and values of communities in choices and interventions, the improvement of implementation, transparency and accountability through community and participant monitoring, and the provision of greater influence of the people on their lives. Measures to achieve participation and the benefits associated with it rest strongly on actions towards good governance in terms of decentralization - in order to take decisions closer to the affected people giving them the chance to influence the decisions on the local level - in terms of greater accountability of public service provision and public administration to local constituents and in terms of increasing the transparency of the decision-making process to the local population. Because of the importance of governmental and public actions on a framework responsive and favorable to the aspirations of the poor, which is summarized in the term "good governance" and which includes diverse measures for fostering an environment conducive to participation of the poor, these shall be discussed in greater detail in the subsequent chapter 5 .

\footnotetext{
${ }^{1}$ In BMZ (1999), p. 7, information and communication are seen as key measures in all types of participation and constitute by themselves the lowest from of participatory involvement. This is reflected for example in the attempts to support free media and the training of journalists towards the end of political participation of the population. See BMZ (2001a), p. 37.

${ }^{2}$ See World Bank (2000a), p. 99.

${ }^{3}$ While for participation in decisions effecting the local community decentralization is the main thought which is broadly reflected in the strategies, the aggregation of voices of the poor to receive impact in national decisions is much less conceptualized and investigated. Yet the extensive problems of ensuring that the voices at the bottom are reflected in the demands at the top justify a deeper concern for this question.

${ }^{4}$ For reference on these objectives and on measures to achieve them in the special contexts of education, infrastructure and forest management, see World Bank (2000a), p. 88-93.

${ }^{5}$ Good governance in general and accountability, decentralization and transparency in special are discussed in depth in the following chapters with the same headings.
} 
To enable the voices of the poor to be heard is not only dependant on public action favorable to greater participation of the poor, but also by initiatives of the poor themselves to take advantage and claim the provision of greater participation in the decision-making process by organizing themselves. Campaigns for social mobilization, which aim at increasing the ability of the poor for self-organization and raising their ability for political dialogue, are directed towards this end. ${ }^{1}$ To strengthen the ability of the poor to become active, self-help projects are regarded as conducive to foster the self-confidence of the poor. Civil society organizations as advocates for the interests of the poor are needed on the national and international level and, especially important, networking and the linkage among the poor are necessary.

This networking is analyzed in detail in the WDR 2000/2001 ${ }^{2}$ along three dimensions. Bonding social capital is characterized by strong links between family members or close friends, which are prevalent in many developing countries and form the basis not only for greater security and economic benefit, but can also provide confidence for the group to speak up.

Bridging social capital, describing weak ties between members of the same social and economic status, becomes an important aspect in order to link poor people among each other and to expend their influence by fostering poor peoples associations. By encouraging these internal connections, the poor increase their voice through bundling of their interests resulting in higher overall impact on the decision making process ${ }^{3}$.

Besides domestic ties and bonds within the same background, linkages between the poor and people in positions of influence become important, the socalled linking social capital. Next to increasing economic opportunities ${ }^{4}$ this provides informal means for making the voices of the poor heard and transferred into action. The state can foster the development of linkages by taking an active role in shaping the context in which people can organize themselves. It can even move into the expansion of linkage social capital by putting up special programs to build up trust between government workers and poor people. ${ }^{5}$

\footnotetext{
${ }^{1}$ For this and the following point see BMZ (2001a), p. 36, 37.

${ }^{2}$ For this discussion see World Bank (2000a), p. $128-131$. The strongly economical analysis prevalent in most of the World Bank work is here transferred to a more political viewpoint that is only a secondary factor in the World Bank analysis.

${ }^{3}$ This neglects the fact that the poor are not a homogeneous group but consist of people with different occupations, problems and attitudes. They might not respond to one united organization that cannot support the potentially divergent interests. Especially the interests of urban and rural poor are potentially highly divergent.

This problem does not imply that linking poor people is not beneficial; rather a system of participation has to accept a wider variety of problems that need to be tackled and potentially a greater number of organizations that reflect the interests of the poor.

${ }^{4}$ These are incurred by linking poor people to influential personnel in banks or agricultural extension offices thus permitting their access to important inputs into their economic activities. See World Bank (2000a), p. 128.

${ }^{5}$ See World Bank, p. 130.
} 
To increase participation by linking poor and influential people, the state should also encourage non-government organizations (NGOs), which are considered as especially helpful as intermediaries in this process - on the economic as well as on the political side. They can help to link poor people to banking institutions by providing intermediary micro-credit services and to public officials and staff at national institutions by providing feedback between these and the grassroots organizations to which NGOs generally have close contacts. ${ }^{1}$ The civil society not only fosters linkage effects, it can also create pressure and carry forward the demands of the poor with greater vigor by making critical ground level information on human rights violations or discriminatory practices widely available and gathering support for corrective action. The influence of an active civil society also provides control over the actions of governmental bodies and helps to spread information to the poor people. Their linkage up to the international level even allows them to represent the interests of the poor in international forums, even though this potential is not yet fully used. ${ }^{2}$

This analysis on NGOs already points at the fact that the poor cannot in all cases handle the representation of their interests on their own. This has several reasons. It is sometimes difficult to identify the poor. Even if this is possible, it is often difficult to ensure their participation because they tend to have little time, insufficient information and lacking access to outside sources for consultation $^{3}$. Also decisions on regional, national or international scope are potentially beyond the reach where individual participation is feasible. Therefore poor communities or civil society organizations are often considered as proxies for the participation of poor individuals and are the targets for participatory attempts. ${ }^{4}$

Which leaves the question to what extend these reflect the interests of the poor - or are counterproductively dominated by the non-poor. Even if communities are poor they tend to have some non-poor members who are prone to have a greater say in the community's decisions due to their higher resources. And even among the poor there are varying degrees of poverty, with the poorest possibly being those least able to take a role in the participatory process and to make their interests heard since they tend to be the least active, the elderly and

\footnotetext{
${ }^{1}$ See World Bank p. 110, 111, 129, 130.

${ }^{2}$ In DfID (2000d), p. 7 it is argued that the international civil society has until recently been unfocused on work to promote economic, social and cultural rights of poor people with some exceptions, thus leaving room for improvement. The analysis also provides a broader overview about the benefits of civil society activities.

${ }^{3}$ See World Bank (2000a), p. 110.

${ }^{4}$ The notion that NGO's and civil society organizations are important actors in the expression of poor people's voice receives attention in DfID (2000e), p. 15 and Sida (2000d). Phrases like "Participation of the poor population and the civil society (are) an important precondition (for the provision of basic social services)" (BMZ (2001a), p. 24 - translated by the author) do not distinguish any more between the participation of civil society organizations and the poor themselves.
} 
the disabled. How the poor and among these the poorest should be detected in poor communities and how they should be integrated into the decision making process is left largely open in the discussion, but needs to be operationalized to enable real pro-poor policies.

Regarding civil society organizations, it is unclear to what extend they actually reflect the interest of the poor and not other priorities in their own regard. The connection that civil society organizations effectively and accurately channel the interests of the poor into the decision-making process ${ }^{1}$ needs to be firmly established before the link from participation of NGOs in the decisionmaking process to pro-poor policies can be drawn. It is acknowledged that "(some) lobbying groups and civil society organizations promote division, represent the interest of elites or misrepresent the interests of the poor."2 Yet, this point is either not regarded at all $^{3}$, not further investigated ${ }^{4}$ or taken up by assessing single-sentence that accountability of civil society organizations' actions especially to the poor people whom they represent, is important ${ }^{5}$.

The rather unreflected believe in the abilities and interests of civil society organizations to correctly reflect their constituents interests is astounding in light of the skepticism that is expressed about exactly this ability in the public and political sector. Since participation is heavily relied on within the new strategies - especially to correct the unresponsiveness of the public sector to the needs of the poor - further investigation should be undertaken to ensure that civil society organizations can live up to this challenge and to analyze which measures are most conducive to prevent the dilution of interests as the scope of the activities of these organizations expands ${ }^{6}$.

\footnotetext{
${ }^{1}$ This seems reasonable for some NGOs, but has to be questioned for their entirety, thus necessitating deeper analysis. This topic is covered in more detail in the chapter 'Differing Accentuations', 'Sweden'.

${ }^{2}$ DfID (2000d), p. 7.

${ }^{3}$ Strategies of Sida and BMZ.

${ }^{4}$ In DfID (2000d), p. 17, it is assessed that civil society organizations "require (...) independently verified signs of the networking improving the lives of poor people". Yet this is not proposed as a measure to avoid the capture of interests other than those of the poor, but as a means to improve their position in international negotiations. A second requirement of "real links back to the grass roots" hints at the problem and at the need to make sure that the poor people are correctly represented, but does not propose any measures.

${ }^{5}$ See World Bank (2000a), p. 111.

${ }^{6}$ It can be assumed that as long as these organizations operate locally and are represented by local poor people, the control of their actions is provided for because their constituents can observe their actions, and misunderstandings are unlikely due to short communication ways. Yet with the linkage of civil society organizations to broader, nationwide networks (see BMZ (2001a), p. 36) the ability of control for the constituents decreases and the communication links increase, thus increasing the room for capture of the orientation of the organization by special interests.
} 


\subsection{Democratization}

In the pursuit of empowerment for the poor people in developing countries democratization and participation are both demanded. While sometimes democracy and participation are mentioned jointly to reflect the same issue ${ }^{1}$, in many cases they present distinctly different concepts ${ }^{2}$. This ambiguity results from the fact that democracy can be both participatory and representative ${ }^{3}$.

In a broad definition democratic development can mean the "broad popular participation in the development process at all levels (... without) prescription of formal multiparty democracy"4. In this perception the concepts of participation and democracy are united into a single objective, which makes obsolete any further substantiation over the preceding paragraph. Yet in the general perception the notion has evolved to link the definition of democracy with the narrower focus on formal multiparty democracy ${ }^{5}$. The formal structures of this narrower view comprise political parties, elections, and parliaments ${ }^{6}$.

Since democratic multiparty systems require even in their representative form a minimum degree of participation, i.e. the participation in the electoral process, this system can be seen as a special case of a participatory process even though participation in the analyzed strategies is attributed generally with a higher intensity of personal involvement and influence than is provided by the electoral process only.

Yet participation can occur without a multiparty political regime (e.g. as participation on local levels while the national government remains totalitarian) or formal multiparty regimes can occur with only a minimum of participation and involvement of the constituents (e.g. only the punctual participatory involvement on election days or only on local issues), which points at democratization and participation as being two distinct concepts. This necessitates a closer look on democratic regimes even though the concept of participation has been already discussed. The unequivocal support for democracy in the bilateral strategies ${ }^{7}$ and the pronouncement of special requirements to make a formal democracy generally effective and inclusive for

${ }^{1}$ See e.g. World Bank (2000a), p. 112.

${ }^{2}$ See e.g. DfID (2000), p. 19, 20 or view in World Bank (2000a) the general distinction of presentation of participation (mainly p. $88-96$ ) and of democracy (only p. 112-115).

${ }^{3}$ See World Bank (2000a), p. 113.

${ }^{4}$ Sida (1996), p. 5.

${ }^{5}$ See also Sida (1996), p. 5. This view is also reflected in World Bank (2000a), p. 113.

${ }^{6}$ See DfID (2000e), p. 4.

${ }^{7}$ See UK government (1997), p. 30, BMZ (2001a), p. 37 and Sida (1996), p. 22. The World Development Report (World Bank (2000a), p. 112 - 115) also lends support to democratic regimes, yet reflects this notion only briefly in comparison to the overall analysis. Yet the WDR $2000 / 1$ is the only document that critically reflects the role of democracy. It emphasizes that despite the spectacular progress in some non-democratic countries on poverty reduction, the abuse of power even in poverty reducing settings and the potential for rapid policy reversal can make the development gains fragile. In this the World Bank follows a tradition of emphasizing not the ability of democratic societies to choose the best leader, but to protect itself from the worst leaders (See e.g. Popper, K. (1945)). 
poor people lend further support to the value of discussing democratic systems in detail.

Multiparty democratic systems are strongly favored in most strategies because of their conflict resolution potential and their positive consequences for poor people with respect to their experience of freedom, security and well-being. ${ }^{1}$ The conflict resolution characteristic is based on the viewpoint that democratic societies provide peaceful methods for coming to a solution or compromise between different interests, without suppressing divergent points of view entirely. Democratic systems are assumed to provide positive consequences for the poor on the basis that their views tend to be better represented and that they are presented with a formal method to hold their government accountable. This in turn is regarded to lead to better quality services for them and a concern for generally pro-poor government initiatives.

These benefits can be realized because democracy can increase the poor people's confidence and opportunities to use social organizations for social action $^{2}$. Powerful and broadly supported social organizations also raise the general ability for participation outside the formal democratic system by lobbying and campaigning for the interests of the poor ${ }^{3}$. Greater participation in turn is generally beneficial to democratic development by bringing into discussion the various views latent within a society and by engaging the people in knowledgeable political interaction. This points at the potential for mutually reinforcing effects between democracy and participation.

Mutually reinforcing effects also accrue in the simultaneous adoption of democracy and liberal economic policies, providing benefits in terms of political inclusion and social well-being. Liberal economic policies encourage power centers outside politics in the private sector, which can influence government policies and add to political pluralism benefiting democratic developments. In turn democratic developments provides the ground for the individual freedom necessary for the development of liberal economies. ${ }^{4}$ These mutually reinforcing effects hint at the potentially increasing returns from fostering democracy, participation and liberal economic policies jointly.

While taking closer looks at the interactions of these three variables, a positive effect of prosperity on democracy as hypothesized by Lipset ${ }^{5}$ does not figure prominently in the analysis in the strategic documents. The ability to build functioning democracies is not seen as dependent on the wealth of a nation.

\footnotetext{
${ }^{1}$ See Sida (1996), p. 22.

${ }^{2}$ See DfID (2000e), p. 4.

${ }^{3}$ See World Bank (2000a), p. 114.

${ }^{4}$ See DfID (2000e), p. 7.

${ }^{5}$ This hypothesis is expanded upon in Lipset (1959).
} 
Formal democratic institutions in a country are encouraged in the strategies, but are no panacea. Under their prevalence the mentioned effects and the general benefits from poor people's inclusion do not necessarily occur. Rather many poor experience powerlessness despite formal democratic institutions ${ }^{1}$. This is mainly viewed as an outcome of the influence in and capture of the political process by the better connected and educated - sometimes referred to as the elites. ${ }^{2}$ Since "democratic political processes alone are not enough" ${ }^{3}$ to ensure the inclusion of the views of the poor, certain additional preconditions have to be in place. These comprise measures generally necessary for the functioning of democracies as well as specific measures aimed at the poor.

General measures univocally include the provision of adequate information fostered by independent and effective media, inclusive and fair electoral processes administered and supported by a loyal but autonomous civil service, open and issue based political parties strong enough to monitor the executive in the parliamentary process, and an independent judiciary able to uphold the constitution and the rule of law. ${ }^{4}$ Supportive measures in this regard include actions like campaigns for broad political education, training of journalists, support for free media and for civil society organizations and transparent public budgeting policies. ${ }^{5}$ The regulatory framework should be shaped in a way to promote freedom of information provision regarding the decisions and actions of the government. New information technology should be employed to enable the vaster spread of information, accompanied by fostering proven technology and local-level information proliferation. ${ }^{6}$

These general actions to foster the functioning of the democratic system should be supplemented by special actions to include the poor. A genuine will of the government to improve the possibilities of the poor people to participate in the electoral process is demanded, accompanied by training on election procedures conducted by organizations receiving broad popular confidence. ${ }^{?}$ Furthermore, the new strategies emphasize that democratic decisions should permeate all major levels of decision-making, since not just central government decisions, but also the lower level decisions affect the circumstances of life especially of poor people. ${ }^{8}$ This links back to the demand for participation, which is entailed in these demands.

Overall, democracy is seen as the form of government most conducive to development - if the right preconditions are in place.

\footnotetext{
${ }^{1}$ See DfID (2000e), p. 4.

${ }^{2}$ See also DfID (2000e), p. 4. Here "elites" is used rather than the better educated and connected.

${ }^{3}$ See World Bank (2000a), p. 113.

${ }^{4}$ See DfID (2000) p. 6 and World Bank (2000a), p. 113.

${ }^{5}$ See BMZ (2001a), p. 37, 38.

${ }^{6}$ See DfID (2000d), p. 21.

${ }^{7}$ See Sida, p. 22.

${ }^{8}$ This is next to vibrant civil society organizations and information provision the main point the World Bank presents on this issue. See World Bank (2000a), p. 114.
} 
After having reviewed the benefits of democracy for the empowerment of the poor, the conditions necessary to realize the benefits and its interaction with economic necessities, in this last paragraph the discussion of the connection of participation and democracy shall be taken up from a more critical viewpoint. It has already been emphasized that participation and democracy are usually mutually reinforcing, as broad participation enables the inclusion of people in the overall democratic process while democratic processes foster the openness of the overall political situation to participatory involvement.

But is it also possible that participation and democratic systems do not reinforce each other? That participation actually puts strains on the democratic system? For this discussion a closer look at the statements of DfID yields some insights. In one of its consultation documents it is phrased: "A second concern on the effectiveness of newer democracies is that communications, between those in power and those representing the interests of the population, are often inadequate." This calls into question the general principle of democracy, which assumes that those elected into power represent the interests of the population; otherwise a representative democracy would not deserve its name. This shows, as pointed out prior, the general disbelieve in the donor community that formal democratic institutions alone ensure the correct functioning of the democratic mechanism. ${ }^{2}$

In an extension of this thought stronger participation in the decisionmaking processes than is currently implemented in the democratic systems of many developing nations are demanded. This shall ensure that the voice of the population is heard in the general policy formulation ${ }^{3}$. As has been argued in the preceding section, the entire population is difficult to involve in the decisionmaking process, thus reliance is put on the participation of civil society organizations. While their influence in the democratic systems of industrialized countries is limited to indirect lobbying and media campaigns, they are in the participatory process proposed for developing countries directly involved in the decision-making.

As long as participation is part of the democratic process, respecting the freedom of choice of the elected representatives by feeding the insights from participation into the debates of the parliament, this process does not imposes any problems. Yet if the influence of participation bypasses the democratically elected representatives or reduces their power to make the final decisions, the question becomes important who really reflects the interests of the population. If civil society does this better than the elected parliaments, such a bypassing move

\footnotetext{
${ }^{1}$ DfID (2000e), p. 4.

${ }^{2}$ The reason for the disbelieve in the general validity of adequate representation of people's interests in the actions of their democratically elected representatives in developing countries is based on the view that the necessary preconditions discussed in the preceding subsection are not sufficiently implemented.

${ }^{3}$ As will be shown in the last subchapter on 'Initiated Reforms', this is an aim of the process that generates the Poverty Reduction Strategies that are required by World Bank and IMF from countries applying for debt relieve under the extended HIPC-Initiative.
} 
is not totally refutable, yet it will be more valuable for the stability of the country and for its internal democratization to pursue the integration of participatory movements into its democratic structures. Bypassing the national democratic institutions is generally not favored despite a concern about their representativeness. Therefore, DfID demands in a different text than that quoted prior that "reform programs led by the Bretton Woods institutions respect national democratic institutions and are evolved and debated through existing formal and informal methods of participation"1. DfID as the only organization hints at potential problems of participation and democracy, yet leaves solutions open as to how participation could be structured and how it is to be integrated if formal and informal methods do not currently exist. The absence of formal and informal methods is precisely the reason why participation receives such a strong focus in the contemporary strategies.

This discussion points at the need to pay closer attention to and conduct research on the connection of participation and democracy, in order to use the mutually reinforcing effects and prevent counterproductive interference of both.

Summarizing, in the new strategies the need to empower the poor is emphasized. The goal is to provide them with a voice within their society. This is regarded as important to ensure their human rights and is fostered by participatory movements and democratic processes. Empowerment is linked back to the economic performance of the poor by affecting the focus of services and expenditures of the state. The need for empowerment is unambiguously stressed, yet not all measures to foster it are fully developed. There also remains scope for conflict between participatory attempts and democratic structures that deserve consideration when designing programs to foster empowerment.

\subsubsection{Good Governance}

\subsection{The Concept}

For the poor, the realization of empowerment, the ability to influence the decisions that affect their lives and the attainment of their human rights depends on more than the establishment of laws granting participation and social, economic and political entitlements. It is also crucial that institutions and administrative bodies respect, enforce and implement these laws. The realization that legislation is not sufficient ${ }^{2}$ has led to a strong focus on good governance in terms of more efficient and responsive administrations, access to the legal system and absence of corruption in all analyzed strategies ${ }^{3}$.

\footnotetext{
${ }^{1}$ DfID (2000d), p. 20.

${ }^{2}$ See DfID (2000d), p. 8.

${ }^{3}$ See e.g. UK government (1997), p. 30; BMZ (2001a), p. 36 - 38; Sida (2000e) and World Bank (2000a), p. 99 to p. 112.
} 
Responsible governance of a country results in increased empowerment of the poor and leads to direct improvements in their lives ${ }^{1}$ by providing a framework conducive to the expansion of the personal capabilities of the poor, by allocating resources to poor and deprived persons, and by providing these resources efficiently and responsive to the poor people's needs. It also leads to indirect improvements of their situation by providing an environment conducive to overall economic growth through improvement of administrative efficiency, enforcement of the rule of law and reductions of regulatory burdens, corruption and graft. The value of good governance for developing and transition economies has been conclusively shown in newer studies by illustrating its strong impact on per capita income, infant mortality and adult literacy ${ }^{2}$ and on growth in investment and security of property rights ${ }^{3}$.

The exact definition of good governance is not unambiguous, ranging from the efficient use of resources for the poor ${ }^{4}$ to spanning a concern for human rights, democratic principles and political participation by civil society ${ }^{5}$. While in some strategies democracy, rule of law and good governance form separate concerns ${ }^{6}$, in others the former two are integrated in the latter ${ }^{7}$. In their research on measurement of governance Kaufmann, Kraay and Zoido-Lobatón provide a very broad-based definition of governance:

"We define governance as the traditions and institutions that determine how authority is exercised in a particular country. This includes (1) the process by which governments are selected, held accountable, monitored, and replaced; (2) the capacity of governments to manage resources efficiently and formulate, implement, and enforce sound policies and regulations; and (3) the respect of citizens and the state for the institutions that govern economic and social interactions." 8

This definition takes into account a broad spectrum of concerns, including government control, efficiency of policy enforcement and the grounding of the institutions within the society. Yet it neglects a focus on the poor people within a society, which is attached to concepts of good governance within most strategic documents. Since in this analysis human rights, participation and democracy have already been discussed in concern with poor people's empowerment, this approach to good governance will be restrained to measures

\footnotetext{
${ }^{1}$ See UK government (1997), p. 30.

${ }^{2}$ See Kaufmann, D. / Kraay, A. / Zoido-Lobatón, P. (1999). For the impact on growth see also Barro, R. (1999).

${ }^{3}$ See Hellman, J. / Geraint, J. / Kaufmann, D. (2000).

${ }^{4}$ See DfID (2000d), p. 8.

${ }^{5}$ See BMZ (2001a), p. 36.

${ }^{6}$ See DfID (2000e), p. 2.

${ }^{7}$ See World Bank (2000a), p. 99.

${ }^{8}$ See Kaufmann, D. / Kraay, A. / Zoido-Lobatón, P. (2000), p. 10.

${ }^{9}$ See e.g. BMZ (2001a), p. 36.
} 
of governance that allow empowerment to take hold ${ }^{1}$. Thus, while empowerment has been discussed regarding necessary rights (legislative sphere), encouragement of participation by linking people (social sphere), and the legitimization of government (questions concerning the sovereign), the concept of good governance presented here is concerned with practical aspects of the executive and judicative powers ${ }^{2}$. Inefficient administrations, inaccessible legal systems and corrupt government agents prevent the proceeds from empowerment to materialize. They curb the ability of poor people to access necessary services, claim their rights and receive the resources intended for them. They also hamper the economic system by diversion and squander of resources, by corruption and inefficiency and by lack of rule of law and the associated insecurity for economic transactions. Because of their importance for the realization of empowerment and for overall economic progress, deficits and improvement possibilities in the executive and legal system shall be of concern in the next sections.

\subsection{Accountability, Decentralization and Transparency}

Inefficiency and ineffectiveness within the governmental and administrative bodies can have many reasons. These may include lack of clear priorities and uncertainty about the tasks to perform, lack of legislative oversight or excessive political pressure on the local administrative bodies, recruitment and promotion based on personal connections or side-payments, discriminatory practices, corruption and unresponsiveness to the people they serve. ${ }^{3}$

The main determinant that underlies all these causes is viewed as the lack of accountability of the public institutions towards their constituents ${ }^{4}$. Effective monitoring and evaluation methods by the population, on local and national levels, reduce the ability of public servants to divert resources or to be unresponsive to their clients needs. Monitoring and evaluation create performance incentives for public servants for responsible and efficient use of the available resources in terms of administrative capacity and monetary budgets. They should be supplemented by government action to foster supportive behavior in terms of merit-based recruitment and rewards for good performance to motive public servants. ${ }^{5}$ Accountability to the constituency resolves the question of priorities to be set and tasks to perform, since it is the clients' views that determine the actions. Ambiguity about what the clients want

\footnotetext{
${ }^{1}$ Since empowerment is closely linked to the benefits for poor people, a focus for their problems is indirectly retained in this approach.

2 Some strategies, like the WDR 2000/1, do not draw a clear distinction between empowerment and good governance. Here is attempted to clarify this distinction by separating legislative, social and sovereignty issues from executive and judicial concerns. Yet the concepts are strongly interrelated and therefore cannot be fully separated.

${ }^{3}$ See e.g. World Bank (2000a), p. 100, 101.

${ }^{4}$ See e.g. DfID (2000d), p. 11, Sida (1996), p. 21, World Bank (2000a), p. $100-102$ and BMZ (2001a), p. 36, 37.

${ }^{5}$ See World Bank (2000a), p. 100.
} 
can be eliminated by increased public participation in the decision-making and implementation process ${ }^{1}$.

Accountability is closely linked to the concept of participation ${ }^{2}$, since the ex post accountability of administrative bodies increases their incentives to engage the population ex ante in the formulation of policies and the setting of priorities. A well-build system of accountability limits the ability of public officials to determine policies on their own terms, out of their rational expectation that the evaluation such policies by the population will tend to be substantially lower than for participatory policies that include the will of the constituents from the start. Since the incentives of accountability might not in all cases outweigh the personal benefits in terms of bribes in the decision-making process or personal desire for power, the establishment of participatory processes should be implemented by the national government on a formal, enforceable basis.

In the establishment of accountable administrative systems, one of the major preconditions is a sufficient information base on which to judge the performance of public officials. To foster this, the policy-making process has to be transparent and the budgeting process and expenditures of the administrative bodies have to open for inspection by the general population ${ }^{3}$.

Measures to increase the transparency of government agencies and administrative bodies comprise the simplification and the clear declaration of the procedures that lead to decisions. Disclosure of the resources used and progress achieved in the implementations of projects is another contributor.

The information made available by the public agencies has to be conveyed to the public. This is most effectively done via independent media ${ }^{4}$ or civil society organizations $s^{5}$. These can also investigate beyond the transparency offered by public administrations to discover undisclosed activities. Sen has shown the immense role of the media in influencing public service provision in his studies on famine prevention. He shows that free media are one of the most important sources to spur preventive government action. ${ }^{6}$ This impact of the

${ }^{1}$ On the connection of participation, accountability and public service provision see the subchapter on 'Poor Peoples Assets'.

${ }^{2}$ These two notions are strongly linked. See e.g. World Bank (2000a), p. 88, 89.

${ }^{3}$ See DfID, (2000d), p. 11.

${ }^{4}$ See World Bank (2000a), p. 101.

${ }^{5}$ See BMZ (2001a), p. 37, 38.

${ }^{6}$ For a short analysis of the Indian and Chinese policies on nutrition and famines see Sen (1983), p. 757 - 760. Here he also notes limitations to the influence of the media. If deprivations are not newsworthy, such as in cases of endemic malnutrition in contrast to famines, the existence of free media does not yield any changes in policy. Yet this argument is based on the Indian system, which is not considered strongly accountable at the local level, especially to the poor. A system that provides more accountability at the local level and gives its citizens the ability to affect public choices on local levels is likely to induce a stronger demand from the local population on local news. Under the assumption of free media und the effect that demand drives supply malnutrition, while not making it into the national news, is 
media is seen as conducive also to prevent less extreme cases of government failure. Measures to improve media coverage are similar to those discussed in the connection with democracy, yet focus more on the local level.

The one-way communication from administrations to the public needs to be accompanied by a reverse flow from information from the public to the administration. This is obvious in a participatory system, but can also be achieved in systems with less user involvement through feedback cards or other mechanisms for learning about the user's demands and concerns. ${ }^{1}$

A second precondition for the establishment of accountability and a strong necessity for the functioning of participatory processes are reforms for greater decentralization in many developing countries. ${ }^{2}$ The potential for the achievement of development goals by decentralization stems from the delegation of control rights to those people that have the necessary information and the incentives to respond to the needs of the poor. The incentives are provided by making local administrators responsible for the political and economic outcomes of their decisions. ${ }^{3}$ The delegation of power enables the participation of and accountability to the local population that is not possible if the decisions are taken at central agencies, which are physically distant and in their accountability removed from the local population whose lives they affect.

The benefits from decentralization will only be realized if the delegation of power to make decisions is accompanied by a delegation of the resources necessary to implement these decisions and by ensuring that decentralization does not merely shift power from central elites to local elites. ${ }^{4}$ To achieve local autonomy it is necessary to supply the local authorities with sufficient resources to fulfill their obligations. These resources need to be at the local administration's independent disposal and need to be firmly set to provide incentives for their efficient use instead of encouraging the expansion of lobbying activities at the center for additional resources.

The shift of responsibility from the central to the local level breaks the power of elite structures at the center and allows for greater focus on local participation. However, placing autonomy at the local level also bears the risk that the local elite may abuse this power to their advantage, especially in countries with highly unequal power structures. Therefore, the mechanisms of downward accountability and participation have to be firmly established from the center to ensure that the interests of the local population are adhered to. Information on the budgets given to the local authorities need to be spread to the

likely to make the local news, which in a system of sufficient local accountability would yield substantial effects.

${ }^{1}$ See World Bank (2000a), p. 102.

${ }^{2}$ For the need for greater decentralization see Sida (1996), p. 34.

${ }^{3}$ For an expansion of this point see Bardhan, P. (1997).

${ }^{4}$ For the following expansion on these points see World Bank (2000a), p. $106-108$, and for the capture of power by local elites see also DfID (1999b), p. 28. 
population and audits and supervisions from the center have to be conducted to ensure the effectiveness of the measures in preventing capture by local elites.

Accountability, transparency and decentralization require additional institutions, such as free and independent media, knowledgeable and capable personnel on the local levels, mechanisms and standards governing the dissemination of information and independent and competent audit institutions that supervise the responsible use of autonomy given to the local level. If these can be put into place, the benefits from this triangle of measures presented in this subchapter can be assumed to provide strong benefits in terms of policy decisions, resource allocations and public service provision that focus on the needs of the population and, thus, lead to overall economic and social benefits for the population. This is especially true for the poor, who otherwise lack measures to influence decisions in their favor.

\subsection{Stemming Corruption}

The prior reference to abuse of power by the local elite already points at a further problem: corruption as a pervasive impediment to poverty reduction. Its strongly negative impact occur in diverting resources from their intended usage, imposing constraints and inefficiencies in the economic system and exerting an especially hard toll on the lives of poor people by reducing employment opportunities, causing higher prices and demanding additional payments for free or low-priced public services. ${ }^{1}$

These detrimental effects are incurred by engagement in grand corruption by government officials. This diverts substantial national resources from the public into the pockets of a corrupt few and by channeling funds into inefficient uses by awarding contracts on graft rather than on efficiency and social desirability. ${ }^{2}$ This imposes social costs (in terms of lost efficiency) in the domestic industry that focuses more on relationships and side-payments than on competition on terms of efficiency and quality by impeding price reductions in the domestic market and by eroding export opportunities and associated additional employment opportunities. The costs incurred by businesses because of bribery and lost economic opportunities can add to costs in excess of $11 \%$ of total gross incomes, as in the case of companies in Georgia. ${ }^{3}$

At least as negative for the quality of life and the economic opportunities of poor people is petty corruption involving bribes for pubic services and transportation. ${ }^{4}$ These costs can be vast and severely limiting for the economic activity of the poor, as costs of bribes can reach nearly seven times the regular

\footnotetext{
${ }^{1}$ See UK government (1997), p. 30.

${ }^{2}$ See DfID (2000e), p. 20.

${ }^{3}$ See Kaufmann, D. / Kraay, A. / Zoido-Lobatón, P. (2000), p. 13.

${ }^{4}$ See World Bank (2000a), p. 102.
} 
costs incurred e.g. in the transport sector ${ }^{1}$. This limits the ability of the poor to expand their markets to more distant locations substantially. ${ }^{2}$ Both types of corruption also have indirect economic impact that constrains economic growth by increasing the uncertainty and unpredictability of costs to prospective investors. $^{3}$

The strong and broad-based negative effects of corruption on the impact of development ${ }^{4}$ justify a separate section on this phenomenon.

Corruption can be defined as "the abuse of public office for private gain." Corruption can logically be separated into administrative corruption in cases where the abuse is initiated by the holder of the official position to extract extra tolls form businesses or private people, and state capture in cases where the business community actively seeks to intervene in politics and policies to its advantage. ${ }^{6}$ While both cases cause important distortions to the business and private environment, the latter especially in transition economies, the focus within the new strategies for poverty reduction lies mainly on the former.

Regardless of the form of corruption, the reasons for its existence lie in the availability of rents to holders of public office. ${ }^{7}$ This leaves open two possibilities for curbing corruption: to reduce the opportunities and needs for corruption, and to impose strict controls and accountability standards. The opportunities for corruption can be tackled by promoting a market-based system, where the role of the state is important in providing the right institutions, but where the state is restraint from direct interventions in the marketplace. ${ }^{8}$ Restrictive use of measures such as quotas or licenses reduces a major source for rents for their owners and those that issue them and, thus, automatically limits

\footnotetext{
1 See Center for Institutional Reform and the Informal Sector and U.S. Agency for International Development (1996) for bribes on transports in Benin. The World Bank also cites side-payments of $75 \%$ of the total transport costs being incurred in Cote d' Ivoire. (See World Bank (2000a), p. 102).

${ }^{2}$ For the benefits for the poor occurring from access to markets see the chapter on Access to Markets.

${ }^{3}$ See DfID (2000), p. 30.

${ }^{4}$ In their extensive statistical study Hellman, Geraint and Kaufmann differentiate corruption on three levels and after accounting for inverse causation find that "a reduction in corruption from the very high level prevalent in Indonesia to the lower level in Korea leads to between a two- and fourfold increase in per capita incomes, a decline in infant mortality of similar magnitude, and an improvement of $15-25 \%$ percentage points in literacy levels". Hellman, J. / Geraint, J. / Kaufmann, D. (2000).

${ }^{5}$ See Hellman, J. / Geraint, J. / Kaufmann, D. (2000). The analyzed strategies take the meaning of corruption for granted and do not provide a definition, therefore this commonsense definition will be used in this exposition.

${ }^{6}$ See Hellman, J. / Geraint, J. / Kaufmann, D. (2000).

${ }^{7}$ For an introduction on the prevalence of rents in public decisions see Meier, G. / Rauch, J. (2000) and for an expansion of this point see Krueger, A. (1974).

${ }^{8}$ For deeper analysis on the economic incentives system see the correspondent chapter in this booklet.
} 
the scope for corruptive activity. Measures to simplify the tax system and to eliminate excessive regulations also limit the opportunities for corruption. ${ }^{1}$ To tackle the need for corruption is another way to reduce administrative corruption. The main idea in this regard: paying state employees a wage above the 'living wage', can be seen as an obvious precondition to discourage the engagement of officials in activities that expand their income. ${ }^{2}$

Opportunities for corruption will remain even under the economic system proposed in the strategies above because the role of the state in actively effecting the institutional environment of business activities persists. In order to discourage corruption despite available opportunities, measures to increase accountability and participation as discussed prior are of vital importance. In order to increase the ability of the public to take over their responsibilities in monitoring, it is important to simplify administrative procedures as much as possible. Independent audit functions and parliament oversight over the standards of conduct should supplement the downward oriented measures of accountability and participation by supervision from above. ${ }^{3}$ The vigorous prosecution and removal of corrupt politicians, police officers and members of the judiciary need to be the result of negative findings in audits or other investigations in order to provide a clear signal to the entire society.

The industrialized countries are also seen in charge for curbing corruption committed by their home residence and businesses. On the level of the OECD this has been taken up by anti-bribery conventions, which make the offering of bribes to foreign public officials illegal and which disallow bribes as a cost against tax. ${ }^{4}$

Overall, the two measures for curbing corruption - the elimination of opportunities and the monitoring of those activities where possibilities remain including the consequential prosecution of abuse of administrative power - need to be in place in order to create a conducive environment for poverty reduction and economic expansion.

\subsection{Rule of Law and Accessibility of the Law}

The main measures presented so far in order to improve the governance of a state comprise the reduction of opportunities for misuse and the control of government and administrative action through the public by increasing accountability. A further major point is the ability of the people to pursue their given rights in court and in the executive systems of law enforcement. Rule of law and accessibility of the law represent a part of good governance and their implementation should be a core priority for government action according to the new strategies. ${ }^{5}$

\footnotetext{
${ }^{1}$ See World Bank (2000a), p. 102.

${ }^{2}$ See DfID (2000e), p. 21.

${ }^{3}$ See DfID (2000e), p. 21.

${ }^{4}$ International measures are discussed e.g. in DfID (2000e), p. 20, 21.

${ }^{5}$ See e.g. UK government (1997), p. 16.
} 
Rule of law can be interpreted to mean "that a country's formal rules are made publicly known and enforced in a predictable way through transparent mechanisms." Achieving progress in this regard also increases the impact on other areas of good governance ${ }^{2}$ in terms of strengthening accountability and curbing corruption. This is achieved because individuals do not solely have to rely on the power of the media and of civil society groups, or of indirect measures of democratic or participatory processes to pressure administrators for changes if they feel deprived of their rights. They are enabled to access their rights individually and directly if the judicial system is favorable to such claims and free from internal corruption and from outside influence.

Prevalence of the rule of law has also economic implications in terms of increased investment and growth, ${ }^{3}$ creating opportunities to substantially raise GNP per head. ${ }^{4}$ It creates foreseeable and secure economic environments by credibly enforcing contractual obligations and providing methods of swift conflict resolution. Thus, it reduces the uncertainty and the transaction costs for economic agents to engage in production, trade and investment. These activities in turn aid the poor via employment and income opportunities. ${ }^{5}$ The rule of law is also immediately influential on the economic situation of the poor. They are likely to be deterred from investing in their own development if they lack safety and security for reaping the proceeds. ${ }^{6}$

Next to economic benefits the rule of law, its accessibility and its undiscriminating and rightful enforcement also contribute to the achievement of human rights with measurable improvements in health and educational achievements ${ }^{7}$ by providing the population with means to claim their rights and to enforce their claims ${ }^{8}$.

\footnotetext{
${ }^{1}$ This definition is taken from World Bank (2000a), p. 102. It reflects the general notion of the terminology and corresponds to the usage of this phrase in the other documents.

${ }^{2}$ See e.g. World Bank (2000a), p. 103.

${ }^{3}$ See DfID (2000e), p. 15.

${ }^{4}$ Kaufmann, Kraay and Zoido-Lobatón (2000) estimate the effects of a change of rule of law from a low to a middle level on their three level scale to result in a two- to four-fold increase in GNP/head in the long run. Barro estimates the effect of each increase of one on his sixlevel scale to result in increased growth rates of GNP/head by $0.5 \%$. In contrast of the finding of Kaufmann et al. he does not find significant coefficients for corruption or political instability if rule of law is added to the system, making rule of law the prior variable in the impact on growth in his study. See Barro, R. (1999), p. $26-28$.

${ }^{5}$ This point is expanded upon in the study of Norton, S. (1998) and taken up in World Bank (2000a), p. 103.

${ }^{6}$ For an expansion of this point see DfID (2000e), p. 16.

7 The already cited study by Kaufmann, Kraay and Zoido-Lobatón (2000) estimates the effects of a change of rule of law from a low to a middle level on their three level scale to result in substantial decline in infant mortality and an improvement in literacy levels between $15 \%$ and $25 \%$.

${ }^{8}$ The connection of rule of law and human rights is expanded upon for example in Sida (1996), p. 22, DfID (2000d), p. 11 and is mentioned in BMZ (2001a), p. 31 and World Bank (2000a), p. 103.
} 
This already points at the fact that a discussion of the legal system needs to start with the laws that it is supposed to enforce. These need to be consistent and easy to understand. ${ }^{1}$ This will enable consistent and unambiguous verdicts and allow predictability and comprehension of the rights within the broader public. The laws need to apply equally to all citizens and the state needs to be subject to the $\mathrm{law}^{2}$, implying a strong degree of independence of the judicative from the influence of executive and legislative powers. Discrimination needs to be prevented in the formulation of laws, especially in the case of gender $^{3}$ where discrimination still widely prevails. Property rights regimes and inheritance laws often strongly disfavor women in developing countries, limiting their ability for economic and social progress and their chances for independence in the decisions on their lives. Some legislation does not even respect the right of physical self-determination of women, for example by not considering wife beating as an offence. Criminal justice and law reforms are demanded to give women a chance to progress in their lives. ${ }^{4}$ This is embedded in a general concern for human rights as the basis on which national law should be developed or reformed and which it should protect. ${ }^{5}$

Since laws tend to reflect the positions of those in power, special concern needs to be given to build coalitions in favor of the poor and by strengthening civil society organizations that can shift the power distribution in favor of the poor and disadvantaged. ${ }^{6}$ This is necessary since absence of discrimination within the law does not necessary imply its tendency to shape the structure of rights in favor of the activities and possibilities of the poor.

The impact of the legal system on the poor is an important issue since the poor lack other, private means to achieve their entitlements. If bribery persists and the poor have no possibility of redress, they are effectively excluded from the service or treatment to which they are entitled. A main concern for poor people is not only the content of the law, but also the accessibility of the law.?

The accessibility of the legal system is limited for the poor through administrative procedures, complexities of the law, exclusionary practices and financial costs. The reliance of most legal systems on written documents limits the knowledge of poor people of their rights and complicates the access for poor

\footnotetext{
${ }^{1}$ See DfID (2000e), p. 17.

${ }^{2}$ See World Bank (2000a), p. 102, 103.

${ }^{3}$ See Sida (1996), p. 21. International Development Targets and on human rights. 2000/2001.

${ }^{6}$ See World Bank (2000a), p. 103, 127 and 128.

${ }^{7}$ See Sida (1996), p. 22.
}

${ }^{4}$ The prevalence of legislative deficiencies, their impact on women and measures to reverse this are discussed in great detail in DfID (2000f), p. 7, 8, 18, 19 and 22 and BMZ (2001a), p. 31. General concerns about the discrimination of women are discussed in the sections on the

${ }^{5}$ See DfID (2000e), p. 17 and World Bank (2000a), p. 103. This is one of the rare instances where the World Bank explicitly acknowledges human rights concerns in the WDR 
people with little formal education. Para-legal organizations that spread knowledge about the law and encourage groups of poor people to organize themselves to use the law are one means to overcome this problem. ${ }^{1}$ Literacy programs and media campaigns are further measures. Simpler and clearer rules also are also needed to convey rights to the impoverished, especially in areas of their immediate concern such as labor disputes, land titling, and human rights and police violence. ${ }^{2}$

This becomes even more necessary in cases where overlapping new laws, colonial legislation and customary law result in confusion and arbitrariness in decisions, benefiting those with greater power to shape the outcome in their favor. While customary rights are not outright rejected because of their benefits in terms of swift, relatively low-cost procedures, they need to be embedded in general legal system to prevent traditional systems of discrimination and favoring of elites to persist. ${ }^{3}$ This concern also applies to alternative conflict resolution methods such as mediation, which are favored for similar reasons but bear equal potential problems. Therefore, the challenge of informal rulings in formal procedures needs to remain possible. ${ }^{4}$ The general weakness and complexity of the procedural progressions in many legal systems is addressed as a need for reform in order to simplify rules, shortening proceedings and allowing parties to represent themselves, thereby lowering the indirect costs for poor people. ${ }^{5}$

Direct costs are another major inhibitive force for the access to the law for poor people. Costs waivers based on indigence and expansion of legal service to poor people can aid in overcoming these barriers. Special attention also needs to be given that non-monetary discriminatory barriers - which might persist in a society and might be the root cause for claims by the poor - do not also proliferate the legal system and effectively prohibit the deprived from accessing their rights.

Another concern rests with the enforcements of the rights, which requires a modern police force, which views its actions as a service to the entire population and extends security to the lives of the poor. This is fostered by creating partnerships between law enforcement agencies, civil society organizations and the local government. ${ }^{6}$

In their approach to improve the legal system, the analyzed donor strategies rely on the counseling of the national government concerning system of justice reform and on the support for para-legal civil society organizations, which

\footnotetext{
${ }^{1}$ See Sida (2000), p. 22.

${ }^{2}$ For this and the following point see World Bank (2000a), p. 104.

${ }^{3}$ See DfID (2000e), p. 16.

${ }^{4}$ See e.g. World Bank (2000a), p. 104.

${ }^{5}$ The need to respect due process has to be kept in mind in the attempts to simplify rules. See World Bank (2000a), p. 104.

${ }^{6}$ See DfID (2000e), p. 16.
} 
educate poor citizens on their rights and enable joint suits of a group of deprived people. Their concern for the rule of law is based on their understanding that it is strongly beneficial to economic progress as well as progress in terms of securing democracy and fulfillment of human rights. Yet despite some ideas about the measures to achieve rule of law that have been presented above, there remain ambiguity on how a "strong, honest and independent judiciary"1 is supposed to be developed in its absence and in a political environment that is prone with corruption and discrimination.

A system of downward accountability to the population coupled with checks and supervision from higher levels of the system as proposed for administrative bodies fails for the judicative since there is a strong need for independence. Some checks have to be in place to ensure that this independence is not used for personal gains, while ensuring that the controlling mechanism cannot exert undue influence on the judicial system and thereby divert its independence. This problem has received little attention and the strategies remain rather on the surface of what should be achieved rather than moving on to how it can be achieved. This requires further research to guide willing governments in the process to reform the national judicative system effectively towards the right ends.

It has been shown that a national environment that empowers poor people to take charge of their lives, backed by measures of good governance, is a major contributor to the extension of personal freedom and human rights in the political and social sphere of the poor individual. It also enables him to pursue economic opportunities available to him without obstacles and expands these opportunities by giving him a voice in public decisions. Thus, he can influence the environment in which he lives as well as some of the public service inputs in his economic activities such as education, health care and commercial infrastructure $^{2}$. A conducive political and legal framework also expands the overall availability of economic opportunities by creating an environment conducive to the activity of all economic agents, the poor as well as the nonpoor. The economic activity of the non-poor spurred by the prevalence of the rule of law and the curbing of corruption leads to increased demand for the main economic asset of the poor, their labor. Yet this connection between political and economic activities, which has been analyzed so far, does not provide the entire picture on poverty reduction, as the dimension of security for the poor plays a major role in their achievement of sustainable reduction of poverty in the contemporary strategies.

\footnotetext{
${ }^{1}$ DfID (2000e), p. 17.

${ }^{2}$ Social infrastructure in health and education can be seen as an input into the economic activity of the poor if it is accepted that labor is their major economic asset, which is strongly effected in their productivity through the provision of social services.
} 


\subsubsection{Measures to Provide Security for Poor People}

\subsubsection{The Need for Security}

The uncertainty in the lives of many poor people on how to cope with possible health or weather-related income shortages and other detrimental effects that threatens their livelihoods is by itself a part of poverty ${ }^{1}$ and leads to deeper poverty in economic terms. Security is seen as a major component of poverty reduction in the analyzed strategies ${ }^{2}$ because it is seen as one of the major problems the poor are faced with and threatens their very survival. The notion that temporary poverty rather than constant poverty can be the prevalent phenomenon ${ }^{3}$ has increased the focus on how to prevent people from falling back into poverty once they escaped it. It also has interactions with overall economic growth, with the opportunities that people can pursue and its provision relies on empowerment of the poor as will be seen in the expansion in this chapter. The provision of security is therefore regarded as the third pillar on the national level next to the creation of opportunities and the empowerment of poor people that needs to be tackled for overall reduction of poverty.

Poor people are regarded as especially prone to risks such as illness, poverty in old age, natural catastrophes and wars and possess only few possibilities to cope with crisis when is occurs. ${ }^{4}$ The increased risk results from higher exposure to hazardous work and environmental conditions ${ }^{5}$, the exposure to unsafe water ${ }^{6}$, the ownership of marginal land ${ }^{7}$ more prone with crop failure, employment situations more likely to be reduced in economic crisis ${ }^{8}$ and higher exposure to national crisis situations ${ }^{9}$. Their coping strategies are also limited because poor people lack assets to deal with unexpected crisis situations and lack formal insurance mechanisms ${ }^{10}$. This doubled disadvantage of higher risk coupled with lower ability to cope with crises of poor people in comparison to the non-poor makes the theme of security especially important poor people and those living close to the poverty line. This is aggravated by the fact that the

\footnotetext{
${ }^{1}$ See the chapter on 'The current poverty definition'

${ }^{2}$ See e.g. Sida (2000e), BMZ (2001b), p. 8, 11, DfID (1999b), p. 15 and World Bank (2000a), p. 10.

${ }^{3}$ This notion has been established e.g. for South India by studies from Ravallion, M. (1988) and Gahia, R. / Deolalikar, A. (1993) where the first estimates the extent of transitionary poverty at about half the total estimated poverty, while the second estimates about $70 \%$ of the population to move in and out of poverty over a nine-year period.

${ }^{4}$ See e.g. BMZ (2001a), p. 25, World Bank (2000a), p. 135 and DfID (1999b), p. 15 and in the context of a possible water crisis see DfID (2000a) p.5.

${ }^{5}$ See DfID (2000c), p. 7, 8.

${ }^{6} \mathrm{BMZ}$ (2001a), p. 28.

${ }^{7}$ DfID (2000a), p. 5.

${ }^{8}$ World Bank (2000a), p. 162.

${ }^{9}$ See Sida (1996), p. 23.

${ }^{10}$ See World Bank (2000a), p. 135.
} 
impact of a shock ${ }^{1}$ is greater for those people living in poverty. The consequences of a drop in income in terms of reduced utility for people struggling with their very survival can be assumed to be much higher than for those with enough resources to protect their basic needs even in cases of adverse conditions. "Vulnerability is for [...poor people] a graver concern because any drop in income can push them into destitute" .

This leads to consequences in their economic activities, since they forego higher-risk, higher-return activities ${ }^{3}$ that could boost their living standards and contribute to overall economic growth, but cannot be backed by adequate insurance to secure their survival in case of adverse outcomes. In the case of shock situations, poor people have to opt for short-term security while incurring long-term costs ${ }^{4}$ because in severe situations poor households have to reduce consumption or increase labor supply.

Long-term effects result from the absence of children from school because they need to work to increase income, or because direct or indirect school expenditures cannot be afforded any longer ${ }^{5}$. This limits the ability of children to escape poverty in their adulthood. Further long-term consequences arise from suffering health and undernourishment ${ }^{6}$, with especially high impact on women and children. These adverse effects on the current fulfillment of basic needs and the future achievement of economic progress highlight the special attention that has to be given to increased security for poor people.

Strive for a socially secured life is a universal desideratum ${ }^{7}$. This fact gives rise to the pursuit of security in its own regard. Enshrined is this view in the Article 22 of the UDHR:

Everyone, as a member of society, has the right to social security and is entitled to realization, through national effort and international cooperation and in accordance with the organization and resources of each State, of the economic, social and cultural rights indispensable for his dignity and the free development of his personality.

\footnotetext{
${ }^{1}$ For a terminology of terms see World Bank (2000a), p. 139. In short: Insecurity is the expose to risk. Vulnerability is the resulting possibility of a decline in well-being. The event triggering the decline is referred to as shock. Risk exposure is a measure of the probability that a certain risk will occur. Vulnerability measures the resilience against a shock.

${ }^{2}$ World Bank (2000a), p. 138.

${ }^{3}$ See World Bank (2000a), p. 135, 138.

${ }_{5}^{4}$ See World Bank (2000a), p. 142.

${ }^{5}$ These effects were shown e.g. by Frankenberg, E. / Thomas, D. / Beegle, K. (1999) for Indonesia and by Jakoby, H. / Skufias, E. (1997) for South India.

${ }^{6}$ Undernourishment and the resulting long-term impact on physical growth is shown by Benson, C. (1997). The effects on mortality rates are shown by Vos, R. / Velasco M. / de Labastida, E. (1999). In both cases the crisis extended beyond the shortfall of individual income to encompass also supply shortages because of the overall consequences of floods and droughts respectively.

${ }^{7}$ See Gsänger, H. (1993), p. 3.
} 
This rights-based view is another determinate for the strong focus on security as part of the new strategies ${ }^{1}$. The large layer of the unsecured especially in the poor countries of Africa and Asia ${ }^{2}$, where the formal systems of security rarely reach more than $10 \%$ of the population ${ }^{3}$, makes the search for measures to increase their security a priority.

The will to increase security is visible in all strategies. Yet the notion what exactly comprises a system providing security and what it should deliver remains rather vague in the various strategies. Security is vaguely described as the responsibility for protecting the vulnerable and assisting those unable to participate in the markets ${ }^{4}$. The German Action program distinguishes social security systems, which are supposed to increase and rehabilitate the self-help abilities of the poor, and emergency help for securing lives in catastrophic conditions ${ }^{5}$. The World Bank defines: "Enhancing security for poor people means reducing their vulnerability to such risks as ill health, economic shocks, and natural disasters and helping them cope with adverse shocks when they do occur" $^{\prime 6}$ while Sida relies more on macroscopic prevention of conflict and achievement internal peace ${ }^{7}$. For a more detailed definition I rely on Gsänger who defines:

Under social security systems one understands the sum of social rules which, through enforcement of formal as well as informal claims on the other members of a society, have the goal to (a) ensure the physical survival in dignity, (b) to secure a minimum level of consumption and (c) to ensure the protection from deterioration of the living situation through risk, which have for objective or subjective reasons been unavoidable and which consequences cannot be coped with by those struck by them. ${ }^{8}$

This broad-based definition, which goes beyond the notion of a safety net, incorporates notions of security for those who cannot participate in the market economy and has strong implications for preventive actions to avoid reductions in living conditions ${ }^{9}$. Since these are notions are reflected in the attempts of the modern strategies, this broad definition serves well for the further analysis.

\footnotetext{
${ }^{1}$ See DfID (2000d), p. 2.

${ }^{2}$ See Elvert, G. / Evers, H. / Wilkens, W. (1983).

${ }^{3}$ See Gsänger, H. (1983), p. 2. Gsänger compares this number to outreach quotas of up to $80 \%$ in some Latin American countries. This also shows the different focal points in different continents. While in Latin America the challenge lies in strengthening the weak and underfunded social systems, the challenge in Africa and Asia rests in extending methods of security - formal or informal - to the broad mass of the people.

${ }^{4}$ See DfID (1999b), p. i, ii.

${ }^{5}$ See BMZ (2001), p. 25.

${ }^{6}$ World Bank (2000a), p. 39.

${ }^{7}$ See Sida (2000d).

${ }^{8}$ This is a direct quote from Gsänger, H. (1983), p. 22, translated by the author.

${ }^{9}$ See also Gsänger, H. (1983), p. 22, 23.
} 


\subsubsection{The Role of Private vs. State Security Provision}

One of the important questions of the design of security schemes for the poor is concerned with the relationship of measures that are provided by the states with those that the individual or a group of people has established. In a scholarly context, this question has been taken up in the comprehensive analysis of Gsänger (1993), who emphasizes the need for decentralized and networked security systems with pluralistic structures extending beyond the single supplyoriented provision through state organizations. ${ }^{1} \mathrm{He}$ argues that security can only be extended if its measures are embedded in an economic policy process with a social orientation and if the group specific coping capacities are enforced ${ }^{2}$. To strengthen the coping strategies of groups he relies on measure of participation and of access to production factors such as credit and land ${ }^{3}$, which takes up major themes in the analyzed poverty reduction strategies. As a hierarchy of subsidiary he proposes local groups and self-help groups on the lowest level, self-help support organizations and NGOs on a secondary level, and social security organizations und funds in state control on the tertiary level ${ }^{4}$, which should be vertically and horizontally connected.

This view of a subsidiary oriented social security system is also at the core of the modern strategies of poverty reduction. Most visible is the parallelism in the German Action program, which describes the basic forms of social security as: solidarity groups (e.g. the family); cooperative, member-based systems; private insurance schemes and forms of state security provision. ${ }^{5}$ Thus, central, state planned security plans are only one part in the system providing security for the poor. Emphasis is placed to extend public and private security methods to the poor and to link different systems. The difference to the presented academic model lies in the stronger emphasis on private insurance schemes in most modern strategies. Methods to save and borrow money are emphasized, as well as their extension to offer individual insurance instruments. ${ }^{6}$ The notion is prevalent that poor people have a need and are willing to use private insurance instruments. They already use very simple ones. Yet the unavailability of more elaborate mechanisms ${ }^{7}$ limits poor people in pursuing security privately, which is caused by the low profitability for commercial insurance companies given the small sums poor people transact.

Departing from the precedent views of nation-wide state provided security systems, the new strategies opt for subsidiary systems that look to support smaller solutions on the cooperative or solidarity group basis where appropriate.

\footnotetext{
${ }^{1}$ See Gsänger, H. (1993), p. 24, 25.

${ }^{2}$ See Gsänger, H. (1993), p. I.

${ }^{3}$ See Gsänger, H. (1993), p. 89, 90.

${ }^{4}$ See Gsänger, H. (1993), p. 91.

${ }^{5}$ See BMZ (2001a), p. 25.

${ }^{6}$ See BMZ (2001a), p. 28, DfID (1999b), p. 18, Sida (1996), p. 32 and World Bank (2000a), p. 141.

7 "Elaborate" is in itself an exaggeration, since simple savings tools beyond the holding of inflation-prone currency or livestock is already beyond the reach of many poor people.
} 
The Anglo-Saxon strategies move even further and start from the individual or household as the smallest unit for security provision, with his assets serving as the main base for individual security provision ${ }^{1}$. Self-insurance as the most basic form of security provision is important in real terms because it is sometimes the only precaution that the impoverished can take. The accumulation of assets in good times and their reduction in bad times is an ancient idea, yet its virtues rest on the assumption that asset accumulation yields positive rates of return and their value remains independent of the income situation. Since many assets that poor people can obtain have negative time preferences and are covariant with the income level, as is the case if many people suffer income losses and thus sell their buffer assets at the same time ${ }^{2}$, the viability of this method is limited. Due to practical limitations of other security methods it still remains an important measure. $^{3}$

A short summary of the various levels of subsidiary schemes is provided in the following table.

Table 1: Levels of Security Provision

\begin{tabular}{|l|l|l|}
\hline \multicolumn{1}{|c|}{ Organization $^{\mathrm{a}}$} & BMZ & World Bank \\
Level
\end{tabular}

a DfID and Sida do not explicitly distinguish between different levels.

${ }^{b}$ This categorization refers to World Bank (2000a), p. 143, 144. The adaptation of the comprehensive view of Holzmann, R. / Jorgensen, S. (2000) in World Bank (2000a), p. 141 yields slightly different categorizations.

These slight differences in the perception on the levels of subsidiary schemes can be distinguished, yet the overall consensus prevails that security provision should be conducted on the lowest level appropriate, and that traditional methods of group-reliance need to be taken into account. They have practical

\footnotetext{
${ }^{1}$ See especially World Bank (2000a), p. 143, 144 and to a lesser degree DfID (1999b), p. 29, 30.

${ }^{2}$ The increased supply of the buffer asset is faced with a reduced demand because of the adverse economic situation of the average household, yielding to a strongly negative impact on the price of the buffer asset in times of macro-economic shock.

${ }^{3}$ An expansion on this point can be found in World Bank (2000a), p. 143.
} 
implications because they are available while state security provision is absent in many cases, and they also have economic benefits because they control the misuse and moral hazard problems through personal supervision. Yet the ideal scheme is still under discussion. State security systems might still be the most economical, because they can diversify their risk over a large area and population. ${ }^{1}$ Still, if trust in the state is low or if state funds during a crisis prove limited, these schemes will fail.

Further factors influencing the level of security provision include the level of the risk, since risks affecting an entire area cannot be insured on a community basis, and the availability of certain insurance methods to the very poor. Here the World Bank argues that formal, public systems benefit the poor more than the informal, private insurances because the latter work against inclusion of the poorest who have a higher perceived risk of default. ${ }^{2}$ This argument strengthens the role of the state in the provision of security as part of social responsibilities. However, the strengthening of informal and private insurance schemes remains of vital importance in the strategies because of their practical relevance in the current absence of state security provision in many countries $^{3}$. Therefore, the relevance of informal, private and state security provision will continue to be discussed and might change in relevance in the specific country situation, yet the idea of a subsidiary method of security provision seems firmly established.

Finally, the provision of security is also often extended to include security from theft and physical harm. ${ }^{4}$ This is especially important for women, who are subject to misuse by men in many societies. ${ }^{5}$ But also the poor people face insecurity in their daily lives if the reach of public law enforcement does not reach out to them or if the law enforcement is prejudiced or corrupt. These problems are mainly tackled by measures of good governance that have been covered in prior chapters, and thus the following discussion of the measures to increase security will avoid this aspect and focus on insurance schemes and crisis prevention methods that should be domestically pursued.

\subsubsection{Measures of State Security Provision}

The previous discussion shed light on the level on which security should be provided and on the question on private vs. public security provision. At the various levels different ways to improve security need to be pursued. As a basic and intuitive strategy to reduce vulnerability the increase in economic activity in a growing economy is mentioned ${ }^{6}$, because it increases the incomes of the poor

\footnotetext{
${ }^{1}$ See World Bank (2000a), p. 148.

${ }^{2}$ See World Bank (2000a), p. 149. encountered.

${ }^{4}$ See e.g. DfID (1999b), p. 15.

${ }^{5}$ See DfID (2000f), p. 7 and DfID (2000e), p. 16.

${ }^{6}$ See World Bank (2000a), p. 135.
}

${ }^{3}$ This problem of exclusion from private insurance and unavailability of public insurance is pointed out in BMZ (2001a), p. 25. The solution to the conflict is left to the specific situation 
and allows them to establish assets to secure themselves against adverse risk. It also increases the ability of people to support the informal support network they belong to, because these networks rest on the ability of some of its members to provide resources for those other members that are currently threatened in their livelihood provision. Yet as it is noted in the same context ${ }^{1}$, the concern for security would be exaggerated if it were not for a deeper search for mechanisms to reduce, mitigate and cope with risks other than improved economic conditions.

As in most contemporary strategies this analysis will look at the measures a state can take to increase its poor citizen's security in two steps. First by considering those methods it can extend to the population to enable them to better cope with the adverse risk in the everyday live of the individual. And second by looking at prevention and mitigation strategies for macro-economic risks and national crisis such as economic and financial shocks, natural disaster and internal and external armed conflict.

On the first, lowest levels - the individual and group level - the new strategies rely strongly on micro-finance systems that extend the possibility to smooth consumption to poor people. ${ }^{2}$ This enables the individual to use credits in the time of need and to save up money when he can spare it without incurring losses in real terms. To avoid failure of these instruments in times when need is greatest- e.g. shocks effecting an entire region and forcing most members of the micro-credit system to draw up credits while no new savings become available for financing - the integration of informal methods of security provision into the larger financial system is attempted ${ }^{3}$. This allows for the diversification of risk over a larger population and area and can secure sufficient funds for microcredit systems in crisis areas even if its member base temporarily needs more funds than it generates. It also allows for easier social transfers to the poorest from the state through this network. The state can actively encourage microfinance programs by providing start-up financial support and knowledge, advance the networking of micro-finance systems with private or public financial institutions and facilitate the spreading of more sophisticated insurance instruments through these channels by allowing initial support for fees ${ }^{4}$.

A further line of thought on the lower levels is concerned with the extension of education and health services. Education is seen as influential on the economic situation and on the physical health of the individual ${ }^{5}$, and education is thus seen

\footnotetext{
${ }^{1}$ World Bank (2000a), p. 135.

${ }^{2}$ See BMZ (2001a), p. 28, DfID (1999b), p. 18, Sida (1996), p. 32 and World Bank (2000a), p. 141.

${ }^{3}$ See e.g. BMZ (2001a), p. 28.

${ }^{4}$ Examples from India in this regard are cited in BMZ (2001a), p. 26 and World Bank (2000a), p. 151.

${ }^{5}$ See chapters on 'Poor people's assets' and 'Human rights and equality'.
} 
as beneficial to reducing vulnerability ${ }^{1}$. Yet this notion still discussed in the strategies $^{2}$. Health concerns on the contrary are unambiguously seen as a major area where security for the poor needs to be increased. One of its main themes is the provision of safe water, whose absence has detrimental impacts on the health situation especially of poor people. ${ }^{3}$ The fecal contamination of water and food due to poor or non-existent excreta disposal systems and inadequate hygiene compounds this effect. ${ }^{4}$ Further preventive factors include adequate nutrition and investment in education for women. ${ }^{5}$ The 20/20 initiative for the promotion of social services is mentioned as one attempt in this regard. ${ }^{6}$

Health insurance is considered a further strong component in the provision of security of livelihood for the poor. Methods can include the free provision of medical care ${ }^{7}$ or targeted subsidies for hospital care, ${ }^{8}$ with the latter being less of an administrative burden but also less comprehensive. The World Bank strategy specifically calls for insurance for less frequent, more serious illnesses, rather than more frequent, less traumatic ones, because poor people are considered more able to cope with small shocks than with larger ones. ${ }^{9}$ If this proves right, current themes, which cover basic care, rather than large illnesses, need to be reconsidered. Currently this thought has not reached overall support throughout the strategies. Next to the public provision of health services the new strategies call for a stronger focus on private health service provision, which is estimated to remain a large provider of health services. ${ }^{10}$ To incorporate this sector stronger, a change in the role of the state from service provider to financier is proposed. ${ }^{11}$

A special concern in the health sector concerns the spread of the HIV/AIDS pandemic. It is to be expected that the pressure for solutions for this problem

\footnotetext{
${ }^{1}$ See BMZ (2001a), p. 28.

${ }^{2}$ Divergent studies for different countries regarding the impact of education in the recovery from shock and expose to risk are cited in World Bank (2000a), p. 140.

${ }^{3}$ See DfID (2000c), p. 7. Further factor effecting health are discussed in the chapter on "

${ }^{4}$ See Sida, (1996), p. 29, 30.

${ }^{5}$ See e.g. DfID (1999a), p. 21, 22. For the discussion of impact factors on health see also the chapter 'Poor people's assets'.

${ }^{6}$ The United Nations 20/20 initiative describes an understanding between the donor country and the recipient country to increase the provision of social services by reserving $20 \%$ of the development aid and $20 \%$ of the national budget for this purpose. See BMZ (2001a), p. 26.

${ }^{7}$ Or equivalently the provision of an insurance scheme with nearly universal coverage. Both measures are equal in effect, with the differences mainly arising in the way of financing (normally taxes vs. insurance fees).

${ }^{8}$ For the argumentation on health insurance systems see primarily World Bank (2000a), p. 152.

${ }^{9}$ This analysis is backed by studies of Gertler, P. / Gruber, J. (1997) and Gertler, P. (2000) in India and China, in which the poor people's ability to cope with moderate health shocks is attested to be substantially higher than their ability to cope with large health shocks.

${ }^{10}$ See DfID (1999a), p. 17.

${ }^{11}$ See World Bank (2000a), p. 86.
} 
will tremendously increase within the next years due to the growing number of millions of AIDS-infected ${ }^{1}$, given an expected growth of the pandemic of $10 \%$ each year ${ }^{2}$. AIDS is regarded as a deep developmental crisis ${ }^{3}$ and the foremost attempt in coping with it is the prevention of further illnesses. ${ }^{4}$

Prevention through information and education and the provision of contraceptives are regarded as the most important measures to this extend. The encouragement of women to use their right of sexual self-determination and to insist on safer-sex is seen as a priority ${ }^{5}$. This is all the more important in light of the fact that the proportion of HIV infected women relative to infected men has doubled from $25 \%$ to $50 \%$ since 1992 , and the number of women being infected is now growing faster than that of men. This is linked to the fact that the transmission from men to women is 2 to 4 times more effective than from women to men. ${ }^{6}$ Additionally, changes in sexual behavior need to be accomplished. ${ }^{7}$

A recent study of Riedlberger emphasizes that this needs to go beyond the explication of the dangers of AIDS, to challenging male self-perception which is defined via frequent, unprotected sex with varying partners and in which contraceptives are rather a sign of being already infected by HIV or of belonging to a risk group than of thoughtful disease prevention. ${ }^{8}$ Thus a lot of effort beyond the information of the public on the disease towards a change of attitudes needs to be accomplished.

Measures to increase the security for the poor individual through national efforts comprise in the World Bank analysis: Old age assistance, unemployment assistance, workfare programs, social funds and cash transfers. ${ }^{9}$ The support for national measures is ambiguous, with workfare programs being supported by $\mathrm{DfID}^{10}$, cash transfers and public social security favored by the $\mathrm{BMZ}^{11}$ and food

\footnotetext{
${ }^{1}$ See Gsänger (1993), p. 83.

${ }^{2}$ See Thiel (1999), p. 123. Growth is measured in number of additional infections per year divided by the number of infected at the beginning of the period.

${ }^{3}$ See BMZ (2001a), p. 25. This shows that HIV/AIDS has taken a dimension beyond affecting the individual, yet because of its connection with the general provision of health services it is covered in this analysis of low-level aspects of security provision.

${ }^{4}$ See e.g. BMZ (2001a), p. 24,25 or DfID (1999a), p. $12-14$ for this and the following argument.

${ }^{5}$ See BMZ (2001a), p. 25.

${ }^{6}$ See DfID (2000f), p. 7.

${ }^{7}$ See DfID (2000f), p. 7.

${ }^{8}$ See Riedlberger (1999) and Riedlberger (1998) on her study of male attitudes and HIV prevention in the Dominican Republic.

${ }^{9}$ See World Bank (2000a), p. 152 - 159. This analysis will be taken up in more detail in the later chapter on 'Different Accentuation', 'World Bank'.

${ }^{10}$ See DfID (1999b), p. 28.

${ }^{11}$ See BMZ (2001a), p. 26.
} 
security supported by Sida ${ }^{1}$. A general consensus on what security systems to deploy nationally is not obvious from the strategies presented.

As a general viewpoint especially in regard to workfare programs and social funds, which help finance small projects identified and implemented by poor communities ${ }^{2}$, their potential for mitigating crisis is stressed. ${ }^{3}$ If these systems are in place on a small scale before a crisis strikes a country, they can relatively easily be extended to larger scale to provide income earning opportunities for the poor and unemployed and build up the infrastructure needed for new growth. This will be substantially harder if these systems need to be built from the ground up if a crisis is already incurred ${ }^{4}$.

This leads over to the second aspect of security provision, the concern for national crisis that impacts most people adversely, with especially high impact on the poor. Here the prevention of conflict ${ }^{5}$ and crisis is the foremost goal. Mitigation - the preparedness for a crisis before it strikes - is considered as the second best option ${ }^{6}$. Both are seen as superior to simply coping with crisis without prior preparations since the costs of prevention and mitigation are considered much lower than the benefits in form of avoided or reduced coping costs. Special concerns in regard to the prevention of crisis are placed on the prevention of economic crisis, the peaceful resolution of conflicts and the reduction of vulnerability to natural disasters.

World Bank ${ }^{7}$ and $\mathrm{DfID}^{8}$ most prominently cover the negative effects of economic downturns on the poor. The negative effects of economic downturns on the poor are most prominently covered by the Macro-economic stability is seen as a key point and is to be achieved through careful management of the economic cycle through monetary, fiscal and exchange rate policy. ${ }^{9}$ Avoidance of profligated fiscal and monetary policies, overvalued exchange rates, and unsustainable current account deficits is recommended in this regard. ${ }^{10}$ Especially the pitfall of inflation ${ }^{11}$ is a major concern, since it hurts the poor disproportional in their ability use savings as risk insurance and also diverts investment and the associated job opportunities. Yet it is annotated that overadjustment in the policy response such as too restrictive monetary and fiscal policy can be self-defeating by leading to larger than expected recessions and

\footnotetext{
${ }^{1}$ See Sida (1996), p. 29, 35.

${ }^{2}$ World Bank (2000a), p. 155.

${ }^{3}$ On this issue see e.g. World Bank (2000a), p. 155, 156.

${ }^{4}$ See World Bank (2000a), p. 169.

${ }^{5}$ See Sida (2000f).

${ }^{6}$ See World Bank (2000a), p. 169.

${ }^{7}$ See e.g. World Bank (2000a), p. 165.

${ }^{8}$ See e.g. DfID (1999b), p. 2.

${ }^{9}$ See DfID (2000e), p. 9.

${ }^{10}$ See World Bank (2000a), p. 165.

${ }^{11}$ See DfID (1999b), p. 7 and also World Bank (2000a), p. 165.
} 
lower government revenues. ${ }^{1}$ Therefore able administrations are needed who can handle this difficult process responsibly. ${ }^{2}$ Institutional rules in the financial sector also play a major role in the prevention of economic crisis in a country ${ }^{3}$. For the prevention of financial crises the prudential regulation and supervision of financial intermediaries needs to be improved. This can be backed by requirements for the dissemination of information by commercial banks ${ }^{4}$ and by implementation of corporate bankruptcy reform.

Domestic efforts of economic stability cannot be separated from the international context, ${ }^{5}$ yet the country can take some unilateral actions to increase the security of its overall economic development. For example a cautious approach for capital account liberalization is recommended; ${ }^{6}$ including a concern for the right sequencing in which a well-functioning macro-economy, open and transparent policy-making and effective financial regulation precede capital account liberalization ${ }^{7}$. Controls on capital inflows are recommended by the World Bank ${ }^{8}$ to decrease the volatility of capital flows and favor a more long-term oriented investment structure, ${ }^{9}$ yet these attempts are cautioned by the U.K. government to be used only transitionary. ${ }^{10}$ Controls on capital outflows are also considered a possible short-term safeguard to limit the exposure to financial risk. Yet this can create problems in implementation, potential for evasion and restrictions to a countries ability to attract foreign capital. ${ }^{11}$ Apart from controls measures to increase liquidity are an option to cope with financial crisis. These comprise the holding of higher reserves with its associated costs, the requirement for higher liquidity requirements in the banking sector with equal costs only born by the private sector, and the establishment of contingent credit lines. $^{12}$

To decrease the vulnerability of poor people to global price fluctuations of export crops, rather than attempting the international stabilization of prices the targeted support for diversification and implemented adjustment programs in the time of crisis might prove more viable and can be implemented on national scale. ${ }^{13}$ While these particular measures receive some attention, the overall consensus for the reduction of economic insecurity is placed on measures of

\footnotetext{
${ }^{1}$ See World Bank (2000a), p. 166.

${ }^{2}$ See DfID (2000e), p. 9.

${ }^{3}$ This point is also drawn most conclusive in World Bank (2000a), p. 165.

${ }^{4}$ See UK government (2000), p. 53.

${ }^{5}$ The international dimension will be analyzed in more detail in the chapter 'International institutional framework'.

${ }^{6}$ See World Bank (2000a), p. 165.

${ }^{7}$ See UK government (2000), p. 51.

${ }^{8}$ See World Bank (2000a), p. 165.

${ }^{9}$ See also further research by De Gregorio, J. / Edwards, S. / Valdés, R. (2000) and Edwards, S. (2000).

${ }^{10}$ See UK government (2000), p. 52.

${ }^{11}$ On this and the next issue see World Bank, p. 181.

${ }^{12}$ For contingent credit lines see the chapter on 'International institutional framework'.

${ }^{13}$ See DfID (1999b), p. 20.
} 
good governance, monetary and fiscal stability, and a national policy aimed at a market economy based in a well-regulated environment. ${ }^{1}$

The peaceful resolution of conflict ${ }^{2}$ emerges as one of the major themes in the discussion of security. Arms races divert scarce resources away from the poor. Violent conflicts impede development and poverty reduction and endanger the security and well-being of the population often for long-term periods because of individual and social traumatism, mining of large agricultural areas and illegal distribution of small arms $^{3}$. Prevention and mitigation play an especially large role in this field, because returns to this activity are seen as especially large. ${ }^{4}$ "Long-term cooperation to reduce structural causes for conflict as well as the peaceful resolution of conflict has strict priority to coping with crisis and stopping violence." 5

The reduction of poverty is seen not only as a outcome of conflict prevention, but as one of the preventive measures needed reduce the potential for violent conflict, because impoverished groups of the population are more easily won to fight the current situation and are more prone to join armed groups out of economic necessity. ${ }^{6}$ Another area of intervention concerns social and ethnical fragmentation are considered as one of the major determinants for internal conflict ${ }^{7}$, with internal conflict comprising the majority of conflicts since the Second World War. ${ }^{8}$ Differences of identity are often accompanied by economic, political and social inequalities ${ }^{9}$ and discrimination ${ }^{10}$. Therefore the reduction of inequalities and associated tensions along ethnic lines are considered as of vital importance, which has to address differences in wealth, accessibility of natural resources and inclusion in the political process ${ }^{11}$. Inclusive governments that break the tension-feeding pattern of 'winner-takesall $^{12}$ can make a big contribution in this regard. The support for the right sort of civil society groups is seen as a viable way for the inclusion of previously marginalized individuals

Internal conflicts are often perpetuated by the involvement of outside nations that see the disorder near their boarders as a threat that might be

\footnotetext{
${ }^{1}$ For a deeper discussion of the role of market forces and regulation see the prior chapter on 'The economic incentive system'.

${ }^{2}$ See e.g. Sida (2000f).

${ }^{3}$ See BMZ (2001a), p. 38, 39.

${ }^{4}$ See DfID (1999b), p. 19.

${ }^{5}$ See BMZ (2001a), p. 39. (Translation by the author).

${ }^{6}$ A similar line of thought is presented in BMZ (2001a), p. 39.

${ }^{7}$ See e.g. World Bank (2000a), p. 126, 127.

${ }^{8}$ See DfID (2000e), p. 18.

${ }^{9}$ See DfID (2000e), p. 18.

${ }^{10}$ See BMZ (2001a), p. 39.

${ }^{11}$ For this and the following point see also BMZ (2001a), p. 39.

${ }^{12}$ See DfID (2000e), p. 19.
} 
exaggerated by the domestic military forces. ${ }^{1}$ Since the interests of the military and even some national governments are not necessarily the interests of the country, it is seen as most conducive for peaceful conflict prevention to establish a high degree of accountability of the armed forces and the government. This helps to determine the right budget level necessary for national security and avoids unnecessary entrance into violent conflict. Military and police forces that are representative of all ethnic and social groups are conducive to prevent the internal misuse of power.

In the case that violent crisis could not be prevented, sequencing of restoration efforts is attempted in the following steps: Restoration of security as a precondition for further efforts, quick restoration of basic civilian government functions, the demobilization of combatants into alternative occupations and reconciliation policies which bring to justice those responsible for violence complemented by indigenous capacities for forgiveness where appropriate. ${ }^{2}$ On the international level these national efforts should be backed by mechanisms that prevent the use of money from drug or diamond trade to finance violent conflict. ${ }^{3}$ Also there is an understanding that the control on the exports on weapons should be increased, with a special focus on small arms which spur internal conflict between ethnic groups. The build-up of international methods for peaceful conflict resolution is also attempted. ${ }^{4}$

The third major cause for crisis is seen in natural catastrophes. This already grave concern for some countries is estimated to rise due to the global climate change and thus will increase in importance. ${ }^{5}$ The rise of the Yangtze river in China which displaced millions of people, the floods in Mozambique and the disastrous effects of Hurricane Mitch in Latin America with more than 11000 deaths mark some of the recent natural catastrophes, which occur at a rate of 50 to 100 a year ${ }^{6}$, claim estimated 50000 lives and cause damage beyond $\$ 60$ billion a year ${ }^{7}$. In order to reduce the impact of natural disaster, the support for national committees for catastrophe prevention and the establishment of early warning systems for natural disasters ${ }^{8}$ is considered.

Specific preventive measures on the national level comprise neighborhood improvement programs that implement low-cost improvements to housing to increase their resistance against natural disaster or that sponsor drainage works

\footnotetext{
${ }^{1}$ For this issue see most prominently DfID (2000e), p. 18, 19.

${ }^{2}$ See DfID (2000e), p. 19.

${ }^{3}$ See UK government $(2000)$, p. 30, 31 .

${ }^{4}$ For these issues see e.g. BMZ (2001a), p. $40-42$.

${ }^{5}$ See World Bank (2000a), p. 170. The global dimensions of natural crisis and its methods for prevention will be covered in more detail under 'International institutional framework'.

${ }^{6}$ See Gilbert, R. / Kreimer, A. (1999), p. 5.

${ }^{7}$ See International Federation of Red Cross and Red Crescent Societies (1999), tables 5 and 12.

${ }^{8}$ See BMZ (2001a), p. 30, 31.
} 
that reduce risks of flooding. ${ }^{1}$ In especially risky areas resettlements are also considered. The establishment of food banks is another mitigation measure to stabilize food prices in the event of crisis. For coping with natural disaster, emphasis is placed on the provision of food, water, shelter and medicine delivered on the base of need. Even though most people in the stricken area are poor, the targeting of aid to those most in need still poses a problem that requires further investigation. ${ }^{2}$ Rebuilding of schools is seen as another priority. Cash transfers to poor families might also prove necessary. For the reconstruction of infrastructure special emphasis is laid on a long-term vision that looks beyond the restoration to the enhancement in a way that reduces or eliminates the vulnerability to future crisis. ${ }^{3}$

Overall, the need to provide security is well established within the new strategies. Most strategies are concerned primarily with the prevention of disaster and national crisis. While crisis are eminently deterrent to development, there is also a general understanding that security also on a smaller scale - on the individual or household level - is of importance. To this extend micro-finance systems play the foremost role, while attempts to spread the benefits of the formal state security systems to the informal sector build the second major line of thought.

This chapter on the domestic framework for poverty reduction has emphasized the main trains of thought in regard to the three areas of the economic framework, the necessary political conditions and the provision of security for poor people. Within each category the list of necessary measures is detailed, and the feasibility to tackle all these questions at the same time remains an issue.

\subsubsection{Comprehensiveness or Excessiveness?}

The new strategies on poverty reduction integrate many demands of past strategies into one framework of poverty reduction, in which the failures of the past serve as a basis for a new orientation. ${ }^{4}$ This has led to the current, comprehensive framework, which describes a number of relevant concerns in relation to economic, political and security-oriented conditions. These range from far-reaching concerns for growth and democracy to immediate concerns for sanitation and micro-finance systems. This approach has the advantage that it is very comprehensive in its analysis. In its comprehensiveness it naturally has

\footnotetext{
${ }^{1}$ For the preventive measures and the coping strategies see the comprehensive analysis in World Bank (2000a), p. 172 - 176.

${ }^{2}$ See Sida (1996), p. 23

${ }^{3}$ See World Bank (2000a), p. 175.

${ }^{4}$ See the chapter on 'The evolution of a consensus'.
} 
the disadvantage to be very vague about the specific aspects that are to be applied in specific situations.

The absence of clear priorities among the proposed measures has sometimes the effect that the strategies seem unfocused, attempting an enumeration of possibilities rather than a guide to concrete action. The comprehensiveness confronts the national governments in developing countries with a wide array of choices for action, yet it might overburden policy makers in the choice of the most conducive starting point for specific action given the limited financial and administrative resources in many developing countries. The breadth of the new agenda for poverty reduction and the associated range of choices for possible action provide the opportunity to fine-tune national attempts to a high degree, yet will likely also increase the need for technical assistance and consulting services that will enable countries to make the right choices. Especially the potential pitfall of spreading the domestic resources in financial and administrative terms too thin over too large a portfolio of measures needs to be avoided.

To put the new strategies into actions will require a potentially difficult search for a manageable number of specific actions with the highest impact in terms of poverty reduction. The quality of this search and the quality of the implementation of the chosen measures in the domestic context will likely be more influential on the impact of the new strategic proposals than the simple explication of the breadth of the options.

This chapter rounds up the analysis of the domestic framework necessary for poverty reduction, which focussed next aspects of providing security and on an economic and political framework conducive to this end. While this analysis has cast light on the main topics on domestic actions in the development agenda, it has to a large extent avoided the international sphere in which development takes place. This perspective is at the heart of the following chapter, which considers the international institutional framework first, and in a second step looks at the actions that the international donor community should take to make their aid delivery more effective.

\subsection{International Regimes}

\subsubsection{International Institutional Framework}

The international dimension of poverty reduction is viewed in current strategies to go beyond the provision of funds for projects of development cooperation to encompass the entire international agenda of bilateral and multilateral treaties and institutions. These constitute important frameworks in which the national development takes place by shaping the rules of the game for international interaction, with their influence increasing through the process of rapid 
globalization. ${ }^{1}$ Of foremost importance in the context of development are the international rules in the areas of trade, finance and the environment, which will be analyzed in turn.

\subsubsection{Trade}

International trade is considered a powerful engine for growth and poverty reduction in developing countries ${ }^{2}$ and has been conducive for those countries that are already strongly integrated into the international markets ${ }^{3}$. The primary institution that governs international trade issues is the World Trade Organization (WTO), which developed out of the General Agreement on Tariffs and Trade (GATT). Its member base comprises 140 nations $^{4}$, of whom the majority are developing countries. ${ }^{5}$ While the WTO system in principle receives support in the analyzed strategies, reforms of the system to take the conditions, problems and priorities of developing countries stronger into account are voiced. ${ }^{6}$

One of the central concerns of the current trading regime are the barriers that exist for the major exports of developing countries in terms of agricultural goods, labor intensive manufactures like textiles and clothing, and services. ${ }^{7}$ These barriers consist of tariffs imposed by industrialized countries that are on average higher for developing countries than for other developed nations ${ }^{8}$ and of subsidies for developed nations' products. Especially in the agricultural sector subsidies for domestic producers by industrialized countries distort world market prices, reduce the ability of developing countries to capitalize on their natural competitive advantage and discourage investment in this sector ${ }^{9}$. The estimated costs of these barriers for developing countries in the agricultural sector alone are estimated at nearly $\$ 20$ billion per year or $40 \%$ of the total yearly ODA flows. ${ }^{10}$ The potential gains to this group of countries from general tariff cuts of $50 \%$ are estimated at $\$ 150$ billion per year ${ }^{11}$ or three times the annual ODA contributions.

To foster development, the international elimination of tariffs and quotas for Least Developed Countries (LDCs) is demanded and a reduction or

\footnotetext{
${ }^{1}$ See Sida (1996), p. 37.

${ }^{2}$ See World Bank (2000a), p. 179.

${ }^{3}$ Ades, A. and Glaeser, E. (1999) show that while rich countries grew faster on average than poor countries, those poor countries strongly integrated into the global economy have grown at a rate equal or grater than the developed countries.

${ }^{4}$ The EU as an independent member is included in this number.

${ }^{5}$ See UK government (2000), p. 69.

${ }^{6}$ See e.g. BMZ (2001a), p. 18 and UK government (2000), p. 69.

${ }^{7}$ See DfID (2000), p. 69 and World Bank (2000a), p. 180.

${ }^{8}$ See World Bank (2000a), p. 180.

${ }^{9}$ See UK government (2000), p. 67.

${ }^{10}$ The costs of $\$ 19,8$ billion in 1998 were estimated by Anderson, K. / Hoekman, B. / Strutt, A. (1999), referenced in World Bank (2000a), p. 180.

${ }^{11}$ See Nagarajan, N. (1999).
} 
elimination of import tariffs for the most important processed goods from developed countries is proposed. The current systems of tariffs that are progressively increasing with the level of processing are deterrent to the industrial efforts in developing countries. ${ }^{1}$ The current reliance of developing nations on unprocessed goods due partly to the tariff structure of industrialized nations exposes developing countries to the especially high volatility of worldmarket prices in the unprocessed goods markets. ${ }^{2}$ The phase-out of subsidies by developed countries is also of major concern - especially in the agricultural sector - as it has often led to unsustainable domestic production. ${ }^{3}$ Moreover, trade protective measures such as anti-dumping rules should receive new investigation and should be built solemnly on factual evidence. ${ }^{4}$ The bilateral strategies view the EU in a precursor role in this regard and express their willingness to influence the EU policies towards stronger focus in poverty reduction. ${ }^{5}$

To tackle these issues a new trade round - a "development round" - is proposed, in which the WTO system is to be made more transparent and in which the interests of the developing countries are to be given more weight. ${ }^{7}$ Special emphasis is placed on enabling countries to participate to the fullest extend in the trading system. A strong concern rests currently on the ability of poor countries to actually exert their influence effectively in the WTO negotiations. ${ }^{8}$ One third of the developing countries lack offices and permanent representation in Geneva despite the roughly 45 meetings of the WTO each week. ${ }^{9}$ Therefore, support for the sophisticated interaction of representatives of developing countries is attempted e.g. through the establishments of an Advisory Center on WTO Law and through technical support for national governments. ${ }^{10}$

This is linked to the attempts to increase the practical impact of trade liberalization through strategies adapted to the circumstances of the individual developing country and through reduction of structural barriers. To accommodate developing countries better in their particular economic circumstances a more adaptive set of country categories is envisioned for further negotiations. ${ }^{11}$ More flexibility in the deadlines for the implementation of reforms and technical support during for the implementation process shall contribute to the more individualistic concern for country specific situations. To

\footnotetext{
${ }^{1}$ See World Bank (2000a), p. 180.

${ }^{2}$ See BMZ (2001a), p. 18, 19.

${ }^{3}$ See UK government (2000), p. 70.

${ }^{4}$ See UK government (2000), p. 70.

${ }^{5}$ See BMZ (2001a), p. 18, 19, UK government (2000), p. 71, 72 and Sida (2000g). Even though Sida goals in the EU engagement remains rather vague.

${ }^{6}$ See BMZ (2001A), p. 18.

${ }^{7}$ See UK government (2000), p. 70.

${ }^{8}$ See BMZ (2001A), p. 19.

${ }^{9}$ See World Bank (2000a), p. 180.

${ }^{10}$ See e.g. UK government (2000), p. 71 or World Bank (2000a), p. 180.

${ }^{11}$ For this and the next point see UK government (2000), p. 71.
} 
increase the benefits of trade liberalization through the WTO round for developing countries, a strategy for improving trading capacity is pursued with a focus on areas of communication, customs simplification and export encouragement. ${ }^{1}$ The realization that halving transport costs can almost double trade volume has also led to an increased focus transportation, which is strongly linked to the establishment of access to markets as discussed in a prior chapter ${ }^{2}$. Thus, adaptation to individual country's and groups of countries' problems and the assistance with transferring negotiation results into actual outcomes is a high concern on the international agenda.

Special sub-themes of the WTO are the intellectual property rights regimes which are governed by the Agreement on Trade-Related Aspects of Intellectual Property Rights (TRIPS) negotiated in the Uruguay Round of trade negotiations in 1986 to 1994. Intellectual property rights, which grant exclusive rights of ownership to creators of knowledge for a specified period of time, provide incentives for the generation of new knowledge. ${ }^{3}$ Developing countries have an important incentive in providing intellectual property rights protection as a way of encouraging more investment, research and innovation. ${ }^{4}$ Yet intellectual property rights bear the disadvantage of excluding some developing countries form helpful international goods because they cannot afford the prices charged by the patent holders. The dispute over necessary incentives for research and exclusion of the poor has recently reached its climax in the dispute between the South African government and the pharmaceutical industry over the country's ability to import or produce necessary AIDS medication from unauthorized cheaper sources. ${ }^{5}$ Both the British and the German strategic documents explicitly acknowledge the TRIPS clause on 'compulsory licensing' in exceptional circumstances - as has been the argument of the South African government - yet prefer a system of preferential prices ${ }^{6}$ as has been the outcome of the South Africa case where price reductions of $90 \%$ have been proposed. Given the inherent conflict between the interest of the individual nation and the pharmaceutical industry, conflicts of this sort will be difficult to avoid in the future ${ }^{8}$.

\footnotetext{
${ }^{1}$ See BMZ (2001a), p. 19.

${ }^{2}$ See UK government (2000), p. 73.

${ }^{3}$ See World Bank (2000a), p. 184.

${ }^{4}$ See UK government (2000), p. 45.

${ }^{5}$ South Africa has the highest population of people affected with HIV: 4.7 million. For background information on the dispute see Polke-Majewski, K. (2001).

${ }^{6}$ See BMZ (2001a), p. 26 and UK government (2000), p. 44, 45. The problem with this measure arises as the pharmaceutical industry has to fear re-imports of pharmaceuticals to industrialized nations that could force them to lower prices even there.

${ }^{7}$ See Polke-Majewski (2001).

${ }^{8}$ The national incentives to pressure the pharmaceutical industry to more preferential terms is visible also in industrialized countries, the latest case being the dispute between the U.S. government and the Bayer AG over the price of the only available product to cure anthrax.
} 
To reduce prices for patent-protected goods the British concept proposes to extend exclusive rights to patent holders for a longer period of time to establish a more affordable price during this time period. ${ }^{1}$ This proposal should be considered with caution. Without heavy regulation the patent holder will simply extend his monopoly price policy over an extended period of time since he does not match his price to his costs but to what the market will bear. Thus, a longer time frame for patents will not lead to lower market prices. Therefore such a policy seems questionable in its impact.

Three developments have made a renegotiation of intellectual property rights more urgent in recent years. Private companies alone increasingly conduct research, which excludes the non-paying public from its use. Industrial countries account for the vast majority of patents world wide, thus capitalizing on their proceeds and potentially excluding the developing countries from gaining prosperity. Moreover, there is a trend in genetic science to patent DNA sequences, which might extend the patent holder's rights to prevent farmers from reusing seeds and developing countries from pursuing adaptations to their needs. $^{2}$

Changes proposed to the international property rights regime as a consequences of these trends and to safeguard developing countries interests are most conclusively summarized in the WDR: "Recognizing the rights of farmers cultivating traditional varieties. Prohibiting the patenting of life forms or biological processes. Reconciling World Trade Organization (WTO) provisions on intellectual property rights with the International Convention on Biodiversity and the International Undertaking on Plant Genetic Resources. Ensuring access to essential medicines at reasonable cost." ${ }^{3}$ This includes the extension of rights to developing countries for their indigenous knowledge and the genetic resources of their species. The quote entails the only slightly less vigorous proposals of the British and German strategies. ${ }^{4}$ The question will remain how these legitimate demands are to be integrated into the intellectual property rights regime without deterring future research.

Another concern that has been linked to trade rules is the provision of basic rights at work. The enforcement of the core labor standards (CLS), already discussed in the chapter on 'Human Rights and Equality', is sometimes viewed in connection with trade sanctions in cases where they are not adhered to. This is

\footnotetext{
Despite its obvious affluence and its ability to pay the price charged previous to the attacks via anthrax-infected mail bombs, the U.S. government considered breaking the intellectual property right if the price were not reduced, as the Bayer AG agreed to finally in the course of a negotiation.

${ }^{1}$ See UK government (2000), p. 44.

${ }^{2}$ For an expansion on these three trends see World Bank (2000a), p. 184, 185.

${ }^{3}$ See World Bank (2000a), p. 185.

${ }^{4}$ See BMZ (2001a), p. 26, 30 and UK government (2000), p. $44-46$. The Swedish documents analyzed for this thesis do not cover this point.
} 
refuted by developing countries that fear protectionist influences. ${ }^{1}$ The analyzed strategies do not promote trade sanctions as a method for enforcement. ${ }^{2}$ Especially the World Bank rejects this practice as unproductive to achieve the desired outcome and detrimental to development. ${ }^{3}$ Rather than protective measures, a broader opening of the markets of industrialized nations in a new trade round is promoted to deter the reservations of developing nations against the $\mathrm{CLS}^{4}$; complemented by technical assistance, capacity building and other initiatives such as social dialogues with all parties concerned ${ }^{5}$.

Next to these supportive measures private initiatives for social (and ecological) labels are championed. ${ }^{6}$ On the one hand these raise the burden for potential exporters who struggle with complying with a proliferation of rules in order to obtain a label for their products. ${ }^{7}$ On the other hand they give the consumer the power to choose those products that serve his interests and encourage the acceptance of minimum labor and environmental standards not through trade sanctions, which due to their large scale approach have a high chance of penalizing the innocent, but through economic incentives of higher earning potentials. Still, national support for core labor standards in developing countries has to be further developed as well, because these incentives only extend to export industries. Incentives through labels thus neglect the large informal sector in developing countries that by large does not work for the export industry.

\subsubsection{Finance}

The international framework for financial flows has received special attention in recent years due to the financial and banking crisis in Asia, Russia and Latin America in 1997 to 1999 . These events have spurred the realization that greater stability of the international financial system is an important prerequisite for long-term worldwide growth and poverty reduction. ${ }^{8}$

The predominant measure for international financial stability is seen in the national efforts of the individual nations in implementing sound macroeconomic policies, adequate prudential regulations and supervision of domestic

\footnotetext{
${ }^{1}$ See World Bank (2000a), p. 74.

${ }^{2}$ While this consensus is endorsed in the strategies, comments for positive incentives in the EU Generalised System of Preferences to link enhanced market access terms to adherence to ILO standards voiced in UK government (1997), p. 65, aim in a different direction. While here the term 'sanctions' is avoided through the positive expression 'incentives', the actual outcome could be the same. This view is not observable in the other strategies.

${ }^{3}$ See World Bank (2000a), p. 74.

${ }^{4}$ See BMZ (2001a), p. 33. Yet the German position considers integrating core labor standards in the conditions for projects of public development cooperation.

${ }^{5}$ See World Bank (2000a), p. 74 and BMZ (2001a), p. 32, 33.

${ }^{6}$ See BMZ (2001a), p. 19.

${ }^{7}$ See DfID (2000), p. 74.

${ }^{8}$ See e.g. BMZ (2001e), p. 21.
} 
financial institutions. ${ }^{1}$ The national efforts are underlined on the international level by attempts to establish and enforce standards on data dissemination and financial practices. ${ }^{2}$ These are seen important to insure that financial markets and the public have timely and reliable data for making decisions and that financial institutions run effectively. ${ }^{3}$

To this extend existing institutions like the IMF and other standard setting bodies ${ }^{4}$ are active as well as newly established bodies like the Financial Stability Forum (FSF), which has the task to assess vulnerabilities affecting the international financial system; to identify and oversee action needed to address these vulnerabilities; and to improve coordination and information exchange among the various authorities responsible for financial stability ${ }^{5}$. Its recommendation are explicitly welcomed in the strategies for poverty reduction. ${ }^{6}$ They focus on measures to increase the stability and functioning of financial markets comprising directives for risk management at the national, public sector, banking sector and non-bank sector level based on prudent behavior and on short-term liability assessment as well as on tighter regulations of institutions that provide credit to highly leveraged institutions. ${ }^{7}$ These codes of conduct for data dissemination and financial practices are to be backed on the international scale by surveillance efforts that ensure their application. In this regard an enhanced IMF surveillance process could play a central role. ${ }^{8}$

These measures should be supplemented by efforts to set up early warning systems that could alert the international community to danger and elicit timely responses to prevent or mitigate approaching crisis. ${ }^{9}$ So far the progress on this issue has been rather marginal. ${ }^{10}$ Further improvements are also demanded in the approaches to crisis resolution. ${ }^{11}$ Contingent credit lines are one approach on international scale to enhance the liquidity of a country endangered by financial crisis. ${ }^{12}$ Such overdraft facilities are already available through private banks or

\footnotetext{
${ }^{1}$ See e.g. World Bank (2000a), p. 180, 181. On this see also the chapter on 'Measures of state security provision'.

${ }^{2}$ See World Bank (2000a), p. 181.

${ }^{3}$ See World Bank (2000a), p. 181.

${ }^{4}$ For a very comprehensive list of standard setting bodies in the financial area see FSF (2000a).

${ }^{5}$ See FSF (1999). Another influential organization founded in 1999 is the G-20 group representing a new international forum of finance ministers and central bank governors representing 19 countries, the European Union and the Bretton Woods Institutions. See G-20 (2000).

${ }^{6}$ See BMZ (2001a), p. 22 and UK government (2000), p. 54.

${ }^{7}$ For further details on these complex issues whose breadth extend beyond the scope of this analysis, see FSF (2000b) and FSF (2000c).

${ }^{8}$ See UK government (2000), p. 53.

${ }^{9}$ See World Bank, p. 181.

${ }^{10}$ See World Bank, p. 181.

${ }^{11}$ See UK government (2000), p. 54.

${ }^{12}$ See UK government (2000), p. 54 and World Bank (2000a), p. 181.
} 
the IMF. In the German view this could be backed by special aid through the World Bank and the IMF for countries whose poverty reduction strategies are threatened by external shocks such as oil price increases. ${ }^{1}$ Yet a guarantee for comprehensive aid packages in cases of financial crisis through the IMF are rejected in the strategy. ${ }^{2}$ Rather, a stronger inclusion of private investors in the resolution of financial conflicts is demanded. To this extend collective action bond clauses are favored, which enforce collective bargaining and, thus, limit the ability of a minority of bondholders of blocking renegotiations of bond repayments. ${ }^{3}$ Yet apart from this measure, efforts to design clear guidelines for private sector involvement in crisis prevention and resolution have been rather unproductive ${ }^{4}$ and need to be taken up vigorously.

Overall, reforms of the financial system to promote stability and ensure the availability of liquidity for countries facing severe adverse shocks ${ }^{5}$ are a high priority in the new strategies, yet concrete measures are still vague.

Next to the importance placed on international financial stability several disjoint themes emerge that are common at least to the German and British position ${ }^{6}$. These include the demand for an international surveillance on new debt for LDCs, so as to insure that their debt level remains sustainable. Furthermore, new credits from OECD countries for Heavily Indebted Poor Countries (HIPCs) shall only be provided for productive purposes. ${ }^{7}$ This precludes especially credits for arms. ${ }^{8}$ The importance of export credit guarantees is stressed and the connection of their granting to the goals of poverty reduction and developmental aspects is demanded. The introduction of private sector capital into the financing of international development projects is considered for those countries where this can be applied.

\footnotetext{
${ }^{1}$ See BMZ (2001a), p. 23.

${ }^{2}$ See BMZ (2001a), p. 21.

${ }^{3}$ See BMZ (2001a), p. 21 and UK government, p. 54.

${ }^{4}$ See World Bank (2000a), p. 181.

${ }^{5}$ See World Bank (2000a), p. 181.

${ }^{6}$ See BMZ (2001a), p. 21 - 23 and UK government (2000), p. 56, 60, 61.

${ }^{7}$ These are countries that are eligible under the enhanced debt reduction initiative (HIPC II) and comprise LDCs with high levels of debt. For more details see the chapter on 'Initiated Reforms'.

${ }^{8}$ This attempt is faced with the problem of the fungibility of funds. It is easily to conceive situations where a country would like to finance unproductive investments and does so from its national budget, while receiving financing for other productive investments that would normally have required the domestic funds now used for unproductive investments. Thus, countries can internally shift their budget in a way that outside financing is only concerned with productive investment while domestic funds are used for to a greater extend for unproductive investment, and in sum the result is similar to a financing of unproductive investment in the first place. Control mechanism to avoid this problem need to be established for any attempt to prevent international financing for unproductive investment to show impact.
} 
The attraction of private capital is overall a major theme, since foreign direct investment contributed three times the level of development aid in 1999 and grew fourfold in the seven prior years while ODA remained nearly constant ${ }^{1}$, and can thus be a major determinate for growth. To spur this investment, the inclusion of international direct investment into multilateral agreements in order to ensure transparency, investor protection, e.g. against expropriation without compensation, and equal rights for national and international investors is attempted. This is supposed to increase investor confidence even in those countries that are currently neglected by FDI. A possible place for such negotiations would be the next WTO trade round.

An innovative attempt in the new strategies is the British government's intention to require pension funds to state the extent to which social, environmental and ethical policies are pursued in order to provide small private investor with a choice to incorporate these concerns into his investment decisions. Yet overall the strategies are rather conservative and vague on the specific attempts the international forums are to play in the provision of security and heightened investment in developing countries. The strongest reliance is given to measures on the national level where measures for the better supervision of the financial sector and a stronger concern for the sustainability and composition of national debt are straightforward. In contrast to this, international action for a greater international stability struggles with an "apparent lack of urgency in the aftermath of the Asian recovery [which] could lead to inaction" - despite real possibilities of future crises ${ }^{3}$.

\subsubsection{Environment}

It is accepted within the strategies for poverty reduction that an intact ecological environment and poverty reduction are strongly intertwined. ${ }^{4}$ In an attempt to address this, it has been agreed upon in the IDTs ${ }^{5}$ that a national strategy for sustainable development (NSSD) should be established in all developing countries by $2005 .{ }^{6}$ This attempt is supported in the new strategies by promises

\footnotetext{
${ }^{1}$ ODA levels range between $\$ 50$ and $\$ 55$ billion (see BMZ (2001a), p. 20), while foreign direct investment in developing countries grew from $\$ 36$ billion in 1992 to $\$ 155$ billion in 1999 (see UK government (2000), p. 48).

${ }^{2}$ World Bank (2000a), p. 181.

${ }^{3}$ See World Bank (2000a), p. 181.

${ }^{4}$ See BMZ (2001a), p. 27. For domestic protection of the environment see the chapter 'Poor peoples assets'. For a broader discussion of environmental concerns in poverty reduction strategies see the chapter on 'The role of poverty reduction: Poverty reduction vs. other developmental goals'.

${ }^{5}$ For details see the chapter on 'International Development Targets'.

${ }^{6}$ See DfID $(2000 \mathrm{c}), \mathrm{p}$. i. The time frame for the NSSD proposes the establishment by 2002 , being in the process of implementation by 2005 and leading to a reversal of the reduction of natural resources by 2015 .
} 
of assistance for capacity building in the area of the environment ${ }^{1}$ through effective partnerships between north and south. ${ }^{2}$ A blueprint for the NSSD and its implementation is deliberately avoided in order to be able to accommodate local priorities ${ }^{3}$ that are to be established on a participatory basis. ${ }^{4}$ This reliance on NSSDs shows that emphasis is placed on national strategies; supported by international efforts.

Yet the realization that environmental problems have large global components and require global agreements for their solution has been realized and is most prominent in the concerns on climate change. ${ }^{5}$ Industrialized nations, which contribute most to environmental degradation by their population's consumption patterns $^{6}$ and their waste production ${ }^{7}$, have taken a lead in international negotiations on environmental issues. To reach agreement with the developing countries, most international treaties rely on financial and technical assistance to help developing nations to comply with the protocol. The arising financial commitments are supposed to be additional to ODA.

One of the first outcomes is the Agenda 21, which was adopted at the Earth Summit in Rio de Janeiro in 1992 by 178 governments. ${ }^{8}$ This program was conceived to integrate development and environmental concerns and covered a wide variety of areas such as protecting of the atmosphere, combating desertification, preserving biological diversity, protecting the quality and supply of fresh water and managing toxic waste among others. ${ }^{9}$ Its purpose is to commit all States to engage in a continuous and constructive dialogue on environmental issues and make these a priority on the international agenda. ${ }^{10} \mathrm{~A}$ main point was the incorporation of the participation of all concerned citizens and the associated flexibility of the program. ${ }^{11}$

This initiative has led to further international conventions that resulted in the adoption of a number of multilateral environmental agreements (MEAs) ${ }^{12}$ on the issues of biological diversity, biosafety, climate change, desertification, hazardous chemicals in international trade and organic pollutants. ${ }^{13}$ To help developing countries tackle these issues despite their financial limitation, the Global Environment Facility (GEF) was established in 1991 by 165 member

\footnotetext{
${ }^{1}$ See Sida (1996), p. 30.

${ }^{2}$ See DfID (2000c), p. 29.

${ }^{3}$ See DfID (2000c), p. 29.

${ }^{4}$ See BMZ (2001a), p. 29.

${ }^{5}$ See DfID (2000c), p. 11, 12.

${ }^{6}$ See UK government (2000), p. 78.

${ }^{7}$ See BMZ (2001A), p. 28.

${ }^{8}$ For this issue see DfID (2000c), p. 41.

${ }^{9}$ See UNEP (2000).

${ }^{10}$ See UNEP (2000).

${ }^{11}$ See DfID (2000c), p. 41.

${ }^{12}$ See DfID (2000c), p. 6.

${ }^{13}$ See DfID (2000c), Annex 1.
} 
countries with the goal to finance or co-finance projects that serve environmental purposes ${ }^{1}$ and to assist developing countries in meeting the additional costs of addressing global environmental objectives. ${ }^{2}$ The poverty reduction strategies analyzed in this context places special emphasis on biological diversity ${ }^{3}$, desertification ${ }^{4}$ and climate change and the depletion of the ozone layer ${ }^{5}$.

The preservation of Biodiversity was internationally agreed upon in the Agenda 21 and became legally binding for the signatories in the Convention on Biodiversity (CBD), which entered into force in 1994. Its main objectives are the conservation of biological diversity, the sustainable use of its components and the fair and equitable sharing of the benefits arising out of the utilization of genetic resources. ${ }^{6}$ The convention is concerned with access and use of genetic resources and indigenous knowledge, with technology transfer and with biosafety ${ }^{7}$. The convention takes a broad-based approach that incorporates the conservation and also the utilization of biodiversity to secure nutrition, health and other needs of the world's growing population. Its measures are based on national strategies and plans for the conservation and sustainable use of biological diversity and their integration into relevant policies. ${ }^{8}$

Desertification has been spotted as one of the major problems facing the African continent, with land degradation having affected $65 \%$ of the soil of this continent in the last 50 years and its continuation is estimated to reduce crop yields by halve during the next 40 years. ${ }^{9}$ The Convention to Combat Desertification (CCD) has been internationally adopted in 1996 to combat desertification and mitigate the effects of drought particularly in Africa. ${ }^{10}$ Developed countries are obliged in this agreement to provide financial resources and other forms of support to help developing countries in their implementation of long-term strategies, and to facilitate access to appropriate technology, knowhow and private funding. These national strategies should focus on improved productivity of the land and the rehabilitation, conservation and sustainable management of land and water resources. This should also address the

\footnotetext{
${ }^{1}$ See World Bank (2000a), p. 187.

${ }^{2}$ This program receives strong support in UK government (2000), p. 83 and BMZ (2001a), p. 28.

${ }^{3}$ See BMZ (2001a), p. 29, UK government (2000), p. 8, Sida (1996), p. 30 and World Bank (2000a), p. 187.

${ }^{4}$ See BMZ (2001a), p. 28, 29 and DfID (2000c), p. 8.

${ }^{5}$ See BMZ (2001a), p. 28, UK government (2000), p. 79, DfID (2000c), p. 8 and World Bank (2000a), p. 187.

${ }^{6}$ See most prominently DfID (2000c), Annex 3. The point of equitable sharing of proceeds is also taken up strongly in BMZ (2001a), p. 30.

${ }^{7}$ Biosafety with special focus on living modified organisms is covered in more detail in the Protocol on Biosafety to the CBD, which was amended and agreed to in 2000 in Montreal.

${ }^{8}$ See DfID (2000c), Annex 3.

${ }^{9}$ See DfID (2000c), p. 10.

${ }^{10}$ See most prominently DfID (2000c), p. 45.
} 
underlying causes of desertification with special attention to socio-economic factors. ${ }^{1}$

Most prominently in the debate on global public goods ${ }^{2}$ has been the concern for the preservation of the ozone layer and the prevention of global climate change. Progress in the preservation of the ozone layer, which is expected to have largely recovered within the next 50 years $^{3}$, is mainly contributed to the Montreal Protocol on Substances that Deplete the Ozone Layer. This protocol, effectively in action since 1987, governs the elimination or reduction of the use of chemicals that damage the ozone layer in order to prevent potential consequences of its further reduction. ${ }^{4}$ While developed nations already have to avoid the use of these chemicals, the protocol takes special account for the situation in developing countries, for whom the deadlines have been extended ${ }^{5}$ and which are to receive financial and technological support to facilitate the transition. A multilateral fund was established to accommodate the agreed incremental costs to developing countries associated with this protocol.

In contrast to the successes regarding the ozone layer, progress on preventing global climate change by reducing international $\mathrm{CO}^{2}$ emissions has not yet been reached, with global emissions in 1996 reaching 23,900 tons or about four times the 1950 total. ${ }^{6}$ The effects of a further continuation of this trend can be devastating especially for developing countries, with the overall impact of a doubling of carbon dioxide in the atmosphere estimated to reduce the GDP of developing countries by $2-9 \%$ compared with a still high $1-1.5 \%$ for developed nations. ${ }^{7}$ First attempts to address this issue during the 1992 Earth Summit in Rio led to the UN Framework Convention on Climate Change (FCCC) which attempts to stabilize greenhouse gas (GHG) concentrations in the atmosphere at a level that will prevent dangerous anthropogenic interference with the climate system. ${ }^{8}$ The time frame of action was conceived to allow ecosystems to adapt naturally to climate change without threatening food production and to enable economic development to proceed in a sustainable manner.

The realization that the herein proposed actions were insufficient to avoid harmful climate change led to the negotiation of the Kyoto Protocol in 1997, which aims to reduce GHG emissions by an average of $5.2 \%$ in industrialized and transitional countries compared to 1990 values during the period 2008-

\footnotetext{
${ }^{1}$ See DfID (2000c), p. 45.

${ }^{2}$ See UK government (2000), p. 77.

${ }^{3}$ See DfID (2000c), p. 6.

${ }^{4}$ See DfID (2000c), p. 44 for reference on this section.

${ }^{5}$ Phase out of CFCs and halons: 2010, freezing of the use of methyl bromide: 2002, freezing of use of HCFCs: 2016 and its phase out in 2040.

${ }^{6}$ See DfID (2000c), p. 6.

${ }^{7}$ Estimates by Pearce, D. et al. (1996) as cited in DfID (2000c), p. 12.

${ }^{8}$ For reference on the FCCC see DfID $(2000 \mathrm{c})$, p. 44.
} 
2012. ${ }^{1}$ Due to the already incurred increase in $\mathrm{CO}^{2}$ emissions since 1990 and the expected increases in absence of the protocol up to 2008, extensive efforts to reach these targets will be necessary by those countries governed by the treatise. Additional measures are included to ensure that countries not restricted by the treaty increase their emissions as slow as possible. ${ }^{2}$ All parties are obliged to prepare national reports which detail the sources and sinks of GHG emissions not controlled by the Montreal Protocol. ${ }^{3}$

While developing countries do not have an obligation to decrease GHG emissions, they will be affected by this protocol via the Clean Development Mechanism (CDM). This mechanism allows the obtainment of Certified Emissions Reduction (CER) from projects in developing countries if the reduction of GHG emissions surpasses the level that would have been realized under 'normal' circumstances without foreign involvement ${ }^{4}$. The CERs will count towards the achievement of the emission target in the country obtaining these. While the percentage of reductions of GHG which have to be conducted within the emitting country's own boarders is still of debate ${ }^{5}$, there seems to be large scope for Joint Implementation practices ${ }^{6}$ and especially for the CDM. These are estimated to have a cost ratio of $1: 10$ between developing and industrialized countries, which makes the CDM attractive ${ }^{7}$. CDM-Projects have to contribute to sustainable development and an additional fee has to be submitted to a fund that uses these resources for measures to facilitate the adjustment of countries that are especially prone to the risk of climate change. ${ }^{8}$ CER for CDM-projects can be obtained as of 2000 and be used to account for reductions of the national emissions quota as of $2008 .^{9}$ International emission

\footnotetext{
${ }^{1}$ See DfID (2000c), p. 44. The further discussion is based strongly on the comprehensive work in Gamperl et al. (2000). A detailed list for further references can be found in Intergovernmental Panel on Climate Change (2001).

${ }^{2}$ See Gamperl, J. / Seifried, R. / Strangmann, U. (2001), p. 3.

${ }^{3}$ See DfID (2000c), p. 44.

${ }^{4}$ The base-line for this argument is hard to determine, which is one of the practical problems this mechanism is faced with. See Gamperl, J. / Seifried, R. / Strangmann, U. (2001), p. 10.

${ }^{5}$ See Gamperl, J. / Seifried, R. / Strangmann, U. (2001), p. 8, 9. Germany for example demands a minimum percentage of emission reduction within the national borders of $50 \%$, the EU proposes free emission trading within EU boarders and the US does not want any reductions on the scope of CDM. Positions as of 2000.

${ }^{6}$ Joint Implementation refers to the process of obtaining emission reduction certificates for a country or company A that conducts emission reduction in a country B that also faces a special target for emission reduction. In contrast: $\mathrm{CDM}$ refers to obtaining emission reduction certificates for reductions in a developing country $\mathrm{C}$ that does not face its own target in GHG emissions. All reductions have to be measured as additionally to any improvements which would have been made under normal circumstance, the so-called base-line. See Gamperl, J. I Seifried, R. / Strangmann, U. (2001), p. 5.

${ }^{7}$ See Gamperl, J. / Seifried, R. / Strangmann, U. (2001), p. 9. Based on expert opinion of Dr. Michaelowa (Hamburg Global Economic Archive).

${ }^{8}$ See Gamperl, J. / Seifried, R. / Strangmann, U. (2001), p. 5.

${ }^{9}$ See Gamperl, J. / Seifried, R. / Strangmann, U. (2001), p. 5. A first start in this direction is the establishment of the Prototype Carbon Fund of the World Bank (see Gamperl (2000), p.
} 
trading ${ }^{1}$ is conceived as one mechanism to foster an efficient allocation of resources to those measures most conducive to GHG reduction. The certificates obtained through these measures can then be traded to the actor with the highest needs. This mechanism can theoretically yield pareto-optimal results.

Despite strong sponsoring of this agreement within the European Union it seemed for a longer period unlikely that the Kyoto Protocol would enter into force due to the announcement of US president Bush within his first 100 days of holding office that the Kyoto Protocol is 'dead'. The agreement becomes effective if 55 member states ratify the agreement, among them a sufficient number of Annex-I-countries ${ }^{2}$ that account for a minimum of $55 \%$ of their total $\mathrm{CO}^{2}$ emissions. ${ }^{3}$ While mathematically the participation of the U.S. is not required for the agreement to become effective, its ratification by sufficient number of countries without U.S. consent was not considered likely as the U.S. represents the largest emitter of GHG in the world. Nevertheless the agreement was established in 2001 without the participation of the U.S. by a sufficient number of signatories. In the long run is argued that the U.S. government will again support the Kyoto protocol. The effects of international emissions trading on the competitive position of international companies due a new focus on innovation are considered by experts as the leading argument for the voluntary joining of U.S. industries of the agreement and for their lobbying of the government to fully support it. ${ }^{4}$

The current repudiation of the U.S. government shows that despite strong efforts since the beginning of the 1990s to find global solutions for problems that cannot be tackled on the national level because of moral hazard and international competition problems ${ }^{5}$, there is no room for complacency. If no

15 - 19) which finances projects that reduce GHG in developing countries for the latter obtainment of CERs. It might be able to trade these in the future. Still, no firm standards for CER have been established yet.

${ }^{1}$ The Kyoto Protocol establishes a mechanism whereby Annex I Parties (listed in Annex B of the Kyoto Protocol) with emission commitments may transfer part of their assigned amount to other Annex I Parties (listed in Annex B of the Kyoto Protocol). The aim of international emission trading is to improve the overall flexibility and economic efficiency in achieving the agreed [...] emission target. Gamperl, J. / Seifried, R. / Strangmann, U. (2001), annex 1 p. 2,3 .

${ }^{2}$ These are the Countries mentioned in Annex I of the Kyoto protocol and which face specific targets for $\mathrm{CO}^{2}$ emissions.

${ }^{3}$ See Gamperl, J. / Seifried, R. / Strangmann, U. (2001), p. 3.

${ }^{4}$ Information taken from the verbal interview with Josef Gamperl, environmentalist expert for the German Bank for Reconstruction (Kreditanstalt für Wiederaufbau). Cited with consent of the expert.

${ }^{5}$ The U.S. government's argument to not want to hurt the domestic industry is a strong example of these problems. If all countries internationally impose the same strict regulations, the incremental costs will be about the same for the industries of all nations, thus preserving competition. The only negative effect will be the slight price increase in high emission industries in comparison to some lower emission industries, which will have small effects due to cross-price elasticity. Yet it will only change competition between industries not between 
working solutions of the environmental problems of the $21^{\text {st }}$ century will be found, the developing nations will be those most vulnerable to the effects because they have the least resources to protect themselves against adverse effects. $^{1}$

The international institutions that have been reviewed here receive attention in the new strategies because they set the framework in which the national efforts to reduce poverty are taking place. Another theme of international scope besides these institutions regards the relationships and actions concerning the donor community. These are covered in the following section.

\subsubsection{The Donor Community}

Reforms of the domestic policies are regarded in the poverty reduction strategies as the foremost measure to reduce the number of impoverished people in this world. To implement these is seen as the obligation of the developing countries as their part in the cooperation for development. The implementation is embedded in the international institutional framework presented above. Yet, the donor community also has to fulfill its share in the development cooperation. The ideas for reorganization of development cooperation from the donor side, though not fully new, are brought forward with new vigor. Three broad themes emerge in this discussion: the redesign of the relationship between the donor and the recipient country, a focus on the responsibilities on the side of the donor policies, and a new concern for international best practices and research. These will be discussed here in turn.

\subsubsection{The Meaning of Partnership: Ownership, Conditionality and Political Dialogue}

Development cooperation, as the name already implies ${ }^{2}$, is based on a partnership between the developing country and the donor nation. One essential question in a partnership involves the role each member plays in leading the

countries. A positive effect for the domestic industry is only to be found if one country (here the U.S.) does not want to implement a costly strategy while the others do, which would raise the costs of all others in comparison to the U.S. Since there is no consent internationally for such one-sided action, chances that the status quo prevails are high. This will not help the U.S., since everyone competes on the same low-cost, high emission basis (which yields about the same competitive equilibrium as competition on the same high-cost, low emission basis), but overall benefits are lower due to lack of environmental protection.

${ }^{1}$ The Netherlands have ordered the improvements in height of all their dikes in 2001 because they are certain of a rise of the water level due to global warming. While the Netherlands have the resources for such action, most costal developing countries lack these and will face changes in natural conditions without necessary preparations.

${ }^{2}$ For a discussion of the term 'development cooperation' in contrast to 'development assistance' see Sida (2000f) 
common path. In the past it has been assessed that donors have been the dominating factor in the project cycle with sometimes inadequate attention to the preferences of the national government or of project beneficiaries. ${ }^{1}$ The new strategies emphasize a shift of dominance to the developing country by promoting domestic ownership as a strong determinant for aid effectiveness. ${ }^{2}$ That means that the basic responsibility for poverty reduction rests with the government of the recipient country ${ }^{3}$, which should self-responsibly, set out its strategy. ${ }^{4}$

Yet ownership of the strategy by a country is not supposed to halt at the governmental level, but extend through a participatory process down to the population and their immanent problems. ${ }^{5}$ These consultations with the local population provide for the identification of the priorities and actions with the greatest impact. The strategies of the developing countries are to form the basis for support through the development agencies. ${ }^{6}$ James D. Wolfensohn, president of the World Bank, has summarized this point conclusively:

"First and foremost, the government and the people of developing countries must be in the driver's seat - exercising choice and setting their own objectives for themselves. Development requires much too much sustained political will to be externally imposed. It cannot be donor-driven.

But what we as a development community can do is help countries - by providing financing, yes; but even more important, by providing knowledge and lessons learned about the challenges and how to address them.

The donor community takes on the role of a partner in that they are consulted about the process of establishing the national strategy ${ }^{8}$ and can provide assistance in the evaluation of policy proposals. The political dialogue with the recipient countries' governments is still a basis for the cooperation ${ }^{9}$ and serves as a measure to convey the donor country's perception of the best way to tackle poverty. As Sida puts it: "a balance must often be struck between cooperating with them on their own terms and persuading them to choose a direction that Sida regards as suitable for creating better living conditions for poor women and men." 10 This balance is shifted in the new strategies stronger to the leadership of

\footnotetext{
${ }^{1}$ For an evaluation on projects in Africa see Van de Walle, N. / Johnston, T. (1996), p. 55.

${ }^{2}$ See World Bank (2000a), p. 193.

${ }^{3}$ See Sida (1996), p. 6 and BMZ (2001a), p. 5.

${ }^{4}$ See UK government (1997), p. 37.

${ }^{5}$ See World Bank (2000a), p. 194.

${ }^{6}$ See BMZ (2001a), p. 8, 9 .

${ }^{7}$ See Wolfensohn, J. (1999).

${ }^{8}$ See World Bank (2000a), p. 194.

${ }^{9}$ See BMZ (2001a), p. 8.

${ }^{10}$ Sida (1996), p. 6. The approach by Sida has changed in recent years. Sida's political dialogue still relies on the establishment of a country strategy through Sida. This takes account of the populations need and is established in consultation with the partner country. But in 1996 the view prevailed that in contrast to the responsibility Sida attributes to the
} 
the developing nations. Simple measures such as the movement of the dialogue to locations within the partner country and handing the chairmanship over to the host country's government are conceived to underline this view. ${ }^{1}$

This approach to focus on the needs and wishes of the recipient country is partly challenged by the demand for greater conditionality and selectivity in the provision of aid $^{2}$. It is widely accepted that financial resources for development cooperation are limited, and one way of increasing its impact is through provision of aid only to those countries who pursue poverty reduction consequentially ${ }^{3}$ and who follow a path of good governance with national structures that increase or at least do not inhibit the impact of aid flows on the situation of the poor population ${ }^{4}$. This form of conditionality, which requires a poverty reduction focus and efforts for good governance prior to granting ODA, is regarded as more effective than program and policy-based aid that is tied to the enactment of certain policy reforms during the implementation. ${ }^{5}$ Countries that lack either one of the conditions of poverty focus and good governance will likely use ODA resources less efficiently, which implies a reduction of aid to these countries. Support is in these cases limited to NGOs and projects aiming directly at the poor people to reduce the worst cases of poverty and to provide some help on a local scale ${ }^{6}$.

Also of concern are questions of the level of poverty in the developing country, the ability of the country to finance poverty reduction by other means than ODA and the ability of the donor country to contribute most effectively to the reduction of the specific problems of a recipient country ${ }^{7}$. This assessment leads to the proposal in most strategies to provide ODA for very poor countries, instead of providing it to middle-income countries with medium poverty rates that are believed to be to able to attract resources on the private market ${ }^{8}$. The cooperation with these countries is limited to the exchange of knowledge, technical assistance and know-how to support their further development ${ }^{9}$. Such a

partner country for poverty reduction (Sida (1996), p. 6), the responsibility for the strategy is kept in Swedish hands. See Sida (1996), p. 10. This view is reversed in the newer document Sida (2000k) to grant needs formulation, planning and implementation fully to the recipient country's responsibility. This exemplifies the change in perception that has occurred in recent years.

${ }^{1}$ See World Bank (2000a), p. 199.

${ }^{2}$ See World Bank (2000a), p. 196 and Sida (2000i).

${ }^{3}$ See BMZ (2001a), p. 8 and Sida (1996), p. 6.

${ }^{4}$ See World Bank (2000a), p. 196 and DfID (1999b), p. 32. These correspond strongly to the measures presented in the chapter on 'necessary political conditions' and 'the economic incentive system'. The concern for human rights is stronger in the case of conditionality for the bilateral strategies, which explicitly refer to them, then in the World Bank strategy.

${ }^{5}$ See World Bank (2000a), p. 193.

${ }^{6}$ See e.g. Sida (1996), p. 6, 7.

${ }^{7}$ See e.g. Sida $(2000 \mathrm{~h})$ and Sida (2000i)

${ }^{8}$ See e.g. UK government (1997), p. 36.

${ }^{9}$ See UK government (1997), p. 40 and Sida (2000i). 
concentration on the basis of high poverty rates and reasonably effective policies and institutions is estimated to double the number of people lifted out of poverty each year from currently 10 million to 19 million. ${ }^{1}$

Yet the discussion on conditional aid for middle-income countries is still going on, as the German government assesses that the majority of the poor live in these countries for which access to capital markets is inadequate, fluctuating and sometimes too expensive. ${ }^{2}$ Therefore ODA is seen as necessary for these countries. Also the World Bank's mandate has recently been reinforced to engage in middle-income countries on the basis that $80 \%$ of the people living on less than two dollars a day live in these countries. ${ }^{3}$ That middle-income countries still need support is unambiguously clear, the point on discussion is weather this should be limited to technical assistance or know-how alone or should include ODA. This discussion is taken up in more detail in the analysis of the accentuation of the German strategy in the next chapter.

The presented approach of conditionality and selectivity of ODA flows limits in a way the ability of a recipient country to take full ownership of his strategy. Its government has to fear that a strategy that is not seen as efficient in poverty reduction by the donor community will not receive donor support, even though the national government believes in its poverty reduction impact. This dilemma results from the scarcity of resources. The developed countries governments are responsible to their constituents concerning the efficient use of funds for development assistance,, and they are also obliged for moral reasons to provide money to those countries where the effect on the poor individual is potentially highest ${ }^{4}$. Despite the limitation of conditionality for national ownership, national ownership can still be strong. This approach to conditionality is mainly concerned with the 'if' - if there is a chance of reduction of poverty given the attitude and broad proposals of the government and the soundness of the national institutions - rather than with the 'how' - how the specific program for poverty reduction looks like.

Once the confidence in a country's strategy is established, there is strong concern to leave the leadership to the recipient country. To foster this, less intrusive ways for providing financing are considered. ${ }^{5}$ The role of the national government can be enforced by making technical assistance more driven by the

\footnotetext{
${ }^{1}$ See Collier, P. / Dollar, D. (2000).

${ }^{2}$ See BMZ (2001a), p. 20.

${ }^{3}$ This has been confirmed on the annual Spring Meeting of the IMF and World Bank in Washington in 2000. See FAZ (2001b).

${ }^{4}$ As each poor individual has the same right - based on the UDHR or pure moral standards to receive help, and given a scarcity of resources, a moral goal would be to help the greatest number, which under uncertainty corresponds to investments where the potential for helping the greatest number of poor people is highest. Under such a framework, which only considers the individual moral, obligations to countries or other higher entities do not exist.

${ }^{5}$ See World Bank (2000a), p. 194, 196.
} 
government's needs, by ending tied aid ${ }^{1}$ and extending debt relief to provide the national government with sufficient resources to fulfill its obligations ${ }^{2}$. If individually financed and supervised projects are favored, they should be embedded in the nationally determined sector framework and should systematically link investments to poverty outcomes. ${ }^{3}$ Instead of individual projects the new strategies explore also sector-wide or budget-wide approaches, in which the financing is not tied to specific projects but rather provided as a contribution to the general funds for a specific sector or for the entire national budget. $^{4}$

Also funds are supposed to be made available on a longer-term basis to allow for a longer planning time frame for the recipient country. ${ }^{5}$ Since sectorwide approaches restrict the ability of the donor to control the usage of funds they are limited to countries where the donors have confidence in the policies and budgetary allocation process ${ }^{6}$, which requires sound national accounting systems and institutions. Sector-wide approaches are regarded as measures to avoid the problem of fundability - where ODA flows free up national resources which are then used for other, unintended purposes ${ }^{7}-$ and is also conducive to donor coordination ${ }^{8}$ because agreement only needs to be reached on the level of support and the general strategy for the usage of funds in the sector but not on each individual project.

\subsubsection{Donor Responsibilities: Donor Coordination, Cooperation and Policy Coherence}

Next to the relationship between the donor countries and the recipient country the relationship between the donor organizations themselves receives attention in the new strategies. Donor coordination emerges as a special responsibility for the donor community ${ }^{9}$. The parallel demands of many uncoordinated donor activities in terms of different reporting standards, individual policy dialogues

\footnotetext{
${ }^{1}$ See World Bank (2000a), p. 200 and UK government (2000), p. 94. 95. Tied aid not only reduces the choices governments have in conduction the projects, it is also estimated to have a 15-30\% lower value than projects contracting the best bids. See Jepma, C. (1991).

${ }^{2}$ This ability is severely limited if new aid money serves merely the fulfillment of old debt obligations. Debt relieve is demanded in all strategies, see e.g. BMZ (2001a), p. 19, 20, Sida (2000d), World Bank (2000a), p. 200 - 203, UK government (1997), p. 71, 72.

${ }^{3}$ See World Bank (2000a), p. 196.

${ }^{4}$ See UK government (1997), p. 38 and World Bank (2000a), p. 194 - 1996. In BMZ (2001a), p. 24, sector-wide approaches are considered for the provision of basic needs in health and educational sectors. In Sida (1996), p. 25, this option is only considered as a replacement for balance of payments support. Thus, there is a trend in this direction, yet there is still reluctance to propose it on a large scale by some donors.

${ }^{5}$ See UK government (1997), p. 38.

${ }^{6}$ See UK government (1997), p. 38.

${ }^{7}$ For a more detailed discussion on fungibility of resources see World Bank (2000a), p. 193.

${ }^{8}$ See World Bank (2000a), p. 197.

${ }^{9}$ See BMZ (2001a), p. 43, 44, Sida (2000g), World Bank (2000a), p. 195 and UK government (1997), p. 38.
} 
and conflicting objectives put a strain on the limited administrative abilities of the developing country and they are likely to overburden it. Situations like that in Tanzania during the early 1990s, where 40 donors conducted over 2,000 projects ${ }^{1}$, exemplify the problem that sheer numbers of agencies and projects cause for the coordination efforts of local administrations. To cope with this problem, suggestions are made to avoid negotiating national strategies individually with each bilateral and multilateral donor. ${ }^{2}$ One proposal to strengthen donor coordination involves the leading agency for a particular country or a sector where it is best situated. ${ }^{3}$ Another strategy relies on the national government to lead donor coordination. In this second approach consultations are held jointly with the donor community based on the national plan for development, which donors support strategically. This approach is followed in the Comprehensive Development Framework (CDF) ${ }^{4}$, which is proposed as a tool to facilitate donor coordination.

The demand for coherence in policies is linked to coordination's responsibility for increasing the effectiveness of aid. The coherence of policies by international organizations in terms of their goals is a precondition for coordinating their efforts. ${ }^{5}$ The IDTs have contributed to a coherence of goals on the international level and the guideline for poverty reduction ${ }^{6}$ that is being prepared by the Development Assistant Committee for the OECD member states is likely to contribute to the coherence of procedures for delivering aid. This will reduce the burden on countries to comply with a variety of different reporting and controlling standards. ${ }^{7}$ Yet coherence has to extend beyond the development organization's goals, to encompass all interactions with developing countries. Such a comprehensive approach can fight poverty by using the synergies between environmental policy, trade, research, technology and trade and fiscal policy. ${ }^{8}$ Disadvantages arising from neglecting this coherence between different

\footnotetext{
${ }^{1}$ See Van de Walle, N. / Johnston, T. (1996).

${ }^{2}$ See UK government (1997), p. 38. While a trend in this direction is visible in German, UK and World Bank strategy, the Swedish strategy still relies strongly on strategies that are individually negotiated with countries. See Sida (1996), p. 10.

${ }^{3}$ See UK government (1997), p. 38. The German government has already signaled its willingness to take over this position for selected countries via its development organizations. See BMZ (2001a), p. 9.

${ }^{4}$ See World Bank (2000a), p. 195. Further detail is provided in the chapter on 'Initiated Reforms'. The CDF does not necessarily exclude the existence of a lead agency in the attempt to facilitate the coordination of donor activities among each other. The CDF is actually explicitly acknowledged in DfID (1999b), p. 32. Yet the recipient country has the highest responsibility for coordination of the activities pursued.

${ }_{6}^{5}$ See BMZ (2001a), p. 43.

6 The Development Assistance Committee (2001) draft guidelines are being currently debated.

${ }^{7}$ See BMZ (2001a), p. 43.

${ }^{8}$ See BMZ (2001a), p. 10. Disadvantages arising out of neglect for this coherence between different policy areas have been discussed, for example.
} 
policy areas have been discussed in the context of international tariffs and trade, for example. ${ }^{1}$

This approach requires cooperation between different international agencies to achieve a mutually agreed, coherent standpoint. It also requires cooperation between different departments within the same international body, whether it be the EU or an OECD member state. ${ }^{2}$ The collaborative work between different departments, which may not perceive the reduction of poverty as their main objective, ensures that the overall policy towards developing countries can be consistent. The German initiative to review all German laws on their possible connection to developmental goals including poverty reduction ${ }^{3}$ is one step in this direction.

Coordination of donor activities behind the national strategy of the recipient country, plus coherence of their overall activities concerning developing countries and cooperation, are the responsibilities of the donor community by ensuring that their contribution can extend the highest possible effect in terms of reducing poverty for the poor individual in the developing world.

\subsubsection{Knowledge, Alliances and Raising Awareness}

Greater effectiveness of the development cooperation is an underlying concern for strategies to reduce poverty. Knowledge about "what will work and what will not work" is required in order to use the available resources in ways that produce the highest benefits. The generation of such knowledge is seen as a priority. ${ }^{5}$

Applied research with a special emphasis on poverty reduction is thus needed to efficiently implement and further develop the proposed strategies. ${ }^{6}$ Research in this area is considered to have significant multiplier effects since it allows solutions to the causes of poverty in one part to be replicated in others. ${ }^{7}$ The dissemination of good practice ${ }^{8}$ is a vital component in this process. The direction of the World Bank to establish itself as a "knowledge bank' exemplifies the increasing value placed on establishing and disseminating knowledge.

Next to applied knowledge on effective measures for reducing poverty, there is also a need for technical or scientific knowledge to deal with urgent

\footnotetext{
${ }^{1}$ See the chapter on 'International Institutional Framework', 'Trade'.

2 This point for internal cooperation between different policy areas is e.g. promoted in BMZ (2001a), p. 10 and by the UK government (1997), p. 20.

${ }^{3}$ See BMZ (2001a), p. 9.

${ }^{4}$ See UK government (1996), p. 48.

${ }^{5}$ See e.g. Sida (2000j). In UK (1997), p. 47 it is emphasized: "Knowledge, research and technology underpin all our work."

${ }^{6}$ See BMZ (2001a), p. 48.

${ }^{7}$ See UK government (1997), p. 48.

${ }^{8}$ See DfID (2000e), p. 26.

${ }^{9}$ See World Bank (1998).
} 
problems in areas like environmental degradation, poor health, food shortages or infectious disease. ${ }^{1}$ The ability to adapt knowledge to the special circumstances in developing countries is the constraint in some circumstances. ${ }^{2}$ Adaptation constraints are a strong concern for developing countries because the substantial scope to benefit from the achievements of industrialized nations is severely limited if existing knowledge cannot be transferred successfully to developing nations.

The generation of new knowledge is equally important to ensure progress on poverty reduction. The fact that $90 \%$ of the world's disease burden receives only $10 \%$ of the international allocations on research and health ${ }^{3}$ shows the need to focus more research on the urgent issues of developing countries. Therefore, the developed nations and their development agencies need to invest directly in research on the urgent scientific problems of poor nations and they should aim at shifting the incentives for private research to take the areas of low purchasing power into their account. ${ }^{4}$ Partnerships between research institutions, support for research facilities in developing countries ${ }^{5}$, their integration in joint research projects and partnerships with private sector companies will be the keys in this area. ${ }^{6}$

Partnerships and alliances are generally highly valued in the new strategies, not just for research. Alliances with the private sector are conducted to integrate their financial resources and their technological expertise in the development process. Public-Private Partnerships in which private companies and development agencies cooperate in the joint realization of projects that serve to reduce poverty and also economic poverty, are an example of such a partnership. ${ }^{7}$ The private sector, together with NGOs, is also consulted in the establishment of country and other developmental strategies. ${ }^{8}$ This integration of the private and non-governmental sector in the strategy formulation is intended to ensure their most successful engagement in the development process. NGOs are considered as valuable intercessor for the concerns of the poor, in this respect. ${ }^{9}$. Their contribution to project implementation in developing countries and their fund raising activities on the national level are also acknowledged. ${ }^{10}$

\footnotetext{
${ }^{1}$ See Sida (2000j).

${ }^{2}$ See UK government (1997), p. 48.

${ }^{3}$ See UK government (2000), p. 43.

${ }^{4}$ See UK government (2000), p. 43.

${ }^{5}$ See Sida $(2000 \mathrm{j})$.

${ }^{6}$ See BMZ (2001a), p. 48.

${ }^{7}$ See BMZ (2001a), p. 44.

${ }^{8}$ See e.g. UK government (1997), p. 45 and BMZ (2001a), p. $46-47$.

${ }^{9}$ See BMZ (2001a), p. 47.

${ }^{10}$ See BMZ (2001a), p. 48.
} 
NGOs also fulfill the important task of raising the awareness within the national population for problems of poverty reduction. ${ }^{1}$ There is a strong understanding that developmental goals need to be firmly founded in society, to achieve the national commitment for poverty reduction. ${ }^{2}$ To further increase national awareness, the British paper considers the integration of developmental matters into the national curriculum and the establishment of an annual Development Policy Forum to allow broad-based sharing of ideas on the issue. ${ }^{3}$ The German government considers a public media campaign sponsored by publicly well-known people to promote awareness on the new poverty reduction focus. ${ }^{4}$ Sida embarks on all three - education, media and public debate - to spread information about the extent and consequences of poverty and the need to contribute to the struggle against it. ${ }^{5}$ Awareness of the national population to the problems of development and poverty reduction is recognized as necessary to secure future commitments in form of ODA flows, private financial contributions or personal, private initiatives.

In summary, donor strategies grant the strategy's ownership to the developing country, yet plan to ensure efficient use of resources by carefully selecting the countries that receive support. Their part in increasing development effectiveness lies in stronger coordination of their activities and in coherence of all interactions with developing countries, for the common goal of reducing poverty. There is a justified reluctance to tackle the broad developmental challenges alone, therefore the inclusion of the research, private and nongovernmental sector is promoted strongly. National awareness and approval of the strategies is seen as a precondition for continued efforts to fight poverty.

\subsection{Synopsis: Novelties and Challenges of the New Strategic Conception}

To sum up the discussion of today's consensus in development cooperation, its contents, its novelties and the challenges arising from it shall be highlighted here shortly. A more extensive summary that integrates the consensus into a hierarchy according to the level of agreement is presented at the end of the following chapter, which enables a view that integrates the commonalities and

\footnotetext{
${ }^{1}$ See BMZ (2001a), p. 48.

${ }^{2}$ See BMZ (2001a), p. 49, Sida (1996), p. 15 and UK government (1996), p. 78. This point cannot readily be extended to the World Bank whose constituents are the nations in its basic membership, rather than a specific population. Yet also the World Bank tries to raise awareness on the international level for the problems of poverty and its measures to fight it. The publication of the annual World Development Reports is one example of its information policy that receives international attention.

${ }^{3}$ See UK government (1997), p. 78.

${ }^{4}$ See BMZ (2001a), p. 49.

${ }^{5}$ See Sida (1996), p. 15.
} 
the accentuations and provides the reader with a more comprehensive overview over the strategies.

The new strategies place great emphasis on national conditions for poverty reduction and on national priorities that will help poor people to make greater use of their own potential to change their situation. The provision of security for the poor and a concern for the political and governance issues that influence national priorities, the country's administration and provide services to the poor, have emerged as new themes in this discussion. This has the benefit that poverty reduction is now viewed from a holistic viewpoint, which explicitly takes account of detrimental circumstances such as corruption or human rights violations that have the potential to severely limit the effectiveness of poverty reduction measures. On the other hand, this holds the danger that developing countries feel too strongly governed in their national policies.

It will be a challenge to demonstrate a firm will on the political level, to tackle even sensitive governance issues in order to improve the effects of the attempts to reduce poverty, while at the same time avoiding the notion that the money of industrialized nations is used to imperialistically enforce the adoption of industrialized nations' values and governmental systems in poorer countries. Argumentation lines that narrowly focus on the outcomes of policies for the poor people rather than discussions of the most appropriate overall governance system might provide a possible bridge. Less intrusive ways of delivering aid once the overall commitment of the government to poverty reduction has been established - are also conducive to this end.

The holistic framework for reducing poverty extends into strategies beyond the national boarders of developing countries, to encompass international treaties and the overall priorities of industrialized countries. While the calls to align developmental policies with other relevant areas, especially concerning trade, are no novelty, the renewed commitment might foster expedited progress in this area. ${ }^{1}$ This broad approach also takes notice of the challenges and advantages offered by the accelerating process of globalization. Unfortunately, this has not yet been translated into workable programs that assess the chances to use globalization in favor of poverty reduction, evaluate methods to mitigate the potential threats of this development and come up with solutions that are customized to the special circumstances in developing countries. ${ }^{2}$ The development of ways to adapt information technology to the problems of developing countries and its integration into the broader

\footnotetext{
${ }^{1}$ The conception of programs at the governmental level rather than at the level of the development organization (see UK white papers and German action program) looks promising. Greater commitment from the entire government for the task of poverty reduction has potential to spur the implementation of coherent strategies.

${ }^{2}$ A notable exception to this is the 2. White Paper of the UK government (2000), which places these concern at the center of its analysis.
} 
strategies for development cooperation will be an especially important task for further strategic conceptions.

While the role of international frameworks for the solution of global problems and the importance of the national government in the design of effective national policies and regulations is enforced, the new strategies manage to place the individual and the local groups in the center of the analysis. Subsidiary approaches in which power and resources are reallocated to the lowest possible level, dominate the discussion on empowerment of the poor. The calls for participation, decentralization and accountability have the potential for increasing the focus of strategies on the needs of the population. This might provide the basis for determining priorities in development efforts that sometimes seem to be missing in the extensive framework of new strategies. ${ }^{1}$ The establishment of local administrative capacity and effective control mechanism will determine the success of this decentralized approach.

Finally, next to the presentation of new concepts and the invigoration of existing ideas, new strategies also serve the important task of spreading awareness of the tasks of reducing poverty, bring renewed movement in processes like debt cancellation and reforms of aid delivery processes and they serve as motivation for the individuals who work in the development arena. The last point stems from the fact that their efforts are again acknowledged as contributing to solving one of the earth's greatest problems and by communicating a strong political will to support their work. Efforts in development cooperation are receiving a socially enhanced value through these strategies and the international concern with the issue. This enforced motivation will be of great importance for actually implementing the reforms that are necessary to translate the strategies into real-life actions.

\subsection{Initiated Reforms}

Although the full implementation of all parts of the presented strategies will require substantial amounts of time and resources in terms of administrative rethinking with the development agencies, setting up individual countries' strategies, increasing national administrative capabilities in the partner countries and redirecting project portfolios, first steps in the implementation process have already begun. Reforms have moved especially swiftly in regard to debt relief for Heavily Indebted Poor Countries (HIPCs), which is mostly referred to as HIPC-Initiative. After a disappointing start with the first HIPC-Initiative the G7 summit in Cologne in 1999 voted to extend the program (HIPC II), which has since then led to agreed debt cancellations of US\$29 billion ${ }^{2}$ (current value

\footnotetext{
${ }^{1}$ For the discussion on priorities in the strategies see the chapter on 'Comprehensiveness or Excessiveness?'

${ }^{2}$ See Kreditanstalt für Wiederaufbau, KfW (2000), p. 7.
} 
1999) for the 10 countries that have reached the decision point. The decision point marks the time when a decision on the extent of the debt relief is taken ${ }^{1}$.

The precondition for debt relief is the submission of a Poverty Reduction Strategy Paper $^{2}$ (PRSP), which lies at the heart of the new initiative ${ }^{3}$. In order to assure that the money that is released in the process of debt relief is used for reducing poverty, each country has to prepare a PRSP that focuses on poverty reduction and economic growth ${ }^{4}$. The themes that the PRSP ideally covers should range from macroeconomic concerns of inflation and budget deficits to human capital, infrastructure, security and empowerment, ${ }^{5}$ which have been discussed above as the domestic framework for poverty reduction. In the establishment of the PRSP, special weight shall be given to "(1) identification of key constraints to economic growth and poverty reduction; (2) consideration of the public actions needed to relieve those constraints; (3) outcome indicators that are set and monitored using participatory process; and (4) a description of the nature of the consultative process by which the strategy was formulated"6. The steps for implementation are illustrated in more detail in Figure 2.

The process of developing the PRSP in a participatory manner that includes the interests of as wide a cross-section of stakeholders as feasible ${ }^{7}$ and that integrates them in the process of monitoring the outcomes is one of the strategy's major advances. This integration of the broad public through mediated group processes shall identify especially vulnerable groups, establish genderdifferentiated criteria for progress ${ }^{8}$ and ensure more effectiveness in poverty reduction attempts and the acceptance of plans by the local population. The partners in this participatory approach should comprise the central government, parliaments and other representative structures, the public, civilian society and external partners. ${ }^{9}$ The formulation of the strategy rests with the national government ${ }^{10}$ to strengthen the domestic ownership of the strategy. ${ }^{1}$ The role of

\footnotetext{
${ }^{1}$ For a more detailed list of countries and their process towards the decision point see annex 4.

${ }^{2}$ For more detailed information on PRSPs by country see also annex 4.

${ }^{3}$ The requirement for PRSP covers all countries applying for debt relieve under the enhanced HIPC initiative, 36 at maximum. This requirement has been broadened now to include all countries where the IMF Poverty Reduction and Growth Facility - formerly the Enhanced Structural Adjustment Facility - is active to absorb the negative aspects of structural adjustment programs on the poor. Also countries applying for aid from the International Development Association of the World Bank group will be required to develop PRSPs. This broadens the group to about 70 low-income countries. See Klugman, J. (2000), p. 2, 3 and KfW (2000), p. 2.

${ }^{4}$ See Klugman, J. (2000), p. 3.

${ }^{5}$ See Klugman, J. (2000), p. 7 - 10.

${ }^{6}$ Klugman, J. (2000), p. 3.

${ }^{7}$ See Klugman, J. (2000), p. 5.

${ }^{8}$ See KfW (2000), p. 5.

${ }^{9}$ See Klugman, J. (2000), p. 5.

${ }^{10}$ See Edgerton, J. (2000).
} 
development agencies should - in the spirit of the Comprehensive Development Framework (CDF) - be limited to the support for the PRSP process by financial and technical contributions from scientific papers and funded workshops. ${ }^{2}$

Figure 5: $\quad$ Poverty Reduction Strategy ${ }^{3}$

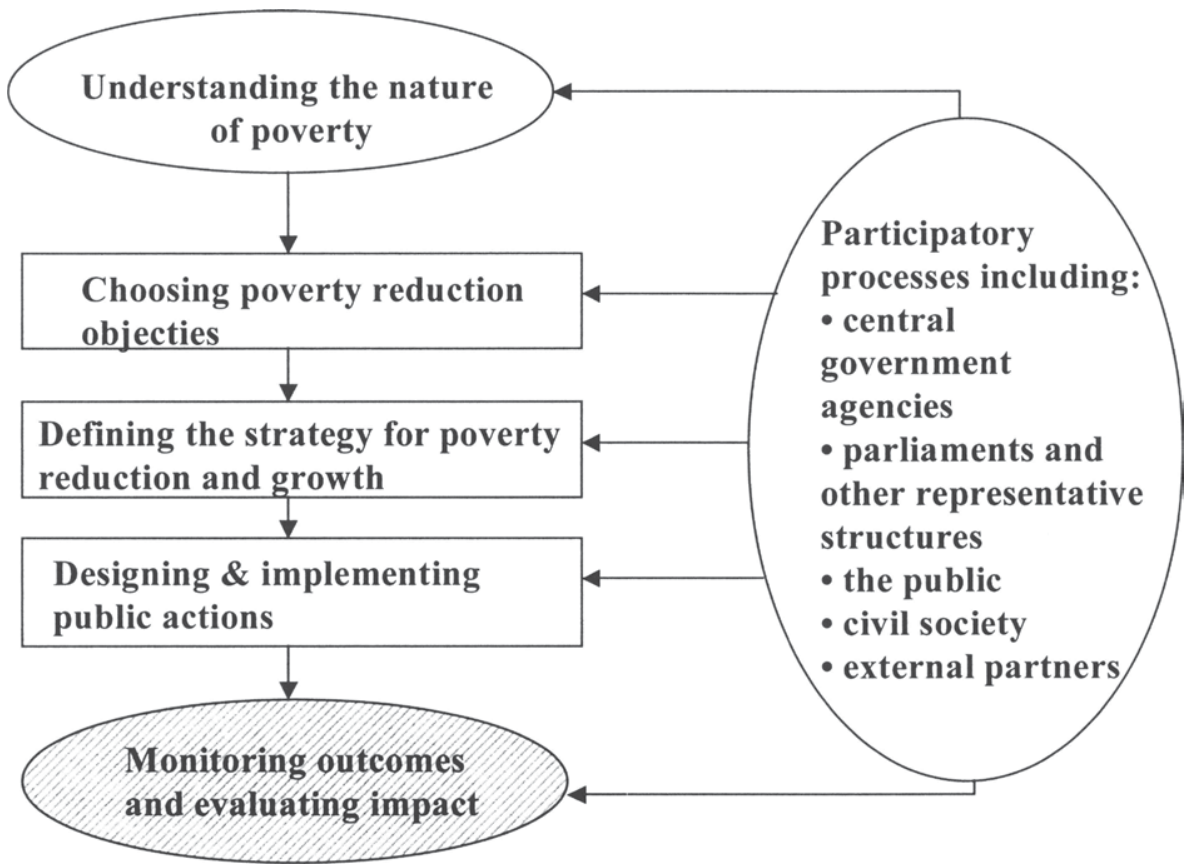

The Comprehensive Development Framework is a systematic approach to tackling some of the problems of donor coordination and it is designed as a third pillar next to the HIPC-initiative and the PRSP processes, for implementing the ideas presented by new strategies. It is an analytical framework ${ }^{4}$ designed to bring people together and build consensus, to forge stronger partnerships, to reduce wasteful competition and to emphasize the achievement of concrete results. ${ }^{5}$ Its conception rests on the vision that macroeconomic aspects conducive to reducing poverty need to be considered jointly with social, structural and human aspects of reducing poverty and cannot be assessed in isolation. ${ }^{6}$ The main objectives in each of the four areas can be determined in the

\footnotetext{
${ }^{1}$ See Klugman, J. (2000), p. 3.

${ }^{2}$ See KfW (2000), p. 3, 4.

${ }^{3}$ Taken from Klugman, J. (2000), p. 5.

${ }^{4}$ See Wolfensohn, J. (1999a).

${ }^{5}$ See World Bank (2001a).

${ }^{6}$ See Wolfensohn, J. (1999a).
} 
PRS process and enter this analysis as a given. ${ }^{1}$ The CDF approach attempts to link these objectives to the individual efforts of various donors and seeks to enable a stronger focus on how the donors can work together to address all objectives in the most efficient way.

The tool to facilitate this cooperative attempt is a simple matrix ${ }^{2}$. For visualization of its components and its link to the PRSPs, refer to annex 2. The horizontal side of the matrix marks the prerequisites for sustainable development and poverty alleviation as have been determined in the PRSP process, e.g. the goals of the development process. These are broadly categorized in the four areas of Structural/Institutional, Social/Human, Physical/Rural/Urban and Macroeconomic/Financial development objectives. The vertical side of the matrix consists of all the activities which participants in the developmental process currently undertake, e.g. the activities of the government, NGOs and bilateral and multilateral development organizations. Each field within the matrix then indicates whether a donor activity contributes to a developmental goal or not. Thus, each horizontal row indicates to which goals a specific donor activity is conducive, while each vertical row indicates all activities that contribute to a certain developmental goal. If a vertical line is not marked at all, that means that no project is conducted towards this goal, while a highly marked vertical row can be an indication that an excessive amount of donor activities is focused on a particular developmental prerequisite or objective.

This simple analysis allows greater cooperation and coordination between all players in the development process, by visualizing any gaps or overlaps and providing a framework to assess future engagements. It is now in the implementation stage in 13 developing countries ${ }^{3}$, for which the success yet needs to be evaluated.

The reformation of the way in which reducing poverty is handled, is still in its start-up phase. In regard to the achieved consensus on the necessity of country ownership of the strategy, participation of civil society and coordination and cooperation, these reforms generally have to be welcomed. Critical review has to be given to the conflict of goals that is obvious in the need to provide fast and broad-based debt relief ${ }^{4}$ and the ambition to provide debt relief only in the light of visible focus of the national priorities on poverty reduction. The time pressure to provide far reaching debt cancellation that is visible in the debate collides

\footnotetext{
${ }^{1}$ This connection is exemplified in the graphical representation in Annex 2 taken from World Bank (2001b).

${ }^{2}$ This discussion is based on Wolfensohn, J. (1999b), p. 25 - 35 and annex.

${ }^{3}$ See World Bank (2001c).

${ }^{4}$ Not least due to the tribute the international development organizations have to pay to the demands of increasingly organized, mobile and aggressive anti-globalization movements that view the indebtedness of poor countries as one of the evils of globalization. In the context of anti-globalization campaigns debt relief seems to be valued as an end justified by the mere inability of the countries to pay back the loans whose collection is considered unethical rather than a means that can be used to push for greater poverty reduction focus.
} 
with the time consuming process of participatory strategy formulation. The introduction of interim PRSPs that provide the basis for a start of debt cancellation, shows that the strategies which can be drawn up in a relatively short time period, do not satisfy the aspirations of the donor community under the lead of the World Bank.

It will have to be seen how far the goal not only to channel the newly available funds, but rather the general priorities of the recipient nations towards poverty reduction can be achieved and how the question of ownership of the PRSP strategy will be handled in cases in which the national strategies lie at odds with those which the donor community deems necessary for poverty reduction. Even though the Joint Staff Assessment of the World Bank / International Monetary Fund (IMF) of the PRSPs is not intended to constitute formal approval of the PRSP, which is a country owned document' ${ }^{1}$, the endorsement required for debt relief calls into question the ownership of the country ${ }^{2}$.

The CDF approach is still in its conceptual phase. The donor community has not yet subscribed to the new idea in its entirety. The approach in itself is extremely simple, which holds the disadvantage of potentially oversimplifying the complexities of the developmental problems faced in a given country. Still, the CDF framework enables the communication between numerous actors, easily identifies the neglected areas and those that deserve coordination and its simplicity allows participation of every organization without training on the issue. This CDF approach therefore looks like a promising coordination tool.

The HIPC initiative, the PRSP process and the CDF approach incorporate many ideas that are commonly believed in the new strategies for reducing poverty and have to be welcomed for the new focus they bring into the reduction of poverty. The value that these reforms will bear depends strongly on the vigor with which these reforms are pursued, the power of the institutions to keep the high standards they have set for priorities to reduce poverty and their ability to pursue high quality rather than public actionism. The progress also requires the restraint of national and organizational interests in favor of cooperation and coordination, which might not help the profile of each individual country or organization, but the profile of all players in development cooperations together and in the progress towards poverty reduction. But coordination and cooperation remains difficult if underlying differences are not taken into account. Therefore, the different accentuations of the strategies are at the center of the following chapter.

\footnotetext{
${ }^{1}$ World Bank (2000a)

${ }^{2}$ Since the donor institutions have the responsibility to their constituents to utilize their funds efficiently, this form of approval - whether admitted or paraphrased - is an obvious necessity. The real challenge will be to walk the fine line of giving the country the freedom to use its funds where it sees the greatest need and the control that the funds are used in a way that the intended goal of poverty reduction will be achieved and that funds are not unduly diverted.
} 
Philipp Kircher - 978-3-631-75366-8 


\section{Chapter 3}

\section{Differing Accentuations}

\subsection{Merits and Difficulties of Differing Focal Points}

The preceding analysis has portrayed the large consensus that is visible within the new strategies for poverty reduction that have been analyzed for this argument. The British, German, Swedish and World Bank ${ }^{1}$ views on this issue have converged strongly and thus build a strong basis for international cooperation. Nevertheless different accentuations are visible in the strategies. This was to be expected given the differences in backgrounds in each country and organization, the different constituents ${ }^{2}$ and the varying magnitude of aid flows.

The differences in the level of aid flows are easiest to quantify and the relative and absolute contribution of each donor is visualized in figures 6 and 7.

Figure 6: Relative ODA Flows in 1998 as Percentage of GDP*

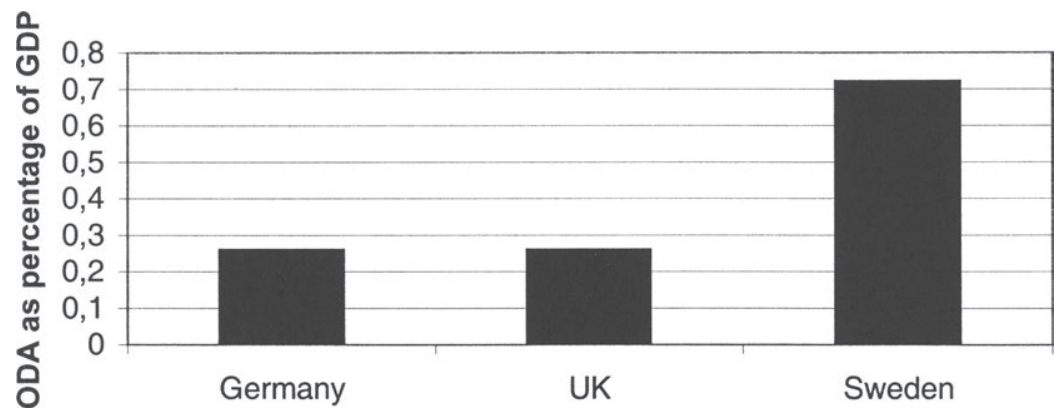

* Source: BMZ (2000d) and BMZ (2000e), p. 57. This graph is not applicable to the situation for the World Bank, as it does not represent the development efforts of any single nation.

\footnotetext{
${ }^{1}$ The German view is taken from the action program of the government where the BMZ was the leading agency. The British view is reflected by an analysis of the UK governmental White Papers on the issue as well as on the newest DfID strategies. The Swedish position reflects the view of Sida. The analysis of the World Bank position has been limited to the WDR 2000/2001, which has been very influential in the international debate. Overall, the attempt has been to portray the most recent strategic considerations, and potential differences between the governmental positions and the position of the national development agency have not been visible.

${ }^{2}$ Especially the World Bank with 181 member states has a different constituent base than the national development organizations.
} 
Figure 7: Absolute ODA Flows in 1998****

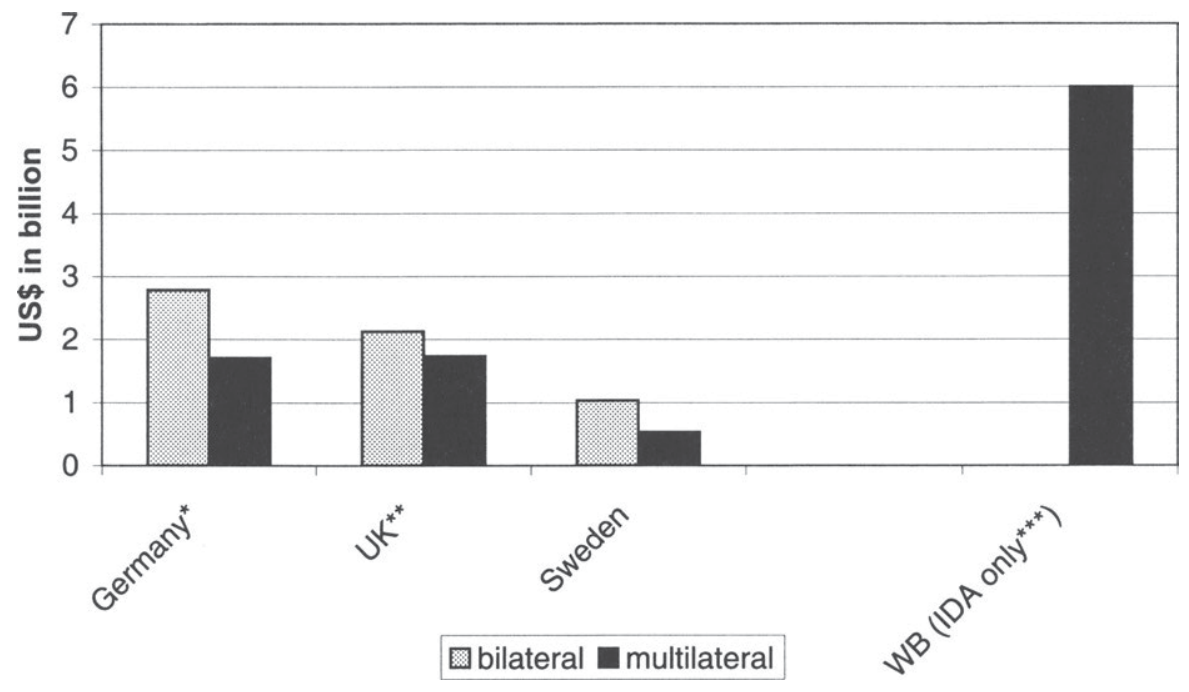

* The percentage distribution between multilateral and bilateral flows as of 1997.

** The contribution of Germany and the UK will be reversed by 2001, with DfID budget at US\$ 4.614 billion and BMZ budget at US\$ 3.375 billion converted at 3.5.2000 exchange rates.

*** For the World Bank average lending through the International Development Association (IDA), which only issues concessional loans, was used as an equivalent for ODA flows. (Data source: World Bank (2001d)). Overall lending of the World Bank Group in 2000 was above US $\$ 15$ billion. (World Bank (2001e)).

**** Source: BMZ (2000d) and BMZ (2000e), p. 57 - 59. For annotation ** see BMZ (2000c) and DfID (1998).

From these figures it is clearly visible that broad differences in the absolute amount of aid flows exist which might have profound influence on the way development assistance is structured, as it is e.g. conceivable that less resources require a stronger concentration in regard to the number of projects and countries that receive support. The relative share of ODA to GDP reflects in part the priorities countries assign to development assistance. As this potentially reflects the political engagement in questions of development and a concern for political dialogue in the development arena, one might expect a higher aspiration in the strategies of countries with a high ODA/GNP ratio than in those with a low ratio. Yet this static picture might be misleading, as the ratio has continually dropped in Sweden from its height of more than one percent in $1992 / 93^{1}$ while it

\footnotetext{
${ }^{1}$ See Lembke, H. (1996), p. 193.
} 
is rising substantially in the UK ${ }^{1}$. In any case there are substantial reasons for differences within the strategies based on different resource availability and different political background and ambitions.

These different focal points of the agencies can have merits if they either lead to specialization in specific developmental issues in which they develop a comparative advantage, or if the broaden the choice for developing countries to choose the donor support most suitable to their national priorities. Specialization can result from concentration on particular geographic regions in which an organization acquires superior competence in understanding the local conditions and problems and can deliver customized assistance in specific country or regional circumstances. Regional specialization can also facilitate cross-boarder communications for projects that span more than one country and bring advantages in the area of conflict prevention due to an increased understanding of the national priorities and superior relationships to the people in charge. Yields from increased specialization can also accrue from a sharper focus on specific issues of development cooperation such as urban development or health care. A special expertise in one area can then be made available to a large number of countries that have concerns in this regard. This specialization on issues is only limited by the potential of strong interrelations between different issues or by locally differing requirements. Strong interrelations between issues reduce the value of specialized knowledge in any one area, as solutions in this area also require knowledge in the related areas. Local adaptation requirements can also negate the benefits from specialization on a particular issue if the local differences become too large. Yet even in these cases, adequate cooperation between specialists can overcome these problems.

Differing focal points of donor strategies could also be beneficial in providing choice for recipient countries in regard to the most suitable funding for their interests; an approach that is demand-driven and allows greater national ownership. Given the scarcity of resources and the strong demand for resources by developing countries, the actual situation is supply-driven and depends largely on the willingness of a donor country to supply funding than on the choice of the recipient country. Thus, since developing countries are not in the position to choose, the benefit of greater choice does not apply here, leaving the benefits of different focal points to greater specialization.

Potential problems of different accentuations arise if these do not contribute to specialization, but lead to conflicting positions in regard to the measures or implementation procedures that are most conducive to development. A coherent and coordinated approach to reducing poverty in a given country can yield

\footnotetext{
${ }^{1}$ See DfID (1998).
} 
benefits because all projects aim in the same direction and do not hinder one another ${ }^{1}$. Yet coherence and coordination become difficult if there is lack of agreement on the measures and priorities that need to be pursued in development. Therefore, the following analysis will portray the differences in accentuations between the strategies and will look at their potential for specialization and their likelihood of disruptions for the developmental process.

\subsection{The World Bank}

\subsubsection{World Bank Background}

The World Bank Group was founded in 1944 and is owned by 182 member countries, which, as shareholders, carry the ultimate decision-making power. ${ }^{2}$ Most matters including the approval of loans are determined on the basis of a majority of shares, which in turn reflect the size of a member country's economy relative to the world economy, giving the G7 states about $45 \%$ of all shares. ${ }^{3} \mathrm{~A}$ Board of Directors handles its operations, which receives its legitimization from a Board of Governors. ${ }^{4}$ It employs about 10,000 employees, of which approximately a fourth work in 100 World Bank operated overseas offices ${ }^{5}$, which shows its efforts to decentralize to the field ${ }^{6}$. The World Bank has established itself as one of the leading players in the development arena and handles the largest source of development assistance, which comprised loans in excess of US\$ 15 billion in $2000 .^{7}$ This gives it a strong position in negotiations with governments to tackle even delicate issues of good governance. The 600 projects it conducts in the area of corruption ${ }^{8}$ alone underline this. Yet its Articles of Agreement explicitly prohibit the Bank from interfering with a country's political affairs and require it to take only economic considerations into account in its decisions", limiting its activities to "economic governance" ${ }^{10}$. It has established itself as the world's largest external funder of education ( $\$ 1.8$ billion on average per year) and of health (\$1 billion to fight

\footnotetext{
${ }^{1}$ This only applies if the overall direction of the approach is beneficial to the desired outcome. That is to say, deviating views on the way that should be pursuit can have their merits if they contribute in the long-term to more efficiency and effectiveness despite short-term disruptions. Yet if the overall direction is already reasonably effective, the occurrence of disruptions is likely to reduce the overall benefit of the actions.

${ }^{2}$ For this introduction see mainly World Bank (2001e).

${ }^{3}$ See World Bank (2001d).

${ }^{4}$ See World Bank (2001f).

${ }^{5}$ See World Bank (2001e).

${ }^{6}$ See World Bank (2001g).

${ }^{7}$ See World Bank (2001e).

${ }^{8}$ See World Bank (2001g).

${ }^{9}$ World Bank (2001d).

${ }^{10}$ See DfID (2000e), p. 22.
} 
communicable diseases in 2001) and considers itself as the leading agency in the struggle against AIDS. ${ }^{1}$ The sheer size of its operations, but also its vast research activities, underlines its exposed position in the field of development cooperation.

The main points where the World Bank establishes stronger accentuations than the other strategies lie in the fields of political systems and coalitions, the provision of security, fiscal and monetary policy and national budgets, and inequality. In these fields its views do not differ strongly from the other strategies, yet they offer much greater insight and precision. A differing view is taken on the issues of democracy and human rights, which in contrast to the bilateral strategies do not figure prominently in the analysis. The practical implication of this point for the implementation of the strategy is not clear, yet there is scope for internal conflict.

\subsubsection{Insights on Political Systems and Coalitions}

The new strategies demand strong changes on the national level of the partner country, in that they promote participatory movements in policies and generally a stronger allocation of resources towards the goal of reducing poverty in the economic sphere. These demands are portrayed in detail in all strategies. Yet the priorities of the population in a developing country is mixed and the interests of the non-poor do not necessarily coincide with those of the poor, nor do the interests of those in power correspond with measures to shift political power to the poor. The problem how the non-poor, yet influential, population shall be convinced to subscribe to the ideas developed by new strategies has received little attention in the recent strategies. ${ }^{2}$ The World Bank takes up this issue by considering the politics of coalitions between poor and non-poor. ${ }^{3}$

One of the insights of this analysis is the accentuation of common interests of the poor and the non-poor. The key is to effectively convey that "reducing poverty is a public good and can further the well-being of the nonpoor." . Examples for the common interests that should be stressed to persuade the non-poor to invest more strongly in the development of the poor are problems of communicable diseases or mass migrations. Communicable diseases affect the poor as well as the non-poor, and their effective reduction in many developing countries is crucially linked to the reduction of poverty and the provision of hygiene facilities to the poor. This is in the interest of the non-poor to protect their own health. Measures of rural development can be promoted to

\footnotetext{
${ }^{1}$ See World Bank (2001g).

${ }^{2}$ Short exception is DfID (2000e), p. 5, 6.

${ }^{3}$ The following discussion is based on the insight presented in World Bank (2000a), p. 81, 93, $94,109-112$ and $127-130$.

${ }^{4}$ World Bank (2000a), p. 109.
} 
the same extent by accentuating the problems the non-poor in the cities will be faced with, if migration tendencies to the urban areas expand. The challenge lies in the communication of these points to the non-poor population in a way that secures national consensus on the need for poverty reduction and for the allocation of resources towards this end. These efforts do not necessarily have to deal with all of the non-poor, who do not form a homogeneous group and might have different interests e.g. in the rural areas than in the cities, but can be targeted to a specific group which currently is helpful for securing a majority for a pro-poor policy.

This also includes the establishment of reform processes that can be mutually beneficial. For example, voluntary land reform strategies based on adequate compensation for the affected farmers have been undertaken. These eliminate the conflict of interests but might be limited by budgetary constraints. Another important measure relies on enabling the poor to voice their interests by removing legal barriers to formation of interest groups and by providing assistance in their organization. This is necessary because otherwise coalitions will be hard to establish because the poor cannot act efficiently as a partner in the arrangement. Linkages between the local organizations of the poor are also important measures to increase their power.

The World Bank's concern for the political constraints in the implementation of poverty reduction measures can be attributed to its strong involvement in the politics of the partner countries, because of the large sums it can provide to them and conditions that are linked to them. It also reflects its increasing regard for governmental issues linked to economic development and poverty reduction. ${ }^{1}$

This consideration of practical aspects of how to reach national commitment for poverty reduction, is important for achieving a higher degree poverty focus in the recipient countries - even though these practical steps are rather vague. It can serve as the baseline for deeper discussions on national strategies to foster this commitment and can set an example for the political considerations of other donors. The current notion of conditionality, which links ODA to the commitment in poverty reduction, will miss an important point if the tools are lacking to help a committed government to promote its strategy successfully. An approach to foster national coalitions is such a tool. It also serves the purpose of confronting the highflying aspirations of some new strategies, which simply take a commitment for poverty reduction as a precondition, with the political realities in developing countries. These have to be taken into account if the strategies shall have real practical impact. Due to its financial influence the World Bank is in a well-suited position to specialize in consulting the political process of enforcing the reduction of poverty, yet might be limited by its mandate to political neutrality.

\footnotetext{
${ }^{1}$ See World Bank (2001d).
} 


\subsubsection{National Security Schemes}

A second point where the analysis of the World Bank expands beyond the analysis presented in the other strategies, concerns the provision of security ${ }^{1}$. The World Bank considers to this extent the security provision by individual and group efforts, by state systems that can support and enhance these efforts and through measures of crisis prevention. In contrast to other strategies it specifically analyses intra-household volatility in income and consumption, the prevalence of which is especially detrimental for the development of children and to a lesser extent to the situation of women. ${ }^{2}$ The World Bank analysis extends beyond those presented by Sida and DfID, which are strongly biased towards crisis prevention, and also beyond the German position, which covers national measures, yet only briefly. The World Bank strategy has deeper insights to offer especially in regard to self-insurance and national security schemes, which are an extension of the general consensus and shall be covered first, while its underlying reluctance towards informal, group-based insurance mechanisms can be seen as a potentially conflicting assessment and will be covered at the end of this paragraph.

The one aspect more strongly pronounced in the World Bank strategy concerns the individual's ability to self-insure his livelihood. This analysis has been integrated in the analysis of the consensus as it relies heavily on measures of micro-finance and micro-insurance, which are common to all strategies. The difference lies in the fact that these are not regarded primarily as a measures to increase the economic opportunities for the poor but to increase security and to avoid some of the short-comings of other buffer items such as livestock who's returns are likely to be covariant with the shocks the individual is faced with.

While some national measures such as health care provision, AIDS/HIV prevention and hygiene promotion also enter the general analysis of most strategies, the World Bank has to offer new, additional insights on insurance schemes that can be implemented on the national level. These comprise old age assistance and pension systems, unemployment insurance and assistance schemes, workfare programs, social funds and cash transfers. ${ }^{3}$ Since these are only vaguely covered in what has been termed the consensus of poverty reduction, yet concentrate on risks that are very eminent for the poor, these points shall be discussed in turn.

The risk that people bear in their older age of having insufficient funds for their survival while being unapt to work for its provision poses a threat to most people, yet is especially high for people who have been poor during their working years. ${ }^{4}$ This assessment, linked to the fact that only a small proportion

\footnotetext{
${ }^{1}$ See World Bank (2000a), p. 19, 20, 135 - 170.

${ }^{2}$ See World Bank (2000a), p. 28, 145.

${ }^{3}$ See World Bank, p. $152-159$.

${ }^{4}$ Flanagan, K. (1999).
} 
of the labor force in developing countries is formally pensionable ${ }^{1}$, leads the World Bank analysis to propose measures that focus on increasing the economic position for today's poor working age people and to contribute to directly ease the burden for today's elderly poor. Poverty reduction for today's working age poor contributes to their self-insurance capability for their later life if coupled with systems that facilitate asset accumulation such as micro-finance schemes. It also enables them to take on their informal obligations towards the poor in their families. Thus, overall measures of reducing poverty are the prime component of securing the old people in need. To assist those aged people who are currently in need, forms of direct and indirect support such as assistance for families who care for live-in elderly and retraining programs to facilitate the continuation of working are proposed. A focus on the poorest, the very old and those without family support is called for $^{2}$, yet questions on how those shall be detected and how such procedures are to be justified towards those families that are left with the burden of caring for the old without receiving assistance is left open.

As long-term design for pension reforms the World Bank proposes a three-pillar model based on a publicly-managed, defined-contribution plan which addresses poverty and equity concerns. Defined contributions of the individual to a public fund under private management shall serve as wage replacement after retirement and as supplemental voluntary retirement savings. ${ }^{3}$ This analysis is only touched on briefly and neglects a discussion of the potential difficulties involved in the implementation. Given the fact that the problems of overpopulation are partly attributed to the fact that a high number of children serves as a measure to increase security ${ }^{5}$, it might be valuable to explore the extension of innovative old age assistance and insurance schemes as a possible solution more deeply.

As with threats of poverty in old age, the proposal of the World Bank for threats in unemployment does not rest on formal insurance schemes. Traditional unemployment insurance is considered inappropriate because poor people's informal working arrangements and the associated fluctuation of income makes it difficult for them to participate in contributory insurance programs ${ }^{6}$. While measures for job creation through sound macro-economic policies, improved

\footnotetext{
${ }^{1}$ The coverage of old age insurance only extends to $16 \%$ of the labor force in developing countries and only to less than $10 \%$ in the poorest south Asian and sub-Saharan African countries, while extending to about $85 \%$ of the labor force in OECD countries (internal World Bank research by Palacios, R. / Pallares-Miralles, M. (1999) cited in World Bank (2000a), p. 153.

${ }^{2}$ See World Bank (2000a), p. 154.

${ }^{3}$ See World Bank (2000a), p. 153.

${ }^{4}$ Except the problem that the poor might not be able to cover the constant insurance premium and are therefore excluded from the program.

${ }^{5}$ See e.g. Birdsall (1988), p. 242.

${ }^{6}$ A point not mentioned in the analysis is the problem of determining the employment status of people working in the informal sector, which exaggerates problems of moral hazard in demanding unemployment benefits while being effectively employed.
} 
efficiency and deregulation of the labor market including allowance for collective bargaining ${ }^{1}$, skill-enhancement programs and microenterprise development are the priority, the remaining threat of unemployment can be most successfully dealt with by public work (workfare) programs or means-tested social assistance. ${ }^{2}$

Workfare programs are publicly financed projects with an especially high degree of manual labor for unskilled unemployed workers, so that the highest proportion of project costs arises in form of wages. Self-targeting of the unemployed can be pursued by payment of below market wages. If poor people are confident that a workfare program will be available in times of crisis, they can give up costly self-insurance in normal times in favor of more productive activities. In times of crisis, the program can be extended to effectively cope with it. Still the costs of the program can be rather high. Yet next to insurance, the work provided can also be used to provide infrastructure for further economic opportunities. Therefore the benefits can also be high if the programs are well planned.

Some of the employment generating effects can also be reached via social funds. ${ }^{3}$ These funds are designed to finance small projects identified and implemented by poor communities that usually provide co-financing. Their prime purpose lies outside of insurance purposes to provide a demand-driven, flexible and cost-effective approach to fields like infrastructure provision, social services or support for decentralization targeted at poor beneficiaries. Their riskmitigation capacity results from enabling and stimulating school enrollment and health center use and by strengthening the social capital of communities as well as creating employment on the local level.

Cash transfers in form of means-tested assistance are proposed as a viable short-term method for reducing poverty ${ }^{4}$. Assistance can be extended to assist the unemployed, as remarked before, the elderly or families and can integrate programs for human resource development. The limiting feature is the possibility to target the programs efficiently. Observable criteria such as children enrolled or participating in a health plan can be some indicators for family assistance. Better targeting is also attributed to decentralization. Especially concerning education cash transfers, food-for-education programs and fee waivers are considered to ensure that - even in downturns - children are kept in school and long lasting impacts of undernourishment and illiteracy are prevented.

In its analysis the World Bank goes beyond the insights of the other strategies in regard to security provision. This is congruent with its pioneer

\footnotetext{
${ }^{1}$ This argument is based on the analysis that improved relationships among labor market partners and forms of collective bargaining lead to more effective labor market outcomes. This relationship has been analyzed in detailed in the WDR 1995, World Bank (1995).

${ }^{2}$ See World Bank (2000a), p. 155.

${ }^{3}$ This analysis draws on World Bank (2000a), p. 155, 156.

${ }^{4}$ For this analysis see World Bank (2000a), p. 158.
} 
vision of establishing security as one of the three large schemes in national efforts to reduce poverty. Its strong concern for the individual and his methods to increase his own security are also in accordance with the general theme that the poor themselves should be enabled to take control of his live and to use his own assets. This view is coupled with the recognition that the state has to take some efforts to address the problem of security of the poor, since they will not be able to secure it entirely by themselves. The proposals for state intervention are then geared to the conditions in developing countries and they do not solely propagate the traditional systems used in industrialized nations. These insights of the World Bank analysis do not collide with any of the other views on the provision of security and can be interpreted as an extension of these views.

While generally supporting the consensus on security provision, the World Bank takes a singular view in its reluctance to support informal, group-based insurance schemes as a viable insurance option. ${ }^{1}$ While it is noted that groupbased informal insurance should not be reduced through individually targeted safety nets if it works well, there is strong concern that it does work well for the very poor because of its reliance on reciprocity ${ }^{2}$. Also, if safety nets target almost everyone and are more cost-effective and sustainable, "the disappearance of informal insurance arrangements may not matter" ${ }^{3}$. In this assessment the World Bank departs from its normally prevalent concern for the reality in developing countries in which a nearly universal coverage is far from normal and the efficiency of public insurance is questionable. ${ }^{4}$ Its underlying reluctance to accept informal arrangements of security provision as a potential by which the position of the poor can be improved, given the reality of security provision in many developing countries is at odds with some research in this area ${ }^{5}$ and bears the potential for conflict or at least hindrance of cooperation between donors ${ }^{6}$. Apart from this point, the World Bank seems to drive the debate on security provision in the overall consensus. It goes farthest among the donor agencies to take concerns for security into account, to the same degree as political and economic measures.

\footnotetext{
${ }^{1}$ This argument relies on the text passage: World Bank (2000a), p. $143-150$.

${ }^{2}$ See World Bank (2000a), p. 149.

${ }^{3}$ See World Bank (2000a), p. 149.

4 The problems are pointed out in the WDR 2000/2001 itself in its analysis of specific instruments for state security provision, World Bank (2000a), p. $151-159$.

${ }^{5}$ E.g. Gsänger, H. calls into question the ability of developing countries to reach a large part of their population via formal, public security systems. He proposes a system where selforganization and solidarity actions are fostered and where security systems are designed in a subsidiary manner at the lowest (possibly informal) level possible. Overall security is ensured through the networking of these systems. See Gsänger (1993), p. 36 - 92-

${ }^{6}$ E.g. in BMZ (2001a), p. 25,26 the increase of effectiveness of informal systems of security is especially taken into account and informal systems are supposed to be strengthened as part of an overall strategy to increase security. This approach conflicts with preferences for broadbased state-led approaches, even though it does not refute them as viable means.
} 


\subsubsection{Concerns for Macroeconomic Policy and Inequality}

The World Bank has nevertheless not departed from its focus on economic (especially macro-economic) criteria in the pursuit of poverty reduction. Fiscal and monetary policy and balanced national budgets ${ }^{1}$ are a deep concern within the analysis of the World Bank. This focus is based on its large experience with structural adjustment programs since the 1980s. The ideas have already been covered in the analysis of the overall consensus, as they do not conflict with the other strategies yet expand their viewpoints.

Notable is the Bank's strong concern for the impact of measures on the poor, which is the baseline for the evaluation of its strategies. In this regard it evaluates the government's expenditure and revenue side. While the priority for pro-poor public spending is acknowledged in all strategies, the World Bank takes explicitly the raising of revenues into account. ${ }^{2}$ It assesses a need to broaden the tax base, lower tax rates and strengthen revenue collection in many countries, which contributes to higher equality in unequal societies by making taxation more efficient and just.

Equality is another point where the analysis of the World Bank extends beyond the focus of the other strategies ${ }^{3}$. Its insights on the reciprocal relationship between equality and human capital and on the detrimental effects of initial inequality for overall growth and collective action have been incorporated into the general analysis. The World Bank's analysis of inequality is, similar to its insights on macro-economic policy, an extension of the views of the other strategies and does not conflict with them. Yet this theme has found greater resonance in the analysis and strategic thinking of the World Bank than of the other donor organizations.

\subsubsection{Reservation with Human Rights and Democracy}

The key point in which the World Bank does not reflect the general consensus of the other three analyzed strategies lies in the smaller importance it places on human rights and democracy as vital components of poverty reduction attempts. This is not to say that the World Bank neglects human rights or does not take them into account. Core labor standards and the prohibition of child labor ${ }^{4}$, discrimination $^{5}$ and a culture of human rights ${ }^{6}$ do figure in the analysis. Yet they do not receive as close attention as in the other strategies where they are regarded as preconditions to any attempts for poverty reduction. The World

\footnotetext{
${ }^{1}$ See World Bank (2000a), p. 49, 61 - 64, 69-73 and 80 - 82.

${ }^{2}$ See World Bank (2000a), p. $80-82$.

${ }^{3}$ See World Bank (2000a), p. $52-60$.

${ }^{4}$ See World Bank (2000a), p. 73, 74 and 154.

${ }^{5}$ See World Bank (2000a), p. 118, 119.

${ }^{6}$ See World Bank (2000a), p. 122.
} 
Bank takes human rights issues into account by exploring their value for the establishment of positive economic conditions for long run poverty reduction. This approach yields similar conclusions by demanding equally in front of the law, the empowerment of women, basic education for all and the abolishment of all forms of discrimination. Yet the approach differs from the other strategies. While in the other strategies human rights are considered primarily in their own right, the World Banks sees them primarily as a means to achieve greater and lasting reduction in poverty ${ }^{1}$. For example, the promotion of education in the bilateral strategies is based to a large degree on the perception that education is a good in itself, while the World Bank analysis takes up this point mainly in its analysis of measures to increase growth and economic opportunities for the poor. Even its analysis under the point empowerment is linked back to the contribution of empowerment to economic development for the poor.

While the discussion of human rights still figures prominently in the analysis through the channels just mentioned, the issue of democratic regimes is omitted from the discussion except from one subchapter. ${ }^{2}$ The World Bank acknowledges the successes in poverty reduction in at least some undemocratic settings such as in the Republic of Korea prior to becoming a pluralist democracy. This shows an open-minded attitude towards the potential breadth of political options of ruling a country that is not ventured into in the other strategies, which take the benefits of democracy as given. In its overall assessment the World Bank lends support to democratic regimes by pointing at their superior accountability requirements and their limitation to the abuse of power. These two reasons are presented as the main determinants for the preference for this political concept. Yet the World Bank's analysis avoids incorporating this assessment of the value of democracy in any other part of its analysis; in contrast to most other topics which are explored in various parts regarding their mutual benefits. Thus, a reluctance to take up the issue of democracy on a broader scale can be identified.

The self-limitation of the analysis on mainly economic terms has to be viewed in the light of the constituency base of the World Bank. The 181 countries of its member base do not all have democratic structures. They have based their membership on the Articles of Agreement, which limits the World Bank engagement to economic concerns and prohibits interference in political matters. ${ }^{3}$ The endorsement of the Universal Declaration of Human Rights by most countries makes it easier for the World Bank to prominently display their virtues in economic terms, while the promotion of democracy is a far more sensible issue given the amount of countries that have not adopted this system.

\footnotetext{
${ }^{1}$ It should be noted here that the broad definition of poverty already includes political and social inclusion and thus already incorporates human rights perspectives.

${ }^{2}$ See World Bank (2000a), p. $112-115$.

${ }^{3}$ How this is reconciled with the World Bank's concern for good governance, which has economic as well as political implications, is not explored in the documents analyzed for this thesis.
} 
This reservation of promoting democracy and human rights contrasts with the vigor of the bilateral strategies in this regard and might be of hindrance in the establishment of close cooperation and coherent approaches ${ }^{1}$.

Overall the WDR 2000/2001 has taken a large step in forming the consensus we see today. Since Germany, Sweden and the UK are members of the World Bank and have representation in the Board of Directors it is not astonishing that the WDR encompasses a broad view that is mainly shared in the bilateral strategies. Still the World Bank document also has its unique accentuations especially in the areas of security schemes and political coalitions that deliver deeper insights for improvements in these areas. Only in the field of democracy and human rights and partly in the area of group-based informal insurance there are certain deviations from the general opinion found in the other strategies.

\subsection{United Kingdom}

\subsubsection{UK Background on Development Assistance}

The UK position on developmental issues has to be interpreted on the background of a former colonial power ${ }^{2}$ with large overseas territories until well into the $20^{\text {th }}$ century. After the independence of the overseas territories and the establishment of the Commonwealth, the UK promoted the so-called "Colombo plan" for economic cooperation between the Commonwealth industrial nations and the countries of South and South-East Asia. Under this scheme successful links between these countries were established which still effect today's relationships. $^{3}$

In recent years there has been a strong movement in the UK towards a higher commitment to developmental efforts, especially towards poverty reduction. This is visible in the reorganization of the development assistance since the change in government in favor of the Labor party in 1997. During the first year in power the central development organization, the Overseas Development Agency, founded in 1964, was renamed Department for International Development (DfID). It was moved from its position as part of the Department for Foreign Affairs to the position as independent governmental department headed by a minister with cabinet rank, reflecting its increased importance. The same year the UK government issued a White Paper on Development for the first time since the early 1970s, followed by a second White Paper in 2000. DfID developed a comprehensive strategy to reach the

\footnotetext{
${ }^{1}$ E.g. in DfID (2000d), p. 21 the World Bank is explicitly encouraged to take human rights concerns more into account. In DfID (2000e) a criticism of the narrow interpretation of the mandate of the World Bank concerning 'economic government' is found.

${ }^{2}$ See Bendix, P. (1994), p. 108.

${ }^{3}$ See Bendix, P. (1994), p. 109.
} 
IDTs in nine strategic documents open for public debate. This large concern with the strategic orientation in development assistance shows the movement and the emphasis put on this issue within the UK government and its development agency. The British ambitions are also visible in their priority to exert influence on multilateral institutions, in many of which it has placed employees for more efficient cooperation, and to augment the overall developmental debate.

DfID is responsible for handling the British development cooperation and has 1650 employees dedicated to this task, 740 of whom work at the London headquarter, 460 in the administrative unit in Scotland and 450 (of whom 280 are local nationals) in decentralized offices in developing countries. ${ }^{1}$ It maintains country offices in countries which receive funding above 35 million pounds. They serve as a link to the field and have the full responsibility including nearly autonomous decisions over projects. Even if country decisions are taken in London in cases where a local office is not warranted, forms of local presence of DfID's staff are available. This decentralized structure facilitates the dialogue with the partner government and with the civil society. The funds for DfID are to rise by $6,3 \%$ annually between 1999 and 2003 after a longer period of decline to a new height of 3.560 billion pound.

The UK position rest strongly on the unambiguous commitment to the IDTs and on a focus on measuring its effectiveness against these targets. This is linked to efforts of greater conditionality and aid concentration and on knowledge generation. Additional insights have been brought into the analysis by focussing on problems of globalization and by specifically addressing water problems and the problems of the urban poor. Unconventional is DfID's accentuation of shortterm losses due to adjustment processes. These focal points of the British strategy will be discussed in the following.

\subsubsection{Concentration}

The approach of the UK towards development cooperation is characterized by a strong concern for effectiveness ${ }^{2}$. One of the distinguishing features of this trait is the focus on the concentration of activities. It proposes that development cooperation shall be limited to those countries where DfID has a comparative advantage in the delivery of aid, where there is a large number of poor people and a high level of need in the recipient country, and where the country commits itself to a poverty reduction scheme and has the internal conditions in place to generate lasting impact from DfID's engagement ${ }^{3}$. The concern for conditionality has been incorporated in the analysis of the general consensus, yet

\footnotetext{
${ }^{1}$ For reference on this paragraph see BMZ (2000b).

${ }^{2}$ See e.g. DfID (1999b), p. 29 and UK government (1997), p. 36.

${ }^{3}$ See UK government (1997), p. 38, 39.
} 
is deepened here by a more detailed analysis on the conditions that DfID considers necessary for a cooperation. These entail an assessment of actual need, which points to a shift in the use of the more concessional funds away from better-off countries in Eastern Asia and Latin America, which shall graduate to loans on near commercial terms, towards the countries of sub-Saharan Africa and South Asia. ${ }^{1}$ Next to the conditions of low-income and a large proportion of poor people, the UK expects the partner government to ${ }^{2}$ :

- have a commitment to the principles of the agreed IDTs

- be committed to pro-poor economic growth and conservation of the environment

- wish to engage with the UK towards this end

- pursue policies which promote responsive and accountable government; promote the enjoyment of civil, cultural, economic, political, and social rights; and which encourage transparency and bear down on corruption.

This concern for human rights, shown here in its impact on conditionality, is especially prevalent in the analysis of $\mathrm{DfID}^{3}$.

The fulfillment of the expectations by the partner government ${ }^{4}$ has to be accompanied by a comparative advantage on the side of DfID to effectively contribute to poverty reduction in the country ${ }^{5}$ in order for DfID to engage itself there. An example for the concentration based on the comparative advantage of DfID is given in the context of support for good governance ${ }^{6}$. In this context DfID pursues a strategy of regional specialization and of issue-based specialization, with both forms of specialization seen as conducive in increasing the efficiency of the development cooperation undertaken by DfID. For regional specialization DfID takes special interest in the countries of the Commonwealth. It regards itself especially situated because of the knowledge on those countries' specific conditions, the long history of cooperation and the long-term relationships to these countries. This gives DfID a specific advantage for the cooperation.

Alongside this regional specialization DfID pursues issue-based specialization. In regard to good governance the areas in which DfID perceives a special expertise include: elections and parliamentary government; civil society; privatization and regulation; public expenditure management, sector-wide approaches and revenue administration; civil service reform, contracting out and public service customer focus, participatory poverty assessments, gender

\footnotetext{
${ }^{1}$ UK government (1997), p. 36.

${ }^{2}$ See UK government (1997), p. 39.

${ }^{3}$ E.g. DfID (2000d) is entirely dedicated to this point. DfID's approach to poverty reduction is generally much stronger influenced by a thinking of the rights of the individual than by the economic outcomes that are the prime concern of the World Bank's approach. Therefore it is surprising that the results of the analysis are very similar.

${ }^{4}$ Or at least a shift in policies that makes an obtainment of the expected level very likely in the future.

${ }^{5}$ See UK government (1997), p. 36.

${ }^{6}$ For this discussion see DfID (1999b), p. 27.
} 
analysis and local institutional assessments; community security and penal reform; reconstruction of government after conflict; and aspects of anticorruption strategies. For the future it wants to engage also in the areas of deepening democracy to promote the participation of poor people in government; developing regulatory systems to assure the quality of private sector providers; promoting accessible, non-discriminatory justice; reforming security sectors and creating inclusive political structures as part of conflict prevention efforts; restricting money laundering globally; and mobilizing the political will for reform. In these areas DfID will establish its comparative advantages in regard to governance, yet DfID will not seek to take a lead in areas where other agencies have greater competence. ${ }^{1}$

The benefits of specialization have already been discussed. Desirable for the specialization on the regional dimension is an international agreement that assures that all developing countries are taken into account in a scheme of greater specialization and that none is left without external funding. Specialization has not yet reached a degree where this imposes a real problem. More acute is the question on the degree of issue-based specialization. Specialization requires a limitation in the number of tasks on which a single agency wants to concentrate in order to build up the necessary know-how in it to reap the benefits from a focused approach. Other areas are in turn neglected and left for the specializing efforts of the partners. It will have to be seen if DfID has chosen its areas of specialization narrowly enough to be able to establish special international expertise in it, the basis for any strategy of specialization. The list of issues in which DfID has already specialized or wants to specialize is very comprehensive in regard to governance issues. The question arises how long the list of issues in which DfID does not want to engage itself would be, and if there is real scope for an international division of expertise in which other agencies take over valuable development positions as well.

Another challenge arises from the concept of focussing aid on the very poor countries. There is a strong likelihood that the difference in income level can be at least partly explained by differences in governance in the past. To exclude better-off countries despite a remaining large portion of poor people has the unintended effect of providing negative incentives to those countries that are on the brink of reaching the middle-income group, an aspect that needs to be taken into account in the implementation of this form of conditionality. The continuation of provision of strong support in from of technical assistance and knowledge transfer ${ }^{2}$ might be one way to reduce this effect.

\footnotetext{
${ }^{1}$ See DfID (1999b), p. 27.

${ }^{2}$ See UK government (1997), p. 40.
} 


\subsubsection{IDTs and Impact Measurement}

In its search for more efficient ways to reduce worldwide poverty, DfID has taken on the challenge proposed in the International Development Targets (IDTs) ${ }^{1}$ vigorously and has linked its own success and effectiveness appraisal to its contribution towards these goals ${ }^{2}$. In its perception of the central value of the IDTs for global cooperation and for greater focus of development efforts the UK position can serve as a role model for other donors if these really wish to take on the IDTs as a commitment. ${ }^{3}$

The UK government has embraced the IDTs already in 1997 as goals, which it welcomes and promotes ${ }^{4}$. It has reaffirmed these goals as "absolutely central to (.. its) development strategy"5 in its second White Paper in 2000. This is the basis on which DfID has drawn up its Strategies for Achieving the International Development Targets. All nine of its recent strategic documents are focused on this goal and describe the problems and the solutions DfID sees in different areas of development cooperation. This accentuation of measurable outcomes of the developmental efforts is stronger established in these strategic documents than in the other analyzed strategies. For DfID the IDTs are not only important as indicators of progress, but as a representation of collective commitment by the international community to work towards global progress. ${ }^{6}$

It has therefore linked its program assessment to its contribution towards poverty reduction. "At its heart [...] are the international development targets and the key indicators which have been identified to measure progress towards the achievement of these. Clear targets and measures of progress are essential to focus minds, to provide encouragement when progress is made, and to strengthen coordination around common goals." ${ }^{77}$ To this end DfID has dedicated the last chapter of every document to the questions of measurement of results. ${ }^{8}$ It is acknowledged that the IDTs only provide general guidance and need to be adapted to suit local conditions. ${ }^{9}$ Additional measures have to be introduced to

\footnotetext{
${ }^{1}$ For more insights see the chapter "International Development Targets".

${ }^{2}$ See e.g. DfID (1999a), p. 3.

${ }^{3}$ The acceptance of the IDTs bears the risk of credibility trap (see chapter on IDTs) because their achievement rests on the contributions of many agencies and the developing countries (as is acknowledged e.g. in the foreword to DfID (2000f)). This risk has to be weighted against the additional resources in terms of personal involvement and increased cooperation that can be reached through this commitment.

${ }^{4}$ See UK government (1997), p. 20, 21.

${ }^{5}$ UK government (2000), p. 12.

${ }^{6}$ See e.g. DfID (1999a), p. 3.

${ }^{7}$ DfID (2000f), p. 25.

${ }^{8}$ DfID (1999a), p. 35, 36; DfID (1999b), p. 35, 36; DfID (2000a), p. 48; DfID (2000b), p. 32, 33; DfID (2000c), p. 38 - 40; DfID (2000d), p. 24, 25; DfID (2000e), p. 29; DfID (2000f), p. $24-27$; and DfID $(2000 \mathrm{~g})$, p. 31,32 . The general theme of these is similar, only adapted to the context of the specific issue at hand.

${ }^{9}$ See DfID (2000f), p. 24.
} 
capture that whole scope of the problem. ${ }^{1}$ Still the IDTs build the core and DfID is willing to have its own performance assessed via an annual Output and Performance Analysis (OPA) Statement against key departmental objectives, which in turn are linked to the IDTs. ${ }^{2}$ Despite the difficulties of absence of direct causal links between DfID's spending and progress towards IDTs, the OPA scheme is seen as an organized and logical way to draw the connection. ${ }^{3}$

Next to the appeal to use the IDTs as means to monitor of the agency's performance, three major themes emerge in the discussion ${ }^{4}$. First, DfID ascertains a need to strengthen statistical capacity to measure performance. Gaps in the statistics and poor quality data on many countries reduce the reliability of impact measurements and their effectiveness in guiding policy responses. DfID wants to tackle this through increased technical assistance in this area and through close cooperation with the World Bank and the UN in this regard. A second point concerns the agreement on milestones, which should be set internationally and nationally, to be able to track the success towards the longer-term objectives. The third point covers the need for "Learning Lessons" . These comprise the need to monitor effectiveness on the project, national and regional level towards the achievements of the IDTs and to feed the results back into the conception of programs. ${ }^{6}$ This also includes the transfer of lessons learned in middle-income countries of Latin America and Asia into its policies for the poorest. ${ }^{7}$

DfID presents in its strategies a great concern for the measurability of the aid effectiveness. It regards the measurement as a key control and motivation mechanism that needs to be implemented to increase the effectiveness of aid flows and to be able to propose policy changes. To this extend the UK also encourages the multilateral development agencies to devote more attention to evaluating and monitoring the output of their activities and to harmonize their impact assessment systems. If DfID is able to translate its ambitions into practical action it can serve as an example for other donors on ways to monitor their effectiveness and thus improve their efforts.

\footnotetext{
${ }^{1}$ See e.g. DfID (2000f), p. 26, 27. It gives an example on a variety of additional measures to assess the impact on the equality of women in terms of productive assets availability, decision-making, personal security and others.

${ }^{2}$ See DfID (1999a), p. 35.

${ }^{3}$ The functioning of the OPA scheme is not explained; therefore the effectiveness of this approach in achieving this difficult link cannot be assessed here.

${ }^{4}$ See e.g. DfID (1999a), p. 35, 36 or DfID (2000b), p. 32, 33 for this discussion.

${ }^{5}$ DfID (1999a), p. 36.

${ }^{6}$ DfID presents a series of indicators in each of the strategies, which are too broad for reference here. It relies heavily on the data collection of the World Bank and the UN in the provision of national data to analyze aid effectiveness on the national level. Its own measures to collect data and to analyze it are not reported in further detail in the strategic documents.

${ }^{7}$ See DfID (1999b), p. 31.
} 
One question only tackled briefly in the DfID strategies is the costs of impact measurement. Only at one point it is assessed that "measurement and analysis of poverty is expensive and it must be primarily designed to influence national debates on poverty." "Yet impact measurement is also necessary for donor evaluation of their policies and for individual project evaluation. The strong approach towards measurement that DfID pursues is restrained by the costs of such measurement. In an economic argumentation the evaluation them makes sense if its benefit outweigh the costs of conducting it. ${ }^{2}$ Since there are potentially high benefits of increased impact measurement, the strategy of DfID might prove sensible, yet this can only be proven empirically by evaluating the impact of poverty assessment in terms of increased efficiency and its costs.

\subsubsection{Knowledge}

The concern for effectiveness of aid flows is also visible in DfID's concern for knowledge and best practice dissemination. To enhance effectiveness, its strategies rely on investments in research on poverty and sustainable development to generate knowledge on the causes of poverty and on approaches to poverty reduction ${ }^{3}$. To use its knowledge, and through that its resources, effectively and efficiently is part of UK's key objectives. ${ }^{4}$ DfID also strongly argues for the generation of knowledge on scientific issues relevant for developing countries and for the adaptation of existing knowledge to their specific needs ${ }^{5}$. The dissemination of this knowledge and of methods of best practice is also strongly encouraged to propagate the gains of efficiency improvements to spread more broadly ${ }^{6}$. This view has been integrated into the discussion of the overall consensus, as it extends the viewpoints present also in the other strategies. Yet the recurrence of this theme and the depth of this discussion on measures to increase knowledge throughout all of DfID's strategies as well as in the governmental White Papers makes this an noticeably important determinant of the overall UK strategy.

\subsubsection{Globalization}

Next to the strong focus on efficiency gains of development budgets, the UK position displays a deep concern for the problems and challenges arising from

\footnotetext{
${ }^{1}$ See DfID (1999b), p. 24.

${ }^{2}$ For a more detailed discussion see the chapter on Excursion: The need to reflect benefits against costs'.

${ }^{3}$ See e.g. UK government (1997), p. 48.

${ }^{4}$ See UK government (1997), p. 30.

${ }^{5}$ See UK government (1997), p. 48.

${ }^{6}$ See e.g. DfID (1999a), p. 30 and DfID (2000e), p. 26.
} 
the process of globalization, defined as a "growing interdependence and interconnectedness of the modern world"1. These have been the theme of the second White Paper ${ }^{2}$ of the UK government. Its insights have been integrated into the general analysis especially in regard to international regimes, as they deepen, but do not conflict with, the insights presented in the other strategies. The UK position also confirms that the measures discussed herein as the domestic framework are also needed in the view of globalization as they help with the successful integration of a country in the global market environment and the realization of benefits from increasing interconnectedness. ${ }^{3}$ It is assessed that only if governance and markets can effectively support the potential gains from trade and transfer of knowledge and can spread these to the broader population, especially to the poor, the chances of globalization can be reaped.

Two themes that extend the presented analysis arise from the British conception: the need for global institutions ${ }^{4}$ and a concern for the drain of qualified people from low-income countries ${ }^{5}$. In the analysis support for global political institutions is announced, since they are seen as crucial to better manage and counterbalance global markets, and to help promote global social justice. ${ }^{6}$ Especially, support is signaled for the UN system and its relevance for peace and development, the multilateral development banks and the IMF. Yet reforms in the management, structures and working methods of these institutions are requested to increase the impact of their actions. The UK demands include higher standards of accountability and disclosure policies, the selection of top management on the basis of merit, and concerning the UN the greater collaboration between its agencies. Inclusive political institutions are seen as especially important in the case of conflict prevention and resolution, where their absence or weakness - and therefore the absence of the means to resolving tensions peacefully - is leading to violence. ${ }^{7}$ In this context the UN system and its Security Council are seen to have major responsibilities. The establishment of an International Criminal Court is regarded as a vital means to promote reconciliation after conflict by prosecuting gross violations of human rights. Yet not only the multilateral institutions, also the individual countries are encouraged to make greater efforts for collaboration for example within the G8. This support for multilateral institutions does not conflict with the other strategies, yet its strong demand on these institutions constitutes a real challenge for these.

\footnotetext{
${ }^{1}$ UK government (2000), p. 15.

${ }^{2}$ UK government (2000).

${ }^{3}$ See UK government (2000), p. $23-31$.

${ }^{4}$ See UK government (2000), p. 20.

${ }^{5}$ See UK government (2000), p. 35.

${ }^{6}$ This paragraph on international political institutions relates to UK government (2000), p. 99 $-103$.

${ }^{7}$ See UK government (2000), p. 103.
} 
A problem area of globalization, which is tackled within the UK strategy, is the concern for "brain drain"1, which describes the enticement of well-educated people by employers in other countries. ${ }^{2}$ The trend to intensify global competition for qualified personnel has been intense in areas where domestic capacity in developed countries has been small, which has been the case e.g. in the health ${ }^{3}$ and information technology sector ${ }^{4}$. The benefits from such a policy accrues to the individuals who gain freedom of choice and earning opportunities and also for the sectors in developed countries which face shortages, yet the outflow of skilled workers can have mixed impact on the developing countries. If the emigrants return after a period of time with new skills, knowledge and contacts $^{5}$, this aids the country in catching up to developed countries, spurs internal growth through increased application of know-how and technology and brings in new capacity for the solutions of the developing country. These factors can be seen as justifications for the push of the UK government towards opting for an opening of the service sector as part of the WTO agreement. ${ }^{6}$

The UK also acknowledges the potential "significant remittances"' of such a policy for the developing country, which at least in the short term, has to deal with an outflow of skilled people that in many developing countries are "in critically short supply"8. Given the fact that all strategies express concern about the developing countries administrative capacity to implement reforms and to manage the domestic economic framework, a concern largely based on the lack of trained people, the emigration on skilled personnel becomes especially detrimental to development. DfID's solution relies on the self-restraining powers of the developed nations themselves. In the UK view these need to ensure that policies concerning the migration of people do not unfairly restrict the ability of developing country service suppliers to sell into their markets, yet also do not worsen skill shortages in developing countries. ${ }^{9}$

While this attempt is honorable, it neglects the pressure the individual developed countries are faced within a world of rapidly increasing global competition. The

\footnotetext{
${ }^{1}$ UK government (2000), p. 35. See UK government (2000), p. 35. process of catching up.

${ }^{3}$ See UK government (2000), p. 43.

${ }^{6}$ See UK government (2000), p. 70.

${ }^{7}$ UK government (2000), p. 43.

${ }^{8}$ UK government (2000), p. 43.

${ }^{9}$ See UK government (2000), p. 43.
}

${ }^{2}$ This discussion is based on UK government (2000), p. 35, 43.

${ }^{3}$ E.g. there are about $1 / 3$ as many doctors employed in South Africa than in Uganda itself.

${ }^{4}$ The German 'green card' rule, which allows up to 20000 IT specialists to enter the country, exemplifies this shortage. The targeting especially to Indian nationals points at the focus on developing countries. Yet the German rule is an insufficient example of brain drain as it is limited to a working period of five years. This might be detrimental to the personal choice of the individual, yet for the developing country it guarantees the return of its citizens with new skills and knowledge about technology that can be used in the home country to speed up the 
detrimental impact of substantial skill shortage on the national economy, the associated political unpopularity and the lobbying activities of the concerned industries call into question the effectiveness of standards relying on national ethical conduct in developing countries. To shift the power to control migration to the developing country is not proposed, potentially because of fear of misuse of this power by developing countries' governments who might unduly restrict the choice of their citizens. Yet it also needs to be considered that the developing country will most likely be able to judge its internal need of skilled people better than the developing countries agencies that are designated this responsibility by the DfID proposal. A third way would be an international allocation mechanism that sets one maximum migration quota applicable for all industrialized nations for a given developing country based on an assessment of its internal need. This limits misuse by the developing country and avoids a spiral of relaxing national immigration limits due to the pressures of globalization, yet is likely to lack political support from either side. This discussion has only just begun with the UK contribution of the topic and an effective solution will require more international work on the issue. ${ }^{1}$

Despite these shortcomings, the UK position of globalization raises many important questions and provides valuable insights, which will gain importance for the future effectiveness of developmental efforts.

\subsubsection{Additional Strategic Areas: Water Scarcity and the Urban Poor}

DfID places specific strategic importance on two areas that do not find strong accentuation in the other analyzed strategies: Water Scarcity and the Urban

\footnotetext{
${ }^{1}$ Full acceptance of the market mechanism is not proposed as an effective solution because it will not yield desirable results under the current framework. First, the developing country finances the education of the individual in many countries, yet the individual would have the chance to work where his personal returns are highest. This will be in developed countries which will for foreseeable time be able to pay higher wage rates. Thus, the developed country will effectively buy the education by paying a high wage rate for the individual's output, yet the benefits will only accrue to the individual and not to the developing country that financed it, leaving it worse off. Second, the developed countries only allow the immigration of skilled personal, but usually prohibit the immigration of 'economic refugees'. The opening of developed countries for both high skilled and low skilled at least has the theoretical possibility of transferring the solution capacity (e.g. the highly trained people) and the problem (e.g. the low skilled and poor people) simultaneously, thus potentially leaving the developing country in a state of equal overall distribution between solution and problem. This short annotation obviously omits all concerns for different migration patters, different marginal utilities of the two groups for the overall economy of the country, the effects of over- and under-population, and so forth. Yet if it explicates that only allowing migration of the skilled and needed people is like picking the raisins without concern for the cake, showing that the free migration of skilled people is not free market economy, but is strongly skewed because the migration of the rest of the population remains highly regulated.
} 
Poor. To both DfID has devoted a strategic document. ${ }^{1}$ Their insights are discussed in turns here.

In DfID's assessment freshwater is "a limited and precious resource which is essential for sustaining life" ${ }^{2}$. It is an essential not only for domestic use, but also for the agricultural, industrial and energy sectors, which taken together outweigh personal consumption by a ration of more than $8: 1$. $^{3}$ The already prevalent scarcity of water resources in many regions is assessed to increase in the future due to a rise in demand and shifts of supply. ${ }^{4} \mathrm{~A}$ trend of rising demand can be traced to the two factors of population growth and rising demand per person. The especially high population growth in developing countries has led to the strongest increases in demand in these countries. The increasing demand for food draws a higher percentage of water to the agricultural sector. ${ }^{5}$ The supply constraint arises from climate change that will shift the rainfall and will leave some regions worse off. Other factors on the supply side include desertification and the lowering of the ground water due to the unsustainable reduction of forests. The over-use of scarce water and the associated drawdown of water tables limit the accessibility of ground water through low-technology solutions even today. ${ }^{6}$ Technical measures such as desalination are only seen as a solution limited to coastal regions. ${ }^{7}$

To tackle the problems arising from water scarcity, DfID promotes on the national level the operational sustainability of water supply ${ }^{8}$. As best practice in this regard it considers the pricing of water at full costs of providing the service including recurrent and capital costs and the costs of ensuring the sustainability of supplies. Exceptions are only envisioned for transparent subsidies targeted to the poor people's demands. Functioning administrative bodies, a demand driven approach and the prevalence of measures of good governance combined with a concern for technical maintenance are seen as crucial for such an attempt. The national governments role in addressing the water-related problems of increasing scarcity, dispute resolution, social barriers to access and pollution abatement is supported. ${ }^{9}$ On the international level DfID promotes the spread of the Integrated Water Resource Management ${ }^{10}$, a national strategic framework that integrates the policies, sectors and players involved in freshwater at the community, national and basin level with emphasis on sustainability considerations. It also supports the World Water Council and the Global Water Partnership and supports and undertakes initiatives to assist in international

\footnotetext{
${ }^{1}$ DfID (2000a) and DfID (2000g).

${ }^{2}$ See DfID (2000a), p. 1.

${ }^{3}$ See DfID (2000a), p. $1-3$.

${ }^{4}$ See DfID (2000a), p. 1 - 6 .

${ }^{5}$ See DfID (2000a), p. 11.

${ }^{6}$ See DfID (2000a), p. 12.

${ }^{7}$ See DfID (2000a), p. 6.

${ }^{8}$ See DfID (2000a), p. $15-18$.

${ }^{9}$ See DfID (2000a), p. 36.

${ }^{10}$ See DfID (2000a), p. 21, 44.
} 
conflict resolution over water and to foster lasting cross-boarder solutions for access to limited water resources. ${ }^{1}$ That way a contribution for international peace and stability is aspired.

DfID regards the tendencies of urbanization as one of its core issues because it considers urbanization as a chance for benefits for the poor despite the problems it currently exerts ${ }^{2}$. Benefits from urbanization arise in DfID's view for the poor through increased access to services in form of health, education, infrastructure and safety nets. It also bears the potential to increase their participation in cultural and political activities that can improve their well-being and status. ${ }^{3}$ Cities can also contribute efficiency improvements in the provision of health, job opportunities, libraries, education, savings and loan facilities and access to environmental services by reaching the people at lower costs. ${ }^{4}$

Yet currently the urban experience makes live in cities particularly difficult for poor people who are living in crowded, unsanitary slum settlements, exposed to risk from hazardous environmental conditions, high risks of accidence and violence. ${ }^{5}$ DfID seeks to improve this situation through better urban management, including a rights based view on the living conditions people are entitled to, more vigorous enforcement of environmental standards to reap the environmental benefits of cities, and the reduction of violence through law enforcement ${ }^{6}$. The efficient management is dependant on a focus on the needs of the poor such as secure tenures and access to public services like waste disposal, water connection and sanitation ${ }^{7}$. A broader framework for assessing the needs of the poor at various poverty levels in regard to the issues of basic survival, security and quality of life is presented in annex 3 . The need for the provision of community services and utilities is viewed herein as at least equally important as funds or food transfers. The absence of a connection to utilities increases the unit costs for the poor and puts them at a strong disadvantage. ${ }^{8}$ As a precondition for this management, the local governments need to establish planning functions and means to secure sufficient revenues and manage them through sound financial practices. ${ }^{9}$ The operation of the utility systems through private providers is also recommended. ${ }^{10}$

Local level management is then to be backed by national public policies that grant a sufficient decentralization of power and recognize the positive impact of prosperous agriculture for urban development. This implies the

\footnotetext{
${ }^{1}$ See DfID (2000a), p. 42, 43.

${ }^{2}$ See DfID (2000g), p. iii.

${ }^{3}$ See DfID (2000g), p. iii.

${ }^{4}$ See DfID (2000g), p. 1.

${ }^{5}$ See DfID (2000g), p. iii, $9-11$.

${ }^{6}$ See DfID (2000g), p. 5, 10, 15, 17.

${ }^{7}$ See DfID (2000g), p. 8, 9.

${ }^{8}$ See DfID (2000g), p. 8.

${ }^{9}$ See DfID (2000g), p. 17.

${ }^{10}$ See DfID (2000g), p. 17, 18.
} 
provision of sufficient financing also for the agricultural sector as a condition to improve the lives of the urban poor. This necessitates considerations and active management on the national level regarding the relationship between urban and rural centers. ${ }^{1}$ The development of the rural areas increases the demand for urban goods if fostered, but in the case of neglect might overstretch the already limited capacities of today's urban centers due to poverty-related migration. ${ }^{2}$ Also public policy needs to pay attention to rural-urban transport networks and to reducing the proliferation of cities into the surrounding rural sector. Next to local and national attention the international community is viewed as necessary in promoting urban development. Towards this end DfID expects that the conference Istambul +5 on human settlements will be beneficial in adding goals for urban development ${ }^{3}$ to the IDTs and to foster stronger commitment for this issue. ${ }^{4}$ Also support for various UN schemes for urban development is signaled, yet their greater coordination is strongly demanded by DfID. ${ }^{5}$

The focus of DfID on the two themes of water scarcity and urban development that have not found strong resonance in the other strategies accounts for DfID ambitions in influencing the current debate in poverty reduction. They also bring to attention areas with rising potential importance for the $21^{\text {st }}$ century. Even though some points such as the relationship between the urban centers and the periphery are not yet analyzed to a degree where the approach for public action is unambiguously clear, this discussion emphasizes the importance of both issues in the international discourse. Since they do not conflict with the general consensus on the approach to poverty reduction, they can be seen as a valuable extension of the area of international concern.

\subsubsection{Long-term vs. Short-term Benefits}

An unconventional annotation within DfID's strategy is the explicit discussion of the limitation of resources in the implementation of pro-poor policies. It articulates the generally unpopular view that: "constraints in implementing some pro-poor actions in the short term in order to foster the economic growth which will reduce poverty more sustainable in the longer term" might prove to be a necessary step. In DfID's assessment the constraints that might be legitimately incurred by governments in order to promote long-term poverty reduction

\footnotetext{
${ }^{1}$ See DfID (2000g), p. 19, 20.

${ }^{2}$ See DfID (2000g), p. 20.

${ }^{3}$ See Annex 5 for a list of possible goals.

${ }_{5}^{4}$ See DfID (2000g), p. 6.

${ }^{5}$ See DfID (2000g), p. 24. The UN schemes include: Local Leadership and Management Training Programme, Urban Management Programme, Sustainable Cities Programme, Public Private Partnerships for the Urban Environment and Local Initiatives for the Urban Environment.

${ }^{6}$ DfID (1999b), p. 8.
} 
despite reducing funds for immediate pro-poor spending include the following: Prudent budgetary policies to maintain economic stability and business confidence; the upholding of property rights with only rare exception to avoid disincentives to private investment; and the inevitability of job losses in competitive environments in those companies which are out-competed. ${ }^{1}$ These constraints are accepted in the general consensus. DfID also considers low rates of taxation on profits and incomes as necessary to foster enterprise and investment despite limiting immediate poverty-reducing programs. This cannot be claimed as general consensus as both Sida and the BMZ do not take this point into account and the World Bank analyses this point from a revenues perspective, exactly in order to ensure sufficient resources to finance pro-poor spending. ${ }^{2}$

The view taken by DfID negates the view that achieving necessary growth for long-term poverty reduction by short-term pro-poor spending could solve the dilemma between encouraging growth and reducing poverty immediately. This view can also be inferred from the proposals in the other strategies, yet these do not take this point explicitly into account. This trade-off should to be managed explicitly in order to achieve a strong reduction of poverty in the long run without neglecting the people currently living in poverty.

In its strategy DfID proposes to focus pro-poor policies on measures that provide opportunities for the advancement of the disadvantaged by investments in basic education, good health, mobility, information and financial markets ${ }^{3}-$ in line with the overall consensus. That means that next to limitations on the current pro-poor spending in favor of long-term growth and thus poverty reduction, the spending is also focused on long-term investments. Therefore, the strategy emphasizes long-term strategies compared to short-term solutions for poverty reduction in both its discussion on constraint budgets and on investment of the limited currently available resources, thus placing relatively small value ${ }^{4}$ on the current situation of the poor. This theme can be extended for the overall consensus on poverty reduction, which views long-term investments, necessarily at the cost of short-term investments given the limited resources, as the key to poverty reduction.

This proposal solves the conflict between long-term and short-term benefits by giving clear priority to long-term benefits. But it does not solve the

\footnotetext{
${ }^{1}$ This discussion is based on DfID (1999b), p. 8.

2 The World Bank also regards the tax rate as high and distorting in many developing countries. This analysis is linked to other factors such as a narrow tax base, weak tax administration and poor public sector governance, which as a whole limit the states ability to collect sufficient taxes. It does not single out lower tax rates as conditional for enterprise development. It actually favors progressive tax rates especially in highly unequal societies. For the World Bank view see World Bank (2000a), p. 81.

${ }^{3}$ For this discussion see still DfID (1999b), p. 8.

${ }^{4}$ Actually in this economic context (DfID (1999b), p. 8) none at all. Nevertheless, other parts of DfID's strategy take immediate help for the poor into account and mitigate this strongly long-term view.
} 
trade-off regarding how these long-term benefits shall be achieved: By financial austerity fostering growth or by strategic investments in the poor; or by a scheme that balances the two in the most conducive way. This trade-off mentioned by DfID itself does not receive a solution in its strategy. DfID's (and the other donors') strategies lack the discussion on criteria by which to judge to what extent financial austerity, with its limitations on pro-poor expenditure ${ }^{1}$, shall be balanced against the need for resources to be invested in poor people. The establishment of such criteria might be beneficial to reach overall consensus on the benefit of structural adjustments vs. current spending in a specific country context, among donors' and recipient country's governments and among the donors themselves.

Overall, DfID's approach spans a wide variety of topics and discusses them in detail. This entails accentuations topics that have not been integrated into the general consensus since other agencies have not included these as major components into their more comprehensive strategies, yet can be inferred as being consistent with the overall framework without leading to conflicts. The concern for water scarcity and the urban poor are such areas. The analysis of the problems of globalization deepens the discussion in this field and can serve to increase the focus on this area that will influence many future aspects of development cooperation. DfID's strong focus on efficiency can yield greater public confidence in the way development funds are used and can serve as an international example if these aims can be translated into real efficiency advantages. One potential inconsistency of DfID's strategy lies in its attested limitation to areas of strategic advantage while its strategies are pronounced so broadly that a limitation is hardly visible. Also a lack of prioritization is visible, yet this extends to all strategies and might portray a general concern to leave open options for assessment at country level. In its discussion on spending constraints DfID takes up an issue that might deserve a lot more attention as it concerns a critical point of implementation in most developing countries.

\subsection{Germany}

\subsubsection{Germany's Background on Development Assistance}

The German development cooperation was initiated shortly after the foundation of the Federal Republic of Germany after the end of World War II, with its first multilateral contributions occurring in $1952^{2}$. In 1961 the coordination of developmental concerns was delegated to an independent ministry, the

\footnotetext{
${ }^{1}$ This limitation holds regardless of the pro-poor expenditure is focused on long-term impact activities such as basic education or short-term impact activities such as cash transfers to the elderly.

${ }^{2}$ For the historical background see Ashoff, G. (1994), p. 62 - 73.
} 
Bundesministerium für Wirtschaftliche Zusammenarbeit und Entwicklung $(B M Z)^{1}$. It is responsible for establishing the principles and guidelines, for the financing and the planning, supervision, exertion of control and coordination of all developmental measures, for contracting with recipient countries and for the coordination with other donors. ${ }^{2}$ Since the early 1990 s the BMZ has focused its activities on the vision of globally sustainable development with key areas in productive economic growth, social justice and ecological sustainability. ${ }^{3}$ In its efforts it has focused its work on the three main issues of poverty reduction, environmental and resource protection and education and vocational training. ${ }^{4}$ The guiding principles for poverty reduction have been self-help orientation and a participatory approach. ${ }^{5}$

The German development assistance under the lead of the BMZ has historically pursued the formulation and implementation of an independent development strategy ${ }^{6}$. This was also a strong bilateral focus in its donations ${ }^{7}$. Yet in recent years there has been a trend for increasing multilateral aid, with its share rising from $30.8 \%$ to $37.5 \%$ between 1990 and $1997^{8}$. The BMZ commands 7.427 billion DM in 2001 for this purpose, which marks an increase of $4.6 \%$ over the previous year. ${ }^{9}$

To take over this role, the BMZ employs 570 people in its Berlin and Bonn offices ${ }^{10}$ as well as some personnel in embassies in developing countries. In contrast to the British organizational structure, the development assistance of the Federal Republic of Germany has historically pursued a more centralized approach, with decisions based in the headquarters in Germany. The small staff size of the BMZ in relation to other organizations, such as the DfID, results from the unique structure of the German development cooperation, in which the operational handling of the development assistance is delegated to autonomous entities in public holding.

The German government has delegated the supervision and implementation of its contributions of financial cooperation to the Kreditanstalt

1 Until $1993 \mathrm{BMZ}$ stood for Bundesministerium für wirtschaftliche Zusammenarbeit (Ministry of Economic Cooperation, the author), when the annotation 'und Entwicklung' (and Development, the author) was added.

${ }^{2}$ Ashoff, G. (1994), p. 72. (Translation by the author).

${ }^{3}$ See BMZ (1997), p. 5.

${ }^{4}$ See BMZ (1997), p. 6

${ }^{5}$ See BMZ (1997), p. 6. See also the self-help concept BMZ (1990). The newly devised participatory concept BMZ (1999) confirms the concern of the BMZ for participatory involvement.

${ }^{6}$ See Ashoff, G. (1994), p. 66.

${ }^{7}$ See Ashoff, G. (1994), p. 66.

${ }^{8}$ See BMZ (2001e), p. 307.

${ }^{9}$ See BMZ (2001c).

${ }^{10}$ See BMZ (2001d). 
für Wiederaufbau ${ }^{1}(\mathrm{KfW}){ }^{2}$ This financial cooperation provides grants and concessional loans mainly in order to finance investments in the economic and social infrastructure as well as reform programs in developing and transition countries $^{3}$. This financial cooperation provides concessional loans in order to provide the structural conditions for development. The Gesellschaft für Technische Zusammenarbeit GmbH (GTZ) is the primary agency delegated to conduct Technical Cooperation ${ }^{4}$, i.e. capacity building and institution building. Technical Cooperation is conducted to enable people and organizations to change their living conditions by their own efforts. The third, smaller component of development cooperation is the Personnel Cooperation. It aims at increasing the personal capabilities of individuals in developing countries through education and training conducted by a variety of organizations ${ }^{5}$ and at aiding development through the dispatch of experienced professionals as collaborators on projects in developing countries through the Deutscher Entwicklungsdienst (DED) ${ }^{6}$.

This structure bears benefits in making available the services of independent and specialized implementing agencies with the potential of relieving the ministry of day-to-day operational issues. The implementation agencies have also accumulated competence that has gained international reputation in the development community ${ }^{7}$. Yet the inadequate distribution of labor between the ministry and the implementing agencies has also been criticized. ${ }^{8}$ The distribution of funds going to the various fields of development assistance is depicted in figure 8 .

The German development cooperation historically has had a broad development portfolio ${ }^{9}$, which was partially influenced by political considerations ${ }^{10}$. In recent

1 All of the Federal Government's shares in the Deutsche Investitions- und Entwicklungsgesellschaft $\mathrm{mbH}$ (DEG), which has the task to support the buildup of the private sector, have been acquired by the KfW in June 2001. See KfW (2001b).

${ }^{2}$ See BMZ (2000d), p. 206.

${ }^{3}$ See KfW (2001a), p. 5.

${ }^{4}$ See BMZ (2000d), p. 215. The GTZ is responsible for the bilateral technical cooperation in the narrower sense, which excludes among others the work of the personnel and scientific cooperation and of churches, political foundations and others. These are included in the term Technical Cooperation in the wider sense, but will be separately acknowledged in this thesis.

${ }^{5}$ The German government has delegated the implementation of its programs e.g. to the CarlDuisberg-Gesellschaft and the Deutschen Stiftung für Internationale Entwicklung (which are about to merge in 2001) among others. See BMZ (2000d), p. 225.

${ }^{6}$ See BMZ (2001e), p. 147.

${ }^{7}$ See Ashoff, G. (1996), p. 73.

${ }^{8}$ The pro and cons of this strategy are discussed in more detail in Ashoff, G. (73).

${ }^{9}$ See Ashoff, G. (1996), p. 67, 68. E.g. in 1992 projects in more than 150 countries were considered, prepared or conducted.

${ }^{10}$ See Ashoff, G. (1996), p. 75. Among economically motivated considerations the prevention of the acceptance of the DDR has played a role in the donations of the Federal Republic of Germany, as well as the containment of communism. After the break-up of the socialist 
years there has been a trend to concentrate the development efforts and make it conditional on the political and economic framework prevalent in a country ${ }^{1}$; consistent with today's overall consensus. The German government has declared its support for the IDTs at the Millennium Conference in New York and has confirmed this support in its action program to reach these targets. ${ }^{2}$

\section{Figure 8: Distribution of German Development Cooperation*}

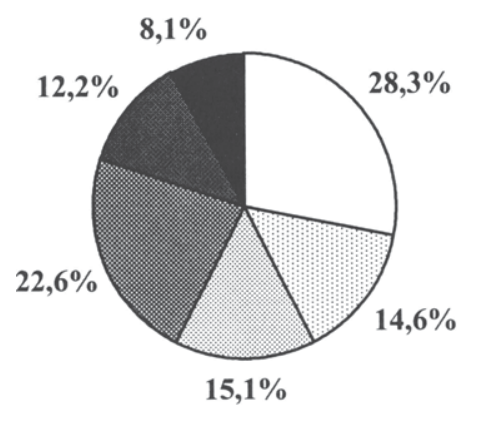

Technical Cooperation

Bilateral Technical Cooperation in the narrower sense

Personnel and Scientific Cooperation, political foundations, churches, ect.

Multilateral Cooperation

European Development Funds

Other

*Source: Internal data of the KfW based on the Einzelplan 23 of the BMZ, see BMZ (2001c).

The action program mentions poverty reduction as the overarching goal of development cooperation and as a priority area for the work of the entire German government ${ }^{3}$, yet this view remains less pronounced than in other strategies ${ }^{4}$. Considering that $\mathrm{BMZ}$ publications as late as of 2000 mention poverty reduction alongside other goals such as environmental protection and education ${ }^{5}$ rather than superordinated to them, it can be inferred that a change in perception in the German development cooperation is still ongoing. The perception of poverty reduction as the central goal of development cooperation was integrated into the action program, yet the dominance that is placed on this point within other programs is not attempted herein.

The German position, in contrast to other positions, accentuates the support for middle-income countries. In its other assessments it extends this general

empire and the German reunification there is now greater scope for focus solely on the issue of poverty reduction.

${ }^{1}$ See Ashoff, G. (1996), p. 69.

${ }^{2} \mathrm{BMZ}(2001 \mathrm{a})$.

${ }^{3}$ See BMZ (2001a), p. 6.

${ }^{4}$ Poverty reduction as overarching goal is only mentioned in one occurrence in the action program, while e.g. the British position drives this point continuously as its central goal.

${ }^{5}$ See BMZ (2000d), p. 154. 
viewpoint. It takes a strong concern in peace and conflict prevention and in efforts to reshape the agrarian sector for greater food security and prosperity. In the environmental sector the German action program accentuates the benefits of a modernized, efficient and environmentally friendly energy supply. The German government also explicitly points at the value of alliances within industrialized nations to spur the progress in the reduction of poverty.

\subsubsection{Support for Middle-income Countries}

In its action program for the achievement of the IDTs the German government, under the lead of the BMZ, embarks in line with the general consensus on conditionality in the provision of ODA support. In this respect, it considers governance issues, human rights concerns and determination of the partner government for poverty reduction. ${ }^{1}$ This is in accordance with its policy in recent years to concentrate its provision of aid on fewer countries. Yet, in contrast to the view outlined for $\mathrm{DfID}^{2}$ in the previous chapter, the German government does not follow the argumentation that ODA flows should be limited to the poorest countries while middle-income countries can gain sufficient funds via the capital markets.

While the German position acknowledges the need for concessional flows for low-income countries, it confirms this need also for advancing and middleincome countries. ${ }^{3}$ Its argument is based on the belief that the "greatest proportion of poor people in this world" 4 still lives in middle-income countries. Yet access for middle-income countries to capital markets is regarded as mostly insufficient, because large regions within middle-income countries are excluded and investment areas such as environmental projects and social infrastructure are not able to attract international capital. ${ }^{6}$ These sectors are considered commercially unattractive by many private investors but have high potential for the future development of the country. Also, the access that middle-income countries have to capital markets is prone to highly volatile fluctuations and is sometimes very expensive.

Based on these considerations, the German government will continue to support middle-income countries not only with technical assistance ${ }^{8}$, but also

\footnotetext{
${ }^{1}$ See BMZ (2001a), p. 8.

${ }^{2}$ The German view is also contrary to the view presented in World Bank (2000a), p. 196.

${ }^{3}$ See BMZ (2001a), p. 20, which serves as reference for this passage.

${ }^{4} \mathrm{BMZ}$ (2001a), p. 20. (Translation by the author.)

${ }^{5}$ The UK governmental paper uses a more moderate statement: "there are many poor people in middle income countries". UK government (1997), p. 40. Both strategies avoid using concrete numbers.

${ }^{6}$ See BMZ (2001a), p. 20.

${ }^{7}$ See BMZ (2001a), p. 20.

${ }^{8}$ As proposed in the DfID conception.
} 
with concessional flows in the field of financial cooperation to increase the impact on poverty reduction.

With regard to the goal to reduce the proportion of people living in poverty by half by 2015 , strategies both pro or contra the concessional support for middleincome countries are viable, given their respective assumptions. If access to capital markets is sufficient for middle-income countries, there seems to be merit in the approach of concentrating development assistance on those countries that cannot attract sufficient flows by themselves. Under the assumption that capital markets are insufficient and that a majority of the poor live in middle-income countries, it seems to be necessary to extend financial assistance to those countries if poverty is really to be reduced by half until 2015 . The accuracy of these assumptions remains to be empirically validated. ${ }^{1}$

While the different strategic concepts analyzed for this thesis have strongly different accentuations, this is one of the few points where the strategies explicitly express opposing views. While this dispute needs further investigation to ensure the most efficient use of developmental resources, it does not pose a threat to the ability of the agencies to cooperate or to pursue coherent policies. It only depicts differences in the selection of countries where the sovereign donor wants to become active, but not concerning the actions it wants to pursue in a given country alongside the other agencies. Still, a challenge might arise within multilateral agencies like the EU or the World Bank, because the divergent views of its members might result in conflicts over the target countries for their multilateral engagement. The solution to such potential problems will be found in further scientific exploration of the consequences of channeling aid on the basis of average national GNP.

\subsubsection{Peace and Conflict Prevention}

In line with the overall consensus is the German position on peace and conflict prevention. While many of its insights have already been incorporated into the discussion of the consensus, the strong importance of this issue is noteworthy as it is listed as one of the foremost strategic elements in the German conception. ${ }^{2}$ Developmental policies and poverty reduction initiatives are seen as one specific part that contributes to the overall efforts of the German government for

\footnotetext{
${ }^{1}$ The analysis in World Bank (2000a), p. 196 that aid to middle-income countries with average GNP per capita six-fold of that of low-income countries is not targeted heavily to the poor needs to be assessed with caution. If development assistance is spread to the entirety of the middle-income country, this statement seems sensible. Yet if the assistance is targeted within a middle-income countries to regions with extremely high poverty rates, there might still be a heavy targeting involved.

${ }^{2}$ See BMZ (2001a), p. 6.
} 
"Prevention of Civil Conflicts, Conflict Resolution and Consolidation of Peace". ${ }^{1}$

In its assessment of the causes of conflict, the German government agrees with the mainstream opinion ${ }^{2}$ : Economic and political discrimination, ethical and religious tensions, poverty, unemployment among adolescents, lack of means for peaceful internal conflict resolutions, disproportional military expenditures and lack of democratic control are all seen as contributing to the outbreak of conflicts. To avoid the detrimental effects of violent conflicts the German government relies on a coherent approach of foreign, security and development politics.

Concrete measures beyond those discussed prior are proposed in the areas of peace missions and international agreements. The action program refers to the deputation of peace specialists. These specially trained experts are dispatched to collaborate with local partners, and under acceptance of the local authorities to strengthen the "peace potential", to mitigate in conflicts of ethnical or interest based background and to contribute to reconciliation and reconstruction. Priorities are perceived in the areas of human rights promotion and support for individuals traumatized in conflict situations.

While this constitutes a measure on local scale, the German government on the other side embarks strongly on international normative and regulatory frameworks, based on the commitment to refrain from violence enshrined in the Charta of the UN. It promotes international rules and enforceable standards, especially in the areas of child soldiers and indigenous people, and is fostered by the establishment of an international court for penal and arbitrages jurisdiction. The international regulations should also be shaped to legally restrict the international trade in arms.

The German position establishes an especially strong focus on the importance of peace as a precondition for development and poverty reduction, which extends the consensus of peace and reconciliation prevalent in all strategies. Through this focus and its emphasis on the education and deputation of peace specialists it might be able to acquire and spread specialized knowledge on how to cope with conflict situations more successfully. Its concern for international enforceable regulations in this area has potential to further the progress in the international arena.

\footnotetext{
${ }^{1}$ BMZ (2001a), p. 6. (Translation by the author.)

${ }^{2}$ The remainder of this chapter on the causes of poverty and measures of its prevention is based on BMZ (2001a), p. $38-42$.

${ }^{3}$ BMZ (2001a), p. 41. (Translation by the author.)
} 


\subsubsection{Agrarian Development}

Also based on international agreements is the German emphasis on agrarian development ${ }^{1}$. This issue, which is one of the ten starting points for the German action program, relates to the UN declaration on economic, social and cultural rights, which encompasses the right for adequate nourishment. The German government seeks to support the initiative of the UN World Summit on Nutrition declared in 1996 to clarify the exact meaning of this right and to make it enforceable.

In contrast to the DfID, which places special emphasis on urban development, the German position accentuates rural development, on the premise that two thirds of all poor live in rural areas, including the majority of those 800 million people who face hunger or under-nourishment. It also looks toward agrarian development, because in countries with a high proportion of GNP related to agriculture, the "growth rate and the tempo of poverty reduction are especially dependant on the growth of the agrarian output and of the rural economic systems as well as the development of rural institutions and of human capital. An insufficient agrarian development leads to further poverty, unemployment, hunger and undernourishment"2.

This necessitates domestic as well as international measures in the developing country. In addition to widely agreed-upon ${ }^{3}$ land reform, including long-term ownership and tenant laws and more equal distribution of land, the action program supports four additional measures. These include agrarian market policy that enhances the chances for small producers, the construction and improvement of social and economic infrastructure in the rural areas, and the extension of financial services to remote areas and agrarian research that focused on the needs of the small farmers. The German government also explicitly acknowledges the right to reuse bought seeds for re-sowing and for local research. The focus of agrarian research according to this conception should lie on nutrition production, especially regarding fishing, the preservation of soil fertility and biodiversity, protection and management of jointly used resources, preservation and efficient use of water resources in agricultural business.

The BMZ seeks to support this by offering counseling and vocational training to enable the local population to develop the necessary skills to be able to take on the new responsibilities associated with agrarian reform successfully. Also it aims to encourage small farmers to organize themselves in order to pursue the chances of a wider market place jointly. This is backed on the national level by a political dialogue concerned with agrarian reforms.

\footnotetext{
${ }^{1}$ For reference on this discussion see BMZ (2001a), p. $15-17$.

${ }^{2}$ BMZ (2001a), p. 14. (Translation by the author.)

${ }^{3}$ Within the strategies analyzed for this thesis. On the national level of the developing countries the agreement of such a policy is exactly the problem that many agrarian reforms face. See e.g. BMZ (2001a), p. 16.
} 
A concern for agricultural progress and rural development can be found in all strategies, yet this is especially dominant in the German concept. It extends the general consensus on agrarian reforms by supportive measures and places them in a context of under-nourishment that is not strongly prevalent in the other strategies. The action program also endorses the goal of the UN World Summit on Nutrition to halve the proportion of people suffering hunger by 2015 , which has not been enshrined in the IDTs and does not receive strong attention within the other strategies. Yet this point can be assumed to have high emotional value for most of the citizens in industrialized countries and might therefore serve to achieve greater national support for the task of fighting poverty.

\subsubsection{Environmental Implications of Energy Supply}

Under the heading "Securing access to vital necessity resources - Supporting an intact environment"1 the German action program displays a strong concern for the preservation of the environment and the resources it provides for poor people. $^{2}$ The main point of accentuation beyond those areas already mentioned as part of the general consensus concerns the supply for energy. Sustainable energy policy is regarded as an important means to reduce poverty.

Sustainable energy policy is characterized by either high-energy efficiency or the use of renewable energy resources ${ }^{3}$. Inadequate supplies of energy have led to increasing deforestation, which in turn has resulted in a reduction of natural resources like wood and biological diversity. ${ }^{4}$ Deforestation has led to a lowering of the ground water table, a reduction of ground fertility and reduced agricultural yields in some regions, which in turn hit the rural poor especially hard and counteract the efforts presented in the prior paragraph. Inefficient energy systems are also associated with a waste of scarce and expensive resources and with environmental pollution.

Therefore, investments in energy infrastructures in favor of energyefficient and environmentally friendly power plants as well as in new technologies like wind and solar energy are supported by the German development assistance. This is combined with efforts to increase the access of the poor to net-based electrical energy to avoid their reliance on other, less environmentally friendly and possibly more costly resources. In rural areas remote from electrical wiring support for local energy generation, renewable resources like wind, solar and biomass is supported. ${ }^{5}$

\footnotetext{
${ }^{1} \mathrm{BMZ}$ (2001a), p. 27. (Translation by the author.)

${ }^{2}$ For the further discussion on environmental issues and especially the encompassed issue of energy supply see BMZ (2001a), p. $27-30$.

${ }^{3}$ Or the combination of both.

${ }^{4}$ See BMZ (2001a), p. 27.

${ }^{5}$ See BMZ (2001a), p. 30.
} 
This concern for the modernization and extension of the energy sector features strongly into the German strategy. While the German analysis affirms that the responsibility for the deterioration of the environment rests mainly with the industrialized nations, its assessment of the energy sector extends the view to measures that could help mitigate the detrimental environmental effects of the rising energy consumption in poor countries. It also provides a focus on the environmental virtues ${ }^{1}$ of extending electrical energy to the poor. To this degree it extends the general consensus on environmental issues.

Yet this analysis neglects to question the virtues of rather costly investments in energy supply in contrast to other measures of poverty reduction. ${ }^{2}$ It also lacks a discussion of to whom the benefits of energy projects mostly accrue. For local energy generation in rural areas this can be easily inferred. However, this question becomes much more difficult for larger power plants that serve a large population, as well as the industrial sector. Since the benefits of environmental preservation are only a small part of the overall benefits created by modernized, more accessible electrification, the question of to whom these economic benefits extend and if this is beneficial to the poor might need to be more strongly integrated into the analysis of the virtues of modernized and better managed energy supply.

\subsubsection{Alliances within Industrialized Nations}

To advance the progress on poverty reduction the German action program takes account of the other national actors that contribute to developmental progress ${ }^{3}$. In interaction with the government on the issue of poverty reduction are the private economic sector, civil society organizations, the research sector and the general public, as depicted in figure 9. While the necessity for national partnerships is included also in other strategies ${ }^{4}$, most pronounced in the British $^{5}$, its special prominence in the German position justifies the discussion in this context.

\footnotetext{
${ }^{1}$ Additional benefits such as increased productivity and increased living standards for the poor are at least equally important.

${ }^{2}$ For a more detailed discussion of the question of the status of 'poverty reduction vs. other developmental goals' see the chapter with this heading.

${ }^{3}$ For this discussion see BMZ (2001a), p. 9, $44-49$.

${ }^{4}$ See e.g. UK government (1997), p. 77.

${ }^{5}$ See e.g. UK government (1997), p. $41-47$.
} 
Figure 9: National Actors in the Fight against Poverty ${ }^{1}$

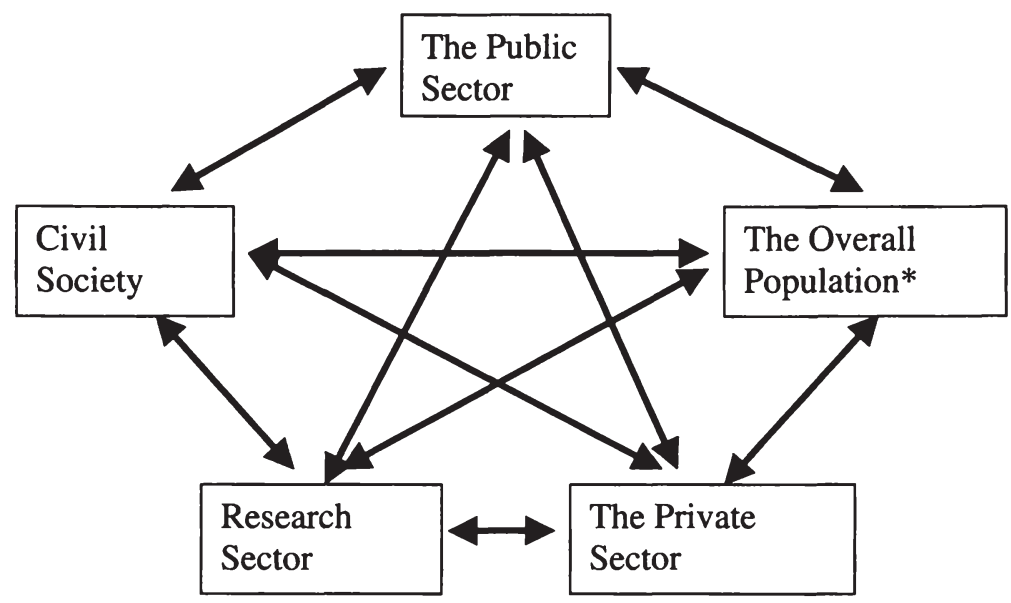

* The overall population is not mentioned in the action program in an explicit paragraph, yet the concern for the general public opinion is voiced in regard to civil society organizations and in the implementation, which justifies their integration.

The German action program confirms in its onset the important role of national economic and societal groups in the fight against poverty. ${ }^{2}$ They can contribute by demanding actions and commitment from the government and the international organizations and by contributing their own individual potential. ${ }^{3}$ Development partnerships between the public development efforts and the private initiatives are considered as especially effective. ${ }^{4}$ This link is also promoted in the British strategy. ${ }^{5}$

In cooperation with the public sector this can be achieved by Public Private Partnerships as portrayed in the discussion of the consensus. The German government promotes this concept also for implementation in the UN development system. ${ }^{6}$ For the engagement of public enterprises in developing countries outside of Public Private Partnerships the German government relies currently on their voluntary commitment to measures to promote sustainable development in their foreign operations. It encourages movements such as

\footnotetext{
${ }^{1}$ This framework is adapted from KfW (2001a), p. 17, yet transferred from the international level to the national level.

${ }^{2}$ See BMZ (2001a), p. 5.

${ }^{3}$ See BMZ (2001a), p. 5.

${ }^{4}$ See BMZ (2001a), p. 9.

${ }^{5}$ See e.g. UK government (1997), p. 41.

${ }^{6}$ See BMZ (2001a), p. 45.
} 
'Corporate volunteering' where companies exempt their employees for developmental engagements, and also demands a greater focus of private research on tasks relevant for developing countries. ${ }^{1}$ It assumes that enterprises increasingly realize the value of complying with human rights resolutions and social and ecological minimum standards ${ }^{2}$ and therefore promote voluntary codes of conduct. The cooperation of the private sector with civil society organizations in the establishment for social and ecological minimum standards and labels to empower the consumer is considered to spur this development. ${ }^{3}$

Civil society organizations engaged in developmental efforts are considered as important interceders for the poor and for the critical dialog on conceptual questions of poverty reduction, ${ }^{4}$ as well as in the implementation of development assistance through partner organizations in developing countries. ${ }^{5}$ The value of NGOs in industrialized nations for the strengthening of basic organizations in developing countries and for the promotion of self-help and participatory concepts through their local partner organizations have been acknowledged in BMZ strategies throughout the last decade 6 . This has been confirmed in the action program. ${ }^{7}$ The central value of self-help oriented and participatory approaches for the BMZ and for a number of German NGOs has recently been confirmed in a joint communiqué. ${ }^{8}$

The German perception of the value of non-government organizations (NGOs) on mobilizing public opinion on developmental issues and the central value of public opinion for the long-term commitment of any government to poverty reduction has already been presented in the general consensus. The action program takes special efforts to promote its concerns to the general public, e.g., to the government's constituents, to strengthen the overall commitment within the nation and thus gain the political leeway to engage in this conduct.

The German government also encourages leading German organizations in the research sector to focus their educational and research efforts on fighting poverty and supporting the action program ${ }^{9}$. Next to social and developmental questions technical and information technology concerns shall be addressed. Yet the discussion of the research sector only receives small attention in the overall program.

A German peculiarity is the independent role of the German states in providing development assistance. The German government attempts a strong

\footnotetext{
${ }^{1}$ See BMZ (2001a), p. 47.

${ }^{2}$ See BMZ (2001a), p. 45.

${ }^{3}$ For reference on this cooperation see BMZ (2001a), p. 46, 47.

${ }^{4}$ See BMZ (2001a), p. 47.

${ }^{5}$ See BMZ (2001a), p. 48.

${ }^{6}$ For an early publication see e.g. BMZ (1990), p. 3. For a very publication referring to this issue see BMZ (1999), p. 10, 11.

${ }^{7}$ See BMZ (2001a), p. 36.

${ }^{8}$ See Arbeitskreis Armutsbekämpfung durch Hilfe zur Selbsthilfe (2000b), p. 10.

${ }^{9}$ See BMZ (2001a), p. 48.
} 
cooperation with the states and communities within Germany in attempts to strengthen national awareness and increase the overall effectiveness of the German development assistance. ${ }^{1}$

The action program of the German government extends the general concern for the various actors in the international domain to those on the national level in Germany. The growing importance of private investments in developing countries is taken into account by the strong integration of the public sector economic activities in the analysis.

Overall, the German action program supports the general consensus we see today and confirms this explicitly: "Today there is a broad international consensus on the most important strategic elements for poverty reduction." ${ }^{2}$ It broadens the analysis in regard to peaceful resolution of conflicts and agrarian reform as well as concerns for energy provision and the inclusion of all actors who can benefit the development process. Yet, the markedly differing approach of concessional financing for middle-income countries establishes the intention of the German government and its developmental agency to pursue an independent developmental concept.

\subsection{Sweden}

\subsubsection{The Background of Sweden's Development Cooperation}

The Swedish development cooperation has a long tradition of strong commitment and efficiency that dates back to the 1970 s, when it strongly promoted its leadership position in the international development arena. ${ }^{3}$ The international reputation that this has established is still visible today ${ }^{4}$ and is fostered by the continuous exceeding of the international target of $0.7 \%$ of ODA to BSP, yet with a steady decline of the contributions during the 1990 s. $^{5}$

Historically the Swedish view has taken a different path than the other donor strategies by promoting a third way between capitalism and communism in the 1970s that favored a socialist development ideology and gave support to

\footnotetext{
${ }^{1}$ See BMZ (2001a), p. 49.

${ }^{2} \mathrm{BMZ}$ (2001a), p. 6. (Translation by the author). In this context the action program also refers explicitly to the WDR 2000/2001.

${ }^{3}$ See Lembke, H. (1996), p. 191, 192.

${ }^{4}$ See e.g. the positive mentioning of the efficiency of the Swedish development assistance in BMZ (2000).

${ }^{5}$ While the ratio was at $1.01 \%$ in $92-93$ this declined to $0.87 \%$ in $95-96$ and down to $0.72 \%$ in 1998. (See Lembke, H. (1996), p. 193 and BMZ (2000b)). This is still more than twice the percentage of the larger European Nations such as Germany and the UK and seven times the ratio of the USA).
} 
non-aligned developing nations. ${ }^{1}$ This view, though prevalent, lost political weight throughout the 1980s and left way to a greater mainstream perception to development with the shift towards a conservative government in 1991. This was not reversed in the 1994 election of a socialist government still in power today. The current goals for developmental assistance established by the Swedish parliament comprise economic growth, economic and social equality, economic and political independence of the partner countries, democratic development, environmental quality and equality between men and women. ${ }^{2}$

The Swedish administrative arrangement is different from those prevalent in Germany and in the UK in that there is no special ministry of development. Its function has been integrated into the Ministry of Foreign Affairs. Still the position of a minister for development exists next to the minister for foreign affairs. He is responsible for establishing the developmental conception.

Strong weight within the Swedish system is lent to the Swedish International Development Organization (SIDA) which handles two thirds of the Swedish development assistance. ${ }^{3}$ To fulfill its developmental responsibility Sida channeled 9.076 billion SEK to programs of international development cooperation in 1997. ${ }^{4}$ About two thirds of these funds are dispersed directly through Sida, another $29 \%$ of funds go to national or international NGOs, as depicted in figure 10 .

\section{Figure 10: Distribution of Sida's Development Contributions by Channel*}
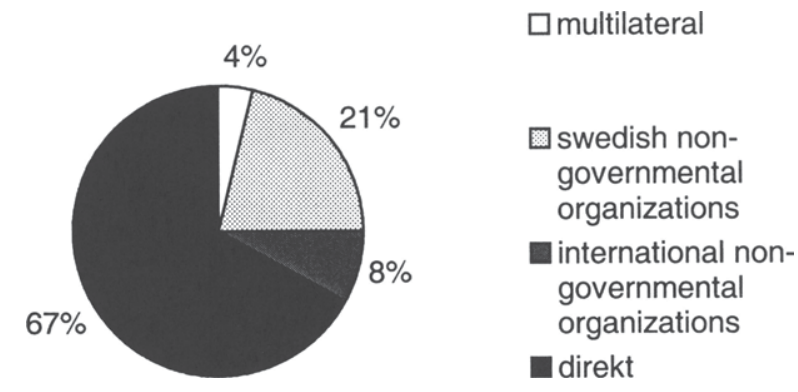

* Source: Sida 1997

\footnotetext{
${ }^{1}$ On this discussion of the historical perspective see Lembke, H. (1996), p. 191 - 197. For deeper insights on the Swedish perception see the influential contribution of Myrdal, G. (1968).

${ }^{2}$ See Sida (2000a).

${ }^{3}$ See Sida (1997). The remainder is channeled directly via the Ministry of Foreign Affairs to multilateral agencies.

${ }^{4}$ See Sida (1997).
} 
Sida's development operations are handled by 550 employees in the Swedish headquarters. A stronger decentralization to the partner countries is attempted via around 100 employees who are integrated into the embassies and consulates in cooperating countries. ${ }^{1}$ The country strategies on which the Swedish contributions are based are developed in cooperation between Sida, the Ministry of Foreign Affairs and the respective embassies. ${ }^{2}$

Within the Swedish strategy ${ }^{3}$ the foremost concern is placed on the generation of knowledge on all levels. While this is generally accepted, the promotion of higher education potentially lies at odds with the World Bank position. Strong emphasis is also placed on support for marginalized groups. For the provision of its development cooperation, the Swedish strategy also relies strictly on a concentration of funds and on the integration of NGOs in its provision.

\subsubsection{Knowledge and Education}

Sida's strategy embarks on the statement: "Knowledge is our most important resource." ${ }^{, 4}$ Knowledge as a key determinant dominates its position on poverty reduction. Its assertion that the "central issue of all development cooperation is to contribute to developing knowledge - in the partner country, in Sweden, and internationally"5 shows the breadth of this approach. As a smaller country within the donor community the accumulation of knowledge generation can serve as a strong measure to leverage the impact of the Swedish development assistance. For example Sida's efforts to build up "banks of experience" gathering information on humanitarian assistance missions aim in this direction.

In the specification of its concern Sida points out five areas of engagement: basic education, human resource development within the framework of projects and programs, support for higher education and research in the poorest countries, research efforts on developmental issues and the generation of knowledge to better prevent conflicts and deliver humanitarian assistance. ${ }^{7}$ Its proposals range from internal staff training ${ }^{8}$, over inclusion

\footnotetext{
${ }^{1}$ On the number of employees and the division of responsibilities see Sida (2001a).

${ }^{2}$ See Sida (2001a).

${ }^{3}$ The Swedish strategy is used here identically with Sida's strategy, even though in contrast to the German and English agencies Sida is not a ministry. Yet Sida is the most influential player in the Swedish discussion on poverty reduction and therefore serves as reference for the overall Swedish position.

${ }^{4}$ Sida $(2000 \mathrm{~m})$.

${ }^{5}$ Sida $(2000 \mathrm{j})$.

${ }^{6}$ See Sida (1996), p. 36.

${ }^{7}$ See Sida $(2000 \mathrm{j})$.

${ }^{8}$ See Sida (1996), p. 27.
} 
developmental content in Swedish curricula, internal studies on food security ${ }^{1}$ and international agricultural research ${ }^{2}$ to the promotion of know-how on hygiene standards in projects of development cooperation ${ }^{3}$. As a theme knowledge generation and transfer runs through Sida's entire analysis, comparable to the emphasis placed on this point by DfID.

A priority for Sida, in line with the broad consensus, is the provision of basic education of acceptable quality. ${ }^{4}$ In this context Sida places special concern on the enhancement of the quality of education. It points at priority areas for action such as availability of teaching materials, teacher training, curriculum development, construction of schools and education adapted for children with special needs. ${ }^{5}$ These point at areas where concerted actions of the donors and the national government is required to keep consistency within the overall educational system. Yet a discussion of sensitive issues such as conducive contents in the curriculum ${ }^{6}$ is avoided in Sida's strategy. Its concept for basic education extends beyond children and adolescents as target groups to also consider adult education ${ }^{7}$, which is seen as essential to enable people to exert their democratic and human rights. ${ }^{8}$ Especially for the poor women this is seen as a means to increase their independence and equip them to exert greater influence on the circumstances that affect their lives. ${ }^{9}$

Adult education and the provision of knowledge is also attempted in order to spread economic benefits. ${ }^{10}$ Education and training projects for the very smallest companies and businesses in the informal sector are seen as a measure to spur their economic success. The dispersion of knowledge on market conditions is promoted as a further measure to aid small businesses in marketing their products most profitable.

Sida also extends the international consensus by its strong commitment to support higher education. ${ }^{11}$ It regards "support to higher education and research at universities in the poorest countries as a prerequisite for the development of knowledge in these countries." ${ }^{12}$ This assessment is based on the belief that this is beneficial to a country's ability to gain from international integration ${ }^{13}$ and know-how. Indigenous research capacity on theoretical and practical levels in a

\footnotetext{
${ }^{1}$ See Sida (1996), p. 29.

${ }^{2}$ See Sida (1996), p. 25.

${ }^{3}$ See Sida (1996), p. 29, 30.

${ }^{4}$ See Sida (2000j) and Sida (1996), p. 19, 20.

${ }^{5}$ See Sida (1996), p. 19.

${ }^{6}$ The question of what should be taught has been raised in the chapter 'Poor People's Assets'.

${ }^{7}$ See Sida (1996), p. 34.

${ }^{8}$ See Sida (1996), p. 34.

${ }^{9}$ See Sida (1996), p. 20.

${ }^{10}$ For this discussion see Sida (1996), p. 31.

${ }^{11}$ The following discussion refers to Sida (1996), p. 13, Sida (2000j) and Sida (2000L).

${ }^{12} \mathrm{Sida}(2000 \mathrm{j})$.

${ }^{13}$ See Sida (2000L).
} 
wide range of subject areas is also seen as essential for a country's ability to analyze its own poverty-related issues and problems. ${ }^{1}$

This approach favoring extensive, in-country research capacity ${ }^{2}$ backed by tertiary education receives some support in the other analyzed strategies, most pronouncedly by that of the $\mathrm{UK}^{3}$, yet is not univocally accepted. Especially the World Bank projects a view in which tertiary education should be traded of against basic education ${ }^{4}$. This is based on its assessment that "distribution within sectors must favor basic services used more by the poor". Since "education [...] resources go disproportionately to tertiary education [...] used more by the better-off groups" 6 a reduction of tertiary education is the logical conclusion. This discrepancy opens room for conflict potentially deterring donor coordination in the educational sector.

Given the strong encouragement of building administrative capacity to manage the reforms and the efficient provision of public services ${ }^{7}$, the importance of research on problems which face the poor countries in e.g. the health sector ${ }^{8}$ and the realization of the importance of information technology for developing countries $^{9}$, it is hard to see how these tasks could be tackled without support for tertiary education. The broadly attested need for stronger statistical capacities and also the potential for the adaptation of international knowledge to the local context also require well-trained specialists. While the bias of public spending on tertiary education in favor of the non-poor, possibly rich proportion of the population might be an unwanted effect, the need for qualified personal to counter the challenges imposed on developing countries refutes the proposal to withdraw support for tertiary education in most countries.

Rather it seems sensible to increase the level of primary education and secondary education without cross financing from the resources of tertiary education. Primary and secondary education forms the basis of the tertiary level. The extension of primary and secondary education to the poor, as well as lowering the financial burden and securing equal access to tertiary education will enable a stronger proportion of poor families to send their children to higher level schools. This leads to stronger social justice in the system while at the same time increasing the country's capacity in terms of higher skilled people.

\footnotetext{
${ }^{1}$ See Sida (1996), p. 13.

${ }^{2}$ See Sida (1996), p. 25.

${ }^{3}$ See UK government (2000), p. 37. The German action program does not take tertiary education strongly into account. It mentions partnerships between German and foreign research institutes (See BMZ (2001a), p. 48), yet this theme is not prominent in its discussion.

${ }^{4}$ See Thiele, R. / Wiebelt, M. (1999), p. 27.

${ }^{5}$ See World Bank (2000a), p. 82.

${ }^{6}$ See also World Bank (2000a), p. 82.

${ }^{7}$ See e.g. World Bank (2000a), p. 99.

${ }^{8}$ See e.g. World Bank (2000a), p. 183.

${ }^{9}$ See e.g. World Bank (2000a), p. 187.
} 
These can provide for adequate administrative management as well as business and scientific progress, which in turn aids the development of the entire country. The contrary point that higher-level education leads to a higher proportion of academically trained people than a developing country has need for, which would negate the value of higher education in developing countries, is refuted in some newer empirical research. Rather, the value of higher education for economic growth in developing countries is emphasized ${ }^{1}$, lending support to Sida's approach to give a high priority to primary education while also supporting higher education and research.

\subsubsection{Disabled People and Marginalized Groups}

In the discussion on education Sida takes explicit account of disabled and handicapped children. ${ }^{2}$ Special projects for children with special needs ${ }^{3}$ are considered as an effective method to combat poverty, as these children constitute an extremely vulnerable category. ${ }^{4}$ This is seen as one measure in Sida's pronounced emphasis to raise the prospects of handicapped people through their integration into society and working life. ${ }^{5}$ People with physical or mental disabilities are one of the groups to which Sida gives special priority in its work. It also takes special attention to women-headed households, mothers and children, households in areas treated inequitably by economic development and minority ethnic groups. ${ }^{6}$ Members of any one of these groups are in a position where they are constrained in their ability to take economic opportunities and contribute themselves to greater personal prosperity.

The social view that Sida brings into the discussion, possibly based on Sweden's socially oriented tradition, extends the general consensus in that it takes explicit account of those people which cannot benefit from the extension of economic opportunities and would be marginalized by a strategy that solely focuses on the poor individuals own efforts and contributions to greater

\footnotetext{
${ }^{1}$ Timmermann concludes from his cross-sectional study of 37 developing countries that primary education is a stronger determinant for economic growth, yet secondary education reaches nearly the same impact. See estimated coefficients in Timmermann, V. (1999), p. 2474. Yet Timmerman refutes the assumption that domestic R\&D efforts are strongly beneficial to growth, withdrawing the scientific background for development contribution to the research sector at least of private companies. In Barro, R. (1999), p. 29 the impact of primary education on growth has been insignificant. Male secondary and tertiary education has proved strongly significant in his study of 114 developing countries. Since primary education is the basis for secondary and tertiary education, this does not refute the concern for primary education. The value of secondary and tertiary education is strongly established in these empirical studies.

${ }^{2}$ See Sida (1996), p. 20, 34.

${ }^{3}$ See Sida (1996), p. 34.

${ }^{4}$ See Sida (1996), p. 20.

${ }^{5}$ See Sida (1996), p. 4.

${ }^{6}$ See Sida (1996), p. 9.
} 
prosperity. While this is acknowledged in other strategies as well, this point is especially dominant in Sida's concept.

\subsubsection{NGOs}

Sida's accentuates the role of NGOs in the development process. About $30 \%$ of its budget is channeled through NGOs, providing financing to about 300 NGOs in Sweden alone. This focus was based on the assumption that NGOs are superior positioned to reach the poorest people. ${ }^{1}$

While Sida continues to support NGOs in their work and relies on them in the provision of aid, it points at internal evaluations that depict weaknesses of NGOs to adjust to the needs of the poorest groups. ${ }^{2}$ It also challenges their effectiveness to deliver long-term solutions to poverty. ${ }^{3}$

In the solution to these finding Sida attempts to integrate NGOs stronger in their long-term planning by inviting their participation in strategic poverty reduction work and by dissemination of Sida's country strategies and poverty profiles. ${ }^{4}$ It also attempts to assist NGOs via consultations, training and exchange of experience ${ }^{5}$ especially on the topics of target group analysis, methods to identify the poor, empowerment of the poor and change of power structures in developing countries. ${ }^{6}$ The last point can be seen as motivated by Sida's reliance on NGOs for engagement in those countries where the conditions are not favorable for broad-based poverty reduction ${ }^{7}$ and need to be reformed from Sida's perspective.

While Sida expresses a special emphasis on the integration of NGOs in the development process, it is also very realistic about the potentials of these organizations. The concern to strengthen the abilities of NGOs for greater effectiveness of aid provision extends the perceptions in the other strategies, which are limited to pointing out the benefits of NGOs. The Swedish concept encourages a realistic view on NGO's abilities and ventures to find solutions to perceived deficits.

${ }^{1}$ See Sida (1996), p. 23

${ }^{2}$ See Sida (1996), p. 11, 23. Sida does not use this point to promote its own profile, as it assesses the same weaknesses for its own aid provision, but detects a need for the improvement of aid delivery through NGOs.

${ }^{3}$ See Sida (1996), p. 23.

${ }^{4}$ See Sida (1996), p. 11.

${ }^{5}$ See Sida (1996), p. 11.

${ }^{6}$ See Sida (1996), p. 35.

${ }^{7}$ See Sida (1996), p. 6. 


\subsubsection{Conditionality}

The Swedish approach to conditionality resembles closely the proposals made in the UK position. In the assessment of the generally scrutinized areas of governance and poverty focus, Sida takes into account non-productive public expenditure, military spending, subsidies for unprofitable government-owned enterprises or activities that favor better-off groups, and the relative distribution of budget expenditure between social and other sectors. ${ }^{1}$ It also promotes the concentration of funds on low-income countries. ${ }^{2}$

In its concept Sida departs from the DfID position in that it follows explicitly a more cautious approach of "gradually" 3 moving to credits and greater cost sharing ${ }^{4}$. Its goals to reduce the number of projects, which it supports by $25 \%$ to increase the quality of aid provision, is ambitious. ${ }^{5}$

To increase the quality and impact of aid provision Sida also attempts to constraint its projects to areas where its possibilities to contribute to cooperation are especially strong. ${ }^{6}$ This relates to single projects conducted to transfer knowhow to middle-income countries ${ }^{7}$ as well as to its engagement in major recipient countries. As examples for focal areas it cites its engagement in the environmental sector where the management of scarce water resources, agriculture and forestry/soil conservation, the marine environment, the urban environment as well as environment-friendly consumption and production of energy are considered key areas. ${ }^{8}$ These focal areas show scope for broad cooperation with other donors, e.g. Germany in the energy sector and Britain in the marine environmental sector.

The Swedish conception supports strongly the consensus on conditionality and has established quantified targets towards this end. Its approach to "gradually wind-up development cooperation with countries which have less need of Swedish support", determined on the basis of their level of development, takes a view closer to the British than to the German perspective on this issue, yet promotes a more cautious approach.

Overall, the Swedish strategic proposal is closely in line with the overall consensus on poverty reduction. In its support for higher education, it points at an area where a consensus on the international level has not yet evolved. But its position promoting the value of higher education receives increasing support

\footnotetext{
${ }^{1}$ See Sida (1996), p. 6.

${ }^{2}$ On this discussion see Sida (2000i).

${ }^{3}$ Sida (2000i).

${ }^{4}$ See Sida (2000i).

${ }^{5}$ See Sida (2000i). The level of effort to reach this target is hard to assess, though, because the base year against which the reduction is attempted is not specified.

${ }^{6}$ See Sida $(2000 \mathrm{~h})$.

${ }^{7}$ See Sida (2000i).

${ }^{8}$ See Sida (2000b).

${ }^{9}$ See Sida (2000i).
} 
also on the research front. Since education is an important component in all strategies and a strong field of investment for the development agencies, the question of the value or detriment of tertiary education has the potential for strong international debate and even inhibition to international cooperation.

Sweden's background favoring a third way in development that was prevalent in its developmental conceptions up to the beginning of the 1990s is not visible in its poverty reductions programs as of today. A topic that reflects the social oriented attitude of the past approach is the strong concern on marginalized groups and disabled people, which can serve as a valuable addition to the focus on creating economic opportunities that might bypass these groups. ${ }^{1}$ Yet the political and economical conditions that Sida promotes for poverty reduction enforce the international consensus and establish a background suitable for strong international cooperation.

\subsection{Accentuations: Benefits or Hindrance?}

The accentuations that are visible in the strategic documents for the most part do not hinder the cooperation between agencies but represent opportunities for the development organizations to specialize themselves. If this can be coupled with a new international approach to aid delivery in which each donor country is engaged in those areas where it has established its advantages, this can lead to higher aid effectiveness and also to faster accumulation of further knowledge. Necessary for such an approach would be a system that ensures the international sharing of knowledge, so that the development organizations can participate from the insights of the respective specialist and are able to keep a holistic view for the overall problems of development cooperation.

Only few areas show real discrepancies of opinions where cooperation will be difficult. This includes the discern over higher education as well as the concessional financial support for middle-income countries. These have the potential of inhibiting collaboration concerning the educational sector and in international organizations. Yet while these differences deserve settlement on empirical basis, they only present small obstacles in contrast to the agreement already reached on many other issues.

While these two fields of accentuation can be seen as a hindrance because they potentially curtail cooperation, most emphasis within the strategies have the potential to yield benefits. The real challenge might be imposed by fostering even greater accentuation. The strategies mostly avoid prioritizing the activities they propose. As already mentioned, this leaves scope for the adaptation of

\footnotetext{
${ }^{1}$ Especially in the case of handicapped and disabled people even the greater concern for empowerment will not enable them to change their situation to participate in economic opportunities. Yet the concern for empowerment and security might be able to extend their rights and their entitlements if these concerns are established with a focus on those people that cannot actively promote their interests.
} 
priorities to the needs of the individual recipient country. Yet specific priorities of each donor would not inhibit adaptation of overall aid to the needs of the developing country as areas that do not receive priority by one donor are left to the specialization of other donor agencies. Even though the engagement in areas of comparative advantage is already discussed in some strategies, these areas are currently by large not made explicit. In order to strengthen international cooperation and the sharing of responsibilities on the basis of comparative advantage this will be a necessary task for future strategic conceptions.

\subsection{Consolidation: Consensus and Accentuations}

\subsubsection{Consensus on Three Levels}

The international consensus presented in the second part of this thesis extends across three areas of analysis. First of all, there is an overall agreement on the central goal of development cooperation: poverty reduction. This facilitates the coordination of activities and the ability for cooperation, as all parties have the same basic perception of what should be achieved in development cooperation. It also has the advantage of repelling pressures to subdue developmental goals to national political or economical priorities, as the international commitment to the same, single goal increases the pressure to direct efforts in this direction. The common interest in all strategies to fight poverty as the foremost measure also increases the ability for policy coherence especially at the multilateral level where international agreement is indispensable to reach progress. ${ }^{1}$

This alone could not ensure close collaboration as the term poverty reduction is too broadly defined for this purpose. Yet agreement is also established on a second level concerning the more specific targets of development cooperation established in the IDTs. They are still broadly defined and need to be complimented by goals suited to the individual country's circumstances, but they provide an overall framework that enshrines the most important global targets for development. They demand strong commitment, since the development agencies' efforts will be measured against the agreed targets. They also provide the general direction on which the broad commitment to poverty reduction can be channeled, which serves as a means to unite international efforts.

The third level of agreement that has been reached concerns the broad conditions, areas of improvements and processes that are conducive to the achievement of the IDTs and the overall goal of poverty reduction. These elements, termed conceptual elements in this thesis, comprise concerns for

\footnotetext{
${ }^{1}$ The problems of poverty reduction as the foremost goal of development assistance as well as the problems of subscribing to the IDTs shall not be discussed here again. For this discussion the reader is referred to the chapter on 'The Role of Poverty Reduction: Poverty Reduction vs. Other Developmental Goals".
} 
domestic action in the partner countries in regard to economic, political and security-related matters as well as efforts on the international front. These are broken down to more defined elements.

In the economic sphere accord is reached on the necessity to promote an economic incentive system conducive to private initiative within a sound regulatory framework, to increase economic opportunities for the poor through pro-poor spending on human capital and providing access to markets, to implement sound fiscal and monetary policies to fosters economic growth and to pursue greater equality of assets and income. Political conditions are to be improved by greater empowerment for the poor through participation, establishment of human rights including a high concern for gender aspects and democratization; backed by processes of good governance including curbing corruption, securing the rule of law and promoting accountability, decentralization and transparency. Increased security for the poor is univocally pursued by measures to prevent, mitigate and cope with crises and also by increasing private and state insurance schemes.

On the international level this is accompanied by a consensus to open international trade for the products of poor countries, to ensure greater international financial stability and to support international treaties for the protection of the environment. The donor community has also agreed on specific elements concerning their provision of aid. These comprise a spirit of partnership with the developing country in which the developing country owns the strategy under the condition to focus on poverty, the assumption of donor responsibilities in coordinating their efforts and assuring coherence in their policies, and by promoting the provision and dissemination of knowledge.

This general agreement on the conceptual elements conducive to the implementation of poverty reduction efforts is the key point in moving from the expressions of goals to concrete action on the country level. For donors it allows a joint approach to policy dialogue with the partner country and to collaborations on the implementation of projects, sector-wide approaches and budget support. It also facilitates development cooperation from the recipient countries perspective as the similarity of the donor concepts allow for joint negotiations instead of accommodation of divergent donor viewpoints. The levels of consensus are portrayed in summary in figure 11 . 
Figure 11: Pyramid of Consensus
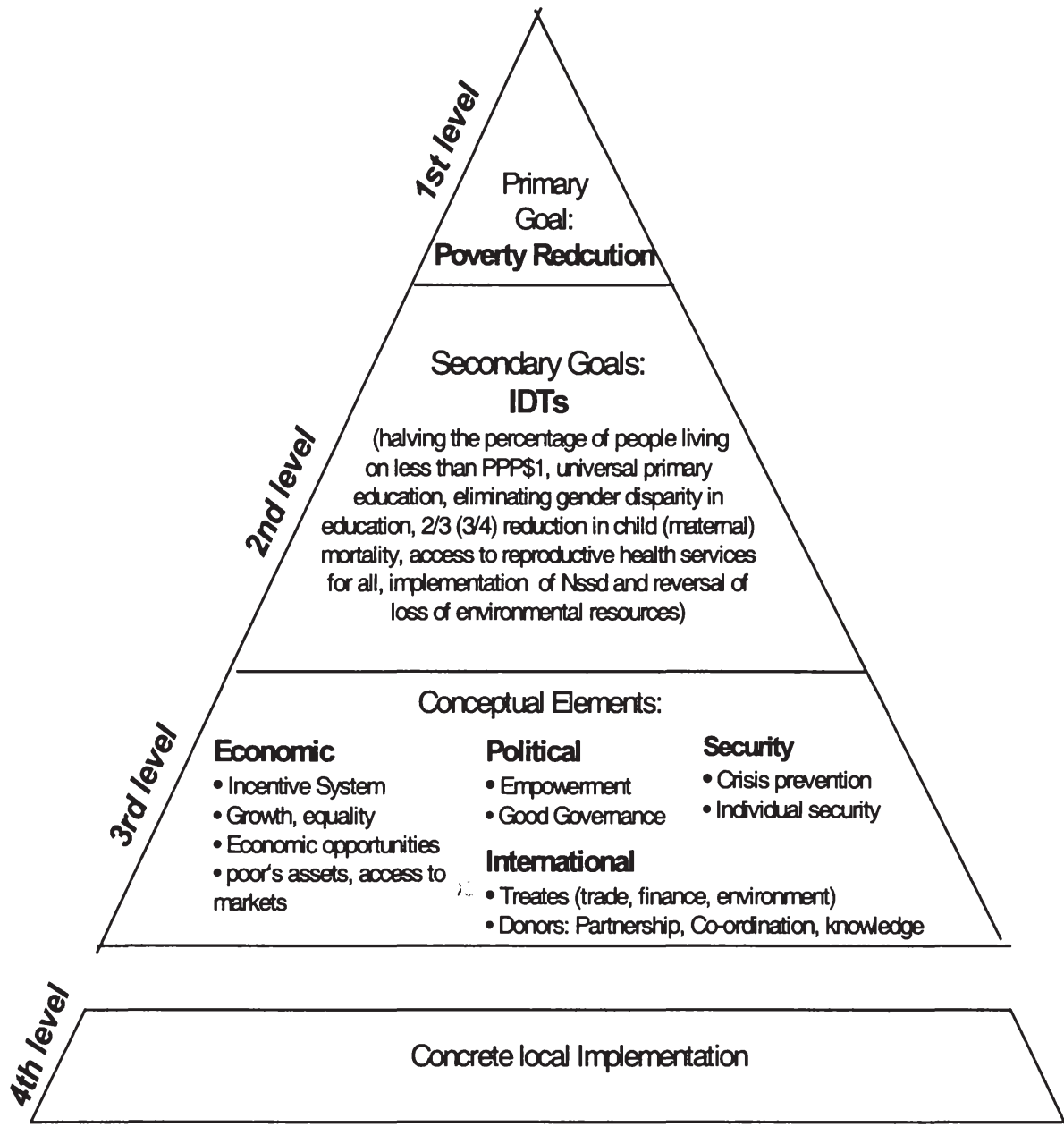

This Pyramid shows that strong commitment has been reached in many areas. This broad consent is one of the main points on which the new strategies rely in their belief that faster progress on poverty reduction can be reached in the future by joint, focused and coherent approaches. This consensus in its breadth tries to avoid the mistakes that led to detrimental impacts in the past. The question of a strong or weak state involvement is tackled by a compromise relying on a strong but limited state that sets the right frameworks but limits itself from active engagement in the economic sphere. In the question of growth vs. development of personal capabilities e.g. in education or health the compromise relies on 
mutually reinforcing effects that requires a joint pursuit of both. This reconciliation of divergent points and the learning from the errors of the past has led to a common basis to which all analyzed strategies subscribe.

\subsubsection{Stronger Accentuations with Decreasing Level of Abstraction}

Nevertheless there is room for different accentuations as pointed out in the majority of the third part of this thesis. The different accentuations and real differences in the strategies increase with lower levels in the pyramid. On the first level, there exists nearly unity. Differences are limited merely to the degree to which poverty reduction as the overarching goal of development cooperation is emphasized, with Germany being rather reserved in its pronunciation while DfID is most forward in this regard. The central goal of poverty reduction in development cooperation is unambiguously acknowledged.

The differences amount slightly stronger on the second level of consensus. While the IDTs themselves receive international agreement, this agreement does not extend towards their comprehensiveness. They do for example not account for any progress on food security as demanded in the German strategy or for urban development as proposed in the British conception. If the IDTs were simply a guiding line, the pronouncement of other relevant areas could be seen as measure for countries to specialize themselves. Yet the goal of the IDTs to serve as targets against which to measure the international efforts promotes a vigorous pursuit of these goals. While this should be welcomed to foster commitment and efficiency, the omission of an important dimension in the IDTs bears the threat that an important factor of poverty reduction is overlooked in the attempt to reach exactly those goals described within the IDTs. This illustrates that even on the second level the consensus we see today is not fully developed and will need further efforts to get full international agreement on all relevant factors, which limits - but does not negate - the current usefulness of the IDTs. There are also intentions to supplement these targets by measures that capture national circumstances and priorities in order to be adaptive to local conditions and needs, which is most pronounced in DfID strategy. While this is undisputed, it serves as an acknowledgement that with the IDTs the efforts of the international community to agree on targets has only just begun and that this needs to be continued on the national basis under the leadership of the national government.

Different accentuations proliferate on the third level of the consensus. Many conceptual elements have already been settled in international agreement ${ }^{1}$. This is a long step towards cooperation on project or sector level. While the IDTs have set the direction but not the means, the agreement on the conceptual elements serves as a baseline for unified, coherent actions. They also settle

\footnotetext{
${ }^{1}$ In contrast to the IDTs this agreement is implicit. It can be inferred from the analysis of the strategies as has been attempted in the second part of this thesis.
} 
unambiguously the question on who is to lead the developmental efforts in favor of the recipient country. Yet there are a number of different accentuations that pertain. Most of these should be welcomed as they provide the potential for development organizations to specialize themselves.

The World Bank takes a special concern for political issues of pro-poor coalitions and macro-economic policy, which reflects its role as largest donor agency with strong involvement in negotiations with national governments on poverty issues and adjustment programs. Its accentuation of security schemes and the causes and effects of inequality establishes its focus on social issues.

The United Kingdom has undertaken large efforts to establish a leading position in aid effectiveness by concentrating on impact measurement, clear connection of development activities to goals and a focus on knowledge generation. Further areas where the UK position provides insights comprise the analysis of effects of globalization, water scarcity and urban development.

The German action program most pronouncedly addresses the questions of conflict prevention and mitigation. It also shows concern for agrarian development and modern, environmentally friendly energy supply. Increased effectiveness is attempted through the integration of all national actors in the process of development cooperation, with special concern for the private sector because of its know-how and financial resources ${ }^{1}$.

The Swedish position promotes strongly the generation, distribution and usage of knowledge as its main resource, which it systematically increases and deploys within the partner country, in Sweden and internationally. It also takes initiative in the protection of the disabled and of marginalized groups. In its efforts it works in closest collaboration with NGOs, yet takes the most critical look at their activities and promotes joint measures for increasing their effectiveness.

The potential for specialization that these different accentuations allow, and the associated potential efficiency gains by engaging the agency with the best skills in a given situation and by sharing the insight gained from specialization, point at their inherent value for the development process. Yet some accentuations also bear the potential of conflict between the agencies. The discussion of concessional lending to middle-income countries, which is promoted by the German government while being rejected in the other strategies, bears such conflict potential. On the national level of the middleincome country, while being grave for the country itself, the withdrawal of a donor does not compromise the ability of the remaining donors to cooperate. Yet this dispute might be a strain on the relationship between the respective donor organizations and also leads to conflicts in international organizations and forums in which the donor nations have influence.

Also the discussion over increasing or decreasing the support for tertiary education, with the former being considered by DfID and Sida and the latter

\footnotetext{
${ }^{1}$ The concern for the integration of the private sector is also pronounced in the British strategies.
} 
implied by the World Bank, is still open ${ }^{1}$. This dispute has pronounced consequences for the coordination on the country level since the education sector as a whole receives strong attention from all donor agencies. Cooperation on sector wide approaches and joint policy dialogue regarding the education sector might be inhibited by discern over this question.

While these two conflict areas explicitly arise from the analysis of the respective strategies, there is also the potential for implicit discern between donor agencies. These may arise because in some important areas, most pronouncedly on issues of globalization and information technology, the strategies only provide vague answers to the current and future challenges. Greater insights in these fields might open up new areas of discern. Another cause for potential disagreement might be the lack of clear priorities for any of the broad elements agreed to on the third level. Concerns for political reform, economic progress and security provision stand side by side, as do their subtopics. This leaves on the one hand sufficient freedom to the partner government to determine its own priorities and thus fosters ownership and can provide for greater donor specialization, yet it also bears the threat that the donor community will not keep up their portrayed unity in questions of priorities in a specific context.

This translates directly to the questions arising on the forth level. This level has purposefully been removed from the main body of the Pyramid, as the consensus does not extend to the area of concrete implementation on the local level. This was not to be expected, as strategic documents such as those presented by the donor agencies cannot take account for all the details of local project implementation. It would also constrain the ability to accommodate specific local circumstances. Yet it should be noted that despite an agreement on general terms there is much room for inconsistencies of actions and for dispute over individual measures on the national or local level. Attempts to unite all donors behind a strategy owned by the national government and coordination approaches like the Comprehensive Development Framework aim at limiting such inconsistencies and at mitigating disputes through prior discussion and agreement.

\subsubsection{Synthesis of the New Consensus and its Accentuations}

In summary of the analysis of the strategic documents, the strategic documents of the World Bank and the British, German and Swedish governments and their respective development agencies show a broad consensus ranging from the overarching goal of poverty reduction down to specific concepts for action on the domestic as well as on the international level. Major themes on the domestic

\footnotetext{
${ }^{1}$ The position of the German government on this point remains unclear in the German action program.
} 
level are the provision of economic opportunities for the poor, creation of favorable political conditions for the poor through measures of empowerment and good governance, and increasing the level of security in poor people's lives. This extension of prior strategies by governance and security issues allows for a stronger focus on the preconditions on the national political level that enable economic progress to take hold, and to integrate a stronger concern of social consequences of crisis and individual misfortune. This broad scope of measure to reduce poverty is established as an answer to the shortcomings of the former strategies.

The broad consensus that is visible on the domestic level facilitates the implementation of the unequivocal demand for greater coordination and coherence in donor policies and activities. The donors also agree to follow the lead of the recipient country's government on poverty reduction in those cases where the conditions of poverty focus and governance are favorable. Also on the international levels efforts are expanded to tackle pressing issues, with high priority on the stronger integration of developing countries in international trade.

These key points in the new strategies have the potential to increase the prosperity of developing countries by opening trade prospects and encouraging domestic private initiative, especially fostered by increasing the opportunities of the poor. To focus national policies on all problems of the poor, including economic, social, political and security issues, and to support positive developments through unified actions of the donor community bears the chance to extend the capabilities and possibilities for the poor and to contribute to lasting improvements for their lives.

The consensus and the associated benefits are currently limited by lack of prioritization and joint procedures for concrete implementation. This is mitigated by assigning the leadership for the strategy and the implementation to the partner government and by coordination mechanisms such as the CDF. Further limitation arise from the discern on higher education and support for middle-income countries, where further empirical evidence might be needed to reach a unified stance, as well as by a lack of insights especially on the new issue of integration of information technology in the developmental process. Especially the last point will require further analytical concern from all parties.

Yet not all differences in the donor strategies have detrimental impacts to the agencies ability to collaborate. The majority of different emphasis bears the potential of specialization in a certain area such as urban or rural development, energy supply or security schemes. This can lead to a transformation of donor agencies from all-round providers of aid to specialized service and finance providers with potential benefits in terms of efficiency and expertise.

Overall, the areas of agreement that are visible in the strategies by far outweigh the areas of actual or potential disagreement, since most of the accentuations are extensions of generally prevalent views rather than departures. This lends 
persuasiveness to the claim that aid effectiveness will be improved in the future through greater collaboration between donor agencies. Greater aid effectiveness will be necessary to improve the rate by which the situation of the poor people in this world will improve and to progress towards the achievements of univocally accepted International Development Targets.

To improve the aid effectiveness of their measures, the new strategies point at the value of impact measurement. This task is already an important part of the project cycle of many donor organizations. It has been chosen here to show the link between the new strategies and the actual work of development agencies. Therefore, the results of an empirical study assessing the current evaluation praxis of the German financial cooperation and recommendations for stronger integration of the insights of the new strategies in the practical evaluation process are presented in the following chapter. 
Philipp Kircher - 978-3-631-75366-8 


\section{Chapter 4 \\ Implications for Project Evaluation}

\subsection{Increasing Importance of Impact Measurement}

To draw a connection between the previous theoretical discussion on poverty reduction strategies and the actual work in the development arena, a process from the end of the project cycle has been chosen for deeper investigation. Impact measurement is for many donor agencies an important part of their work. It is reviewed here because the focus of the new strategies on the main goal of poverty reduction will likely require shifts in the emphasis of the evaluations process, which shall be portrayed here. Most of the new strategies explicitly acknowledge the high importance of the evaluation process and the establishment of statistical capacity for their ability to reach their goals ${ }^{1}$. This concern is attributable to the need to increase the effectiveness of development efforts.

Improvements of aid effectiveness follow directly from the pursuit of the IDTs, since progress towards their achievement has only been a third of the required average rate since their establishment ${ }^{2}$, requiring faster progress in the future. The ability to learn lessons from one's experience in order to increase aid effectiveness is dependent on a functioning monitoring system on the project, sectoral and national level. ${ }^{3}$ As financial involvement in specific projects currently constitutes the largest financial involvement for many donor organizations ${ }^{4}$ and will likely continue to remain of importance ${ }^{5}$, there is large scope for impact assessment on the disaggregated level - i.e. project level - to contribute to the effectiveness of overall aid delivery. ${ }^{6}$

\footnotetext{
${ }^{1}$ Most prominently in the strategy of DfID. See the chapter on 'United Kingdom', 'IDTs and Impact Measurement'. Further reference to measurement concerns can be found i.e. in World Bank (2001a), p. 21.

${ }^{2}$ See KfW (2001a), p. 18.

${ }^{3}$ See i.e. DfID (1999a), p. 36. The sectoral and regional level receive strong concern in the recent strategies as the countries ability to gather and evaluate information is seen as a precondition to design and implement effective national policies. Since this is not the concern of this empirical part of the analysis, the reader is referred for further information to Achikbache, B. et al. (2000), who thoroughly analyse the expansion of statistical capacity in connection of the PRSP process.

${ }^{4}$ I.e. for the German financial cooperation handled through the $\mathrm{KfW}$ this has been around over $80 \%$ of the projects and the finance volume as of 1996/97. See KfW (1999), p. 7.

${ }^{5}$ The move towards sector-wide approaches is still in the experimental phase. See i.e. BMZ (2001a), p. 23.

${ }^{6}$ While countrywide statistical measurement is necessary for the formulation of overall policies and for the assessment of overall progress on poverty reduction, the effectiveness of the individual projects cannot be assessed via this approach. Therefore, the evaluation of single projects still needs to be conducted.
} 
While the systems for impact monitoring on the project level are already in place in most donor agencies, the shift of importance towards poverty reduction as the overarching goal necessitates a review of the current praxis of impact evaluation. Poverty reduction as the major goal for development cooperation requires the linkage of all analysis back to this goal, which essentially calls for a concern for the poor individuals in the assessment of the impact of a project. Since evaluation systems developed in the past might not have placed such a high emphasis on the measurement in terms of reductions in poverty, there is potentially large scope for improvements. Assessing the current evaluation praxis in regard to its concern for poverty reduction and locating areas for improvements in line with the new strategic concepts are the goals of this analysis.

\subsection{Background: The German Financial Cooperation and the KfW}

To this end the monitoring praxis of the German financial cooperation handled through the KfW has been investigated ${ }^{1}$. The financial cooperation is a distinct part of the German development cooperation. Its conception and the background of the $\mathrm{KfW}$ as the implementing agency shall be introduced prior to going into the details of the analysis.

Financial cooperation has the objective to "contribute to improving the economic and social conditions of the people in developing [and transitional] countries" $^{2}$ and to achieve structural preconditions for development ${ }^{3}$ through financing of investments and reform programs. This is achieved indirectly through the formation and financing of investments in economic and social infrastructure and directly through support for structural change on the general economic and sectoral level. ${ }^{4}$ More specifically, the economic and social position of the people in developing countries is to be improved through

\footnotetext{
${ }^{1}$ The German cooperation praxis can serve as an example for the changes that the new strategies require in impact evaluation despite the absence of concern for monitoring within the German action program, since on the level of the BMZ the importance of impact measurement is well acknowledged. On ministerial level it has been established that "development policies can only be successful if they are soundly planned, competent and efficiently managed and critically reviewed and evaluated. Only in this way it is possible to learn from the mistakes as well as the successes for future efforts. [.. The German] government therefore attributes special importance to the impact measurement in development cooperation." Wieczorek-Zeul, H. (1999). (Translation by the author.) This points out the concern for aid effectiveness mentioned above as one reason for choosing this topic.

${ }^{2}$ See KfW (2001a), p. 5.

${ }^{3}$ See BMZ (2000d), p. 206.

${ }^{4}$ See BMZ (2000d), p. 206.
} 
increase and better utilization of production potential, the construction of social and economic infrastructure and the protection of the environment. ${ }^{1} 28 \%$ of the volume of the German development cooperation is dedicated to this purpose, ranging in value at 2 billion $\mathrm{DM}^{2}$

The KfW has been charged by the BMZ with the responsibility to investigate and implement the German financial cooperation. ${ }^{3}$ The BMZ has delegated the evaluation of projects to the $\mathrm{KfW}$ to be performed in its own responsibility according to BMZ guidelines. ${ }^{4}$ This delegation of the execution of the evaluations to the $\mathrm{KfW}$, combined with the obligation to follow the rules for evaluation established by the BMZ, establishes the connection between the KfW evaluations as part of the German evaluation praxis and the newly established German action program as part of the consensus in poverty reduction discussed prior.

The Kreditanstalt für Wiederaufbau (KfW) was established in 1948 as a public holding with $80 \%$ of its capital stock held by the Federal Republic of Germany and the other $20 \%$ held by the German states. ${ }^{5}$ It assumes the role of a supportive bank for the national economy and of a developing bank for developing countries. ${ }^{6}$ In the scope of its activities the support for the German and European economy through financing of investments $(65 \%$ of its commitments) and export and project financing (31\%) make up the largest share, while the promotion of developing and transitional countries makes up $4 \%$ of the yearly portfolio. ${ }^{7}$

Nevertheless the support for developing countries amounted to new commitments valued at 1.5 billion EURO in $2000 .^{8}$ Thereof 0.9 billion EURO have been provided by the $\mathrm{BMZ}$ on concessional terms, ranging from nonrepayable contributions for $\mathrm{LDCs}$ to $2 \%$-interest 30 -year loans ${ }^{9}$. The remaining 0.6 billion EURO are contributions of the KfW at market condition ${ }^{10}$ which are granted in combination with ODA flows in form of mixed financing, either secured by German export credit insurance agency or by combined financing

\footnotetext{
${ }^{1}$ See KfW (2000b).

${ }^{2}$ Value of 2000 . See KfW (2000b).

${ }^{3}$ See BMZ (2000d), p. 206.

${ }^{4}$ See BMZ (2000d), p. 38.

${ }^{5}$ See KfW (2000b).

${ }^{6}$ See BMZ (2000d), p. 211.

${ }^{7}$ Data as of 2000 is based on the overall commitments of loans and grants, adding up to 36.2 billion Euro. A small part of the KfW's activities is also dedicated to consultation and other services for the government. The data was provided by the $\mathrm{KfW}$ foreign secretariat, Frankfurt. ${ }^{8}$ See KfW (2001a), p. 8 and 10 for the data value for new commitments.

${ }^{9} 2 \%$ interest loans are means for financing for middle-income countries, yet even for these grants are available for special project types. For a deeper insight see KfW (2001a), p. 64.

${ }^{10}$ See KfW (2001a), p.8.
} 
without tying of aid. ${ }^{1}$ This policy to mix concessional credits with those on commercial terms is undertaken to accommodate the rising financial needs of many developing countries ${ }^{2}$ despite limited ODA resources and to implement projects that would otherwise not have been possible. This involvement of commercial loans has surged enormously between 1998 and $2000 .^{3}$

The regional distribution of support provided by the $\mathrm{KfW}$ spans all major regions troubled by severe poverty. The five-year average distribution of new commitments is shown in figure 12. Regarding the sectoral distribution the $\mathrm{KfW}$ shows a concentration on social and economic infrastructure. Within the social sector, water and sewage systems received the foremost priority, implicit in a $36 \%$ share of funds in $2000 .^{4}$ Also of importance is support to the financial sector. Figure 13 shows the five-year average distribution of new commitments by sector. Since large deviations from the average can be made out for some regions and sectors, the respective value for the year 2000 is provided in brackets.

The KfW's main activity rests with the provision of financing in the pursuit of investment projects ${ }^{5}$ and support of the financial sector ${ }^{6}$. The responsibilities of the concrete implementation of the projects rest with a local organization. As a development bank, the KfW shares in the success of projects and supports its partners in developing countries with technical planning, implementation and monitoring of projects. A small part of its activities is also extended to studies and other supportive measures ${ }^{7}$ and the training of local personnel, yet the role of providing know-how and consulting services for the partner country is left mainly to the GTZ, with which a number of projects are conducted in close cooperation $^{8}$. Aside from the financing of individual projects the $\mathrm{KfW}$ also provides a small part of its aid in terms of support for the import of generally

\footnotetext{
${ }^{1}$ See KfW (2000b) and BMZ (2000d), p. $209-211$. For combined financing the goods involved secure the credit volume, while in combined financing the security for the loan is guaranteed via a new federal guarantee scheme. Combined financing is limited to countries with a limited risk of default on credit.

${ }^{2}$ See BMZ (2000d), p. 209.

${ }^{3}$ See KfW (2001a), p. 10. While market funds have only accounted for 33 million Euro in 1998 after a sharp drop compared to the previous year (262 million Euro in 2997), this value has risen to 601 million Euro in 2000, including a 495 million Euro loan to the Poverty Reduction and Growth Facility of the IMF.

${ }^{4}$ See KfW (2001a), p.11.

${ }^{5}$ This includes social and economic infrastructure, support for the productive sector and the protection of the environment. See KfW (2000b).

This includes the introduction of new financial instruments, the recapitalization and reorganization of existing banks and the support for decentralized financial systems such as micro-credit schemes. See KfW (2000b).

${ }^{7}$ These are conducted to aid the partner country in the preparation of projects and to aid in the implementation. See KfW (2000b).

${ }^{8}$ Cooperative projects amounted to 184 projects in 2000 . See KfW (2001a), p. 12.
} 
needed goods and as structural adjustment support for reforms on the national or sectoral level. ${ }^{1}$

Figure 12: KfW Regional Distribution in 2000*
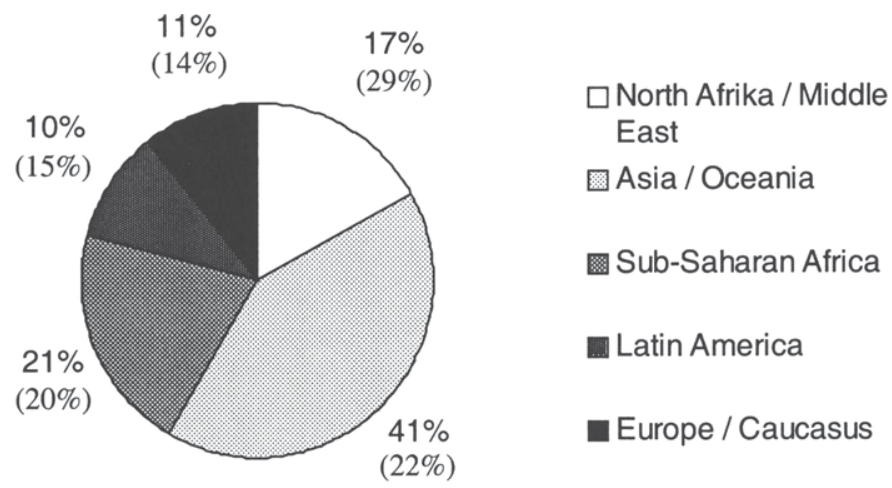

* Source: KfW (2001a), p. 61.

Figure 13: KfW Sectoral Distribution in 2000**

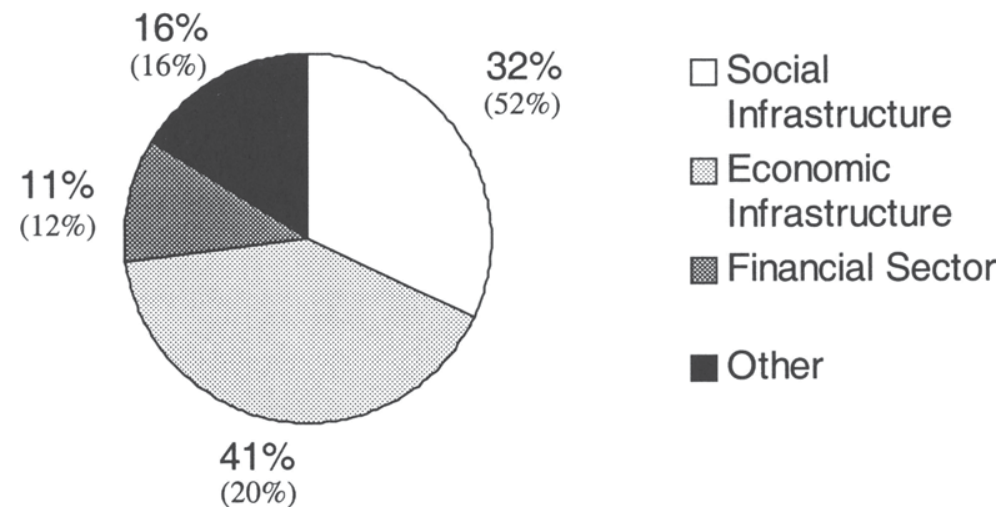

** Source: KfW (2001a), p. 62 and KfW (2000b)

The project cycle in the responsibility of the KfW spans the project assessment prior to financial involvement, project monitoring during implementation and

${ }^{1}$ See KfW (2000b). 
project evaluation after the termination of the project. The emphasis in the following empirical study is placed on the stage of the final evaluation. In this evaluation the $\mathrm{KfW}$ considers the following aspects in the evaluation of the success of a project ${ }^{1}$ :

- $\quad$ Sectoral Framework

- $\quad$ Achievement of Target (comparison of target to actual outcomes based on measurable indicators)

- Individual economic aspects

- General economic aspects

- $\quad$ Socio-economic and -cultural implications

- Environmental effects and

- $\quad$ Sustainability of effects over time.

Due to the multiple dimensions of the definition of poverty, poverty reduction can be measured within all of these variables. In most cases where it is considered it is regarded within the assessment of socio-economic and -cultural implications.

In its impact assessment the KfW uses a six-level scale established by the BMZ to evaluate its projects. This scale translates as follows ${ }^{2}$ :

Level 1: $\quad$ very good and good

Level 2: $\quad$ satisfactory

Level 3: overall sufficient

Level 4: overall insufficient

Level 5: clearly deficient

Level 6: the project has clearly failed.

According to the above criteria and this evaluation scale, $75 \%$ of all projects of the KfW evaluated in 1996/97 have been successful in its own assessment. ${ }^{3}$ The majority of these have been in the first two levels - $44 \%$-, with the remaining $31 \%$ being sufficient. In its own benchmarking against other agencies concerning its evaluation systems and success level the results of the KfW lie within or above the comparable ranges. ${ }^{4}$ The success by region and sector is presented in figures 14 and 15 . They show that the success has been fairly equally distributed over regions and sectors, with especially high success quotas in Asia. ${ }^{5}$

\footnotetext{
${ }^{1}$ Source: KfW (2000b).

${ }^{2}$ Source: KfW (2000b).

${ }^{3}$ See KfW (1999), p. 14. According to the volume of aid this success reaches $72 \%$.

${ }^{4}$ See the benchmarking against the World Bank and the Agence Francaise Développement in KfW (1999).

${ }^{5}$ These do not reflect the consequences of the Asian crisis, which have not been reflected in the final evaluations. The negative deviations for Europe and North Africa have been attributed mainly to exceptional experiences such as failure of large-volume projects in these areas. See KfW (1999), p. 19.
} 
Figure 14: Success of Projects by Region (1996/97)*

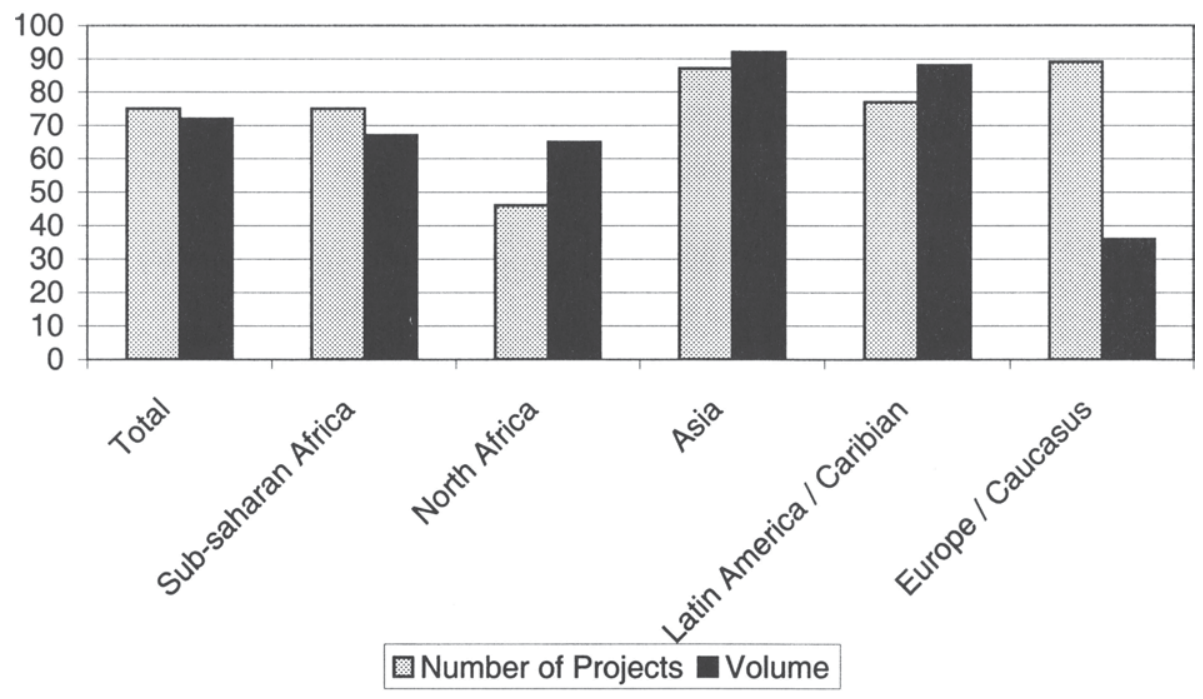

*Source: KfW (2000b), also published in KfW (1999).

Figure 15: Success of Projects by Sector (1996/97)**

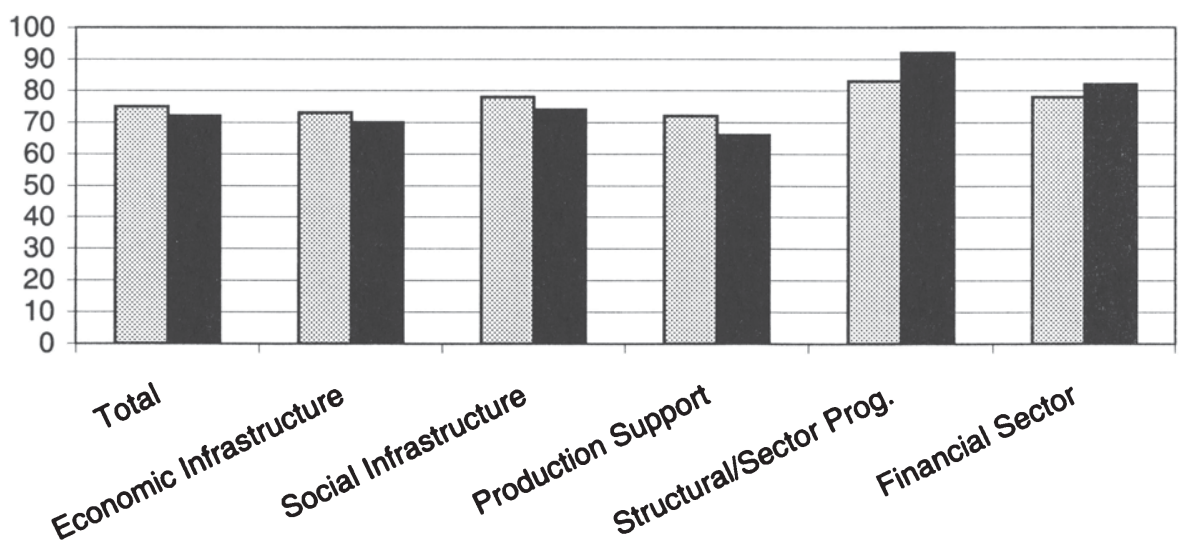

\section{Number of Pojects QVolume}

**Source: $\mathrm{KfW}(2000 \mathrm{~b})$, also published in KfW (1999). 
The procedure of evaluation that has established these numbers and the implications of the new consensus on it are at the heart of the following analysis.

\subsection{Aim of the Empirical Study}

As pointed out prior, this analysis aims at linking the discussion of the new strategies of poverty reduction to the practical work of development agencies, in particular to the task of impact evaluation. As has been portrayed in the Pyramid of Consensus ${ }^{1}$, the highest level of agreement has been reached regarding the priority of poverty reduction in development cooperation. ${ }^{2}$ This requires evaluation mechanisms to evaluate the success of projects against the baseline of the reduction of poverty that they have achieved. As the strategies and their focus on poverty reduction have been established recently, this concern of poverty reduction as the central measure for impact evaluation might not have been fully translated into the praxis of development cooperation yet. This study outlines the current procedures of the impact evaluation of the German financial cooperation and outlines improvements for progress in line with the new strategic concepts.

Therefore, this study takes a look at the degree to which the situation of the poor people and the change of their situation has been regarded in the evaluation praxis of the KfW. It explores in which situations a focus on the poor people's situation has been especially strong and which factors contribute to a higher or lower concern for their situation. It also explains how the situation of the poor was assessed, i.e. the chain of argumentation in cases of inductive reasoning or the analysis of data in quantitative analysis. Based on these assessments, recommendations are provided on two areas: internal regulatory measures within development agencies to increase the focus on the poor people's situation and measures to foster the generation and use of necessary data. For the second point the costs of data gathering are taken into account as an important factor.

In the evaluation of this analysis it has to be taken in mind that many of the projects evaluated in recent years and thus subject to this study have been devised a decade or more ago, when the current focus on poverty reduction was not yet established. While this does not have to affect the current procedure of measuring the poverty impact of projects, it can help to explain the lack of ex

\footnotetext{
${ }^{1}$ For reference see the chapter on 'Consensus on three Levels'.

${ }^{2}$ Even though it has been pointed out that the German government does not explicitly present poverty reduction as the overarching goal of poverty reduction, the action program and even more the BMZ has established poverty reduction as its major concern. The embracement of the IDTs and the special pronouncement of the goal to cut by half the percentage of people living in poverty point at the fact that poverty reduction can be seen as the strongest priority also in the German development cooperation.
} 
ante data gathered prior to the project start in order to allow meaningful comparisons to the ex post situation. This study also does not cover the work of the newly established independent evaluation unit at the $\mathrm{KfW}^{1}$, whose evaluation reports were not yet available at the completion of this study.

This analysis antecedes two studies commissioned by the BMZ in the mid 1990 s on poverty reduction and reach of the target group ${ }^{2}$ and successes and problems ${ }^{3}$ in the German development cooperation. The latter includes a broad analysis of the evaluation praxis, but provides only brief insights on the inclusion of poverty reduction, while the former provides deep insights into the topic of poverty reduction but only briefly assesses the evaluation praxis. Therefore, the combination of concerns on the evaluation praxis and on poverty reduction provides a real extension to these analyses, while drawing on their conclusions where appropriate.

This analysis has a narrow focus on the combination of the two themes of poverty reduction and impact evaluation, limiting itself to the investigation of the inclusion of the situation of poor people in the evaluation of projects. A discussion of the effectiveness or the overall adequateness of the evaluation system is not attempted in this study. It also does not question the methods deployed by the KfW to assess the success of a project unless they refer to the assessment of poverty reduction, nor does it investigate the effectiveness of the German financial cooperation. The evaluation system and its methods have been extensively analyzed e.g. in Borrmann (1999), who attests a creditable quality control and ex-post impact evaluation system corresponding to internationally accepted standards. ${ }^{4}$ The effectiveness of the financial cooperation based upon these standards has also been sufficiently discussed. ${ }^{5}$ For these reasons the analysis focuses on the single aspect of the inclusion of the situation of poor people within the process of impact evaluation.

\subsection{Study Design}

This study has been conducted on a sample of 75 reports of the final evaluations undertaken by the KfW between 1997 and 1999. On the basis of these reports the integrations of the situation of the poor in the final analysis has been

\footnotetext{
${ }^{1}$ See KfW (2001a), p. 9. The central independent evaluation unit was established in September 2001.

${ }^{2}$ See Kranz-Plote, J. / Micha, F. (1996).

${ }^{3}$ See BMZ (1999c).

${ }^{4}$ See Borrmann, A. (1999).

${ }^{5}$ Results from the years 1996/97 are examined in detail in KfW (1999). For results on newer periods see KfW (2001a).
} 
evaluated. Since the sampling procedure is based on some of the variables used in the analysis, these are defined before explaining the procedure.

\subsubsection{Variables}

The study uses a series of variables that are readily available from the reports presented:

Financing: Costs of the project in million DM.

Fin_Quint (Fqu): Ordinal measures constructed on the basis of the variable Financing. The sample population has been split in five groups of 15 projects based on the level of financing. The group with the lowest Financing received the ordinal value 1, going up in unity steps to the value 5 for the group with the highest financing. Thus the value corresponds to the respective quintile.

Impact_Level (IL): This variable describes the distance from the project impact to the immediate circumstances of the poor. It is based on a categorization scheme of the BMZ. ${ }^{1}$ The values assigned here are listed below including a short explanation. The scheme of the BMZ as assembled by the KfW is presented in annex 6 .

IL 1: $\quad$ SHA - Selbsthilfeorientierte Armutsbekämpfung (selfhelporiented project to fight poverty). Projects "directed at target groups with a significant share of poor people (aimed at helping) (...) the target group directly to take responsibility and organize the themselves in improving their living conditions"2.

IL 2: $\quad$ SUA - Sonstige unmittelbare Armutsbekämpfung, v.a. soziale Grunddienste (other direct poverty reduction projects, especially social services). Projects "directed at target groups with a significant share of poor people (aimed at supporting) (...) the target group's participation in the project" ${ }^{3}$. In contrast to IL1

\footnotetext{
${ }^{1}$ The BMZ uses this categorization to generate a classification of projects on the basis of their focus on fighting poverty corresponding to DAC conventions. Level 1 and 2 projects are according to the BMZ scheme automatically assessed to focus primarily on poverty reduction, for level 3 projects fighting poverty is secondary goal and for level 4 projects fighting poverty is not relevant. See KfW (2000c). This does not correspond to the broad consensus of fighting poverty as outlined prior, which acknowledges strategically oriented measures as conducive to long-term poverty reduction. Therefore this automatic relationship between level of impact and fighting poverty is not used in this analysis.

${ }^{2}$ KfW (2001a), p. 23. The separation of the quotation to distinguish between IL1 and IL2 variables is based on the BMZ categorization explained in more detail in annex 7 .

${ }^{3} \mathrm{KfW}$ (2001a), p. 23.
} 
the target group is not self-responsible in the organization of the project.

IL 3: $\quad$ MSA - Übergreifende Armutsbekämpfung auf Makro- und Sektorebene (poverty reduction on macro- or sector level). In contrast to projects on level 1 and 2, level-3 projects cannot clearly identify the target group and cannot reach this group immediately, but only through more complex chains of effects. Yet indirect benefits in significant magnitude accrue to the poor in the area and the chain of effects is plausible. ${ }^{1}$

IL 4: $\quad$ EPA - Allgemeine entwicklungspolitische Ausrichtung (general development oriented projects). The projects are supported out of general development oriented considerations ${ }^{2}$ but do not fulfill the constraints of the lower levels. I.e. the poverty reduction impact is more complex and "less directly inferable "3.

Success 6: $\quad$ Evaluation of the success of a project on a scale from 1 (best) to 6 (total failure). The scale has been presented in the discussion of the background of the KfW.

Success (s): This variable is constructed via a transformation of the variable success 6 on a three-level scale. This simplifies the investigation via correspondence analysis and was used in the sampling process to avoid to too narrow splitting of groups. The new scale was constructed as follows:

s 1: Level 1 and 2 of the success 6 scale (very good, good and satisfactory projects).

s 2: $\quad$ Level 3 on the success 6 scale (sufficient projects).

s 3: Level 4,5, and 6 on the success 6 scale (overall insufficient, clearly deficient, clearly failed projects). ${ }^{4}$

CRS: $\quad$ Industry code on the level of highest aggregation (1 digit), with the following meanings:

crs 1: $\quad$ Social infrastructure

crs 2: $\quad$ Economic infrastructure

${ }^{1}$ See KfW (2001a), p. 23, 24.

2 Projects contributing "to dynamising the economic and social development where developmentally propitious conditions prevail". KfW (2001a), p. 24.

${ }^{3} \mathrm{KfW}$ (2001a), p. 24.

${ }^{4}$ This transformation has been proposed within the $\mathrm{KfW}$, because the differences between the $\mathrm{BMZ}$ categories 1 and 2 are perceived as smaller than between 2 and 3. Level 3 projects are close to failure and therefore receive special scrutiny within the KfW process. Level 4 could have also received a special value since its failure only touches part of the implementation, but the number of projects within this category was too limited to justify a single category, since only around $25 \%$ of all $\mathrm{KfW}$ projects are of value 4 and below. The scheme proposed here has been used similarly in the analysis in KfW (1999), p. 14. 
crs 3: $\quad$ Production and trade

crs 4: $\quad$ Multisectoral / Cross-sectional

crs 5: $\quad$ Support for import goods / general program aid

crs 7: $\quad$ Emergency aid

The preceding variables can either be retrieved directly from the reports, or can be obtained from a short conversion of the existing data. This has been supplemented by an additional variable where the values have been assigned based on the insights of the respective final evaluation given in the reports. This variable aims at assessing the degree to which poverty reduction has been taken into account in the final evaluations. Therefore, it stands at the core of the following analysis. It is designed as follows:

Poverty Focus (Pov): This variable evaluates to what extend the situation of the poor has been analyzed in the final evaluation. Four different levels have been distinguished for this purpose.

Pov 0: Poverty was not regarded. The report does not include reference to the effect of the project on the poor people and their situation.

Pov 1: $\quad$ Poverty was implicitly regarded. The report does not make a clear statement on the effect on the project on the situation of the poor people. Yet it can be inferred from the context that positive effects for the poor have been achieved, as the report delivers hints in this direction.

Pov 2: $\quad$ Poverty was explicitly regarded. The effect of the project on the situation of the poor has been argumentatively accounted for. This is the case if reference within the report is directed directly to the change of the situation of the poor and if the effects of the project to their advantage are conclusively pointed out.

Pov 3: $\quad$ Poverty reduction was empirically or measurably accounted for. This is the case if data that quantifies the benefits of the project for the poor has been gathered.

This variable only distinguishes broad categories, as a more refined framework brings up too many questions in the categorization of the individual project. The variable has been developed using distinctions similar to those drawn by KranzPlote / Micha in their assessment of the target group definition. ${ }^{1}$ This variable will be at the core of the quantitative analysis.

The assessment of the value for this variable is based on a rather mechanic approach that takes into account formal criteria, but not the strength of the data or argumentation deployed or the inclusion of the results in the final evaluation. Therefore, for each project evaluation the way poverty has been assessed has also been recorded and will be presented in the qualitative analysis.

\footnotetext{
${ }^{1}$ Kranz-Plote, J. / Micha, F. (1996).
} 
Some of the variables assessed here, especially the variable Poverty Focus, are concerned with the situation of poor people, without specifying the definition of poverty. Poverty is a multidimensional problem, as has been pointed out in the discussion of the consensus. As this analysis spans many different types of projects from a variety of sectors, the definition of poverty in each individual case might vary considerably. This impedes the use of a general definition of poverty. Therefore, this analysis leaves the definition of poverty to the individual evaluation. Based on the definition of poverty in a given report ${ }^{1}$, the parameter value of each variable was assessed.

\subsubsection{Sampling Procedure}

The base population for this sample are all 435 projects with final evaluations in the years 1997 to 1999 . The procedure has been based on a partial random sampling method, accounting for frequency distributions along two dimensions.

The success of projects might have profound influences on the way the situation of the poor has been assessed or vice versa. On theoretical grounds, it is conceivable that projects that have failed due to technical or managerial reasons will not justify a special concern for the situation of the poor, as the assumed benefits cannot have materialized. Also the distance of the project to the poor people (Impact_Level) bears by its definition potentially high influence on the analysis of poverty within the final evaluations, as projects with low distance to the poor can be argued to be easier to assess than those with a high distance. For determining the impact of both variables, a sufficient sample size for each combination of parameter values of the parameters Success and Impact_Level has been pre-specified ${ }^{2}$. For each of the 12 combinations five projects have been assessed, except for combinations with an impact level of three, where ten projects have been sampled due to the frequency of this level in the base population. ${ }^{3}$ The overall sampling distribution is shown in table 2.

\footnotetext{
${ }^{1}$ Most times no clear definition of poverty was rather vague, based either implicitly or explicitly on a certain minimum level of income or assets.

${ }^{2}$ It should be noted here that under- or oversampling of units based on exogenous variables does not give rise to sample selection bias. See for example Verbeek, M. (2000), p. 216-220. Therefore, if both success and impact_level are exogenous, this procedure does not raise problems of selection bias. For impact_level, strict exogeneity seems reasonable. For success, endogeneity could potentially be a problem. Since neither the results of the correspondence analysis, which shows little impact of either success on poverty focus or vice versa, nor the stepwise regression approach undertaken in appendix six point at the existence of endogeneity problems, success is treated as endogenous.

${ }^{3}$ Impact level 3 is with 100 projects in the base population about twice the size of level 1 (51) and level 2 (62). The projects on impact level four dominate the base population with 202 projects, yet their specification as being far removed from the base population made an evaluation of the situation of the poor unlikely, negating the benefit of a large sample from this group compared to the costs involved. For the parameter success, the base population the distribution has been fairly equal at success level one: 165 projects, success level two: 130
} 


\section{Table 2: Sampling Distribution}

\begin{tabular}{l|c|c|c|c}
\multicolumn{1}{c|}{ Success } & Level 1 & Level 2 & Level 3 & $\Sigma$ \\
Impact Level & & & & \\
\hline Level 1 & 5 & 5 & 5 & 15 \\
\hline Level 2 & 5 & 5 & 5 & 15 \\
\hline Level 3 & 10 & 10 & 10 & 30 \\
\hline Level 4 & 5 & 5 & 5 & 15 \\
\hline$\Sigma$ & 25 & 25 & 25 & 75
\end{tabular}

These twelve individual random samples have been joined to allow the analysis of 75 projects.

\subsection{Findings}

\subsubsection{Procedure}

In its procedure, the analysis considers in a first step the quantitative data. For this purpose descriptive techniques have been deployed as well as more sophisticated statistical tools. The procedure of analysis had to be fit to the data requirements, which causes problems in the use of many statistical instruments because much of the data is not cardinal but ordinal. This inhibits e.g. the use of methods of factor analysis, which require cardinal data. The methods of multivariate correspondence analysis have been taken to avoid potential pitfalls. In some cases averages, regressions and analysis of variance have been deployed for more quantifiable results where their use seemed justifiable. ${ }^{1}$

The analysis of the data only vaguely reflects the current evaluation praxis. This is especially attributable to the fact that the measures cannot portray the procedures that underlie the evaluations. Therefore, in a second part qualitative reasoning is deployed to assess the current evaluation praxis more comprehensively. Commonalities in the argumentation processes and in the methodic of measurement are used as baselines for this discussion.

In a third step, the results are discussed in their relevance to the new consensus and compared with results from other studies. Recommendations for further improvements are issued and finally the results are summarized.

projects, success level three: 140 projects, an equal distribution in the sample population seems justified.

${ }^{1}$ The reader should keep in mind that these are not invariant against changes in scale, which can be undertaken for any ordinary scale. The difference between ordinary values by unity seems justified in this study in the pursuit of the aim to quantify the effects of impact measurement. 


\subsubsection{Quantitative Analysis}

In a first step of this analysis the characteristics of the sample shall be explored before the relationships between different parameters are assessed.

The most striking point directly assessable from the sample data is the low number of projects that have quantified the impact on poverty reduction. This is depicted in table 3 and figure 16.

Table 3: Poverty Focus

\begin{tabular}{|c|c|}
\hline Poverty Focus & Number of Projects \\
\hline Pov 0 (none) & 20 \\
\hline Pov 1 (implicit) & 22 \\
\hline Pov 2 (explicit) & 23 \\
\hline Pov 3 (measured) & 10 \\
\hline
\end{tabular}

Figure 16: Projects by Poverty Category

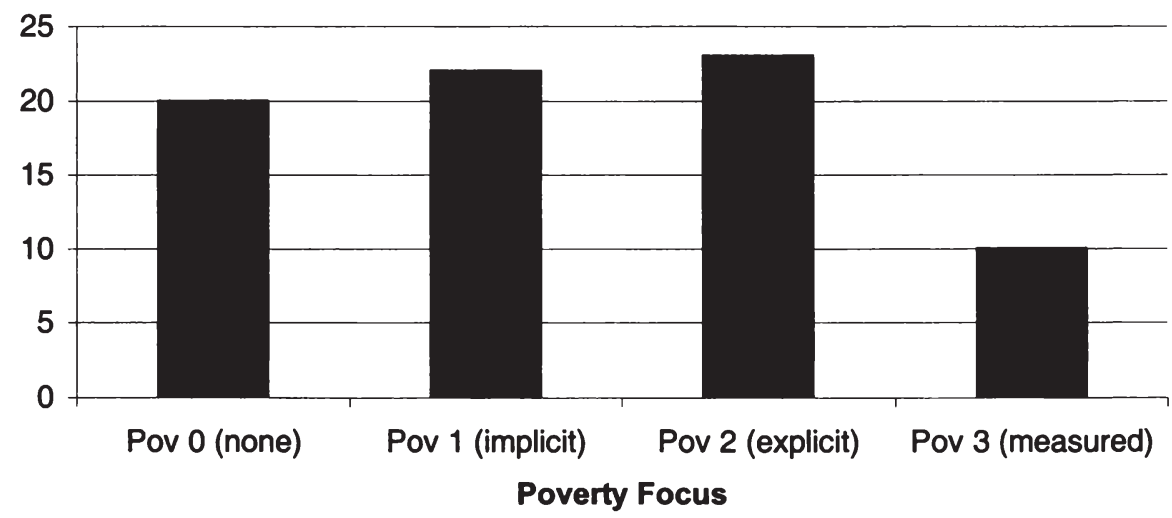

Less than $15 \%$ of all final evaluations sampled thus used quantitative approaches to the impact on poverty. Considering the fact that the first two levels do not take clear reference to the reduction of poverty in their final evaluation ${ }^{1}$, more than $50 \%$ of the sampled final evaluations do not use poverty reduction as a criterion for impact measurement.

${ }^{1}$ For Pov 0 that is clear per definition. Pov 1 means that poverty has only implicitly been taken into account, which means that the report does not include a part where poverty reduction is assessed. The potential poverty impact had to be inferred by the reader by hints from the text. 
Since the variables success and impact level had been pre-specified in the sampling procedure, their distribution is unspectacular. The distribution by sector resembles the overall distribution of projects by the $\mathrm{KfW}$ as presented in the background discussion, with the sector production and trade being somewhat over-represented and economic infrastructure somewhat underrepresented ${ }^{1}$. The three dominant sectors economic infrastructure, social infrastructure and production and trade account for $88 \%$ of the analyzed projects and will receive most attention in the rest of the analysis. See figure 17 for the details. The distribution of the financial involvement per project is right-skewed. This points at a preference for smaller, less costly projects rather than large investments. Noteworthy are a couple of outliers. These are attributable to large economic infrastructure projects, whose average financing is 4.5 times that of social infrastructure projects in this sample. See figure 18 for the histogram.

\section{Figure 17: Histogram by CRS Code}

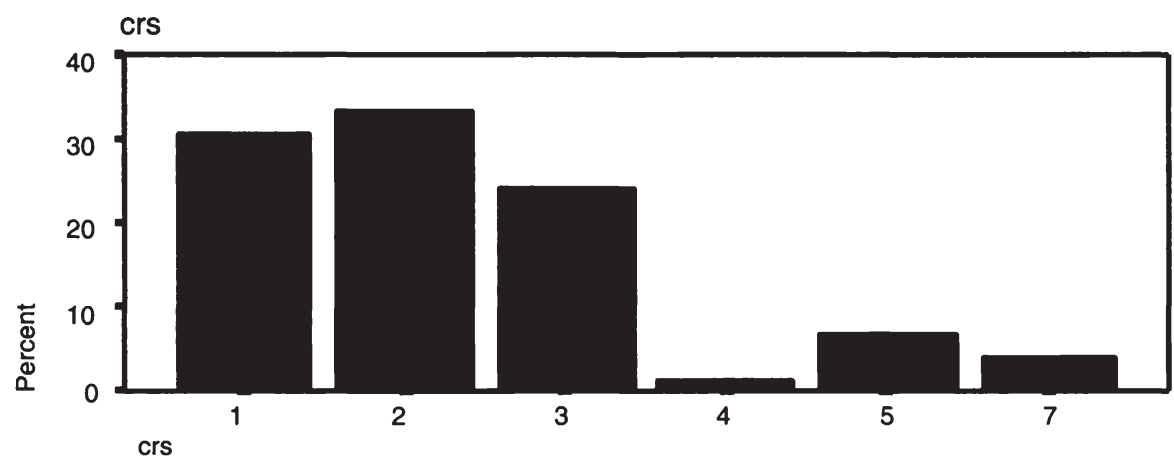

Figure 18: Histogram by Financial Costs

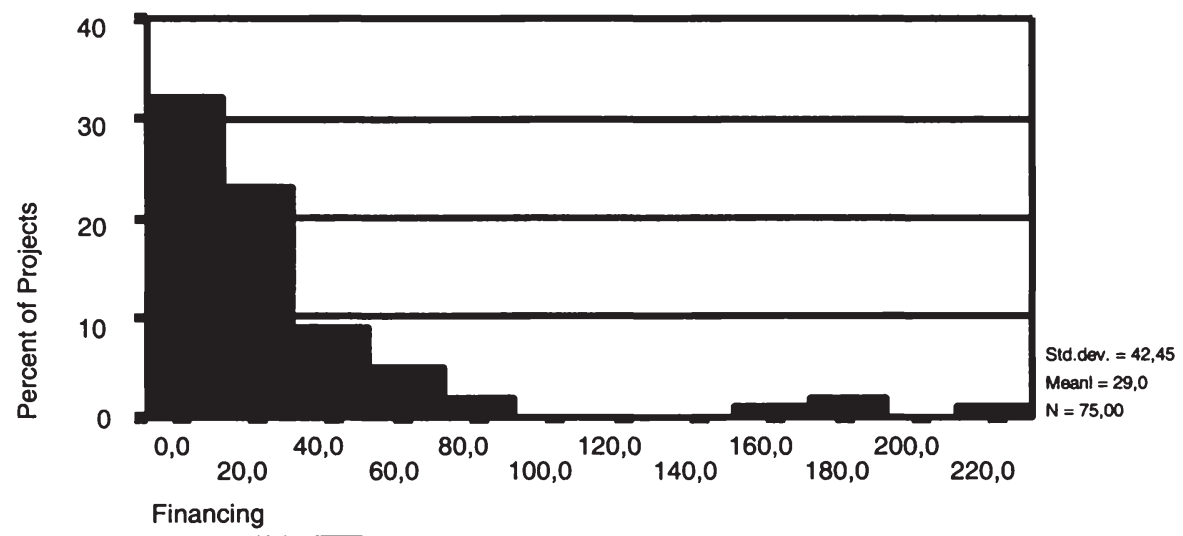

${ }^{1}$ The financial sector is in this evaluation integrated into economic infrastructure, as defined by the CRS codes used in this analysis. 
The main task of this quantitative section is to investigate dependencies or correlations between the various variables or even the parameter values of the variables. Especially the connection of success (s), sector (crs), impact level (IL) and financial involvement (fqu) ${ }^{1}$ to the way poverty has been regarded (pov) is of interest. To get a first handle on this, bivariate and multivariate correspondence analysis was deployed. Despite the mathematical complexity this method provides easily interpretable data by reducing the dimensions of the parameter values to a manageable level that can be graphically displayed. ${ }^{2}$ For a thorough discussion of the background of this method, the reader is referred to the specialized literature ${ }^{3}$. In the present context I shall only attempt a short introduction to enable the interpretation of the results.

The method uses as inputs categorial variables with a limited number of parameter values, i.e. normally qualitative data. To include continuous variables like the level of financing in the analysis, they have to be brought into ordinal form via categorization. This has been done via the categorization into five groups of equal frequency. ${ }^{4}$ The resulting $n$-dimensional space, where $\mathrm{n}$ is the number of parameter values after categorization, is projected via matrix transformations into another $\mathrm{n}$-dimensional space based on the eigenvectors of the original matrix. The new dimensions are strictly ordered on the basis of their explanatory value $e^{5}$ in regard to the observed parameter values. In this setting we use the first two dimensions to display the parameter values in two-dimensional form. The explanatory power of these two dimensions is the cumulative power of each dimension, which tends to be lower for increasing numbers of original parameter values. The method resembles that of the more commonly used factor analysis, but does not impose the requirement of cardinal data. This in turn prohibits the determination of the load of each resulting dimension and thus limits the ability to identify the meaning of each dimension. However, detecting

\footnotetext{
1 The quintiles have been used in order to accommodate the needs of the statistical instruments.

${ }^{2}$ In this analysis only the first so-called main plane (i.e. the first and second dimension of the resulting space) is analyzed. This procedure has been used because the additional information from an analysis of the second main axis (i.e. the first and third dimension of the resulting space) only delivers marginal additional insights while potentially contributing to confusion of the reader.

${ }^{3}$ For a comprehensive discussion including examples for interpretation of the data for bivariate and multivariate correspondence analysis the reader is referred to Jambu, M. (1992), p. 149 - 264. Further discussion of this topic is provided in Andersen, E. (1994) and Greenacre, M. (1984). A condensed presentation of the methods for graphical interpretation can be found in Edwards, D. / Kreiner, S. (1983).

${ }^{4}$ Normally the procedure is to divide the range of values for the continuous parameter into $n$ classes of equal amplitude, ordered in magnitude from 1 to $\mathrm{n}$. Each observation that falls into the $\mathrm{i}$. class is given the value $\mathrm{i}$. This simple procedure to construct ordinal parameters causes problems in highly skewed distributions. In these cases classes with equal frequency provide a solution. See Jambu, M. (1992), p. 214.

${ }^{5}$ The explanatory power can be determined on the base of the eigenvalue.
} 
patterns in the projection of the parameter values may help to interpret the axes and the dependencies between certain parameter values or variables.

The proximity of parameter values in the two-dimensional representation is an indication for high correspondence of these parameter values, i.e. high likelihood of simultaneous occurrence. This fact is used to determine clusters of values within the graphic representation. These clusters are then used to interpret the relationships of the various parameters to the degree to which poverty has been taken into account, i.e. the parameter pov.

For this analysis a top down approach has been chosen in which the highest possible number of variables have been included in the analysis (multiple correspondence analysis) and have been reduced when necessary to achieve further insights. This approach has the advantage of accounting for all interrelationships between the variables instead of only accounting for dual relationships (bivariate correspondence analysis). It also increases the comprehensiveness of this study. ${ }^{1}$ The highest level of analysis involving all five parameters does not yield interpretable results, as the reduction of 22 dimensions on two dimensions leads to too low values in explanatory power. Therefore a selection of four variables - poverty focus, success, crs and fin_quint, has been analyzed in a first step. The results are shown here:

Figure 19: Correspondence Analysis: poverty focus (pov), success (s), crs and fin_quint (Fqu)

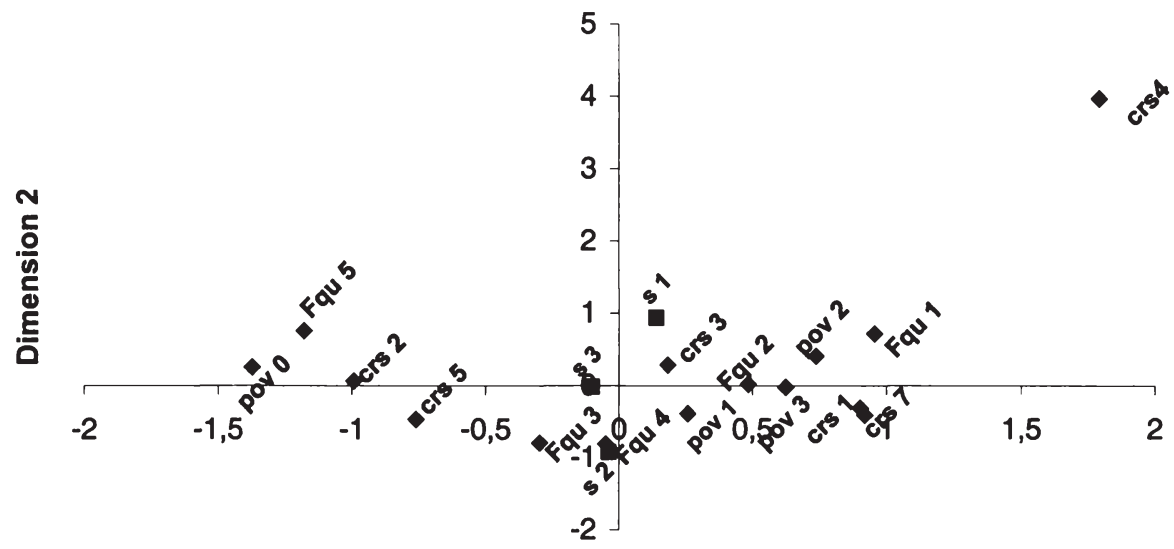

Dimension 1

${ }^{1}$ Drawbacks to this approach are the lower explanatory power in correspondence analysis involving many parameter values. 
Statistical Annotations:

Inertia and Chi-Square Decomposition

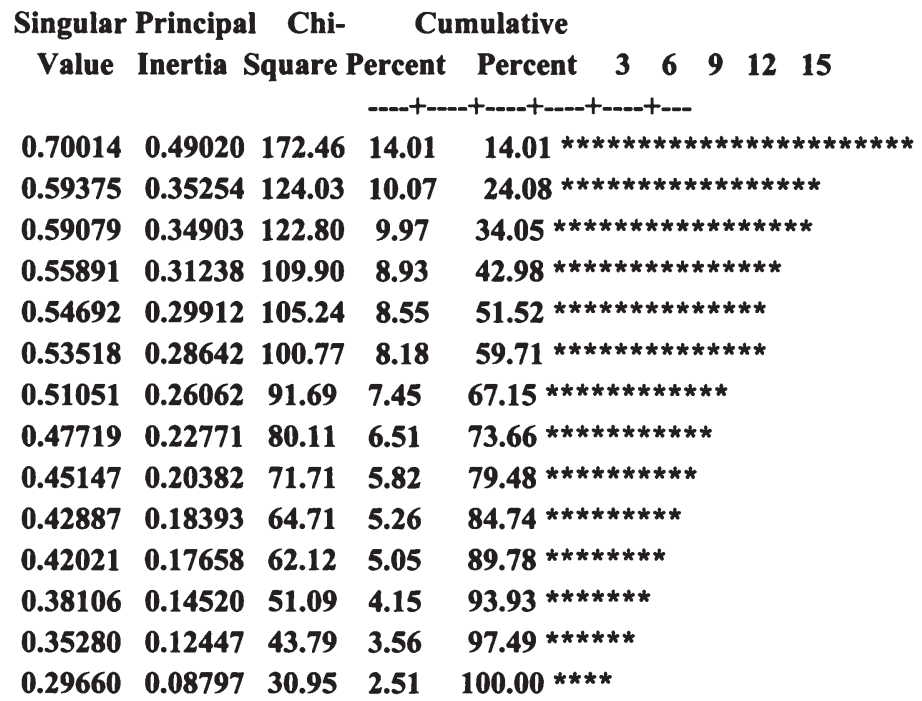

Total $3.500001231 .37 \mathbf{1 0 0 . 0 0}$

The first two dimensions only contribute a cumulative explanatory power of $24.08 \%$, but that is sufficient to draw some first conclusions. When taking a closer look at the graphic, one can see economic infrastructure projects, extreme high financial involvement and absence of regard for poverty to the far left. To the right lower cost projects, social infrastructure and production and trade as sectors and higher levels of poverty focus are gathered. While this will be discussed in more detail later, the most important finding is that the poverty focus (pov) of a project does not have a significant influence on its success (s) or vice versa, and that success does not interrelate with either impact level or sector $^{1}$. The parameter values of success are clustered at the center of the graphic close to the y-axis, not closely related to any other parameter values ${ }^{2}$. This fact shows up in a series of other graphs at lower levels of aggregation and is supported by regression analysis ${ }^{3}$.

\footnotetext{
${ }^{1}$ Aside from a potential correspondence between crs 3 and $\mathrm{s} 1$.

${ }^{2}$ Except for the financing level 4, which might indicate a high frequency of sufficiently successful projects at this level. Yet this is not of great concern here.

${ }^{3}$ Regression analyses could have potentially become difficult because success and poverty focus could be suspected to be mutually dependent. Poverty might have impact on success, since a stronger inclusion of the impact of the project on the poor might change the assessment of the success of the project. In turn, success is dependent on many variables, and if a project fails due to e.g. technical reasons there is little reason to believe that the situation
} 
In the interpretation of this finding the lack of a causal relationship from poverty focus to success is of interest. ${ }^{1}$ If the level of focus for poverty, which ranges from absence of any focus to inclusion of measurable results, does not have any significant impact on the level of success, this can be explained by two factors. A greater concern for poverty could have increased the success of projects in the same number of cases as it decreased it, leaving on average no detectable impact. A second possibility is that a greater focus on poverty did not translate into the evaluation of the project, thus leaving the final evaluation of the success to other determinants. From the qualitative discussion the second point receives some support ${ }^{2}$.

Due to the insignificance of the factor success in the analysis, it was replaced for the further discussion by the factor impact level. All four variables - poverty focus, impact level, fin_quint, CRS - have been analyzed at once, and partial samples on the immediately lower level have also been conducted because they illuminate some aspects more clearly. The three resulting graphs are presented here in summary; the corresponding statistics have for clarity reasons been banned to annex 8 .

of the poor will have improved, thus there might not be a concern for the poverty situation in the final analysis. Since both directions are possible, as simultaneous equation model was tempting - especially as instruments for the success variable are not available in the data set. Yet the low explanatory value of the sampled variables on the equation including success as dependent variable leads to residuals of a magnitude that does not allow for reasonable calculations in the second step of the simultaneous approach. The results of the correspondence analysis (little relation between poverty focus and success in either direction) and the implications of a stepwise regression analysis performed in appendix six on the depend variable success lead the author to conclude that if present, endogeneity is only of minor magnitude and will not offset the supportive results of the simple ordinary least squared regression.

${ }^{1}$ Both directions of causal effects, from success to poverty focus and vice versa, are possible since the correspondence analysis does not allow any automatic reasoning on the chain of effect. Here, causal effects in both directions could have been suspected. Poverty might have impact on success, since a stronger inclusion of the impact of the project on the poor might change the assessment of the success of the project. In turn, success is dependent on many variables, and if a project fails due to e.g. technical reasons there is little reason to believe that the situation of the poor will have improved, thus there might not be a concern for the poverty situation in the final analysis.

${ }^{2}$ The focus on poverty only takes a small portion of the entire report and is often not strongly referred to in the discussion of the overall success grade. 
Figure 20: $\quad$ Correspondence Analysis: poverty focus (pov), impact level (IL), crs and fin_quint (Fqu)

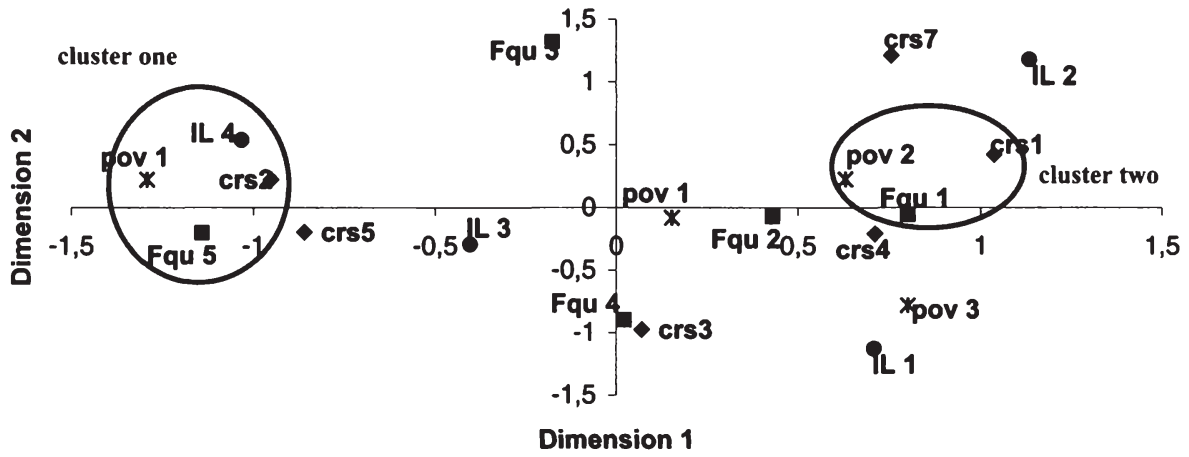

- CRS $\square$ Financing Quintile * Poverty Focus - Impact Level

Figure 21: Correspondence Analysis: poverty focus (pov), crs and fin_quint (Fqu)

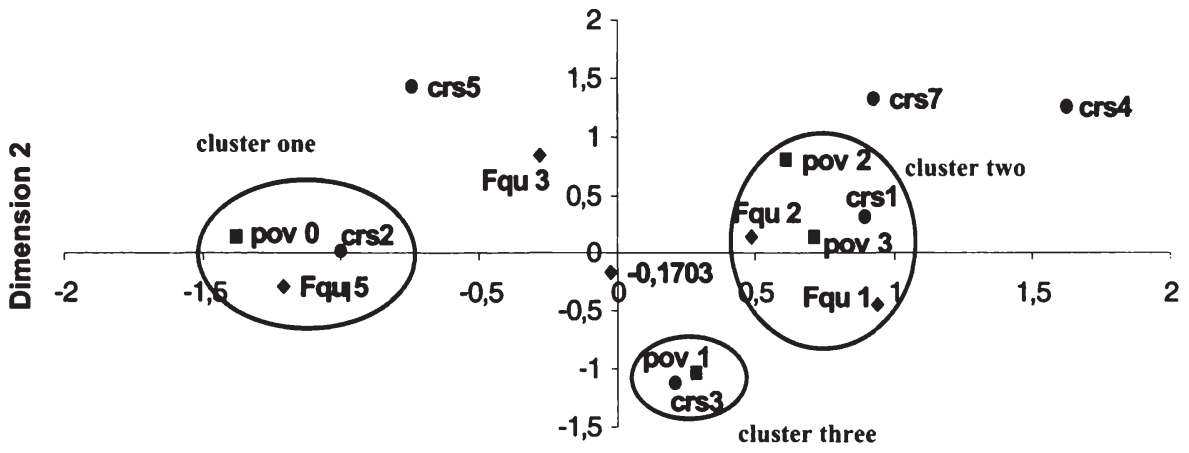

Dimension 1

- CRS • Financing Quintiles - Poverty Focus 
Figure 22: Correspondence Analysis: poverty focus (pov), impact level (IL), crs

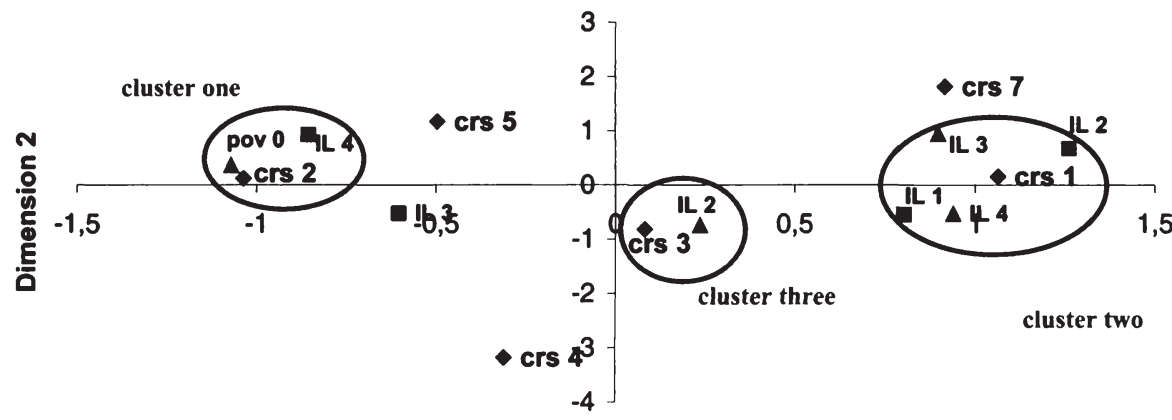

Dimension 1

- CRS a Impact Level $\Delta$ Poverty Focus

These three graphs point at three detectable clusters within the data. The explanatory value of the graphs at between $26 \%$ and $32 \%$ was to be expected given the still large number of dimensions. The results have been found to be very robust in different combinations of the parameter values.

The first broad cluster (cluster one) is visible to the far right of all three graphs. It points at high correspondence between the parameter values of very high financing, high distance to the target group, economic infrastructure and absent analysis of poverty. In the interpretation this cluster consists of economic infrastructure projects of the category EPA with very high financial costs. For EPA projects no regard for the poverty impact is required by the BMZ. Yet it is noteworthy that despite the high financial costs involved a concern for the impact on the poor people was not visible.

The second broad cluster (cluster two) is visible at to the right in the graphics. It includes parameter values of very low or low financing, argumentative or qualitative concern for poverty, low or very low distance to the target group and social infrastructure. In the interpretation this cluster includes social infrastructure projects with low or very low investment costs. These are conducted mainly in close cooperation with the poor, resulting in SHA or SUA as classifications. The poverty focus is of high concern in the final evaluations. This can be attributed to the proximity to the target group and to the limited scope of most of these rather low costs projects, which makes the assessment of poverty impact easier. 
A third cluster (cluster three) can be detected near the y-axis, consisting of parameter values of implicit poverty reduction and the sector production and trade. This sector, thus, takes poverty reduction mainly implicitly into account, while not being linked to a particular level of financing or proximity to the target group.

These results are also partially visible when running a step-wise regression with poverty focus ${ }^{1}$ as the dependent variable and financing, success, impact level and sector as independent variables. Success (s) ${ }^{2}$, impact level (IL) and sector (crs) are constructed as dummy variables, taking success level one, impact level four and a joint dummy variable for all crs values above three as baselines. Stepwise regression takes all factors and eliminates in each regression step the factor with the lowest significance until all remaining factors are significant at $10 \%$ level $^{3}$. The results for the final equation are shown below, the full step-wise regression analysis can be found in annex 9 .

Table 4: Results from Step-wise Regression

\begin{tabular}{|l|l|l|l|l|l|}
\hline Factor & Coefficient & $\begin{array}{l}\text { Stand } \\
\text { ard } \\
\text { Error }\end{array}$ & $\begin{array}{l}\text { Beta- } \\
\text { Coefficient }\end{array}$ & $\begin{array}{l}\text { T- } \\
\text { Statistic }\end{array}$ & P-value \\
\hline (constant) &, 949 &, 279 & & 3,405 &, 001 \\
\hline crs2 & $-1,069$ &, 261 &,- 499 & $-4,091$ &, 000 \\
\hline crs3 &,- 498 &, 260 &,- 211 & $-1,915$ & 060 \\
\hline dummy s 1 &, 338 &, 199 & 156 & 1,694 & 095 \\
\hline dummy IL 1 & 1,142 &, 312 &, 454 & 3,656 &, 001 \\
\hline dummy IL 2 &, 843 &, 326 &, 335 & 2,581 &, 012 \\
\hline dummy IL 3 &, 811 &, 261 &, 391 & 3,107 &, 003 \\
\hline
\end{tabular}

$\mathrm{R}^{2}=0,44$

These results support the findings of the correspondence analysis. Both impact level and sector are highly significant for the poverty focus. Taking the

\footnotetext{
${ }^{1}$ The problem of reverse causality between poverty reduction and success is only hinted at here. Since simultaneous equation models did not yield improvements over the current model, this simple regression was used here.

${ }^{2}$ Regression analyses could have potentially cause problems because success and poverty focus could be suspected to be mutually dependent. In that case either instrumental variables or simultaneous regression models would need to be deployed. The results of the correspondence analysis (little relation between poverty focus and success in either direction) and the implications of a stepwise regression analysis performed in appendix six on the depend variable success lead the author to conclude that if present, endogeneity is only of minor magnitude and will not offset the supportive results of the simple ordinary least squared regression performed here.

${ }^{3}$ For background literature on regression methods the reader is referred to Gujarati, D. (1995), Greene, W. (1996) or Koutsoyiannis, A. (1981).
} 
first cluster with projects from the economic infrastructure sector with low proximity to the target group, i.e. crs2 and no dummy impact variable, the regression yields a value close to zero in terms of poverty focus, as has been the case in this cluster. Concerning the second cluster, projects of social infrastructure, low proximity to the target group and low costs range in the regression between 1.8 and 2.5 at the high end, which resembles the findings in the cluster analysis. For the third cluster with sector crs3, the focus on poverty ranges from 0.5 to nearly 2 , depending on the success of the project and the impact level, which have not been constrained for this sector. A high frequency of observation of implicit poverty focus, i.e. poverty focus 1 , is not refuted by these results.

In contrast to the observations of the cluster analysis financing does not play a significant role in the regression. Thus, while financing plays a role in the examined clusters, it seems to be driven stronger by the other factors, possibly the sector in which the project takes place, and has on its own no strong effect on the focus that is placed on poverty. This analysis also shows an impact of high success (dummy s1) compared to failure (parameter value s 3 ) on the level of regard for poverty. The effect is the smallest of all the dummy variables and the least significant, yet it does lend some credibility to the reasoning that failed projects take lower account for poverty reduction. This reasoning is based on the assumption that projects that fail for other reasons than low impact on the situation of the poor, e.g. because of technical failures, have little scope for improvements in terms of reductions of poverty and therefore poverty reduction might not be regarded. ${ }^{1}$

For the impact level it is interesting that the differences in impact for SUA and MSA projects (second and third level) are nearly equal, while SHA projects (first impact level) have markedly stronger regard for poverty. This is noteworthy as SUA projects resemble SHA projects in their conception concerning the requirements for the target group and the rather direct provision of aid on the local level, while MSA projects are specifically attributed to macro- or sector level, thus they are far more remote from the target group. Since participation is the main differentiating factor between SHA projects, which demand participation, and SUA projects, which do not, this is likely to be the driving factor for the stronger regard for poverty visible in SHA projects.

For the sectoral level, projects in the economic infrastructure sector have markedly lower regard for poverty than those in the social infrastructure sector, resulting in a decline of a full level on the scale for the regard for poverty. This finding is significant at the $1 \%$ level. Most of this can be attributed to the energy sub-sector, for which there are no projects that take account for poverty more than implicitly, and even implicit hints occur in only $25 \%$ of the cases. These are

\footnotetext{
${ }^{1}$ This significance could also support the fact that poverty is not without influence on success, as both are potentially mutually dependent. This assumption does not receive support form the regression results presented in annex 7 .
} 
also the projects with the highest demands on financing and constitute most of the outliners in the histogram on financial costs.

Further variables have not been found to have explanatory value in this context. The continent on which the project was conducted and the duration of the project have been analyzed to this regard without any noteworthy results, pointing at the fact that the analysis of the projects was similar along these variables.

Overall, the concern for the effects on poverty reduction has been very limited in this sample, with more than half of the project not taking it into account. Evidence to conclude that the regard for the reduction of poverty has made a significant impact on the grade of this project for its success is lacking. Least regard of poverty is taken in infrastructure projects with high levels of financial involvement and high distance to the target group. Implicit concern for poverty is mostly expressed in projects of the sector production and trade. Highest regard for poverty has been placed in the evaluation of low cost projects in the social infrastructure sector that are conducted in close proximity to the poor. Here the participatory concept can be seen as associated with higher concerns for the effects in terms of poverty reduction in the final evaluation.

\subsubsection{Qualitative Analysis}

For a comprehensive picture of the evaluation praxis, the quantitative analysis is not sufficient and shall be complemented here by a qualitative reflection of evident commonalities within the sampled reports. This analysis progresses by the level on which poverty was regarded.

From the analysis of the final evaluations and from the quantitative analysis it becomes obvious that projects that omit comments on the effect of the project in terms of poverty reduction (first cluster) generally are categorized as impact level 4 (EPA). In some of these projects positive consequences for the poor were likely, since non-realization would have placed the poor most at disadvantage, such as in projects to sustain energy supply during the Mongolian winter. In these cases the explication of the chains of effects that lead to benefits for the poor would be feasible and would be in line with the consensus of putting poverty reduction at the center of the development efforts. Still, in a sizeable number of other EPA projects where comments on poverty reduction effects were omitted a clear argumentative connection is not feasible.

In many projects there seem to exist positive effects for the poor, yet their consideration within the report remains implicit. In basic needs oriented projects this accrues sometimes in cases where the actual users were not observed. A 
contribution to poverty reduction is to be expected but cannot be confirmed due to the unsureness about the beneficiaries. Many projects in support of private business (third cluster) pursue an indirect argumentation that a better economy creates jobs that in turn benefit the poor. Whether jobs for high qualified personnel or low qualified personnel are generated, and whether rationalization effects might have actually eliminated jobs is not investigated in most evaluations, thus weakening the chain of reasoning.

A number of final evaluations take account of the project's impact in terms of poverty reduction by presenting argumentative reference. This argumentative reasoning follows in most cases a similar line of thought: In a first step, the occurrence of poverty within the target group is established. This is sometimes conducted for the immediate area in which the project takes place, yet in other cases this is established on the regional or sometimes on the country level only. Data is usually taken from national or World Bank statistics. In a second step, the contribution of the project of improving the possibility for the people to secure their basic needs is shown. In a last step, it is analyzed whether the costs of the service is bearable by the poor, normally by assessing the percentage of costs for the service in terms of daily income of the poor. If this has been established, it is reasoned that the project benefited the poor.

In this procedure, the goal to reduce poverty is assessed mainly via the provision of the possibility to use the service, for example the installation of water supply in a certain spot. This input oriented approach is sometimes accompanied by a registration of the actual use of the service, yet rarely with further disaggregation into poor users and those who were able to obtain a similar service already prior to the project. This might overlook some problems facing the poor such as the physical distance to the location of the service ${ }^{2}$, which might limit their usage despite monetary affordability.

In some cases the argumentation is stringent in a way that further empirical analysis of the actual use disaggregated by user group are not likely to deliver further insights. This is the case especially for projects that eliminate obvious grievances in very poor areas. Yet for many projects an empirical analysis of the actual benefits for the situation of the poor would bring more objectivity and clarity to the assessment of the impact on the poor and allow for greater learning of lessons about the optimal site, the costs and other details of providing the service. The current procedure also bears the risk of becoming a mechanical process. In a few cases the entire analysis was treated in only two

\footnotetext{
${ }^{1}$ While in view of the new strategies failure of the price structure to accommodate the needs of the poor should be regarded as a knockout criteria leading to failure of the investment, the only project that failed to deliver services at affordable price still received a sufficient success grade. This was a single occurrence, and the power to set prices lay with the implementing agency of the partner country, yet if poverty reduction were taken as the primary goal of development cooperation this assessment would need to be changed.

${ }^{2}$ Costs and distance are both mentioned as impediments to the use of poor people of services provided through development cooperation in BMZ (1999c).
} 
sentences, providing such an impression. An ex-post analysis would in some cases necessitate a more in-depth discussion of the effects on the very poor individuals.

Only few projects assess the impact on the situation of the poor people quantitatively. For projects that provide quantitative data and are targeted to a limited target group (second cluster), the majority relies on selection of poor beneficiaries prior to the start of the project. This is done via self-selection - by providing services which only poor people will find attractive ${ }^{1}$ - or by preselection on the basis of income. The second approach is more problematic in areas with large informal sectors, where real income is hard to identify. Once it is established that the beneficiaries of a project are altogether poor ${ }^{2}$ and the number of beneficiaries is known, it becomes easy to quantify the benefits per user. The benefits are measured usually in units provided, such as square meters of habitation, rather than satisfaction defined by the beneficiaries. Ex-post evaluations are rare. Only one project mentions an ex-post survey; in this the satisfaction of the poor target group was assessed. Statistical tools were not deployed.

On the other end, projects with a large area of reach (mostly MSA projects which do not correspond to any broader cluster of variables) sometimes present quantitative data on the entire area, in one case of the entire country. Quantities such as health statistics, literacy levels, number of schools or rise in income were used and linked to poverty reduction by considering the level of poor people in the area. In most cases the overall level of poverty is quantified, in some cases it is only assumed. Statistical tools were omitted in these studies.

Overall, the assessment of the impact of the projects on the reduction of poverty does not receive a high priority within the final evaluations. Even in argumentative analysis it only covers a fraction of the total report.

Positive to mention are the exemplary analysis of the local implementing agency, whose management capabilities and implementation skills are thoroughly assessed. This corresponds to the high emphasis of the new strategies on good governance in terms of administrative capabilities and efficient delivery of services to the poor. Also the ability of the project to deliver benefits over a longer time frame is evaluated in nearly all circumstances. Generally only projects that deliver sustainable benefits are considered a success. Economic cost-benefit analysis are also common to the reports, yet their focus is usually narrowly limited to the economic achievements of the implementing agencies in

\footnotetext{
${ }^{1}$ For example housing of a quality that only the poor will find attractive.

${ }^{2}$ The poverty of the target group is in most cases not checked again in the ex-post evaluation, but reliance is placed on a functioning selection process.
} 
terms of earnings and do not quantify wider socio-economic benefits for the population ${ }^{1}$.

Problems might arise out of the limitation of the analysis to input factors rather than to output that benefits the poor. The view of the poor is seldom incorporated in the assessment of the projects. The goals for most projects are expressed in technical or economic specifications, but only rarely in terms of effects on poverty reduction. Therefore, also in the determination of the grade for the success of the projects technical and economic criteria dominate the discussion strongly, while poverty reduction only receives very limited attention in this determination.

\subsection{Discussion of the Findings}

The results of the preceding analysis point at areas where the evaluation procedures could be brought more in line with the focal points of the new strategic consensus. The consensus places great value on the goal of poverty reduction. This is currently not reflected in the evaluation praxis, as the majority of projects evaluations do not focus on this point.

This might be partly due to the rare inclusion of poverty reduction as explicit goals ${ }^{2}$ for the project. This has been assessed by Franz-Plote and Micha ${ }^{3}$ and is confirmed in this sample. Since the goals for each project were thoroughly discussed in the final evaluations, an integration of explicit requirements for the effects on the poor in the hierarchy of goals is likely to increase the concern devoted to this topic.

Projects that do not take account of poverty reduction have been found in clusters one and three, i.e. projects of impact level four (EPA) from the economic infrastructure sector (crs 2) and projects from the production and trade sector (crs 3). As an assessment of poverty reduction for EPA projects is not required by the BMZ, these results for cluster one are not surprising. In the light of the action program of the German government in support of the IDTs, an assessment of the effects of these projects to contribute to the IDTs might receive more relevance. Since the projects of cluster one are associated with the highest quintile of financing, an assessment of their impact on the situation of the poor people has potentially high payoffs. Projects within the third cluster already point at potential benefits for the poor through increased generation of jobs. An analysis of this point by data that establishes the impact on the poor rather than on the entire population would lead to more precise assessments.

\footnotetext{
${ }^{1}$ I.e. welfare increases, greater ability of poor people to work productively because of better health, improved productivity due to reduced water-related diseases or education and the like.

${ }^{2}$ The technical and economic goals for the projects are in many cases likely to have positive impact on the reduction on poverty reduction. Yet this impact remains implicit and does not become the concern in the final evaluations.

${ }^{3}$ See Kranz-Plote, J. / Micha, J. (1996), p. 2.
} 
The lack of an empirical data base is a main concern also in those projects that focus on poverty reduction. This has also been assessed in earlier studies ${ }^{1}$, in which the following three conclusions are drawn. Most evaluations do not examine the actually reached beneficiaries and the extent to which they have been poor. ${ }^{2}$ Meaningful and verifiable data on this is usually not presented. ${ }^{3} \mathrm{~A}$ clear definition of the term 'poverty' is usually missing ${ }^{4}$, which aggravates the problems of ex-ante and ex-post assessment of the poverty situation. These prior findings correspond to a large extend to the findings in the qualitative part of this study. As poverty reduction is the main baseline against which to judge the success of development cooperation according to the new strategic documents, greater clarity about the operationalization of the term 'poverty' and the ways to measure the effects against them will increase in importance.

Quantitative data analyses have to weigh their benefits against the costs of the survey or other data-retrieval method. Currently this seems to be viewed favorable mainly for cluster one projects, which bring direct benefits to the poor and where the data selection is facilitated due to pre-selection of poor individuals, or for impact level three (MSA) projects in cases where readily available macro data can be used. These approaches have the limitation that they still do not account for the viewpoint of the poor in the assessment of the value of the project. This "lack of diversity of perspectives" is a critical point that can be avoided by ex-post surveys.

Since the cost-benefits ratio of quantitative analysis determines the use of this instrument, the components of this ratio shall be discussed shortly. The initial costs of implementing quantitative surveys on a larger scale will likely be high for any development organization, as the internal skills and procedures needed for such an approach need to be build up. These costs are likely to decline substantially due to learning-curve effects in the organization, thus improving initially insufficient cost-benefit ratio over time. Standardizations in the statistical procedures can, where possible, reduce the costs even further. Many projects in the large sector of water access and sanitation (partially also in house building, irrigation and electricity generation and supply) seem to show similarities in the implementation process and the underlying goals, which could serve as the basis to build standardized survey procedures.

The benefits that are attainable accrue mainly from improved design and implementation for further projects, because the perceptions of the target group and their suggestions can be fed back into the planning of other projects. Benefits also arise indirectly as results from the analysis can be shared with

\footnotetext{
${ }^{1}$ See Kranz-Plote, J. / Micha, J. (1996), p. 8 and the review in BMZ (1999c), p. 7,8, which covers the entire German development cooperation, not the financial cooperation in specific.

${ }^{2}$ See Kranz-Plote, J. / Micha, J. (1996), p. 8.

${ }^{3}$ See Kranz-Plote, J. / Micha, J (1996), p. 3 and BMZ (1999c), p. 3.

${ }^{4}$ See Kranz-Plote, J. / Micha, J. (1996), p. 2.

${ }^{5}$ BMZ (1999c), p. 7 (translation by the author). Next to this critique in BMZ (1999c) the lack of subjective appraisals by the target group has also been pointed out in Kranz-Plote, J. I Micha, J. (1996), p. 3.
} 
other organizations to increase the overall effectiveness of aid provision. Therefore the benefits extend wider than only to the organization undertaking the survey.

For both reasons, the potential to lower the costs of quantitative assessments of poverty and to increase the range of benefits, an increase in the scope of quantitative analysis seems a feasible option. This might even be the case for structural oriented projects with low proximity to the target group, where the costs of data gathering are high. Since the financial involvements in these projects are also mostly high, the potential benefits might still outweigh the costs.

Not in all cases empirical data evaluations are beneficial. As pointed out in the qualitative section of the preceding analysis, some argumentative reasoning is conclusive to a level where further analysis is not likely to add additional valuable information. In these cases the retrieval of information is counterproductive to development efforts, since unnecessary costs are incurred. An assessment of the benefits and costs thus has to be undertaken for each individual case, yet the limitations of argumentative reasoning ${ }^{1}$ points in many cases at the potential for quantitative analysis as presented in the preceding paragraph.

Even in those cases where valuable information might be available, the costs might be prohibitive ${ }^{2}$. In these cases qualitative analysis builds the only means of assessing the benefits for the poor. In line with the new consensus and the importance that is placed on poverty reduction within it, projects where an argumentative connection cannot be conclusively drawn should receive special scrutiny in regard to the value that they deliver.

The new consensus on poverty not only considers the direct situation of the poor, but also the administrative framework that allows benefits to spread to them and the sustainability ${ }^{3}$ and efficiency of efforts. These aspects are diligently and thoroughly inspected in the final evaluations sampled for this treatise. Cost benefit analyses have also been deployed in most cases. Concerns raised in BMZ (1999c) about insufficient cost-benefit analysis ${ }^{4}$ and desiderative analysis of the abilities of the local implementing agency ${ }^{5}$ in the evaluations of

\footnotetext{
${ }^{1}$ These limitations occur in most cases, since the beneficiaries, their level of poverty and the actual effects of the projects on their situation are often not conclusively inferable.

${ }^{2}$ Despite learning-curve effects, cost reductions are limited by the quantity of labor that necessarily has to be expanded for the gathering of data in the location of the project.

${ }^{3}$ Sustainability is used in this context to describe the ability of projects to provide benefits for a long time frame after the initial investment has been made. In this context it does refer to environmental concerns.

${ }^{4}$ See BMZ (1999c), p. 7.

${ }^{5}$ See BMZ (1999c), p. 4. The a priori analysis of the implementing agency as demanded here is difficult to assess from the final reports. Yet the ex-post concern for this topic as part of the
} 
within the German development cooperation thus do not receive support in this sample of evaluations from the financial cooperation.

While the background aspects of poverty reduction ${ }^{1}$, the technical issues and the explicit goals of the project have been profoundly measured, the concrete definition of poverty and the conclusive analysis of the impact of the projects in terms of reduced poverty are only partially undertaken in the sampled project evaluations. In most cases where it has been undertaken, this assessment only receives a small portion of the overall discussion of the effectiveness of the project. Since this does not reflect the high importance that is placed on poverty reduction in the new strategic documents, ways to improve the poverty focus are presented in the following.

\subsection{Recommendations}

These recommendations for a greater integration of effects in terms of poverty reduction in the final evaluations of projects are not limited to the financial cooperation, but are applicable to many development organizations facing the same situation of realigning their existing procedures with the increased strategic emphasis on poverty reduction. Therefore these recommendations, while building on the prior analysis, are presented in general terms applicable to a broader range of development organizations, and to partner countries that undertake internal project reviews. The recommendations comprise four main points:

1. The specifications for all projects should include explicit objectives for the impact on poverty in their hierarchy of goals. Where possible these poverty-focused goals should be expressed in terms of quantifiable indicators.

2. A focus for poverty reduction should be included in the mandatory aspects that each final evaluation has to take into account. ${ }^{2}$ The depth of the analysis should not be lower than for the other aspects considered. Its result should be given adequate weight in the evaluation of the overall success of the project.

final evaluations and the ability to learn lessons from this for further engagements with this agency is substantial.

'The term 'background aspects' is used here to include the concern placed on sustainability of the project in terms of ability of the implementing agency and of lasting impact of the project, which in most cases are necessary preconditions for any lasting impact in terms of poverty reduction to be able to occur.

${ }^{2}$ As for the KfW, it could be added as an eighth aspect to those already mention in the discussion of its background. 
3. Standardized questionnaires, survey methods and procedures for quantitative evaluation should be developed for projects with similar characteristics and goals. Initial costs might be kept low by bundling the statistical know-how through a designated statistical specialist that can further the development of procedures, establish a workable definition of poverty and adapt the standardized models to the individual circumstances.

4. Ex-ante evaluations of the poverty situation should be conducted with the same depth of analysis as the ex-post evaluations to enable a comparison of the resulting situation after project implementation with the prior situation. ${ }^{1}$

Implementation of these recommendations should serve to advance the concern for poverty reduction within the entire organization of the development agency, increase the knowledge about contributing factors to reduce poverty and improve the efficiency of projects through more knowledge and better control. Thus, it fosters the transformation of the strategic documents into the development praxis.

\subsection{Synopsis of the Empirical Study}

This empirical study has linked the new strategic proposals and their concern for reducing poverty to one aspect of practical work by development organizations. It has analyzed the current focus on poverty in the evaluation process that was undertaken by German financial cooperation, based on a sample of 75 projects and their respective final reports.

An explicit focus on poverty was only found in the minority of final evaluations; mainly in projects with close proximity to the target group and associated with low financial involvement. These projects mainly belong to the social infrastructure sector. Only $15 \%$ of all projects used quantifiable data. In the quantitative analysis, little influence of the degree to which an evaluation focused on the situation of the poor on the level of the success that was attributed to the project was detected, which corresponds also to the qualitative findings.

Projects that took least account of the reduction in poverty have been found to comprise economic infrastructure projects with a low proximity to the target group and high financial involvement. Projects in the production and trade sectors have mainly taken implicit account of the effects on poverty.

The assessment of poverty impact mainly relies on the evaluation of input factors. Utilization by poor people is assumed but the actual group of

\footnotetext{
${ }^{1}$ For this point recommendation 3 is also applicable to achieve a low cost approach towards this end.
} 
beneficiaries is rarely evaluated. Tailored quantitative ex-post analyses with statistical inference are rare, even in cases of quantitative reasoning. Quantitative comparisons to the ex-ante situation are infrequent due to lack of ex-ante data.

Concern for the fulfillment of explicit goals, sustainability factors, cost and benefits for the local agency and implementation abilities of local agencies is high. Yet reducing poverty is seldom explicitly mentioned as a goal. The data base for evaluations has scope for improvement, because benefits are potentially large and learning-curve and standardization effects can decrease the costs of data collection and analysis.

Recommendations for a greater focus on reducing poverty comprise an explicit formulation of (measurable) goals to improve the situation of poor people, requirements of focussing on poverty in the final evaluation, development of standardized methods for quantitative analyses and stronger concern for ex-ante evaluations.

The new strategies have profound implications for the work of development agencies, as the recommendations point out. Shifting the focus in the concrete evaluation of projects according to the central goal of the new strategies has implications for the entire project cycle. Donors will apply a greater concern for poverty reduction throughout their organization and in their project conception and implementation if this is the basis against which their efforts will be measured. To this extent, the focus on the final stage of the project cycle serves to create the right incentives for overall implementation of the strategic concepts, which are presented in the first part of this thesis. 
Philipp Kircher - 978-3-631-75366-8 


\section{Chapter 5}

\section{Concluding Remarks}

In this treatise three main conclusions are developed. A broad consensus exists in today's development strategies regarding the focus of their efforts - poverty reduction - and regarding the associated measures to achieve progress; thereby taking a holistic approach that comprises economic, political, protective and international issues. Differing accentuations persist in the strategies; most of which have the potential for greater donor specialization, while some pose a threat to donor cooperation. These new strategies have implications for the concrete work of donor organizations, as exemplified by the task of impact evaluation: this can be improved in its orientation towards the situation of poor people.

The consensus is visible on three levels. First and foremost, agreement is reached on the importance of poverty reduction as the main goal of development cooperation. On a second level, the International Development Targets are confirmed within all strategies and further amendments are proposed for some of them. On a third level, the measures or conceptual elements conducive to poverty reduction have found overall agreement, even though some points remain in dispute. The emphasis in all strategies has been placed on the importance of economic development (i.e. GDP growth), pro-poor spending by the state, creation of economic opportunities for the poor, participation of the poor in political processes, decentralization of state power, curbing corruption and the provision of security for the poor; to name the most important. At the international level, open trading systems, coherent policies, donor cooperation led by the developing country and the imposition of conditionality are priorities.

Areas which are still under dispute include the promotion of primary education at the expense of secondary level education, the provision of concessional flows for middle-income countries and - to a lesser degree - the importance of democracy and human rights. These issues receive opposing views from different organizations and, thus, hold a potential for conflict and impediments to donor cooperation. The further accentuations that distinguish the strategies refer to emphases that are presented by one agency without being challenged by the strategies of the others; thus indicating areas where specialization of the donor agency might develop.

The new strategies lack a deeper discussion of the role of poverty reduction vs. other developmental goals and are generally vague on how to set priorities between potentially competing measures. Improvements in the strategies need to be made on the issue of using information technology, the importance of which is acknowledged but deeper insights are still lacking. 
Despite these shortcomings and some inter-strategic disputes, the new strategies markedly increase the potential for cooperation among donor agencies and between donor agencies and the partner countries. They portray a strong commitment to poverty reduction and serve as a means to keep this point on the international agenda, within the consciousness of populations in industrialized countries. The new vigor that these strategies are bringing to the development process and the additional insights that they portray over preceding strategies have the potential for a strong impact on poverty reduction. The greatest challenge will lie in convincing the partner governments to support this agenda and in transferring these conceptual strategies into real action and implementation.

The aspect of project evaluation has been investigated in order to illustrate the link between the new strategic concepts and the daily operations of development agencies. The current evaluation practice of German financial cooperation has been quantitatively and qualitatively analyzed regarding its focus on poverty reduction. The lack of focus on the poverty situation in the majority of the sampled evaluations indicates a potential for improvement in order to bring the evaluation practice in line with the high emphasis placed on poverty reduction by the new strategies. The recommendations in this regard are applicable to the operations of many development organizations. They comprise the issuance of explicit goals for reducing poverty in each project, the requirement of evaluating the reduction of poverty as a mandatory component of impact assessment, the establishment of standardized procedures for quantitative analysis and a concern for ex-ante - ex-post comparisons. A greater concern for the reduction of poverty in the evaluation process will pressure the entire project cycle to focus on this issue. This is one step in converting the new strategies into concrete actions.

The aim of this analysis was to provide scholars and practitioners with a review of recent developments in strategic thinking about development cooperation separated into areas where consensus is reached and those where single or conflicting opinions prevail. This was coupled with the goal of pointing out shortcomings in strategic concepts and assessing their practical implications, with the latter focused on - but not limited to - the evaluation process. If this contributes to spreading knowledge about ways how to fight poverty more effectively, it might aid the process of searching for, communicating and implementing more successful ways to eradicate poverty. 
Annex 1

\section{The Universal Declaration of Human Rights}

Table 2: The Universal Declaration of Human Rights ${ }^{1}$

Internationally Agreed human rights provide a common set of principles for tackling the many facets of poverty and inequality. The human rights set out in the UDHR and international legal instruments include:

- the rights to life and liberty

- the rights to a standard of living adequate for health and well-being of the individual and his/her family, including food, water and housing, and the right to continuous improvements of living conditions

- the right to social protection in times of need

- the right to freedom from discrimination

- the right to the highest attainable standard of physical and mental health

- the right to work and to just and favorable conditions of work

- the rights to privacy and family life

- the right to education and access to information

- freedoms of religion, opinion, speech and expression

- freedom of association

- the right to participate in political process

- the right to participate in cultural life

- freedom from slavery and servitude

- the rights to be free from arbitrary arrest or imprisonment, and to a fair trial, freedom from torture and from cruel, inhuman or degrading treatment or punishment

- the right of civilians to be protected in times of armed conflict

- the right of international protection from persecution

\footnotetext{
${ }^{1}$ Source: DfID (2000f), p. 33.
} 
Annex 2

Comprehensive Development Framework ${ }^{1}$

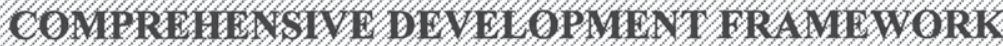
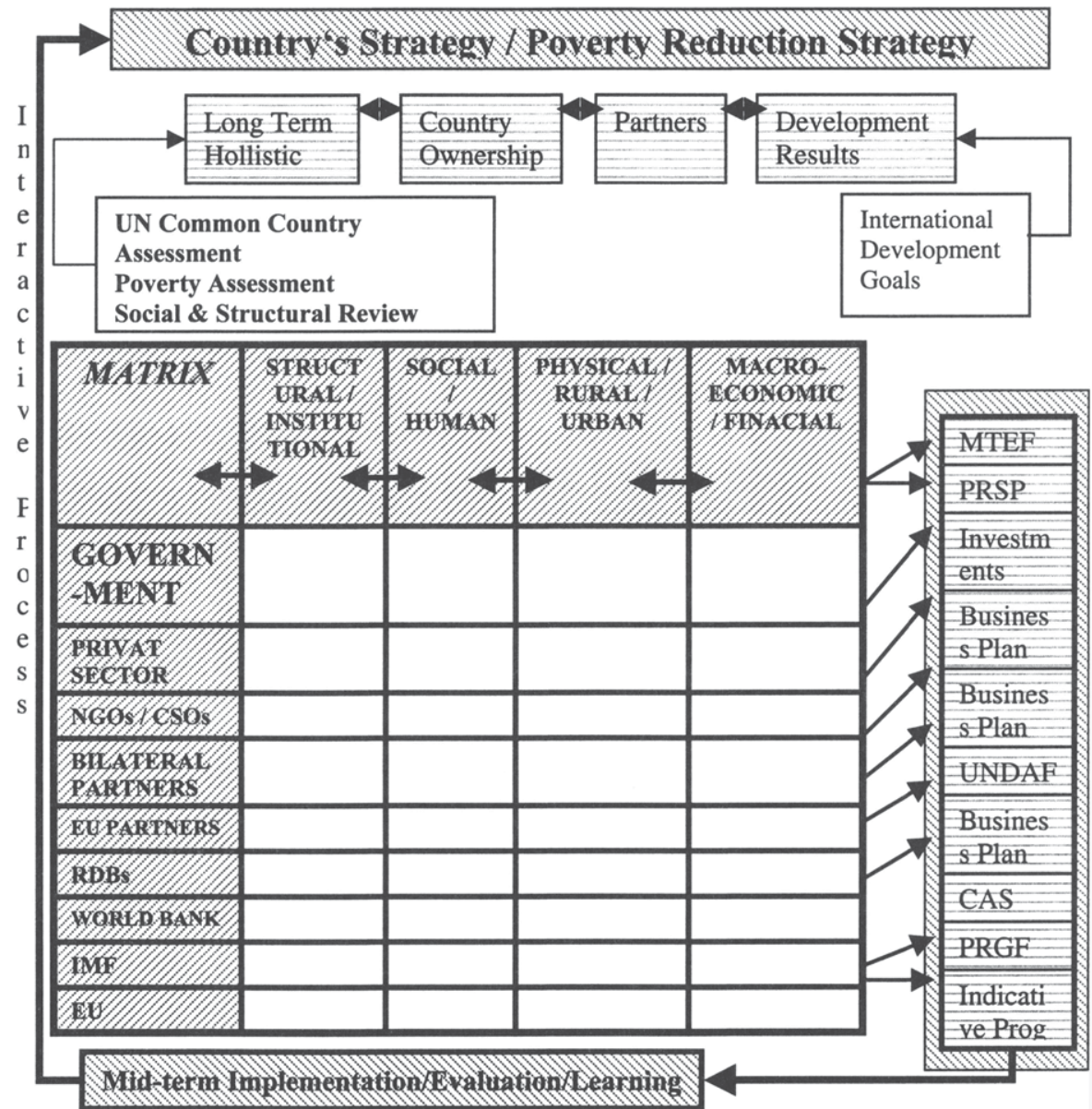

CAS: World Bank's Country Assistance Strategy

MTEF: Medium-Term Expenditure Framework, prepared by government

PRGF: International Monetary Fund's Poverty Reduction and Growth Facility

RDB: Regional Development Bank(s)

UNDAF: United Nations system's Development Assistance Framework

PRSP: Poverty Reduction Strategy Paper, prepared by government (required for IDA, HIPC, PRGF countries only)

\footnotetext{
${ }^{1}$ Source: Wolfensohn, J. (1999a).
} 


\section{Annex 3}

\section{Poor People's Priorities ${ }^{1}$}

\begin{tabular}{|c|c|c|c|}
\hline $\begin{array}{r}\text { Level o } \\
\text { Povert } \\
\text { Level of } \\
\text { needs }\end{array}$ & Declining Poor & Coping Poor & Improving Poor \\
\hline Survival & $\begin{array}{l}\text { Free and accessible } \\
\text { health care; } \\
\text { Cash, Pensions, } \\
\text { unemployment and } \\
\text { disability benefits; } \\
\text { Food subsidies, legal aid } \\
\text { Housing/shelter, Free } \\
\text { and affordable health } \\
\text { care }\end{array}$ & $\begin{array}{l}\begin{array}{l}\text { Free and accessible } \\
\text { health care }\end{array} \\
\text { Food subsidies and } \\
\text { public works programs } \\
\text { Financial services } \\
\text { Community-based } \\
\text { support }\end{array}$ & 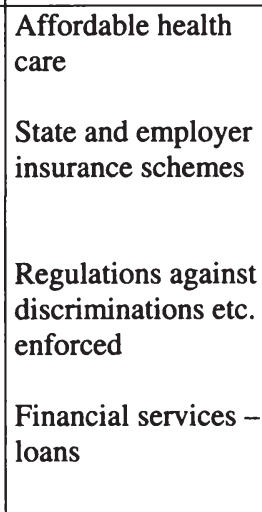 \\
\hline Security & $\begin{array}{l}\text { Income stream } \\
\text { Tenure rights } \\
\text { Basic education, plus } \\
\text { some skill training } \\
\text { Savings schemes } \\
\text { Community support } \\
\text { systems }\end{array}$ & $\begin{array}{l}\text { Income stream } \\
\text { Secure housing } \\
\text { Tenure/ ownership } \\
\text { Skill up-grading } \\
\text { opportunities } \\
\text { Education, legal support } \\
\text { Savings and credit }\end{array}$ & $\begin{array}{l}\text { Income stream } \\
\text { Home ownership } \\
\text { Enterprise } \\
\text { development } \\
\text { schemes } \\
\text { Loans for } \\
\text { enterprises } \\
\text { Legal support }\end{array}$ \\
\hline Quality of Live & $\begin{array}{l}\text { Participate in decision- } \\
\text { making about matters of } \\
\text { immediate concern } \\
\text { Environmental } \\
\text { improvements }\end{array}$ & $\begin{array}{l}\text { Participate in } \\
\text { community based } \\
\text { decision-making } \\
\text { Environmental } \\
\text { improvements }\end{array}$ & $\begin{array}{l}\begin{array}{l}\text { Health and safety at } \\
\text { work }\end{array} \\
\text { Political role }\end{array}$ \\
\hline
\end{tabular}

${ }^{1}$ See DfID (2000g), p. 16. 


\section{Annex 4}

\section{PRSP and HIPC Initiative}

Table 1: PRSP and HIPC Initiative - Progress ${ }^{1}$

Possible Country Timelines for Poverty Reduction Strategy Paper (PRSP), Interim PRSP, Country Assistance Strategies (CAS), Poverty Reduction and Growth Facility (PRGF), and HIPC Decision and Completion Points through June 2001

\begin{tabular}{|c|c|c|c|c|c|c|}
\hline Country & $\begin{array}{l}\text { Jan - } \\
2000\end{array}$ & $\begin{array}{c}\text { MarApr - J } \\
2000\end{array}$ & $\begin{array}{l}\text { nJul - } \\
2000\end{array}$ & $\begin{array}{c}\text { SepOct - } \\
2000\end{array}$ & $\begin{array}{c}\text { DecJan - N } \\
2001\end{array}$ & $\begin{array}{c}\overline{\text { MarApr - Jun }} \\
2001\end{array}$ \\
\hline Angola & $\ldots$ & $\ldots$ & $\ldots$ & $\ldots$ & $\ldots$ & $\mathrm{I}, \mathrm{F}$ \\
\hline Albania & $S$ & $\mathrm{I}, \mathrm{R}$ & $\ldots$ & $\ldots$ & ... & $\mathbf{P}$ \\
\hline Armenia & $\ldots$ & $\ldots$ & $\ldots$ & $\ldots$ & $\mathrm{I}, \mathrm{F}, \mathrm{S}$ & $\ldots$ \\
\hline Azerbaijan & $\ldots$ & ... & $\ldots$ & $\ldots$ & $\mathrm{I}, \mathrm{F}$ & $\ldots$ \\
\hline Benin & $\ldots$ & $\ldots$ & $\mathrm{I}, \mathrm{F}, \mathrm{D}$ & $\mathbf{S}, \mathbf{R}$ & ... & $\mathbf{P}$ \\
\hline Bolivia & I,D & $\ldots$ & $\ldots$ & $\mathbf{P}, \mathbf{R}$ & C,S,R & $\ldots$ \\
\hline Boznia and Herzegovina & $\ldots$ & $\mathrm{S}$ & $\ldots$ & $\ldots$ & $\mathrm{I}, \mathrm{F}$ & $\ldots$ \\
\hline Burkino Faso & $\ldots$ & $\mathrm{P}, \mathrm{C}, \mathrm{R}, \mathrm{D}$ & $\ldots$ & S,R & $\ldots$ & $\ldots$ \\
\hline Cambodia & $S$ & $\ldots$ & $\mathrm{R}$ & $\mathrm{I}, \mathrm{R}$ & $\ldots$ & $\ldots$ \\
\hline Cameroon & $\ldots$ & S,R & $\ldots$ & I,F,D & $\ldots$ & $\ldots$ \\
\hline Central African Republic & $\cdots$ & $\ldots$ & $\ldots$ & I,R & $\ldots$ & $\mathrm{D}, \mathrm{R}$ \\
\hline Chad & $\ldots$ & $\ldots$ & $\mathrm{I}, \mathrm{S}, \mathrm{R}$ & $\mathrm{D}$ & $\mathbf{R}$ & $\ldots$ \\
\hline Côte d'Ivoire & $\ldots$ & $\ldots$ & $\ldots$ & $\ldots$ & $\mathrm{I}, \mathrm{F}, \mathrm{D}$ & $\ldots$ \\
\hline Djibouti & $\ldots$ & $\ldots$ & $\mathbf{R}$ & $\mathrm{I}, \mathrm{R}, \mathrm{S}$ & $\mathbf{R}$ & $\mathbf{R}$ \\
\hline Ethiopia & $\ldots$ & $\ldots$ & $\ldots$ & $\ldots$ & $\mathrm{I}, \mathrm{F}, \mathrm{D}$ & $\ldots$ \\
\hline Gambia, The & $\ldots$ & $\mathbf{R}$ & $\ldots$ & $\mathrm{I}, \mathrm{R}, \mathrm{D}$ & $\ldots$ & $\ldots$ \\
\hline Georgia & $\ldots$ & $\ldots$ & $\ldots$ & $\mathrm{I}, \mathrm{F}$ & $\ldots$ & $\ldots$ \\
\hline Ghana & $S$ & $\ldots$ & I,R & $\ldots$ & $\ldots$ & $\mathbf{P}, \mathbf{R}$ \\
\hline Guinea & $\ldots$ & $\ldots$ & $\ldots$ & I,R,D & $\mathrm{F}$ & $\ldots$ \\
\hline Guinea-Bissau & $\ldots$ & $\ldots$ & $\ldots$ & $\mathrm{I}, \mathrm{F}, \mathrm{D}$ & $\mathbf{R}$ & $\ldots$ \\
\hline Guyana & $\ldots$ & $\ldots$ & $\ldots$ & $\mathrm{I}, \mathrm{R}, \mathrm{D}$ & $\mathbf{P}$ & $\mathbf{R}$ \\
\hline Haiti & $\ldots$ & $\ldots$ & $\ldots$ & $\ldots$ & $\mathrm{I}, \mathrm{F}$ & $\ldots$ \\
\hline Honduras & $\ldots$ & I,R & $\mathrm{D}$ & $\ldots$ & $\mathbf{P}, \mathbf{R}$ & $\ldots$ \\
\hline Kenya & $\ldots$ & $\ldots$ & $\mathrm{I}, \mathrm{F}$ & $\ldots$ & $\ldots$ & $\mathrm{P}, \mathrm{S}$ \\
\hline Kyrgyz Republic & $\ldots$ & $\ldots$ & $\mathbf{R}$ & $\ldots$ & $\mathrm{I}, \mathrm{F}, \mathrm{S}$ & ... \\
\hline Lao, PDR & $\ldots$ & $\ldots$ & $\ldots$ & $\ldots$ & $\mathrm{I}, \mathrm{F}$ & $\ldots$ \\
\hline Lesotho & $\ldots$ & $\ldots$ & $\ldots$ & $\mathrm{I}, \mathrm{F}$ & $\ldots$ & ... \\
\hline Macedonia, FYR & $\ldots$ & $S^{*}$ & $\ldots$ & $\mathrm{I}, \mathrm{F}$ & $\ldots$ & $\mathbf{R}$ \\
\hline Madagascar & $\ldots$ & $\mathbf{R}$ & $\ldots$ & $\ldots$ & $\mathrm{R}, \mathrm{I}, \mathrm{F}, \mathrm{D}$ & $S$ \\
\hline Malawi & $\ldots$ & $\ldots$ & $\ldots$ & $\mathrm{I}, \mathrm{F}, \mathrm{D}$ & $\mathrm{R}$ & $S$ \\
\hline Mali & $\ldots$ & $\ldots$ & $\mathrm{I}, \mathrm{R}, \mathrm{D}$ & $\mathrm{S}^{*}$ & $\ldots$ & $\mathbf{P}$ \\
\hline Mauritania & $\mathrm{D}$ & $\mathbf{R}$ & $\ldots$ & $P, R$ & $\ldots$ & $\ldots$ \\
\hline Moldovia & $\ldots$ & $\ldots$ & $\ldots$ & $\mathrm{I}, \mathrm{F}$ & $\ldots$ & $\ldots$ \\
\hline Mongolia & $\ldots$ & $\mathbf{R}$ & $\ldots$ & $\mathrm{I}, \mathrm{F}$ & $\ldots$ & $\mathbf{R}$ \\
\hline Mozambique & $\mathrm{R}$ & $\mathrm{I}, \mathrm{S}, \mathrm{D}$ & $\ldots$ & $\mathrm{R}$ & $\ldots$ & $\mathrm{C}, \mathrm{P}$ \\
\hline Nepal & $\ldots$ & $\ldots$ & $\ldots$ & ... & $\mathrm{I}, \mathrm{F}$ & ... \\
\hline Nicaragua & $\ldots$ & $\ldots$ & $\ldots$ & $\mathrm{I}, \mathrm{R}, \mathrm{D}$ & $\mathbf{R}$ & $\mathbf{P}$ \\
\hline Niger & $\ldots$ & $\ldots$ & $\ldots$ & $\ldots$ & $\mathrm{I}, \mathrm{F}, \mathrm{D}, \mathrm{S}$ & $\ldots$ \\
\hline
\end{tabular}

\footnotetext{
${ }^{1}$ Source: World Bank, IMF (2000b), last updated Sept. $7^{\text {th }} 2000$.
} 
(Continued from previous page)

\begin{tabular}{lllllll}
\hline Pakistan & $\ldots$ & $\ldots$ & $\ldots$ & I,F & R & S,R \\
Rwanda & $\ldots$ & $\ldots$ & $\mathrm{R}$ & I,R,D & $\ldots$ & S,R \\
São Tomé and Príncipe & $\ldots$ & I,F & $\ldots$ & R & D,R & $\ldots$ \\
Senegal & $\ldots$ & I,R,D & $\ldots$ & $\ldots$ & R & R \\
Sierra Leone & $\ldots$ & $\ldots$ & $\ldots$ & $\ldots$ & I,S*,F & $\ldots$ \\
Sri Lanka & $\ldots$ & $\ldots$ & $\ldots$ & $\ldots$ & I,F & $\ldots$ \\
Tajikistan & $\ldots$ & $\ldots$ & $\ldots$ & I,R & R & R \\
Tanzania & $\ldots$ & I,F,D & R & P & R & $\ldots$ \\
\hline Togo & $\ldots$ & $\ldots$ & $\ldots$ & $\ldots$ & $\ldots$ & I,F \\
Uganda & $\mathrm{D}$ & P,S,C & R & $\ldots$ & R & $\ldots$ \\
Vietnam & $\ldots$ & S* & $\ldots$ & I,F & $\ldots$ & $\ldots$ \\
Yemen, Republic of & $\ldots$ & R & R & I,R & $\ldots$ & $\ldots$ \\
Zambia & $\ldots$ & $\ldots$ & I,R & D & $\ldots$ & $\ldots$ \\
\hline Iam
\end{tabular}

I - Interim PRSP

P - PRSP

$F$ - new PRGF 3-year arrangement

R - Review of PRGF arrangement, or new arrangement

D - HIPC decision point under enhanced Initiative

C - HIPS completion point, enhanced or original Initiative

S - Country Assistance Strategy

S* - Country Assistance Strategy Update

1 A brief statement on the relationship between the CDF and the PRSP by Messrs. Wolfensohn and Fischer. 


\section{Annex $5^{1}$}

\section{Proposed Urban Goals for Istanbul +5 (June 2001)}

\section{The Habitat Goals, Nairobi, May 2000}

Within a context of reducing extreme poverty by half by 2015 :

a) Demonstrated progress ${ }^{2}$ towards shelter for all and access to basic services in every community.

b) Demonstrated progress in improving urban governance, particularly in promoting economic and social policies that are favourable to the poor and inclusive.

c) Demonstrated progress in the removal of discriminatory legislation and practices that prevent women from inheriting and owning land and property.

d) Continued excellence within the Centre [Habitat], in the management of its resources, development of its staff and in the quality and integrity of its work.

\section{The Commonwealth Target, Durban, $1999^{3}$}

To achieve demonstrated progress towards shelter for all, with secure tenure and access to essential services in every community, by 2015 .

\footnotetext{
${ }^{1}$ Taken from DfID (2000g), p. 23.

2 "Demonstrated Progress" has been identified as "the progressive implementation of a plan of action".

${ }^{3}$ The Commonwealth Consultative Group on Human Settlements (CCGHS) 1999: Focus On The Habitat Agenda, The Commonwealth Development Framework for Human Settlements; Commonwealth Human Ecology Council, (UK).
} 


\section{Annex 6}

\section{Scheme for Identification of the Poverty Impact Level ${ }^{1}$ :}

\begin{tabular}{|c|c|c|c|c|}
\hline & \multirow{2}{*}{\multicolumn{2}{|c|}{\begin{tabular}{|l} 
Direct poverty \\
reduction \\
Projects with \\
identifiable and \\
directly (through \\
short chains of \\
effects) reachable \\
target groups
\end{tabular}}} & \multirow{4}{*}{\begin{tabular}{|l} 
Overarching \\
poverty reduction \\
Projects with non- \\
identifiable and \\
indirect (through \\
longer chains of \\
effects) reachable \\
target groups \\
MSA \\
Poverty reduction \\
on macro or sector \\
level
\end{tabular}} & \\
\hline & & & & \\
\hline & \multirow{2}{*}{\begin{tabular}{|l|} 
SHA \\
Self-help \\
oriented poverty \\
reduction
\end{tabular}} & \multirow{2}{*}{$\begin{array}{l}\text { SUA } \\
\text { Other direct } \\
\text { poverty } \\
\text { reduction, } \\
\text { especially basic } \\
\text { social services } \\
\end{array}$} & & \multirow{2}{*}{$\begin{array}{l}\text { EPA } \\
\text { General } \\
\text { development } \\
\text { orientation }\end{array}$} \\
\hline Criteria & & & & \\
\hline $\begin{array}{l}\text { 1. Are poor people } \\
\text { part of the target } \\
\text { group? }\end{array}$ & \multicolumn{2}{|c|}{$\begin{array}{l}\text { Proportion of the poor in the target } \\
\text { group reaches } \\
-\quad \text { at minimum } 50 \% \text { or } \\
-\quad \text { at least a proportion of poor } \\
\text { people in the general } \\
\text { population in the concerning }\end{array}$} & $\begin{array}{l}\text { Poor people in the } \\
\text { region or the } \\
\text { country receive } \\
\text { appreciable utility } \\
\text { from the indirect } \\
\text { effects of the } \\
\text { project }\end{array}$ & \multirow{5}{*}{$\begin{array}{l}\text { The criteria } \\
\text { are not or } \\
\text { only } \\
\text { partially } \\
\text { fulfilled; the } \\
\text { projects are } \\
\text { supported } \\
\text { due to } \\
\text { general } \\
\text { development } \\
\text { al } \\
\text { objectives. }\end{array}$} \\
\hline $\begin{array}{l}\text { 2. Does the project } \\
\text { improve the } \\
\text { situation of the } \\
\text { poor or does it } \\
\text { improve their } \\
\text { economic } \\
\text { opportunities? } \\
\end{array}$ & $\mathrm{X}$ & $\mathrm{X}$ & $\mathrm{X}$ & \\
\hline $\begin{array}{l}\text { 3. Do the poor } \\
\text { participate? }\end{array}$ & $\begin{array}{l}\text { Self-responsibly } \\
\text { and in self- } \\
\text { organization }\end{array}$ & $\begin{array}{l}\text { Participation and } \\
\text { identification } \\
\text { with the project }\end{array}$ & $\begin{array}{l}\text { The main } \\
\text { mechanisms for } \\
\text { the poor to } \\
\text { participate in the } \\
\text { political and social } \\
\text { process are } \\
\text { generally existent }\end{array}$ & \\
\hline \multirow{2}{*}{$\begin{array}{l}\text { 4. Is the project } \\
\text { embedded in a } \\
\text { poverty oriented } \\
\text { environment }\end{array}$} & \multicolumn{2}{|c|}{$\begin{array}{l}\text { The local framework of the project } \\
\text { environment is conducive }\end{array}$} & & \\
\hline & $\begin{array}{l}\text { Freedom for } \\
\text { NGO's to } \\
\text { engage } \\
\text { themselves is } \\
\text { provided }\end{array}$ & & $\begin{array}{l}\text { Plausible chains of } \\
\text { effects between } \\
\text { the project and an } \\
\text { improvement of } \\
\text { the situation of the } \\
\text { poor }\end{array}$ & \\
\hline
\end{tabular}

\footnotetext{
${ }^{1}$ Source: Documentation of the KfW (translated by the author).
} 


\section{Annex 7}

\section{Annotation Concerning Inverse Causality and Endogeneity}

The regression analysis presented in the qualitative part of this study could potentially be faced with the problem of endogeneity of the variable success due to the problem that success might depend on poverty focus and vice versa. If present, this could be solved using instrumental variables or simultaneous equation procedures. Both methods have their drawbacks: Instrumental variables increases the variance covariance matrix in regression approaches, leading to less reliable results if used unnecessary. Simultaneous equation approaches will not even be possible given the low explanatory power of the other variables on success visible in the following step-wise regression. The correspondence analysis found little relationship between the variables success and poverty focus. In the step-wise regression, an adjusted R-squared below $6 \%$ and little explanatory power of poverty focus for determining the level of success underlines the lack of influence from poverty focus on success. Both analysis combined lead us to believe that the endogeneity problem, if present, is negligible for the analysis.

Discussion of results of step-wise regression with success as dependent variable:

A step-wise regression model whose results are presented below shows that very limited effect can be made out if success is used as independent variable and dummies for poverty focus, impact level and crs together with financing are deployed as dependent variables. The low overall explanatory value of the variables, characterized by a maximum R-squared of 0.136 (max. adjusted: 0.58 ) shows little explanatory power of the included variables on the variable success. Moreover, this low R-squared makes a simultaneous equation model superfluous, as the resulting large residuals will prohibit the approach of this model. The low explanatory value of the sampled variables leads to residuals of a magnitude that does not allow for reasonable calculations in the second step of the simultaneous approach.

From the step-wise regressions it can be inferred that poverty focus has little impact on success. The first equations do not provide reliable results. All variables from the model specification used to explain poverty focus were deployed, and the resulting high degree of freedom and the obviously low explanatory power of the included variables lead to rejections of the $\mathrm{F}$ test. Starting from equation 7 we are left with a regression model that includes a limited number of variables of some explanatory power, indicated by a F-test at significant level. In these the individual dummy variables for poverty focus are not highly significance, even though poverty level 2 seems to have some significance compared to the other levels. The last equation that is retained by this approach does not contain any dummies for poverty reduction. crs 3 is retained as the only significant variable. As this is parameter value is close to the parameter value $\mathrm{s} 1$ in the correspondence analysis, this can be seen as supportive to the findings of this analysis.

All of the results should be viewed with caution, as a maximum R-spared below 0.14 and a maximum adjusted $\mathrm{R}$-squared below 0.06 show that these regressions do not explain much of the variance of the factor success. This should, more importantly than the preceding results, be taken as the an indication that the link from poverty level on success of a project is weak. 
Regression results from step-wise regression. Dependent variable: Success. Factor elimination for significance below $10 \%$.

Modell Summary

\begin{tabular}{|c|c|c|c|c|}
\hline Modell & \multicolumn{2}{|c|}{ RR-squared } & Adjusted R- & Standard Error \\
\hline 1 & ,369 & ,136 &, 001 & ,8295 \\
\hline 2 & 364 & 133 &, 013 & 8248 \\
\hline 3 &, 360 &, 130 &, 024 &, 8200 \\
\hline 4 & ,359 &, 129 & ,038 & ,8143 \\
\hline 5 & ,352 &, 124 &, 046 &, 8106 \\
\hline 6 &, 347 &, 120 &, 056 &, 8063 \\
\hline 7 &, 329 &, 109 &, 058 &, 8058 \\
\hline 8 & ,293 &, 086 &, 048 &, 8101 \\
\hline 9 & ,263 & ,069 &, 043 & 8119 \\
\hline 10 & 198 & ,039 &, 026 &, 8191 \\
\hline
\end{tabular}

1 Independent Variables: (Konstante), financing, dummy IL3, crs3, dummy pov3, dummy pov1, dummy IL2, dummy pov2, dummy IL1, Übergeordneter Sektor, crs1

2 Independent Variables: (Konstante), financing, dummy IL3, crs3, dummy pov3, dummy pov1, dummy IL2, dummy pov2, dummy IL1, crs1

3 Independent Variables: (Konstante), financing, dummy IL3, crs3, dummy pov3, dummy pov1, dummy IL2, dummy pov2, crs1

4 Independent Variables: (Konstante), financing, crs3, dummy pov3, dummy pov1, dummy IL2, dummy pov2, crs1

5 Independent Variables: (Konstante), financing, crs3, dummy pov3, dummy pov1, dummy IL2, dummy pov2

6 Independent Variables: (Konstante), financing, crs3, dummy pov3, dummy pov1, dummy pov2

7 Independent Variables: (Konstante), financing, crs3, dummy pov3, dummy pov2

8 Independent Variables: (Konstante), financing, crs3, dummy pov2

9 Independent Variables: (Konstante), financing, crs3

10 Independent Variables: (Konstante), crs3

ANOVA

\begin{tabular}{|r|r|rr|r|r|r|}
\hline Model & & $\begin{array}{r}\text { Sum of } \\
\text { Squares }\end{array}$ & df & $\begin{array}{r}\text { Average } \\
\text { Squares }\end{array}$ & F & Significance \\
\hline 1 & Regression & 6,954 & 10 &, 695 & 1,011 &, 444 \\
\hline & Residua & 44,033 & 64 &, 688 & & \\
\hline & Sum & 50,987 & 74 & & & \\
\hline 2 & Regression & 6,767 & 9 &, 752 & 1,105 &, 372 \\
\hline & Residua & 44,220 & 65 &, 680 & & \\
\hline & Sum & 50,987 & 74 & & &, 296 \\
\hline 3 & Regression & 6,612 & 8 &, 826 & 1,229 & \\
\hline & Residua & 44,375 & 66 &, 672 & &, 215 \\
\hline & Sum & 50,987 & 74 & & & \\
\hline 4 & Regression & 6,557 & 7 &, 937 & 1,413 & \\
\hline & Residual & 44,430 & 67 &, 663 & & \\
\hline & Sum & 50,987 & 74 & & & \\
\hline
\end{tabular}


(Continued from previous page)

\begin{tabular}{|r|r|r|r|r|r|r|}
\hline 5 & Regression & 6,302 & 6 & 1,050 & 1,598 &, 161 \\
\hline & Residua & 44,684 & 68 &, 657 & & \\
\hline & Sum & 50,987 & 74 & & & \\
\hline 6 & Regression & 6,128 & 5 & 1,226 & 1,885 &, 108 \\
\hline & Residual & 44,859 & 69 &, 650 & &, 086 \\
\hline & Sum & 50,987 & 74 & & & \\
\hline 7 & Regression & 5,533 & 4 & 1,383 & 2,130 &, 092 \\
\hline & Residual & 45,454 & 70 &, 649 & & \\
\hline & Sum & 50,987 & 74 & & & \\
\hline 8 & Regression & 4,392 & 3 & 1,464 & 2,231 & \\
\hline & Residual & 46,595 & 71 &, 656 & & \\
\hline & Sum & 50,987 & 74 & & & \\
\hline 9 & Regression & 3,528 & 2 & 1,764 & 2,676 & \\
\hline & Residual & 47,459 & 72 &, 659 & & \\
\hline & Sum & 50,987 & 74 & & & \\
\hline 10 & Regression & 2,007 & 1 & 2,007 & 2,991 & \\
\hline & Residual & 48,980 & 73 &, 671 & & \\
\hline & Sum & 50,987 & 74 & & & \\
\hline
\end{tabular}

Dependent Variable: success

1 Independent Variables: (Konstante), financing, dummy IL3, crs3, dummy pov3, dummy pov1, dummy IL2, dummy pov2, dummy IL1, Übergeordneter Sektor, crs1

2 Independent Variables: (Konstante), financing, dummy IL3, crs3, dummy pov3, dummy pov1, dummy IL2, dummy pov2, dummy IL1, crs1

3 Independent Variables: (Konstante), financing, dummy IL3, crs3, dummy pov3, dummy pov1, dummy IL2, dummy pov2, crs1

4 Independent Variables: (Konstante), financing, crs3, dummy pov3, dummy pov1, dummy IL2, dummy pov2, crs1

5 Independent Variables: (Konstante), financing, crs3, dummy pov3, dummy pov1, dummy IL2, dummy pov2

6 Independent Variables: (Konstante), financing, crs3, dummy pov3, dummy pov1, dummy pov2

7 Independent Variables: (Konstante), financing, crs3, dummy pov3, dummy pov2

8 Independent Variables: (Konstante), financing, crs3, dummy pov2

9 Independent Variables: (Konstante), financing, crs3

10 Independent Variables: (Konstante), crs3 
Coefficients of Step-wise Regressions

\begin{tabular}{|c|c|c|c|c|c|c|}
\hline & & $\begin{array}{r}\text { Non- } \\
\text { standardized } \\
\text { coefficients }\end{array}$ & & $\begin{array}{r}\text { Standardize } \\
\mathrm{d} \\
\text { coefficients }\end{array}$ & $\mathrm{T}$ & Significance \\
\hline Model & & & $\begin{array}{r}\text { Standard } \\
\text { Error }\end{array}$ & Beta & & \\
\hline 1 & (constant) & 2,389 &, 376 & & 6,355 &, 000 \\
\hline & $\begin{array}{r}\text { dummy } \\
\text { IL1 }\end{array}$ & 200 & 366 &, 099 &, 547 &, 586 \\
\hline & $\begin{array}{r}\text { dummy } \\
\text { IL2 }\end{array}$ & ,376 & 391 & ,182 & ,961 & 340 \\
\hline & $\begin{array}{r}\text { dummy } \\
\text { IL3 }\end{array}$ & ,183 & 299 & ,108 & ,613 &, 542 \\
\hline & $\begin{array}{r}\text { dummy } \\
\text { pov1 }\end{array}$ &,- 301 & ,313 &,- 168 &,- 963 & ,339 \\
\hline & $\begin{array}{r}\text { dummy } \\
\text { pov2 }\end{array}$ &,- 602 & ,343 &,- 332 & $-1,756$ & ,084 \\
\hline & $\begin{array}{r}\text { dummy } \\
\text { pov3 }\end{array}$ &,- 597 & ,409 &,- 246 & $-1,459$ & 149 \\
\hline & crs 1 &,- 280 & ,383 &,- 157 &,- 733 & ,466 \\
\hline & crs2 &,- 189 &, 363 &,- 108 &,- 521 & ,604 \\
\hline & crs3 &, 192 &, 364 & ,099 &, 527 &, 600 \\
\hline & financing & $-4,786 \mathrm{E}-03$ &, 003 &,- 244 & $-1,844$ &, 070 \\
\hline 2 & (constant) & 2,262 & 285 & & 7,943 &, 000 \\
\hline & $\begin{array}{r}\text { dummy } \\
\text { IL1 } \\
\end{array}$ & 171 & ,359 & 085 & ,477 & 635 \\
\hline & $\begin{array}{r}\text { dummy } \\
\text { IL2 }\end{array}$ & ,346 & ,385 & ,168 & ,899 & ,372 \\
\hline & $\begin{array}{r}\text { dummy } \\
\text { IL3 }\end{array}$ & 144 & 288 & ,085 & ,499 & ,619 \\
\hline & $\begin{array}{r}\text { dummy } \\
\text { pov1 }\end{array}$ &,- 266 & ,304 &,- 149 &,- 877 & 384 \\
\hline & $\begin{array}{r}\text { dummy } \\
\text { pov2 }\end{array}$ &,- 536 & 317 &,- 296 & $-1,691$ & ,096 \\
\hline & $\begin{array}{r}\text { dummy } \\
\text { pov3 }\end{array}$ &,- 541 & ,392 &,- 223 & $-1,377$ &, 173 \\
\hline & crs 1 &,- 175 & ,323 &,- 098 &,- 542 & 590 \\
\hline & crs3 & ,313 & ,279 &, 162 & 1,119 & ,267 \\
\hline & financing & $-5,039 \mathrm{E}-03$ &, 003 &,- 257 & $-1,988$ &, 051 \\
\hline & (constant) & 2,306 & ,268 & & 8,612 &, 000 \\
\hline & $\begin{array}{r}\text { dummy } \\
\text { IL2 }\end{array}$ & 233 & ,302 & ,113 & ,772 & ,443 \\
\hline & $\begin{array}{r}\text { dummy } \\
\text { IL3 } \\
\end{array}$ & $6,833 \mathrm{E}-02$ & ,239 &, 040 & ,286 & ,776 \\
\hline & $\begin{array}{r}\text { dummy } \\
\text { pov1 }\end{array}$ &,- 254 & ,301 &,- 142 &,- 844 &, 402 \\
\hline & $\begin{array}{r}\text { dummy } \\
\text { pov2 }\end{array}$ &,- 485 & ,297 &,- 268 & $-1,635$ & , 107 \\
\hline & $\begin{array}{r}\text { dummy } \\
\text { pov3 }\end{array}$ &,- 480 & 369 &,- 198 & $-1,300$ & ,198 \\
\hline
\end{tabular}


(Continued from previous page)

\begin{tabular}{|c|c|c|c|c|c|c|}
\hline & & $\begin{array}{r}\text { Non- } \\
\text { standardized } \\
\text { coefficients }\end{array}$ & & $\begin{array}{r}\text { Standardize } \\
\mathrm{d} \\
\text { coefficients }\end{array}$ & & Significance \\
\hline Model & & $\mathrm{B}$ & $\begin{array}{r}\text { Standard } \\
\text { Error }\end{array}$ & Beta & & \\
\hline & crs1 &,- 142 &, 314 &,- 079 &,- 452 & ,653 \\
\hline & crs3 & 345 & ,269 &, 179 & 1,280 & ,205 \\
\hline & financing & $-5,069 \mathrm{E}-03$ & ,003 &,- 259 & $-2,013$ & ,048 \\
\hline & (constant) & 2,342 &, 236 & & 9,923 &, 000 \\
\hline & $\begin{array}{r}\text { dummy } \\
\text { IL2 }\end{array}$ &, 210 & 289 & , 102 &, 727 &, 470 \\
\hline & $\begin{array}{r}\text { dummy } \\
\text { pov1 }\end{array}$ &,- 226 & ,283 &,- 127 &,- 800 & ,426 \\
\hline & $\begin{array}{r}\text { dummy } \\
\text { pov2 }\end{array}$ &,- 472 & ,291 &,- 261 & $-1,622$ &, 110 \\
\hline & $\begin{array}{r}\text { dummy } \\
\text { pov3 }\end{array}$ &,- 463 & ,362 &,- 191 & $-1,280$ & ,205 \\
\hline & crs 1 &,- 177 & ,286 &,- 099 &,- 620 &, 538 \\
\hline & crs3 &, 321 &, 255 &, 166 & 1,261 & ,212 \\
\hline & financing & $-5,148 \mathrm{E}-03$ &, 002 &,- 263 & $-2,071$ &, 042 \\
\hline & (Konstante) & 2,323 & ,233 & & 9,972 &, 000 \\
\hline & $\begin{array}{r}\text { dummy } \\
\text { IL2 } \\
\end{array}$ & ,134 & ,261 &, 065 & ,515 & ,608 \\
\hline & $\begin{array}{r}\text { dummy } \\
\text { pov1 }\end{array}$ &,- 279 & ,269 &,- 156 & $-1,038$ & ,303 \\
\hline & $\begin{array}{r}\text { dummy } \\
\text { pov2 }\end{array}$ &,- 515 & ,282 &,- 285 & $-1,830$ &, 072 \\
\hline & $\begin{array}{r}\text { dummy } \\
\text { pov3 }\end{array}$ &,- 550 & ,332 &,- 227 & $-1,660$ & ,102 \\
\hline & crs3 & ,386 & ,231 & ,200 & 1,668 &, 100 \\
\hline & financing & $-4,982 \mathrm{E}-03$ &, 002 &,- 254 & $-2,025$ &, 047 \\
\hline & (constant) & 2,339 &, 230 & & 10,192 &, 000 \\
\hline & $\begin{array}{r}\text { dummy } \\
\text { pov1 }\end{array}$ &,- 250 & ,261 &,- 140 &,- 957 & ,342 \\
\hline & $\begin{array}{r}\text { dummy } \\
\text { pov2 }\end{array}$ &,- 473 & ,268 &,- 261 & $-1,766$ &, 082 \\
\hline & $\begin{array}{r}\text { dummy } \\
\text { pov3 }\end{array}$ &,- 531 & ,328 &,- 219 & $-1,620$ &, 110 \\
\hline & crs3 & ,355 & ,222 & , 184 & 1,597 &, 115 \\
\hline & financing & $-5,190 \mathrm{E}-03$ &, 002 &,- 265 & $-2,149$ & ,035 \\
\hline & (constant) & 2,187 &, 166 & & 13,178 &, 000 \\
\hline & $\begin{array}{r}\text { dummy } \\
\text { pov2 }\end{array}$ &,- 324 & ,218 &,- 179 & $-1,488$ &, 141 \\
\hline & $\begin{array}{r}\text { dummy } \\
\text { pov3 }\end{array}$ &,- 383 & ,289 &,- 158 & $-1,326$ &, 189 \\
\hline & crs3 & ,323 & ,219 & ,167 & 1,471 &, 146 \\
\hline & financing & $-4,527 \mathrm{E}-03$ &, 002 &,- 231 & $-1,958$ &, 054 \\
\hline
\end{tabular}


(Continued from previous page)

\begin{tabular}{|r|r|r|r|r|r|r|}
\hline & & $\begin{array}{r}\text { Non- } \\
\text { standardized } \\
\text { coefficients }\end{array}$ & $\begin{array}{r}\text { Standardize } \\
\text { d }\end{array}$ & T & Significance \\
coefficients & & & \\
\hline Model & & $\begin{array}{r}\text { Standard } \\
\text { Error }\end{array}$ & Beta & & \\
\hline 8 & (constant) & 2,090 &, 150 & & 13,969 &, 000 \\
\hline & $\begin{array}{r}\text { dummy } \\
\text { pov2 }\end{array}$ &,- 241 &, 210 &,- 133 & $-1,147$ &, 255 \\
\hline & crs3 &, 341 &, 220 &, 177 & 1,551 &, 125 \\
\hline & financing & $-3,929 \mathrm{E}-03$ &, 002 &,- 201 & $-1,724$ &, 089 \\
\hline 9 & (constant) & 2,002 &, 128 & & 15,579 &, 000 \\
\hline &, 351 &, 220 &, 182 & 1,593 &, 115 \\
\hline crs3 & financing & $-3,397 \mathrm{E}-03$ &, 002 &,- 173 & $-1,519$ &, 133 \\
\hline 10 & (constant) & 1,895 &, 108 & & 17,464 &, 000 \\
\hline &, 383 &, 221 &, 198 & 1,730 &, 088 \\
\hline
\end{tabular}

Dependent Variable: success 


\section{Annex 8}

Statistical Annotations to the Correspondence Analysis

Statistical Annotation to Figure 20:

The CORRESP Procedure

Inertia and Chi-Square Decomposition

\begin{tabular}{|c|c|c|c|c|}
\hline $\begin{array}{l}\text { Singular } \\
\text { Value }\end{array}$ & $\begin{array}{l}\text { Principa } \\
\text { Inertia }\end{array}$ & $\begin{array}{l}\text { Chi- } \\
\text { Square }\end{array}$ & Percent & $\begin{array}{llllll}\text { mulative } & & & & & \\
\text { Percent } & 3 & 6 & 9 & 12 & 15\end{array}$ \\
\hline & & & ---+-- & +----+----+----+--- \\
\hline 0.78187 & 0.61132 & 236.56 & 16.30 & 16.30 $2 * * * * * * * * * * * * * * * * * * * *$ \\
\hline 0.63081 & 0.39793 & 153.99 & 10.61 & $26.91 * * * * * * * * * * * * * * * * * * *$ \\
\hline 0.59326 & 0.35195 & 136.19 & 9.39 & 36.30 $2 * * * * * * * * * * * * * * *$ \\
\hline 0.55178 & 0.30446 & 117.82 & 8.12 & $44.42 * * * * * * * * * * * * * * *$ \\
\hline 0.54676 & 0.29894 & 115.68 & 7.97 & $52.39 * * * * * * * * * * * * *$ \\
\hline 0.52728 & 0.27803 & 107.59 & 7.41 & $59.80 * * * * * * * * * * * *$ \\
\hline 0.52063 & 0.27106 & 104.89 & 7.23 & $67.03 * * * * * * * * * * * *$ \\
\hline 0.49097 & 0.24105 & 93.28 & 6.43 & $73.46 * * * * * * * * * * *$ \\
\hline 0.47372 & 0.22441 & 86.84 & 5.98 & $79.44 * * * * * * * * * *$ \\
\hline 0.43953 & 0.19319 & 74.76 & 5.15 & $84.60 * * * * * * * * *$ \\
\hline 0.41690 & 0.17381 & 67.26 & 4.63 & $89.23 * * * * * * * *$ \\
\hline 0.37744 & 0.14246 & 55.13 & 3.80 & $93.03 * * * * * *$ \\
\hline 0.33415 & 0.11166 & 43.21 & 2.98 & $96.01 * * * * *$ \\
\hline 0.30237 & 0.09143 & 35.38 & 2.44 & $98.44 * * * *$ \\
\hline 0.24148 & 0.05831 & 22.57 & 1.56 & $100.00 * * *$ \\
\hline
\end{tabular}

Total 3.750001451 .13100 .00

Degrees of Freedom $=324$

Statistical Annotation to Figure 21:

The CORRESP Procedure

Inertia and Chi-Square Decomposition

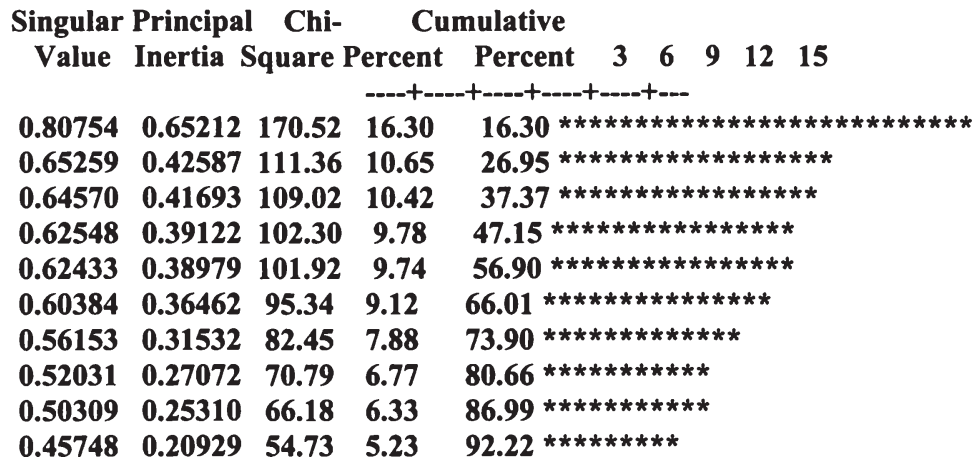


(continued from previous page)

\section{$\begin{array}{lllll}0.43426 & 0.18858 & 49.31 & 4.71 & 96.94 * * * * * * * *\end{array}$ \\ $\begin{array}{lllll}0.34992 & 0.12244 & 32.02 & 3.06 & 100.00 * * * * *\end{array}$}

Total 4.000001045 .93100 .00

Degrees of Freedom $=196$

Statistical Annotation to Figure 22:

\section{The CORRESP Procedure}

Inertia and Chi-Square Decomposition

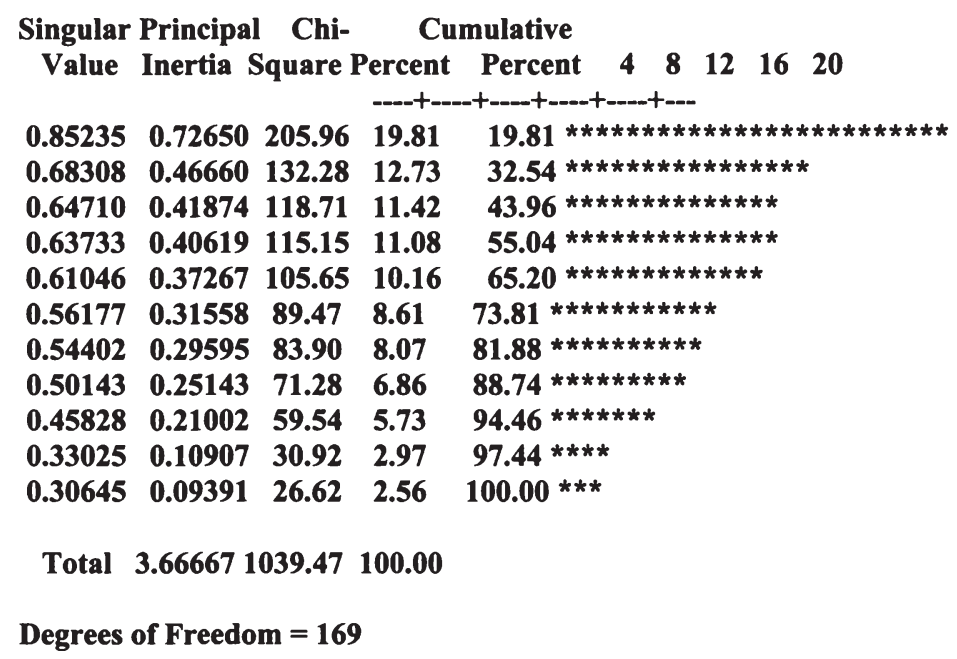




\section{Annex 9}

\section{Results from Step-wise Regression (Extension of Table 4)}

\section{Regression results from step-wise regression. Dependent variable: Poverty Focus.} Factor elimination for significance below $10 \%$.

Model Summary

\begin{tabular}{|r|r|r|r|r|}
\hline Modell & R & $\begin{array}{r}\text { R- } \\
\text { Squared }\end{array}$ & $\begin{array}{r}\text { Adjusted } \\
\text { R- } \\
\text { Squared }\end{array}$ & $\begin{array}{r}\text { Standard } \\
\text { Error of } \\
\text { the } \\
\text { estimator }\end{array}$ \\
\hline 1 &, 677 &, 458 &, 381 &, 8049 \\
\hline 2 &, 677 &, 458 &, 391 &, 7988 \\
\hline 3 &, 676 &, 457 &, 399 &, 7934 \\
\hline 4 &, 665 &, 443 &, 392 &, 7979 \\
\hline
\end{tabular}

1 Independent Variable: (Konstante), dummy impact level 3, dummy success 2, financial involvement, crs3, dummy impact level 1, dummy success 1 , crs1, dummy impact level 2 , crs2

2 Independent Variable: (Konstante), dummy impact level 3, financial involvement, crs3, dummy impact level 1, dummy success 1 , crs1, dummy impact level 2, crs2

3 Independent Variable: (Konstante), dummy impact level 3, financial involvement, crs3, dummy impact level 1, dummy success 1 , dummy impact level 2, crs2

4 Independent Variable: (Konstante), dummy impact level 3, crs3, dummy impact level 1, dummy success 1 , dummy impact level 2 , crs2

ANOVA

\begin{tabular}{|c|c|c|c|c|c|c|}
\hline Model & & $\begin{array}{r}\text { Sum of } \\
\text { Squares }\end{array}$ & $\mathrm{df}$ & $\begin{array}{l}\text { Average } \\
\text { Squares }\end{array}$ & $\bar{F}$ & Significance \\
\hline 1 & Regression & 34,557 & 9 & 3,840 & 5,927 & .000 \\
\hline & Residuals & 40,813 & 63 & ,648 & & \\
\hline & Total & 75,370 & 72 & & & \\
\hline 2 & Regression & 34,537 & 8 & 4,317 & 6,767 &, 000 \\
\hline & Residuals & 40,832 & 64 & ,638 & & \\
\hline & Total & 75,370 & 72 & & & \\
\hline 3 & Regression & 34,453 & 7 & 4,922 & 7,819 &, 000 \\
\hline & Residuals & 40,917 & 65 &, 629 & & \\
\hline & Total & 75,370 & 72 & & & \\
\hline 4 & Regression & 33,357 & 6 & 5,559 & 8,733 &, 000 \\
\hline & Residuals & 42,013 & 66 & ,637 & & \\
\hline & Total & 75,370 & 72 & & & \\
\hline
\end{tabular}


(continued from previous page)

Dependent Variable: poverty focus

1 Independent Variable : (Konstante), dummy impact level 3, dummy success 2, financial involvement, crs3, dummy impact level 1 , dummy success 1 , crs 1 , dummy impact level 2 , crs2

2 Independent Variable: (Konstante), dummy impact level 3, financial involvement, crs3, dummy impact level 1, dummy success 1 , crs 1, dummy impact level 2, crs 2

3 Independent Variable: (Konstante), dummy impact level 3, financial involvement, crs3, dummy impact level 1 , dummy success 1 , dummy impact level 2 , crs 2

4 Independent Variable: (Konstante), dummy impact level 3, crs3, dummy impact level 1, dummy success 1 , dummy impact level 2 , crs2

\section{Coefficients}

\begin{tabular}{|c|c|c|c|c|c|c|}
\hline & & $\begin{array}{r}\text { Not } \\
\text { standardized } \\
\text { coefficients }\end{array}$ & & $\begin{array}{l}\text { Standardized } \\
\text { Coefficients }\end{array}$ & $\mathrm{T}$ & Significance \\
\hline model & & $\mathrm{B}$ & $\begin{array}{r}\text { Standard } \\
\text { error }\end{array}$ & Beta & & \\
\hline 1 & (constant) & 955 & 379 & & 2,518 &, 014 \\
\hline & $\begin{array}{r}\text { financial } \\
\text { involvement }\end{array}$ & $-3,294 \mathrm{E}-03$ &, 003 &,- 138 & $-1,291$ & ,201 \\
\hline & crs1 & 126 & 380 & ,058 & ,331 & ,742 \\
\hline & crs2 &,- 886 &, 356 &,- 414 & $-2,487$ &, 016 \\
\hline & crs3 &,- 388 & ,364 &,- 165 & $-1,067$ & 290 \\
\hline & dummy success 1 &, 408 & ,241 &, 188 & 1,690 &, 096 \\
\hline & dummy success 2 & $4,218 \mathrm{E}-02$ & 243 &, 020 &, 173 &, 863 \\
\hline & $\begin{array}{r}\text { dummy impact } \\
\text { level } 1\end{array}$ & 1,057 & 325 &, 420 & 3,247 &, 002 \\
\hline & $\begin{array}{r}\text { dummy impact } \\
\text { level } 2\end{array}$ & ,707 & ,355 & ,281 & 1,991 &, 051 \\
\hline & $\begin{array}{r}\text { dummy impact } \\
\text { level } 3\end{array}$ & ,737 & 270 & 355 & 2,733 & ,008 \\
\hline 2 & (constant) & ,971 & ,365 & & 2,660 &, 010 \\
\hline & $\begin{array}{r}\text { financial } \\
\text { involvement }\end{array}$ & $-3,251 \mathrm{E}-03$ & ,003 &,- 136 & $-1,290$ & ,202 \\
\hline & crs1 & 136 & 373 &, 062 & ,365 & ,717 \\
\hline & crs2 &,- 883 & 353 &,- 412 & $-2,501$ & 015 \\
\hline & crs3 &,- 394 &, 360 &,- 167 & $-1,095$ & ,278 \\
\hline & dummy success 1 & ,385 & 204 &, 178 & 1,894 &, 063 \\
\hline & $\begin{array}{r}\text { dummy impact } \\
\text { level } 1\end{array}$ & 1,058 & ,323 &, 421 & 3,279 &, 002 \\
\hline & $\begin{array}{r}\text { dummy impact } \\
\text { level } 2 \\
\end{array}$ & ,704 & 352 & ,280 & 2,000 &, 050 \\
\hline & $\begin{array}{r}\text { dummy impact } \\
\text { level } 3\end{array}$ & ,741 & ,267 &, 357 & 2,773 & ,007 \\
\hline
\end{tabular}


(Continued from previous page)

\begin{tabular}{|c|c|c|c|c|c|c|}
\hline & & $\begin{array}{r}\text { Not } \\
\text { standardized } \\
\text { coefficients } \\
\end{array}$ & & $\begin{array}{r}\text { Standardized } \\
\text { Coefficients }\end{array}$ & $\mathrm{T}$ & Significance \\
\hline model & & $\mathrm{B}$ & $\begin{array}{r}\text { Standard } \\
\text { error }\end{array}$ & Beta & & \\
\hline 3 & (constant) & 1,052 & ,288 & & 3,653 &, 001 \\
\hline & $\begin{array}{r}\text { financial } \\
\text { involvement }\end{array}$ & $-3,298 \mathrm{E}-03$ & 002 &,- 138 & $-1,320$ & , 192 \\
\hline & crs2 &,- 964 & ,272 &,- 450 & $-3,546$ &, 001 \\
\hline & crs3 &,- 484 & ,259 &,- 205 & $-1,872$ &, 066 \\
\hline & dummy success 1 & ,388 & ,202 & , 180 & 1,923 &, 059 \\
\hline & $\begin{array}{r}\text { dummy impact } \\
\text { level } 1 \\
\end{array}$ & 1,083 & ,314 & ,430 & 3,450 &, 001 \\
\hline & $\begin{array}{r}\text { dummy impact } \\
\text { level } 2\end{array}$ & ,743 & ,333 & ,295 & 2,228 &, 029 \\
\hline & $\begin{array}{r}\text { dummy impact } \\
\text { level } 3 \\
\end{array}$ & ,740 & ,265 & 356 & 2,788 &, 007 \\
\hline 4 & (constant) & ,949 & ,279 & & 3,405 & ,001 \\
\hline & crs2 & $-1,069$ & ,261 &,- 499 & $-4,091$ &, 000 \\
\hline & crs3 &,- 498 & 260 &,- 211 & $-1,915$ &, 060 \\
\hline & dummy success 1 & ,338 & , 199 &, 156 & 1,694 &, 095 \\
\hline & $\begin{array}{r}\text { dummy impact } \\
\text { level } 1\end{array}$ & 1,142 & ,312 & ,454 & 3,656 &, 001 \\
\hline & $\begin{array}{r}\text { dummy impact } \\
\text { level } 2 \\
\end{array}$ & ,843 & ,326 & ,335 & 2,581 &, 012 \\
\hline & $\begin{array}{r}\text { dummy impact } \\
\text { level } 3\end{array}$ & ,811 & ,261 & ,391 & 3,107 &, 003 \\
\hline
\end{tabular}

a dependent variable: poverty focus

Excluded Variables:

\begin{tabular}{|r|r|r|r|r|r|r|}
\hline & & Beta In & T & Significance & $\begin{array}{r}\text { Partial } \\
\text { Correlation }\end{array}$ & $\begin{array}{r}\text { Colliniarity } \\
\text { Statistic }\end{array}$ \\
\hline Model & & & & & & Tolerance \\
\hline 2 & dummy success 2 &, 020 &, 173 &, 863 &, 022 &, 680 \\
\hline 3 & dummy success 2 &, 025 &, 229 &, 820 &, 029 &, 696 \\
\hline & crs 1 &, 062 &, 365 &, 717 &, 046 &, 291 \\
\hline 4 & dummy success 2 &, 012 &, 112 &, 911 &, 014 &, 702 \\
\hline & crs1 &, 073 &, 429 &, 670 &, 053 &, 292 \\
\hline & $\begin{array}{r}\text { financial } \\
\text { involvement }\end{array}$ &,- 138 & $-1,320$ &, 192 &,- 162 &, 760 \\
\hline
\end{tabular}

Dependent variable: poverty focus

1 Independent variables: (Konstante), dummy impact level 3, financial involvement, crs3, dummy impact level 1, dummy success 1 , crs1, dummy impact level 2, crs2

2 Independent variables: (Konstante), dummy impact level 3, financial involvement, crs3, dummy impact level 1, dummy success 1 , dummy impact level 2, crs2

3 Independent variables: (Konstante), dummy impact level 3, crs3, dummy impact level 1, dummy success 1 , dummy impact level 2 , crs2 


\section{References}

ACHIKBACHE, B. / BELKINDAS, M. / DINC, M. / IVANOVA, O. / PATEL, C. / SWANSON, E. (2000)

Building Statistical Capacity for Poverty Reduction, in: World Bank (ed.): Poverty Reduction Strategy Sourcebook, Part I: Core Techniques (draft version), Washington D.C.

ADES, Alberto / GLAESER, Edward (1999)

Evidence on Growth, Increasing Returns and the Size of the Market, in: Quarterly Journal of Economics, Vol. 114 (3): 1025 - 1046.

ANDERSEN, Erling B. (1994)

The Statistical Analysis of Categorial Data, Heidelberg.

ANDERSON, Kym / HOEKMAN, Bernard / STRUTT, Anna (1999)

Agriculture and the WTO. Next Steps, paper presented at the Second Annual Conference on Global Economic Analysis, Avernaes Conference Centre, 20 - 22 June, Henaes, Denmark.

ARBEITSKREIS ARMTUSBEKÄMPFUNG DURCH HILFE ZUR SELBSTHILFE (ed.) (2000a)

Comments by the Permanent Working Group on 'Poverty Reduction - Helping People to Help Themeselves' (AKA) on the World Bank's Draft World Development Report 2000/1, 'Attacking Poverty', transmitted to the World Development Report 2000/2001 team of editors in Washington, D.C.

ARBEITSKREIS ARMUTSBEKÄMPFUNG DURCH HILFE ZUR SELBSTHILFE (ed.) (2000b)

Die Kluft überwinden - Wege aus der Armut, published by the BMZ, Bonn.

ASHOFF, Guido (1996)

Bundesrepublik Deutschland. Entwicklungspolitisch reformorientiert, politisch ein schwaches Ressort, in Thiel, R. (ed.) (1996): Entwicklungspolitiken - 33 Geberprofile, Schriften des Deutschen Übersee-Instituts Hamburg Vol. 36, Hamburg.

BARRO, Robert (1999)

Determinates of Economic Growth. A Cross-Country Empirical Study, Second paperback edition, Cambridge, USA

BEITZ, Charles (1979)

Global egelitarianism: Can we make out a case? in Dissident, Vol. 26, Nr.1

BELL, C. L. G. (1974)

The Political Framework, in Chenery, Hollis et al. (1974): Redistribution with Growth. Policies to improve income distribution in developing countries in the context of economic growth - a joint study by the World Bank's Development Research Denter and the Institute of Development Studies, University of Sussex; Glasgow, $52-71$. 
BENDIX, Paul (1996)

Großbritannien. Vorm Weltreich zu mittelgroßen Geber mit Einfluß, in Thiel, R. (ed.) (1996): Entwicklungspolitiken - 33 Geberprofile, Schriften des Deutschen Übersee-Instituts Hamburg Vol. 36, Hamburg.

BENSON, Charlotte (1997)

The Economic Impact of Natural Disasters in the Philippines, Overseas Development Institute Working Paper No. 99, London.

BIRDSALL, Nancy (1996)

Public Spending on Higher Education in Developing Countries: Too Much or Too Little?, in: Economics of Education Review, Vol. 15 (4), 407- 419.

BIRDSALL, Nancy (1988)

Economic Approaches to Population Growth, in: Chenery, Hollis / Srinivasan, T.N. (eds): Handbook of Development Economics, Volume I, Amsterdam, 497 - 521, reprinted in Meier, Gerald / Rauch, James (eds.) (2000): Leading Issues in Economic Development, seventh edition; New York, 242 - 248.

BMZ (ed.) (2001a)

Armutsbekämpfung - eine globale Aufgabe. Aktionsprogramm 2015. Der Beitrag der Bundesregierung zur weltweiten Halbierung extremer Armut, http://www.bmz.de/medien/aktuell/Aktion2015/ap2015_lang.pdf (last visited: 18.4.2001)

BMZ (ed.) (2001b)

Armutsbekämpfung - eine globale Aufgabe. Aktionsprogramm 2015. Der Beitrag der Bundesregierung zur weltweiten Halbierung extremer Armut - Kurzfassung, http://www.bmz.de/medien/aktuell/Aktion2015/ap2015_lang.pdf (last visited: 18.4.2001)

BMZ (ed.) (2001c)

Der Einzelplan 23 im Überblick, http://www.bmz.de/medien/aktuell/haushalt/haushalt_1.html\#h1.1body (last visited: 4.5.2000).

BMZ (ed.) (2001d)

Die Aufgaben und der Aufbau des BMZ, http://www.bmz.de/about/o1.html (last visited: 9.5.2001).

BMZ (ed.) (2001e):

Medienhandbuch Entwicklungspolitik 2000, Bonn.

BMZ (ed.) (2000a)

Aktionsplan 2015. Der Beitrag der Bundesregierung zur weltweiten Minderung extremer Armut, internal draft document, Bonn.

BMZ (ed.) (2000b)

Geber im DAC: Entwicklungspolitische Schwerpunkte, Strukturen, Adressen, Ansprechpartner, internal document of the BMZ Referat 404, Bonn. 
$\mathrm{BMZ}$ (ed.) (2000c)

Internationaler Tag der Armut (17. Oktober): Bundesentwicklungsministerium entwickelt nationalen Aktionsplan zur Armutsbekämpfung, press release of the BMZ from 16.10.2000, http://www.bmz.de/presse/presse0210.html (last visited 31.01.2001).

BMZ (ed.) (2000d)

Journalistenhandbuch Entwicklungspolitik, Berlin.

BMZ (ed.) (1999)

Übersektorales Konzept. Partizipative Entwicklungszusammenarbeit - Partizipationskonzept, in: BMZ aktuell Vol. 20, Bonn

BMZ (ed.) (1999b)

Globalisierung und Entwicklungszusammenarbeit. Stellungnahme des Wissenschaftlichen Beirats beim Bundesministerium für Wirtschaftliche Zusammenarbeit und Entwicklung, in: BMZ aktuell, Vol. 103 (June 1999), Bonn.

BMZ (ed.) (1999c)

Entwicklungszusammenarbeit - Erfolge und Probleme. Auswertung der 1996/97

durchgeführten Evaluierungen des BMZ, in: BMZ aktuell, Vol. 97 (April 1999), Bonn.

BMZ (ed.) (1997)

Grundlage der Deutschen Entwicklungszusammenarbeit, in: Materialien Vol. 97, Bonn.

BMZ (ed.) (1990)

„Armutsbekämpfung durch Hilfe zur Selbsthilfe“. Selbsthilfebewegungen als Partner der Entwicklungszusammenarbeit, in: BMZ aktuell Vol. 6, Bonn.

BORRMANN, Axel (1999)

Reform der Erfolgskontrolle in der deutschen Entwicklungszusammenarbeit. Eine Zwischenbilanz, Baden Baden.

BOWMAN, Mary / ANDERSON, C. Arnold (1963)

Concerning the Role of Education in Development, in: Geertz,, Clifford (ed.) (1963): Old Societies and New States, New York, 247 - 279.

BRADHAN, Pranab (1997)

The Role of Governance in Economic Development: A political economy approach. OECD Development Centre Study. Washington, D.C.

CENTER FOR INSTITUTIONAL REFORM AND THE INFORMAL SECTOR AND U.S. AGENCY FOR INTERNATIONAL DEVELOPMENT (eds.) (1996)

Governance and the Economy in Africa: Tools for Analysis and Reform of Corruption. Washington, D.C. (eds.)

CHENERY, Hollis et al. (1974)

Redistribution with Growth. Policies to improve income distribution in developing countries in the context of economic growth - a joint study by the World Bank's Development Research Denter and the Institute of Development Studies, University of Sussex; Glasgow. 
CHENERY, Hollis (1986)

Growth and Transformation, in: Chenery, Hollis / Robinson, Sherman / Syrens, Moshe (1986): Industrialization and Growth, New York, 13 - 32, reprinted in Meier, Gerald M. (ed.) (1989): Leading Issues in Economic Development, fifth edition; New York, 97 - 101.

COLLIER, Paul / DOLLAR, David (1999)

Aid Allocation and Poverty Reduction, Washington, D.C.

CORNIA, Giovanni Andrea (1988)

Economic Decline and Human Welfare in the First Half of the 1980s, in: Cornia, Giovanni Andrea / Jolly, Richard / Frances, Stewart (eds.): Adjustment with a Human Face, $2^{\text {nd }}$ reprint, New York, 11 - 47.

DE GREGORIO, José / EDWARDS, Sebastian / VALDES, Rodrigo (2000)

Controls on capital inflows. Do they work?, in: Journal of development economics, Vol. 63

(1), $59-83$.

DEPARTMENT FOR INTERNATIONAL DEVELOPMENT (ed.) (1999a)

Strategies for Achieving the International Development Targets. Better Health for Poor People (Consultation Document), accessible via http://www.dfid.gov.uk, link 'International Development Targets' (last visited: 5.10.2000).

DEPARTMENT FOR INTERNATIONAL DEVELOPMENT (ed.) (1999b)

Strategies for Achieving the International Development Targets. Economic Well-being (Consultation Document), accessible via http://www.dfid.gov.uk, link 'International Development Targets' (last visited: 5.10.2000).

DEPARTMENT FOR INTERNATIONAL DEVELOPMENT (ed.) (2000a)

Strategies for Achieving the International Development Targets. Addressing the Water Crisis - Healthier and more productive lives for poor people (Consultation Document), accessible via http://www.dfid.gov.uk, link 'International Development Targets' (last visited: 5.10.2000).

DEPARTMENT FOR INTERNATIONAL DEVELOPMENT (ed.) (2000b)

Strategies for Achieving the International Development Targets. Education for All - The Challenge of Universal Primary Education (Consultation Document), accessible via http://www.dfid.gov.uk, link 'International Development Targets' (last visited: 5.10.2000).

DEPARTMENT FOR INTERNATIONAL DEVELOPMENT (ed.) (2000c)

Strategies for Achieving the International Development Targets. Environmental Sustainability and Eliminating Poverty (Consultation Document), accessible via http://www.dfid.gov.uk, link 'International Development Targets' (last visited: 5.10.2000).

DEPARTMENT FOR INTERNATIONAL DEVELOPMENT (ed.) (2000d)

Strategies for Achieving the International Development Targets. Human Rights for Poor People (Consultation Document), accessible via http://www.dfid.gov.uk, link 'International Development Targets' (last visited: 5.10.2000). 
DEPARTMENT FOR INTERNATIONAL DEVELOPMENT (ed.) (2000e)

Strategies for Achieving the International Development Targets. Making Government Work for Poor People (Consultation Document), accessible via http://www.dfid.gov.uk, link 'International Development Targets' (last visited: 5.10.2000).

DEPARTMENT FOR INTERNATIONAL DEVELOPMENT (ed.) (2000f)

Strategies for Achieving the International Development Targets. Poverty Eradication and the Empowerment of Women (Consultation Document), accessible via http://www.dfid.gov.uk, link 'International Development Targets' (last visited: 5.10.2000).

DEPARTMENT FOR INTERNATIONAL DEVELOPMENT (ed.) (2000g)

Strategies for Achieving the International Development Targets. Meeting the Challenge of Urban Poverty (Consultation Document), accessible via http://www.dfid.gov.uk, link 'International Development Targets' (last visited: 10.3.2001).

DEPARTMENT FOR INTERNATIONAL DEVELOPMENT (ed.) (1998)

Britain's investment in development set for rises year on year, DfID news 7.14.1998, http://www.dfid.gov.uk/ (last visited: 4.5.2001).

DEVELOPMENT ASSISTANCE COMMITTEE (ed.) (2001)

Draft DAC Guidelines on Poverty Reduction. Note by the Secretariat; document for official use, submitted for review and discussion at the meeting of the DAC Informal Network on Poverty Reduction on 13 - 14 February 2001, Reference Number DCD/DAC (2000)26/REV2.

ELVERT, G. / EVERS, H. / WILKENS, W. (1983)

Die Suche nach Sicherheit. Kombinierte Produktionsformen im sogenannten informellen Sektor, in: Zeitschrift für Soziologie, Vol. 12(4), 281 - 296.

EDGERTON, J. (2000)

Participatory Processes in the Poverty Reduction Strategy, in: World Bank (ed.): Poverty Reduction Strategy Sourcebook, Part I: Core Techniques (draft version), Washington D.C.

EDWARDS, D. and KREINER, S. (1983)

The analysis of contingency tables by graphical models, in: Biometrica, Vol. 72, 339-351.

EDWARDS, Sebastian (2000)

Captial flows, real exchange rates, and capital controls: some Latin American experiences, in: Edwards, Sebastian (ed.) (2000): Capital flows and the emerging economies: Theories, evidence and controversies, Chicago, $197-246$.

EUROPEAN UNION (ed.) (2001)

Entwicklungszusammenarbeit. Vorrangige Ziele und Tätigkeiten.

http://europa.eu.int/abc/doc/off/rg/de/2000/pt0841.htm\#anch0391, last updated: 09.02.2001 (last visited 11.03.2001).

FAZ - FRANKFURTER ALLGEMEINE ZEITUNG (ed.) (2001a)

„Armut ist Nährboden für Terrorismus“. Vorsitzende der Welthungerhilfe: Mehr Geld für Entwicklung, in: Frankfurter Allgemeine Zeitung, Vol. 232 (4.10.2001), 4. 
FAZ - FRANKFURTER ALLGEMEINE ZEITUNG (ed.) (2001b)

Die EZB hat dem Druck gut standgehalten. Währungshüter sehen keinen Grund für Zinssenkungen / Frühjahrstagung von IWF und Weltbank beendet, in: Frankfurter Allgemeine Zeitung, Vol. 101 (2.5.2001), 17.

FAZ - FRANKFURTER ALLGEMEINE ZEITUNG (ed.) (2001c)

Die Telekom muß keine Großhandels-Flatrate anbieten. Die Regulierungsbehörde unterliegt vor Gericht / AOL: Herber Rückschlag, in: Frankfurter Allgemeine Zeitung, Vol. 65 (17.3.2001), 13.

FLANANGAN, Kerry (1999)

Aging and Poverty: A Policy for the Elderly Poor, Washington, D.C.

FRANKENBERG, Elizabeth / THOMAS, Duncan / BEEGLE, Kathleen (1999)

The Real Costs of Indonesia's Economic Crisis. Preliminary Findings from the Indonesia Family Life Surveys, Labor and Population Working Paper Series, No. 99-04, Santa Monica.

FRY, Marxwell (1980)

Savings, Investment, Growth and the Cost of Financial Repression, in: World Development, Vol.8 (April 1980).

FSF (1999)

Financial Stability Forum. About FSF: Objectives, http://www.fsforum.org/About/Objectives.html (last visited: 30.5.2000).

FSF (2000a)

Financial Stability Forum. Compendium of Standards: Who are the standard-setting Bodies?, http://www.fsforum.org/Standards/WhoAre.html (last visited: 30.5.2000).

FSF (2000b)

Report of the Working Groups on Capital Flows, http://www.fsforum.org/Reports/RepCF.pdf, (last visited: 30.5 .2000 ).

FSF (2000c)

Report of the Working Groups on Highly Leveraged Institutions, http://www.fsforum.org/Reports/RepCF.pdf, (last visited: 30.5.2000).

G-20 (2000)

Backgrounder, http://www.g20.org/docs/bkgrnd-e.html (last visited: 30.5.2000).

GAMPERL, Josef / SEIFRIED, Rolf / STRANGMANN, Uwe (2001)

Klimaschutz. Die Kyoto-Instrumente "Clean Development Mechanism" und "Joint Implementation" und die Rolle von Banken bei ihrer Umsetzung, internal report to the Kreditanstalt für Wiederaufbau, March 2001, Frankfurt a.M.

GERTLER, Paul (2000)

Insuring the Economic Cost of Illness, in: Lustig, Nora (ed.) (2000): Shielding the Poor. Social Protection in the Developing World, Washington D.C.

GERTLER, Paul / GRUBER, Jonathan (1997)

Insuring Consumption against Illness, National Bureau of Economic Research Working Paper 6035, Cambridge, Massachusetts 
GILBERT, Roy / KREIMER, Alcira (1999)

Learning of the World Bank's experience of Natural Disaster Related Assistance, Washington, D.C.

GOLDBERG, Jörg (2000)

Zur Kritik der jüngsten Strategie von IWF und Weltbank: Armutsbekämpfung contra Strukturanpassung?, in Weltwirtschaft \& Entwicklung Vol. 3/2000.

GRAF, Michael (1995)

Bildung und technischer Fortschritt als Determinanten wirtschaftlicher Entwicklung. Eine Theoretische und empirische Untersuchung, Heidelberg

GREENE, William H. (1996)

Econometric Analysis, New Jersey.

GREENACRE, M. J. (1984)

Theory and Applications of Correspondemce Analysis, New York.

GSÄNGER, Hans (1993)

Soziale Sicherungssysteme für arme Bevölkerungsgruppen, Berlin.

GUJARATI, Damodar (1995)

Basic Econometrics, New York.

HAUSER, Richard / NEUMANN, Udo (1992)

Armut in der Bundesrepublik Deutschland. Die öffentliche und sozialwissenschftliche Thematisierung nach dem Zweiten Weltkrieg, in: Kölner Zeitschrift für Soziologie und Sozialpsychologie - Sonderheft 32/1992: Armut im Modernen Wohlfahrtsstaat, 237 - 271.

HELLMAN, Joel / GERAINT, Jones / KAUFMANN, Daniel (2000)

Seize the State, Seize the Day. State Capture, Corruption, and Influence in Transition, World Bank Policy Research Working Paper, Vol. 2444, synthesis.

HELLMAN, Joel / GERAINT, Jones / KAUFMANN, Daniel (2000)

Beyond the ,Grabbing Hand' of Government in Transition: Facing up to ,State Capture' by the Corporate Sector, in: Transition (May-June-July 2000), 1 - 5.

HERNÁNDEZ-CATÁ, Ernesto (2000)

Raising Growth and Investment in Sub-Saharan Africa. What can be done?, in: Finance and Development, December 2000, Vol. 37, No 4, 30 - 33.

HOLZMANN, Robert / JORGENSEN, Steen (1999)

Social Protection as Social Risk Management. Conceptual Understandings for the Social Protection Sector Strategy Paper, Social Protection Discussion Paper 9904, World Bank, Washington, D.C.

HULME, David / MOSLEY, Paul (1996)

Finance against Poverty, New York

INTERGOVERNMENTAL PANEL ON CLIMATE CHANGE (2001)

IPCC special report on emissions scenarios,

http://www.grida.no/climate/ipcc/emission/index.htm (last visited: 2.5.2001) 
INTERNATIONAL LABOR ORGANISATION (1976)

Beschäftigung, Wachstum und Grundbedürfnisse: Ein weltweites Problem, Genf

INTERNATIONAL FEDERATION OF RED CROSS AND RED CRESCENT SOCIETIES (1999)

World Disaster Report 1999, Geneva.

INTER-AMERICAN DEVELOPMENT BANK (1995)

Overcoming Volatility: Economic and Social Progress in Latin America - 1995 Report, Washington

JACOBY, Hanan / SKOUFIAS, Emmanuel (1997)

Risk, Financial Markets and Human Capital in a Developing Country, in: Review of

Economic Studies, Vol. 64(3), 311 - 335.

JAMBU, Michael (1992)

Explorative Datenanlyse, translated into German by Egle, Kuno, Stuttgart.

JENTSCH, Gero (2000)

Kann wirtschaftliches Wachstum die Armut vermindern? Neue Erkenntnisse zu Ungleichheit, Wirtschaftswachstum und Armut; in Entwicklung und Zusammenarbeit, Vol. 41, Nr. 6.

JEPMA, Catrinus (1991)

The Tying of Aid, Paris.

JUNGFER, Joachim (1991)

Grundbedürfnisstrategie oder Ordnungspolitik als Wege zur Überwindung wirtschaftlicher Unterentwicklung; Bern

KAUFMANN, Daniel / KRAAY, Aart / ZOIDO-LOBATÓN, Pablo (2000)

Governance Matters. From Measurement to Action, in Finance \& Development, June 2000, $10-13$.

KAUFMANN, Daniel / KRAAY, Aart / ZOIDO-LOBATÓN, Pablo (1999)

Governance Matters, World Bank Policy Research Papers, Vol. 2196, Washington, D.C.

KFW (ed.) (2001a)

Economic Activity is the First Step to End Poverty. 2000 Annual Report on Financial Cooperation with Developing and Transition Countries, Frankfurt a. M.

KfW (ed.) (2001b)

KfW acquires Governments Shares in DEG. Agreement signed in Frankfurt, KfW press release $(19.07 .2001)$, http://www.kfw.de/de/presse/presse_suche.asp?sprache=english\&lang=2\&status=archiv\&rubr $\mathrm{ik}=\mathrm{all} \& \mathrm{zeit}=2001 \& \mathrm{zeit}=1999 \&$ freitext=DEG (last visited: 08.10.2001)

KFW (ed.) (2000a)

Poverty Reduction Strategy Papers and HIPC - Sachstandsbericht. Internal document, Frankfurt a. M. 
KFW (ed.) (2000b)

Standard Presentation of the KfW's Financial Cooperation, presented in part in the lecture'Berufsmöglichkeiten in der Entwicklungszusammenarbeit' in the series 'Global Governance und die Zukunft der Entwicklungspolitik' of the Johann Wolfgang Goethe Universität Frankfurt, 2.11.2000, Frankfurt.

KFW (ed.) (2000c)

Einführung neuer übersektoraler Kennungen durch das BMZ, Document of the KfW, Frankfurt a.M.

KFW (ed.) (1999)

Ergebnisse der Finanziellen Zusammenarbeit. Fünfter Auswertungsbericht über geförderte Vorhaben in Entwicklungsländern, Frankfurt a. M.

KLUGMAN, J. (2000)

Overview, in: World Bank (ed.) (2000): Poverty Reduction Strategy Paper Sourcebook, Draft for Comments, April 20, 2000, Washington

KOUTSOYIANNIS, A. (1981)

Theory of Econometrics, London.

KRANZ-PLOTE, Jutta / MICHA, Josef (1996)

Hauptbericht zur Serienevaluierung. Armutsminderung und Zielgruppenerreichung in Vorhaben der Entwicklungszusammenarbeit, document of the BMZ, Referat 201, Bonn.

KRUEGER, Anne (1974)

The Political Economy of the Rent-Seeking Society, in: American Economic Review, Vol. 64 (June 1974), $291-302$.

KUZNETS, Simon (1955)

Economic Growth and Income Inequality, in: American Economic Review, Vol 45 (March 1955), 1 - 28.

LEMBKE, Hans (1996)

Schweden. Befürworter des "Dritten Weges" reformiert seine EZ, in Thiel, R. (ed.) (1996):

Entwicklungspolitiken - 33 Geberprofile, Schriften des Deutschen Übersee-Instituts Hamburg Vol. 36, Hamburg, 191 - 198.

LEWIS, Arthur (1954)

Economic Development with Unlimited Supplies of Labor, in: Manchester School, Vol. 22 (May 1954), 139 - 191.

LIPSET, Seymour (1959)

The Social Prerequisites for Democracy Revisited. Economic Development and Political Legitimacy, in: American Sociological Review, Vol. 59 (February 1959), 1 - 22.

MEIER, Gerald (1989)

Analytical Perspectives. Evolution of Development Economics - Note, in: Meier, Gerald M. (ed.) (1989): Leading Issues in Economic Development, fifth edition; New York, 82 - 85. 
MORRIS, Cynthia / ADELMAN, Irma (1989)

Nineteenth- Century Development Experience and Lessons for Today, in: World

Development, Vol. 17, 1417 - 1432.

MYRDAL, Gunnar (1968)

Asian Drama: An inquiry into the Poverty of Nations, New York.

MCNAMARA, Robert (1973)

Speech to the Board of Governors, Nairobi.

NAGARAJAN, Nigel (1999)

The Millenium Round. An Economic Appraisal, European Commission Economic Papers No. 139.

NORTON, Seth (1998)

Poverty, Property Rights and Human Development: A Cross-National Study, in: Cato Journal, Vol. 18 No. 2, $233-450$.

NORWEGIAN MINISTRY OF FOREIGN AFFAIRS (ed .) (2000)

Principals for Norwegian Development Co-operation; http://odin.dep.no/ud/engelsk/publ/veiledninger/032001-990331/index-hov002-b-na.html\#hov2.1 (last visited 26.2.2001)

ORGANISATION FOR ECONOMIC CO-OPERATION AND DEVELOPMENT (ed.) (1999)

Development Indicators. Goals, www.oecd.org/dac/Indicators/htm/goals.htm (last visited 7.2.2001).

\section{ORGANISATION FOR ECONOMIC CO-OPERATION AND DEVELOPMENT (ed.)}

(2000)

Development Indicators. A Working Set of Indicators of Development Progress, www.oecd.org/dac/Indicators (last visited 7.2.2001).

PALACIOS, Robert / PALLARES-MIRALLES, Montserrat (1999)

International Patterns of Pension Provision, World Bank Social Protection Department Discussion Paper, Washinton, D.C.

PALMA, Gabriel (1978)

Dependency: A Formal Theory of Underdevelopment or a Methodology for the Analysis of Concrete Situations of Underdevelopment?, in: World Development, Vol. 6, 899 - 902, reprinted in Meier, Gerald M. (ed.) (1989): Leading Issues in Economic Development, fifth edition; New York, 105 - 109.

PEARCE, David et al. (1996)

The social costs of climate change, in : Climate change, 1995. Economic and Social dimensions of Climate Change, Contribution of Working Group III to the Second assessment Report of the Intergovernmental Panel on Climate Change.

PINSTRUP-ANDERSEN, Per / JARAMILLO, Maurice / STEWARD, Frances (1988) The Impact on Government Expenditure, in: Cornia, Giovanni Andrea / Jolly, Richard/ Frances, Stewart (eds.): Adjustment with a Human Face, $2^{\text {nd }}$ reprint, New York, 73 -89. 
POLKE-MAJEWSKI, Karsten (2001)

Aids-Medikament. Kontrahenten wollen sich außergerichtlich einigen, in FAZ.net (18.4.2001),http://www.faz.net/IN/INtemplates/faznet/default.asp?tpl=uptoday/content.asp\&d $\mathrm{oc}=\{846 \mathrm{BBDAA}-\mathrm{E} 5 \mathrm{~A} 1-4 \mathrm{~B} 0 \mathrm{C}-\mathrm{A} 7 \mathrm{CD}-437 \mathrm{DFAF} 8 \mathrm{EA} 12\} \& \mathrm{rub}=\{9 \mathrm{E} 7 \mathrm{BDDB} 7-469 \mathrm{E}-11 \mathrm{D} 4-$ AE7B-0008C7F31E1E\}, (last visited: 29.5.2001).

POPPER, Karl (1945)

The Open Society and Its Enemies, London.

MEIER, Gerald / RAUCH, James (eds.) (2000)

Rent seeking and Government Failure. What are Rents?, in: Meier, Gerald / Rauch, James (eds.) (2000): Leading Issues in Economic Development, seventh edition; New York. 434 436.

RAWLS, J. (1971)

A Theory of Justice, Cambridge, MA.

REYNOLDS, Lloyd (1983)

The Spread of Economic Growth to the Third World; in Journal of Economic Literature, Vol. 21 (September 1983): 941 - 975; reprinted in Meier, Gerald M. / Rauch, James E. (ed.) (2000): Leading Issues in Economic Development, seventh edition; New York. 80 - 95.

RIEDLBERGER, Irmela (1999)

AIDS-Prävention und Männlichkeitsvorstellungen. Eine Untersuchung in der Dominikanischen Republik, , in: Entwicklung und Zusammenarbeit, Vol. 40 (1999:5), 134 135.

RIEDLBERGER, Irmela (1998)

Uno es hombre - Man is Mann. Männlichkeit, Familienplanung und AIDS-Prävention in der Dominikanischen Republik, Doctoral Thesis at the University of Gießen.

SAUTTER, Hermann (1999)

The Institutional Possibilities and Ethical Quality of Development Cooperation, in Institute for Scientific Co-operation (ed.): Economics, Vol. 59, Tübingen.

SAUTTER, Hermann (1996)

Die Ethik der Entwicklungshilfe und der Entwicklungszusammenarbeit; in E+Z Vol. 11, 1996.

SAUTTER, Hermann (1995)

Moralisches Urteil und ökonomisches Kalkül; in Zeitschrift für Evangelische Ethik, 35. Jg., Vol. 2, 1995.

SAUTTER, Herrmann / SCHINKE, Rolf (1994)

Die sozialen Kosten wirtschaftlicher Reformen - ihre Ursachen und die Möglichkeiten einer Abfederung, Ibero-Amerika Institute for Economic Research, Discussion Papers Vol. 62, Göttingen.

SAUTTER, Hermann / SERRIES, Christoph (1993)

Inhalt und Methodik von Armutsanalysen, Cologne. 
SEN, Armartya (1983)

Development: Which Way Now?, in: The Economic Journal, Vol. 93 (December 1993), 745 762.

SWEDISH INTERNATIONAL DEVELOPMENT AGENCY (ed.) (2001)

Sida's Organization, http://www.sida.se/Sida/jsp/Crosslink.jsp/d,160/a,4123 (last visited: 12.5.2001).

SWEDISH INTERNATIONAL DEVELOPMENT AGENCY (ed.) (2000a) Sida's Programme for Global Development. The goals of Swedish development cooperation, http://www.sida.se/Sida/jsp/Crosslink.jsp/d,176/a,4916; (last visited: 8.2.2001).

SWEDISH INTERNATIONAL DEVELOPMENT AGENCY (ed.) (2000b)

Sida's Programme for Global Development. Sida's key areas, http://www.sida.se/Sida/jsp/Crosslink.jsp/d,176/a,4922, (last visited: 8.2.2001).

SWEDISH INTERNATIONAL DEVELOPMENT AGENCY (ed.) (2000c) Sida's Programme for Global Development. An Instrument for Mutual development, http://www.sida.se/Sida/jsp/Crosslink.jsp/d,176/a,4920, (last visited: 8.2.2001).

SWEDISH INTERNATIONAL DEVELOPMENT AGENCY (ed.) (2000d) Sida's Programme for Global Development. From aid dependency to partnership, http://www.sida.se/Sida/jsp/Crosslink.jsp/d,176/a,4927, (last visited: 8.2.2001).

SWEDISH INTERNATIONAL DEVELOPMENT AGENCY (ed.) (2000e) Sida's Programme for Global Development. The task is to create the right conditions, http://www.sida.se/Sida/jsp/Crosslink.jsp/d,176/a,4921, (last visited: 8.2.2001). SWEDISH INTERNATIONAL DEVELOPMENT AGENCY (ed.) (2000f) Sida's Programme for Global Development. Development cooperation, http://www.sida.se/Sida/jsp/Crosslink.jsp/d,176/a,4919, (last visited: 8.2.2001).

SWEDISH INTERNATIONAL DEVELOPMENT AGENCY (ed.) (2000g) Sida's Programme for Global Development. International Networks for Development, http://www.sida.se/Sida/jsp/Crosslink.jsp/d,176/a,4926, (last visited: 8.2.2001).

SWEDISH INTERNATIONAL DEVELOPMENT AGENCY (ed.) (2000h) Sida's Programme for Global Development. Each country or region needs its own strategy, http://www.sida.se/Sida/jsp/Crosslink.jsp/d,176/a,4923, (last visited: 8.2.2001).

SWEDISH INTERNATIONAL DEVELOPMENT AGENCY (ed.) (2000i)

Sida's Programme for Global Development. Focus on better quality, http://www.sida.se/Sida/jsp/Crosslink.jsp/d,176/a,4924, (last visited: 8.2.2001).

SWEDISH INTERNATIONAL DEVELOPMENT AGENCY (ed.) (2000j)

Sida's Programme for Global Development. Knowledge is the key to development, http://www.sida.se/Sida/jsp/Crosslink.jsp/d,176/a,4925, (last visited: 8.2.2001).

SWEDISH INTERNATIONAL DEVELOPMENT AGENCY (ed.) (2000k)

Sida's Programme for Global Development. Partnership for development, http://www.sida.se/Sida/jsp/Crosslink.jsp/d,176/a,4928, (last visited: 8.2.2001). 
SWEDISH INTERNATIONAL DEVELOPMENT AGENCY (ed.) (20001)

Sida's Programme for Global Development. A world in imbalance,

http://www.sida.se/Sida/jsp/Crosslink.jsp/d,176/a,4917, (last visited: 8.2.2001).

SWEDISH INTERNATIONAL DEVELOPMENT AGENCY (ed.) (2000m)

Sida's Programme for Global Development. A world in the process of change, http://www.sida.se/Sida/jsp/Crosslink.jsp/d,176/a,4917, (last visited: 8.2.2001).

SWEDISH INTERNATIONAL DEVELOPMENT AGENCY (ed.) (1997)

Annual Report 1997, http://www.sida.se/Sida/jsp/Crosslink.jsp/d,194/a,824 and

http://www.sida.se/Sida/jsp/Crosslink.jsp/d,194/a,825 (last visited: 12.5.2001).

SWEDISH INTERNATIONAL DEVELOPMENT AGENCY (ed.) (1996)

Sida's poverty programme. Action Programme to Promote Sustainable Livelihoods for the Poor and to Combat Poverty; Department for Policy and Legal Services, Stockholm

STREETEN, Paul et al. (1981)

First Things First. Meeting Basic Human Needs in Developing Countries, New York.

THIEL, Reinold (1999)

Der Kampf gegen AIDS hat gerade erst begonnen, in: Entwicklung und Zusammenarbeit, Vol. 40 (1999:5), 123.

THIELE, Rainer / WIEBELT, Manfred (1999)

Kurzgutachten. Entwicklungsverträglichkeit der Strukturanpassungspolitik in

Entwicklungsländern, Institut für Weltwirtschaft, Kiel

TIMMERMAN, Vincenz (1999)

Education as a Determinant of Economic Growth, in: Dahya, Shri Bagwan (ed.): The Current State of Economic Science, Vol. 5, Rohtak, 2467 - 2479.

TOMMASI, Mariano / VELASCO, Andrés (1996)

Where are we in the Political Economy of Reform?, in: Journal of Policy Reform, Vol. 1 (2), $187-238$.

UNDP (1995)

Human Development Report 1995, New York.

UNEP (2000)

Agenda 21. Introduction, http://www.unep.org/Documents/Default.asp?DocumentID=52\&ArticleID=50 (last visited: 1.5.2000).

UNITED NATIONS GENERAL ASSEMBLY (1948)

Universal Declaration of Human Rights, http://www.un.org/Overview/rights.html (last visited: 18.4.2001)

UK GOVERNMENT (1997)

Eliminating World Poverty. A Challenge for the $21^{\text {st }}$ Century, White Paper on International Development, London. 
UK GOVERNMENT (2000)

Eliminating World Poverty. Making Globalisation Work for the Poor, White Paper on International Development, London.

VAN DE WALLE, Nicolas / JOHNSTON, Timothy (1996)

Improving Aid to Africa, Overseas Development Council Policy Essay 21, Washington, D.C.

VERBEEK, Marno (2000):

A Guide to Modern Econometrics, Chichester, UK

VOGEL, Ulrich (1999)

37 Millionen Infizierte. Die Bekämpfung von HIV/AIDS darf sich nicht auf den

Gesundheitssektor beschränken, in: Entwicklung und Zusammenarbeit, Vol. 40 (May 1999).

VOS, Rob / VELASCO, Margarita / DE LABASTIDA, Edgar (1999)

Economic and Social Effects of El Niňo in Ecuador, 1997-1998, Inter-American Development Bank, Washington D.C.

WIECZOREK-ZEUL, Heidemarie (2000a)

Speech at the Opening of Global Dialogue 4: Fighting Poverty: Social Innovations and New Coalitions, on July 252000 , at EXPO, Hannover.

WIECZOREK-ZEUL, Heidemarie (2000b)

Speech given to the German parliament at the 1. reading of the budget 2001 on Sept. 13 $3^{\text {th }}$ 2000 , approved long version as of 13.9.2000, 13.00 o'clock.

WIECZOREK-ZEUL, Heidemarie (1999)

Preface to: KfW (ed.): Ergebnisse der Finanziellen Zusammenarbeit. Fünfter

Auswertungsbericht über geförderte Vorhaben in Entwicklungsländern, Frankfurt a. M.

WOLFENSOHN, James (2000)

Foreword, in World Bank (ed.) (2000): World Development Report 2000/2001. Attacking Poverty, Washington D.C.

WOLFENSOHN, James (1999a)

A Proposal for a Comprehensive Development Framework. A discussion draft, http://www.worldbank.org/cdf/cdf-text.htm (last visited: 3.5.2001).

WOLFENSOHN, James (1999b)

Ein Vorschlag für einen umfassenden Diskussionsrahmen, Discussion Draft by the president of the World Bank Group, www.worldbank.org (visited 10.9.2000).

WOLFENSOHN, James (1997)

The Challenge of Inclusion, annual meetings address, Hong Kong SAR, China (23.9.1977), http://www.worldbank.org/html/extdr/am97/jdw_sp/jwsp97e.htm (last visited: 2.5.2001).

WORLD BANK (ed.) (2001a)

Background and Overview of the Comprehensive Development Framework, http://www.worldbank.org/cdf/overview.htm (last visited: 3.5.2001). 
WORLD BANK (ed.) (2001b)

Comprehensive Development Framework, http://www.worldbank.org/cdf/cdfprsplink.pdf (last visited: 3.5 .2001 ).

WORLD BANK (ed.) (2001c)

The CDF pilots, http://www.worldbank.org/cdf/piloting.htm (last visited: 5.3.2001).

WORLD BANK (ed.) (2001d)

The World Bank's role, http://www.worldbank.org/html/extdr/backgrd/ibrd/ro.e.htm (last visited: 4.5.2001).

WORLD BANK (ed.) (2001e)

About the World Bank Group, http://www.worldbank.org/html/axtdr/about/ (last visited:

4.5.2001).

WORLD BANK (ed.) (2001f)

Membership in the World Bank Group,

http://www.worldbank.org/html/extdr/about/members/ (last visited: 4.5.2001).

WORLD BANK (ed.) (2001g)

Ten Things You Never Knew About the World Bank, http://www.worldbank.org/html/extdr/pb/10things.html (last visited: 4.5.2001).

WORLD BANK (ed.) (2000a)

World Development Report 2000/2001. Attacking Poverty, New York.

WORLD BANK (ed.) (2000b)

Voices of the Poor. Can Anyone Hear Us?, New York.

WORLD BANK (ed.) (1998)

World Bank calls for narrowing the 'knowledge gap' between rich an poor, World Bank news release No. 99/1955 (2.10.1998),

http://wbln0018.worldbank.org/lo+web+sites/bangladesh+web.nsf/1382158c33bcc8dd462566 7200239762/01 fd034al f66c733462566f8003386c8 (last visited: 2.5.2001).

WORLD BANK (ed.) (1993)

The East Asian Miracle: Economic Growth and Public Policy: Summary, reprinted in Meier, Gerald M. / Rauch, James E. (ed.) (2000): Leading Issues in Economic Development, seventh edition; New York. 36 - 41.

WORLD BANK (ed.) (1995)

World Development Report 1995. Workers in an Integrating World, New York.

WORLD BANK AND IMF (eds.) (2000)

Poverty Reduction Strategy Papers-Progress in Implementation, last updated 7. Sept. 2000, http://www.imf.org/external/np/prsp/2000/prsp.htm (visited: 23.10.00). 
Philipp Kircher - 978-3-631-75366-8 


\section{Göttinger Studien zur Entwicklungsökonomik Göttingen Studies in Development Economics}

Herausgegeben von / Edited by Hermann Sautter

Bd.Nol. 9 Hermann Sautter / Rolf Schinke (eds.): Social Justice in a Market Economy. 2001.

Bd.Nol. 10 Philipp Albert Theodor Kircher: Poverty Reduction Strategies. A comparative study applied to empirical research. 2002. 


\section{Fighting Poverty in Developing Countries}

\section{Principles for Economic Policy}

Frankfurt/M., Berlin, Bern, Bruxelles, New York, Oxford, Wien, 2000. XV, 242 pp., 7 fig., 16 tab.

Schriften zur Internationalen Entwicklungs- und Umweltforschung.

Herausgegeben vom Zentrum für internationale Entwicklungs- und

Umweltforschung der Justus-Liebig-Universität Gießen. Bd. 1

ISBN 3-631-37145-4 · pb. € 40.40*

US-ISBN 0-8204-4824-9

Poverty is one of the most depressing facts in the world today. This book is written in order to provide a new perspective to the problem of poverty and to the discussion of anti-poverty policies in developing countries, including aspects of child labour and systemic transition, which are currently at the center of political debate. The intention of the book is to provide a common base for discussion for those professionals in developed, as well as those in developing countries. The authors hope that this book will be of use to those professionally occupied with these problems as well as to those "only" interested in issues of development economics.

Contents: Foundation of an economic analysis of poverty - The economic causes of poverty - Principles of anti-poverty policies - Points of departure and problems in the fight against poverty - Special issues in the fight against poverty

Frankfurt/M - Berlin · Bern - Bruxelles · New York · Oxford · Wien

Auslieferung: Verlag Peter Lang AG

Jupiterstr. 15, CH-3000 Bern 15

Telefax (004131) 9402131

*inklusive der in Deutschland gültigen Mehrwertsteuer

Preisänderungen vorbehalten

Homepage http://www.peterlang.de 